\title{
ANÁLISIS EXPERIMENTAL DE LA CURVA DE DISPERSIÓN DE VELOCIDADES DE ONDAS SUPERFICIALES EN MORTEROS A EDAD TEMPRANA
}

\section{Trabajo de Investigación \\ Máster en Ingeniería de Estructuras}

Autor: Fernando Martínez Soto

Tutor: Prof. Dr. Rafael Gallego Sevilla 
Trabajo Fin de Máster

Fernando Martínez Soto

Diciembre, 2011

MÁSTER EN INGENIERÍA DE ESTRUCTURAS

Universidad de Granada

Revisor: Prof. Rafael Gallego Sevilla

Departamento de Mecánica Estructural e Ingeniería Hidráulica 
Informe de valoración del proyecto

El tribunal constituido para la evaluación del Proyecto Fin de Máster titulado:

\section{ANÁLISIS EXPERIMENTAL DE LA CURVA DE DISPERSIÓN DE VELOCIDADES DE ONDAS SUPERFICIALES EN MORTEROS A EDAD TEMPRANA}

Realizado por el alumno: Fernando Martínez Soto

Y dirigido por el tutor: Rafael Gallego Sevilla

Ha resuelto la calificación de:

$\square$ SOBRESALIENTE (9-10 puntos)

$\square$ NOTABLE (7-8.9 puntos)

$\square$ APROBADO (5-6.9 puntos)

$\square$ SUSPENSO

Con la nota ${ }^{1}: \longleftarrow$ puntos.

El Presidente:

El Secretario:

EI Vocal: 


\section{Listado de Símbolos}

\begin{tabular}{|c|c|c|}
\hline Símbolo & Unidades & Descripción \\
\hline$a / c$ & - & Relación agua/cemento (dosificación mortero) \\
\hline$f / c$ & - & Relación fino/cemento (dosificación mortero) \\
\hline$F F T$ & - & Transformada rápida de Fourier de una señal en el dominio del tiempo \\
\hline$f$ & {$[\mathrm{~Hz}]$} & Frecuencia o rango de frecuencias de una señal \\
\hline$f_{r}$ & {$[\mathrm{~Hz}]$} & Frecuencia de resonancia fundamental (amplitud máxima del autoespectro) \\
\hline$f_{N Y Q}$ & {$[\mathrm{~Hz}]$} & Frecuencia de Nyquist (la mitad de la frecuencia de muestreo) \\
\hline$G_{21} ; C P S$ & - & Espectro de potencia cruzado en valor absoluto (CPS, cross power spectrum) \\
\hline End $(N D T)$ & - & Evaluación no destructiva (Non destructive method) \\
\hline $\boldsymbol{F}_{\boldsymbol{c}}$ & {$[\mathrm{N}]$} & Carga máxima en rotura a compresión \\
\hline $\boldsymbol{E}_{s}$ & {$[\mathrm{~Pa}],\left[\mathrm{N} / \mathrm{m}^{2}\right]$} & Módulo de Young Elástico estático (MOE) \\
\hline $\boldsymbol{E}_{\boldsymbol{d}}$ & {$[\mathrm{Pa}],\left[\mathrm{N} / \mathrm{m}^{2}\right]$} & Módulo de Young Elástico dinámico (MDE) \\
\hline $\boldsymbol{G}$ & {$[\mathrm{Pa}],\left[\mathrm{N} / \mathrm{m}^{2}\right]$} & Módulo de Rigidez transversal o de torsión \\
\hline$l$ & {$[\mathrm{~mm}]$} & Distancia entre soportes de probeta \\
\hline$n$ & {$[\mathrm{~Hz}]$} & Frecuencia fundamental de resonancia en vibración transversal \\
\hline$n^{\prime}$ & {$[\mathrm{Hz}]$} & Frecuencia fundamental de resonancia en vibración longitudinal \\
\hline$n ”$ & {$[\mathrm{~Hz}]$} & Frecuencia fundamental de resonancia en vibración a torsión \\
\hline$\tau$ & {$[\operatorname{seg}]$} & Periodo característico inversamente proporcional a la frecuencia \\
\hline$\varnothing$ & {$[\mathrm{mm}]$} & Diámetro (en áridos, probetas, punta martillo...) \\
\hline $\boldsymbol{R}_{f}$ & {$[\mathrm{Mpa}]$} & Resistencia a flexión \\
\hline $\boldsymbol{R}_{c}, f_{c d}$ & {$[\mathrm{Mpa}]$} & Resistencia a compresión \\
\hline$T^{a}$ & ${ }^{\circ} \mathrm{C}$ & Temperatura \\
\hline $\mathrm{Hr}$ & $\%$ & Humedad relativa \\
\hline$D, d 1$ & {$[\mathrm{~cm}]$} & Distancia o separación entre fuente de impacto y $1^{\circ}$ acelerómetro \\
\hline$X, d 2$ & {$[\mathrm{~cm}]$} & Distancia o separación entre ambos acelerómetros \\
\hline$v$ & - & Coeficiente de Poisson \\
\hline$\rho$ & {$\left[\mathrm{g} / \mathrm{cm}^{3}\right]$} & Densidad de masa \\
\hline $\boldsymbol{\beta}$ & - & Factor de forma de la sección transversal en probetas prismáticas \\
\hline $\boldsymbol{R}$ & - & Factor de forma para una probeta prismática (ASTM C215) \\
\hline$S$ & {$\left[\mathrm{~mm}^{2}\right]$} & Superficie de carga de una probeta en un ensayo de resistencia \\
\hline$M$ & {$[\mathrm{~kg}]$} & Masa del espécimen de ensayo \\
\hline
\end{tabular}




\begin{tabular}{|c|c|c|}
\hline$T$ & {$[\mathrm{~cm}]$} & Espesor de placa, probeta o modelo de ensayo \\
\hline$T_{1}$ & - & Factor de corrección del modo fundamental en flexión en método FFRC \\
\hline$C_{p}$ & {$[\mathrm{~m} / \mathrm{s}]$} & Velocidad aparente de onda $\mathrm{P}$ en morteros \\
\hline$C_{\text {plate }}$ & {$[\mathrm{m} / \mathrm{s}]$} & Velocidad aparente de onda $\mathrm{P}$ en elementos tipo placa $\left(C_{\text {plate }} \approx 0.96 C_{p}\right)$ \\
\hline$t c$ & [seg] & Tiempo de contacto o duración del impacto en la superficie \\
\hline$\Delta f$ & {$[\mathrm{~Hz}]$} & Diferencial de frecuencia entre dos puntos (Frequency interval) \\
\hline$\Delta t$ & [seg] & Duración de la señal en el tiempo o tiempo de viaje \\
\hline Fs & {$[\mathrm{Hz}]$} & Frecuencia de muestreo de la señal (Sampling frequency) \\
\hline$N$ & - & Número de puntos de muestreo de la señal (Sampled points) \\
\hline$\delta t$ & {$[\mu \mathrm{s}]$} & Diferencia de tiempo entre dos puntos cercanos (Sampling interval) \\
\hline $\boldsymbol{e}_{f}$ & {$[\%]$} & Error sistemático o porcentaje de error máximo $\left(\Delta f / 2 f_{r}\right)$ \\
\hline$\eta$ & - & Coeficiente de amortiguamiento \\
\hline$\gamma_{m}$ & {$\left[\mathrm{KN} / \mathrm{m}^{3}\right]$} & Peso unitario o específico del mortero (masa-gravedad) \\
\hline$\varepsilon$ & {$[\mathrm{mm} / \mathrm{mm}]$} & Deformación unitaria del material sometido a un esfuerzo unitario \\
\hline$\lambda$ & {$[\mathrm{cm}]$} & Longitud de onda \\
\hline$\gamma^{2}$ & - & Función de coherencia entre señales \\
\hline$S_{1}, S_{2}$ & - & Autoespectro de energía a partir de la FFT de cada señal \\
\hline$S_{x x}, S_{x y}$ & - & Densidad espectral directa ; Densidad espectral cruzada \\
\hline$\Theta_{12(f)}$ & o & Función de fase del promedio de señales en función de la frecuencia \\
\hline$\emptyset_{f} ; \Delta \varphi_{(f)}$ & [rad] & Desfase entre señales expresado en forma angular \\
\hline SSRM & - & $\begin{array}{l}\text { Steady State Rayleigh method (Primera caracterización geotécnica no } \\
\text { intrusiva) }\end{array}$ \\
\hline$Z$ & {$\left[\mathrm{~kg} / \mathrm{m}^{2} \mathrm{~s}\right]$} & Impedancia acústica específica \\
\hline
\end{tabular}




\section{Terminología}

Definición

AEOS

Antinodos

CEM-I42,5N.<smiles></smiles>

Espectro de amplitud

\section{Espectro de energía}

Flexión en el plano

Flexión externa

Frecuencia de resonancia

"Hanning window"

Homogéneo

$\mathrm{Hz}, \mathrm{KHz}$

I-ECO

Impedancia acústica

Intervalo de muestreo
Significado o uso

Análisis Espectral de Ondas Superficiales (Spectral Analysis of Surface waves [SASW]): Método de análisis no destructivo y no invasivo, efectuado en la superficie de objetivo del trabajo de investigación presente, en la cual se generan vibraciones sinuosoidales estacionarias con diferentes elementos de oscilación sísmica a distancias conocidas.

Localizaciones, generalmente dos o más, de desplazamiento local máximo de una barra fina o varilla en resonancia no sometida a esfuerzo. Para la resonancia fundamental en flexión, los antinodos están localizados en los dos extremos y en el centro de la probeta.

Nomenclatura EHE08 Cemento común I, resistencia caract.42,5MPa, consistencia normal

Velocidades de onda Rayleigh, onda $S$ y onda $P$, respect. Se miden en $\mathrm{m} / \mathrm{seg}$.

Gráfica de la amplitud relativa frente a la frecuencia que se obtiene a partir de la Transformada Rápida de Fourier (FFT) en el análisis de señales en el dominio del tiempo al de la frecuencia.

Es la representación estadística de la onda de energía en función de la frecuencia con una amplitud característica del intervalo tomado, y un estimado empírico de la función espectral.

Modo de flexión de las probetas en forma de paralelepípedo rectangular en donde la dirección de los desplazamientos se sitúa en el plano principal de la probeta.

Modo de flexión de las probetas en forma de paralelepípedo rectangular en donde la dirección del desplazamiento es perpendicular al plano principal de la probeta.

Frecuencias naturales de vibración de un cuerpo sometido a una vibración de flexión. Se determinan mediante el módulo de elasticidad, la masa y las dimensiones de la probeta. La frecuencia de resonancia más baja en un modo de vibración es la fundamental de ese modo.

Función "ventana" que se aplica en el análisis de señales para filtrar un registro debido a la presencia de ruido, efecto leakage o para cortar un rango de datos de la señal. En el dominio de la frecuencia se expresa como la convolución del espectro de la función con el autoespectro de la señal mediante análisis de Fourier.

Composición, densidad y textura uniforme. El inverso de heterogéneo (Ej. hormigón).

Unidad de medición de la frecuencia de muestreo de la señal (Hertcio, Kilohertz $\approx$ ciclos/seg)

Método no destructivo de Impacto-Eco (ASTM C1383-04 Standard test method for measuring the Pwave speed \& the thickness of concrete plates) para cálculo de velocidad de onda $P$ y el alcance en profundidad al contorno o a un defecto interno.

"Principio de la impedancia acústica": la impedancia acústica es el producto de la velocidad de la onda y la densidad del material. (En hormigón es de $7-10 \bullet 10^{6} \mathrm{~kg} / \mathrm{m}^{2} \mathrm{~s}$ ). Dicho principio establece que la energía reflejada será tanto mayor cuanto mayor sea la diferencia entre las impedancias de los dos medios que forman la interfase del material de ensayo.

Es el tiempo entre cada punto de muestra en la forma de onda temporal. El inverso del intervalo de muestreo es la frecuencia de muestreo. 


Isótropo
Límite
proporcional
Longitud de
registro
MASW
MOE

Nivel de
disparo
(“Trigger”)

Onda Superficial

Probeta ensayo

\section{Rango de voltaje (Voltaje level)}

Rayleigh

"Signal trigger"

"Span"

$S W M$

Transductor

TEDS

Tiempo de contacto

Vibración de flexión
Condición de una probeta tal que los valores de las propiedades elásticas son los mismos en todas las direcciones de la probeta.

Es el esfuerzo más grande que un material es capaz de soportar sin alejarse de la proporcionalidad esfuerzo/deformación (Ley de Hooke).

Número de puntos en la forma de onda del dominio del tiempo multiplicado por el intervalo de muestreo.

Método AEOS de varios acelerómetros equidistantes (Multiple analysis of surface waves)

Relación entre el esfuerzo y la deformación por debajo del límite proporcional.

Se utiliza para indicar al sistema de adquisición de datos cuándo iniciar el almacenamiento de datos. Cuando la señal desde el receptor coincide con la condición de desencadenamiento, el número de puntos de datos especificado se almacena en la memoria. Normalmente, también se almacena una determinada duración de señal. Esta información "pre-trigger" es útil para evaluar la validez de la señal. En los casos donde hay un alto nivel de ruido ambiental o vibraciones, será necesario un mayor nivel de activación para evitar un falso trigger.

Aquella onda que se genera cuando una onda de cuerpo se encuentra con una superficie libre, para propagarse en una dirección paralela a la superficie con una amplitud que decrece con la distancia y la profundidad. Son ondas de dos tipos: Rayleigh o Love.

Probeta donde la relación entre la longitud y el espesor mínimo es como mínimo 5.

Rango máximo de amplitud que debe coincidir con el nivel más alto que se generará por el receptor durante una prueba. La salida depende de factores como la distancia entre el receptor y el punto de impacto, la suavidad de la superficie de ensayo, la distancia a la interfaz reflectante, el tipo de elemento que se está probando y el tiempo de contacto. El nivel de tensión debe ser el suficiente para que la forma de onda registrada se observe fácilmente cuando se procese. Esto permite al usuario la oportunidad de comprobar si la forma de onda es válida.

Tipo de onda superficial de baja frecuencia y mayor energía que las ondas $P$ o $S$

Evento correspondiente al nivel de disparo de la señal de entrada transitoria, donde configuramos el decaimiento de la señal (hold off), la hysteresis (contenido en ruido), el porcentaje o nivel de referencia de cálculo para que no muestre retardo el registro temporal.

Selección del rango de frecuencia de muestreo de la señal. "Bandwith” o ancho de banda máximo de frecuencias posibles debido a la limitación del equipo analizador de señales.

Método original de análisis de ondas en geofísica (Spectral Waveform method)

Receptor o acelerómetro de captación de ondas (piezoeléctricos) o de velocidad (captadores).

(Transducer electronic data sheet) Siglas del tipo de acelerómetros de transmisión automática de datos del sensor, conocidos como transductores inteligentes.

Es la duración del impacto en el choque con la superficie del material, entendido como el tiempo que transcurre desde que se generan ondas en el contorno del modelo. Una aproximación se deduce de la medición del desfase entre dos puntos en la primera onda generada en la señal.

Desplazamientos en una probeta situados en el plano perpendicular a su longitud. 


\section{Listado de Figuras}

Referencia

Figura 1

Figura 2

Figura 3

Figura 4

Figura 5

Figura 6

Figura 7

Figura 8

Figura 9

Figura 10

Figura 11

Figura 12

Figura 13

Figura 14

Figura 15

Figura 16

Figura 17

Figura 18

Figura 19

Figura 20

Figura 21

\section{Explicación}

Fabricación de mortero durante la preparación de los modelos de ensayo. Modelos finales.

Tabla de dosificaciones analizadas correspondientes a estudios previos relacionados.

Características del cemento tipo CEM I 42,5R.

Tablas de dosificación y componentes de la fabricación de la pasta de cemento y del mortero.

Ensayos de consistencia del mortero en la mesa de sacudidas. Muestra de mortero.

Agua para consistencia normal y tiempos de fraguado del cemento CEM I 42,5 R.

Control de producción y muestras de contraste.

Principio y final de fraguado para el CEM I 42,5 R determinado por el organismo certificador (AENOR).

Ejemplos de oquedades presentes en los primeros modelos de losas realizados para ensayo AEOS.

Densidad real y porosidad del árido.

Tabla de dosificación inicial para tres tipos de morteros.

Ejemplo de probetas de ensayos. Modelo de losa 40x40x10cm. Preparación y desmoldado de probetas 40x40x160mm para ensayos varios.

Tabla de desarrollo experimental (dosificaciones, especímenes y fechas de fabricación).

Naturaleza del cemento con Clinker Portland.

Ensayo de propagación de ondas superficiales en modelo tricapa de losa de mortero 40x40x20cm.

Ejemplo en PULSE v.16 de una señal temporal, espectro de Fourier y autoespectro.

Decaimiento amplitud de onda $R$ en profundidad. Esquema medio lineal homogéneo [Richart \& Woods 1970]. Relación entre coeficiente de amplitud vs profundidad en función de la longitud de onda en un medio lineal elástico.

Relación entre coeficiente de Poisson y las velocidades de propagación de ondas $(P),(S)$ y $(R)$ en un medio lineal y homogéneo elástico. Desplazamiento de la partícula [Richart \& Woods 1970].

El comportamiento de una onda P en una interfaz entre dos medios diferentes: A). Reflexión y refracción; (B) Conversión.

Esquema experimental de los ensayos AEOS con equipo Brüel\&Kjaer.

La velocidad de propagación de las ondas tipo Rayleigh o velocidad de fase de cada componente armónica, depende de la frecuencia, debido a lo cual las ondas de distinto período viajan con distinta velocidad, por lo que la señal se extiende en el tiempo al aumentar la distancia recorrida. 
Figura 22

Figura 23

Figura 24

Figura 25

Figura 26

Figura 27

Figura 28

Figura 29

Figura 30

Figura 31

Figura 32

Figura 33

Figura 34

Figura 35

Figura 36

Figura 37

Figura 38

Figura 39

Figura 40

Figura 41

Figura 42

Figura 43
Esquema general de la configuración de un ensayo AEOS (Fuente: "NDT Methods in concrete" Malhotra,2005).

Montaje típico del ensayo AEOS.

Ejemplo de captura de señales mediante ensayos AEOS. Detalle colocación de acelerómetros y configuración para la realización de mediciones en probetas y losas de mortero.

Montaje superficial y distanciamientos de acelerómetros.

Esquema y conclusiones derivadas del proceso experimental desarrollado en este trabajo. Tipos de martillos empleado en las mediciones AEOS en este trabajo (modelos 8206/8204 Brüel\&Kjaer).

Ficha principal de aplicación del filtrado de datos en la curva final de dispersión. Aporta además las recomendaciones básicas de distancias para obtener un ensayo AEOS ideal.

Ejemplo gráfico de coherencia en Matlab. Obsérvese como se consideran todos los registros en frecuencia y mediante una rutina implementada se filtran aquellas que no cumplen con una coherencia $>0.95$

Esquema del periodo característico de la señal en una configuración típica AEOS y definición de diferencia de fase entre dos puntos en una onda periódica.

Esquema de interpretación del análisis espectral de ondas superficiales

Salida gráfica de la rutina implementada en Matlab para un mortero bicapa (fase del espectro cruzado -wrapped phase- y despliegue de ángulos de fase-unwrapped phase-).

Efecto de campo cercano en transductor.

Ejemplo de despliegue de ángulos de fase (radianes) en modelo de una losa de $40 x 40$ de mortero tricapa: fase del espectro cruzado de energía (arriba), unwrapped phase (centro), coherencia (abajo).

Ejemplos de curvas de dispersión individual en modelos de morteros unicapa homogéneo y tricapa heterogéneo.

Configuración de análisis FFT en módulo de señales.

Ejemplo de curvas de dispersión en función de la velocidad de fase frente al contenido de frecuencias (izq) o frente a la longitud de onda (der). Coherencia de las señales con filtro de ventana Hamming.

Promedio de curvas de dispersión (velocidad fase vs frecuencias) identificando el intervalo de datos con coherencia válida. Representación de curva global mediante tendencia lineal.

El espectro de fase se representa en frecuencias (eje horizontal) y como ángulo de fase en radianes (eje vertical). Obsérvese que el espectro de fase muestra una gráfica en diente de sierra característica de alcanzar los valores mínimos de fase en -p. Ejemplo de promedio de curvas de dispersión en losa de $40 \times 40 \mathrm{~cm}$.

Coherencia, curva de dispersión experimental y curva global promediando registros a d:5,10 y $18 \mathrm{~cm}$ para losa $40 \times 40 \times 15 \mathrm{~cm}$ a la edad de 11 horas. Obsérvese como se invierte el perfil aumentando la velocidad proporcional a la longitud de onda.

Criterios de dispersión de velocidad.

Equipo de ensayo superficial. Ejemplo ensayo AEOS a losa bicapa 40x40x (10+5) cm con impacto largo.

Configuraciones típicas para la realización de ensayos AEOS.

Realización de ensayos AEOS con las dos configuraciones típicas con fuente común (der) y con punto central (izq) en modelo de losa de mortero $40 \times 40 \times 10 \mathrm{~cm}$. 
Figura 44

Figura 45

Figura 46

Figura 47

Figura 48

Figura 49

Figura 50

Figura 51

Figura 52

Figura 53

Figura 54

Figura 55

Figura 56

Figura 57

Figura 58

Figura 59

Figura 60

Figura 61

Figura 62

Figura 63

Figura 64
Ejemplo de espectro de potencia cruzado (magnitud y fase).

Ejemplo análisis AEOS mediante software de adquisicón de datos PULSE v.16 (Brüel\&Kjaer). (Izq/Der.) Desfase entre señales (der.); Autoespectros de energía (arriba); densidad espectral cruzada, fase del espectro cruzado, partes real e imaginaria espectro cruzado (centro); coherencia entre señales, unwrapped phase (abajo).

Detalle del efecto leakage en el espectro de Fourier de un registro temporal.

Detalle de la configuración del módulo de adquisición de datos (FFT Analyzer). Ejemplo de disparo o impacto en la superficie de un mortero, generado como una función escalón.

Detalle de adquisición del registro correspondiente al primer receptor debido al impato anterior que provoca la propagación de la onda.

Definición de señales en el dominio del tiempo. Introducción de datos FFT Analyzer.

Definición de espectros de Fourier y autoespectros de energía de cada registro.

Desarrollo de los pasos a seguir en el método AEOS. Detalle de su aplicación en modelo tricapa.

Determinación de espectros de energía, la densidad espectral cruzada y el periodograma de ambas señales.

Interpretación de la función de transferencia, densidad espectral y desarrollos en serie de Fourier.

Estimación de la cuota de densidad espectral cruzada entre señales, función de coherencia, "wavelet coherence method" y corrección de leakage mediante función ventana Hamming, correlación cruzada y co-varianza.

Espectro cruzado de potencia (magnitud, fase, partes real e imaginaria). Unwrapping method.

Espectograma de Fourier del espectro cruzado de energía, espectro de fase. Desenmascaramiento de ángulos de fase para obtener los ángulos de fase reales previos a la obtención de las velocidades de fase.

“Time histories” entre señales. Curva de dispersión bruta (sin promediar) $\operatorname{Vr} v \mathrm{\lambda}$.

Construcción de la curva de dispersión aplicando rangos de frecuencias válidas.

Curvas de dispersión globales. Promedio de ensayos a diferentes separaciones entre acelerómetros.

Tabla tipo ensayos AEOS y almacenamiento de resultados para la edad de 12horas.

Distribución de la dispersión de las partículas con la profundidad de dos ondas de superficie de diferentes longitudes de onda (RIX \& STOKOE, 1989).

Tabla de resultados para cada espécimen de 1, 2 y 3 capas de losas de mortero.

Modelo bicapa de mortero. Reparación de oquedades debido al desprendimiento de la nueva capa sobre el modelo de losa unicapa a la edad de 45 días de su curado. Estos defectos fueron apreciables en las pruebas de Impacto Eco. Posteriormente se rigidizó el conjunto.

Ejemplo gráfico de detección de defectos internos bajo capa de $5 \mathrm{~cm}$. El modelo bicapa es una losa de 40x40x(10+5)cm fabricada para ensayo AEOS a edades tempranas. (Arriba) Espécimen, detección de coqueras y reparación mediante sellado. (Izq.) Curva de dispersión de capa con defecto, menor velocidad y mayor dispersión de onda a bajas frecuencias. (Der.) Curva de dispersión de modelo sin defectos. 
Figura 65

Figura 66

Figura 67

Figura 68

Figura 69

Figura 70

Figura 71

Figura 72

Figura 73

Figura 74

Figura 75

Figura 76

Figura 77

Figura 78

Figura 79

Figura 80

Figura 81

Figura 82

Figura 83

Figura 84

Figura 85

Figura 86
Tabla a 28 días de los parámetros elásticos relevantes de cada modelo de losa.

(Izq.) Señal captada sin ruido aparente. (Der.) Señal captada con ruido aleatorio de fondo.

Espectro de magnitud y fase de la señal con ruido incoherente. Representación del espectrograma.

Configuración típica del ensayo I-Eco. Distanciamiento, señales de fuerza y desplazamiento.

Espectros de amplitud en el ensayo I-Eco variando la frecuencia resonante conforme detecta defectos internos. Montaje y equipo para el desarrollo experimental del trabajo con este técnica no destructiva.

Ejemplo de cálculo para una probeta de dim.40x40x160mm. Detalle de ensayos previos.

Definición del factor de forma indicado en la norma ASTM C1383. Ensayos en probetas de mortero de varias dosificaciones.

Espectro de amplitud mostrando la frecuencia pico. Función escalón de impacto generado tc:1ms. Señal temporal generada por el impacto afectada por ruido debido a la heterogeneidad del material a edad temprana.

Ejemplo de I-Eco en probetas (Detalle de señal de impacto, espectros Fourier, respuesta).

Resultados I-Eco (mortero a/c:0,5; f/c:2,25 a edades tempranas)

Comparativa de métodos AEOS, FFRC e I-Eco para una Losa TRI-capa de 40x40x(10+5+5)cm de mortero inferior 1;0,6;3,25 de 56dias; central (1;0,5;2,25) de 14 días; superior de 8horas de dosif. a/c:0,5; f/c:2,25 a edades tempranas.

Configuración de un ensayo típico mediante el método de Frecuencia Resonancia. Detalle equipo.

Esquema de la disposición FFRC para determinar la frecuencia de resonancia.

Montaje experimental de los ensayos en probetas prismáticas. Ejemplo de espectro y frecuencia de resonancia.

Detalle de cálculos propuestos en la norma ASTM E1876/09 Dynamic Young's Modulus, Shear Modulus \&Poisson's ratio by Impulse Excitation.

Tabla tipo con entrada de datos y salida de resultados de ensayos a rotura y método FFRC en probetas de mortero.

Ensayos a rotura posteriores a FFRC e I-ECO en probetas de mortero $4 x 4 x 16 \mathrm{~cm}$ a cada edad temprana (7h-24h). Amasada (1/0,4/2,70). En cada ensayo se ejecutan 2-3 probetas promediando los resultados.

(Izq). Esquema de la disposición de apoyos y zonas de impacto en FFRC. (Der.) Esquema en rotura.

Superposición de registros de disparo para configurar la señal de impacto ("triggers")

Configuración en PULSEv.16 de señal generada para Fs:20KHz y N:1024 ptos minimo en ensayos FFRC.

Tablas resumen de procesamiento de datos para determinación de módulos mediante FFRC en mortero tricapa.

El desarrollo analítico-experimental del método AEOS, se realizó en el Laboratorio de Materiales de la E.T.S. Ingeniería de Caminos, Granada, durante Noviembre 2011-Abril 2012, período de fabricación, fraguado y curado de especímenes de morteros confeccionados para este trabajo (...) 
Figura 87

Figura 88

Figura 89

Figura 90

Figura 91

Figura 92

Figura 93

Figura 94

Figura 95

Figura 96

Figura 97

Figura 98

Figura 99

Figura 100

Figura 101

Figura 102

Figura 103

Figura 104

Figura 105

Figura 106

Figura 107
Explicación del acelerómetro piezoeléctrico y sus efectos. Ruido triboeléctrico. Adhesivos.

Las probetas prismáticas de 40x40x160mm ideales para los métodos de análisis vistos, estaban compuestas de cemento Portland I, agua y áridos lavados de Ønominal 2,5-4mm a nivel general. El ensayo AEOS se preparó con posición inicial “Common source” entre los acelerómetros, con distancia contorno-fuente $=4 \mathrm{~cm}$; impacto-receptor, $d 1=6 \mathrm{~cm}, d 2=5,10,20 \mathrm{~cm}$ (SASW_01), y contrastando a distancias d2: $6,12,18,24,30 \mathrm{~cm}$, de un segundo ensayo (SASW_02), ortogonal al anterior.

Esquema proceso del método AEOS desde la adquisición de datos, procesamiento de señales hasta la curva de dispersión bruta y global [promedio de ensayos a distancias d2:6/12/18/24cm].

Comparativa de resultados a la edad de 6 días para cada método de ensayo no destructivo. Validez del método AEOS en modelo de losa unicapa homogénea. Obsérvese como la curva de dispersión es de Vr constante vs longitud onda $5 \mathrm{~cm}$. La linealidad de la curva de dispersión muestra la homogeneidad de la mezcla de mortero ensayada.

Comparativa de resultados a la edad de 28 días para cada método de ensayo no destructivo. Validez del método AEOS en modelo de losa unicapa homogénea de mayor espesor. (Error<5\%).

Esquema de los pasos a seguir para obtener la curva de dispersión en un ensayo tipo por el método AEOS.

AEOS mediante rutina en Matlab para determinar la curva de dispersión (velocidad de fase vs $\lambda$ ). Edad 36 horas.

Evolución velocidades de onda vs Edad curado [Mientras que el ensayo AEOS_02 muestra similitud con las técnicas I-E y FFRC, el ensayo AEOS_O1 se aleja en un margen intermedio para después alcanzar un paralelismo].

Comparativa resultados a la edad final de 36horas por cada método para la losa de 40x40x15cm.

Esquema de la reducción de pasos que constituyen un ensayo del método espectral de ondas superficiales para determinar la curva de dispersión.

Configuración de "Trigger". Impactos realizados. Procesamiento de señales temporales identificando desfase.

Configuración de disparo (trigger) en módulo de señales “Pulse v.16”.

Ejemplo de promedio de espectro cruzado, densidad espectral cruzada, partes real e imaginaria del espectro de fases y rango válido de frecuencias a partir de la función de coherencia. Detalle del método de despliegue de fase.

Proceso de filtrado de discontinuidades de fase y frecuencias incoherentes para la construcción de la curva local de dispersión. Observar como se elimina de las señales en el tiempo el intervalo de ruido correspondiente a las reflexiones de onda con el contorno del modelo. (Arriba). Curva de dispersión final evitando fallos locales.

Ejemplo para el registro con $d_{1}: 6 \mathrm{~cm}$ y $d_{2}: 12 \mathrm{~cm}$. Obsérvese el efecto de las discontinuidades de fase en la curva bruta de dispersión, por lo que será necesario filtrar las frecuencias no válidas.

Filtrado de la curva de dispersión para el ensayo con $d_{2}: 24 \mathrm{~cm}$

Promedio en frecuencia de la función de coherencia de los 5 registros anteriores. Filtrado para valores $>0.95$

Detalle del procesamiento de las curvas de dispersión en Matlab. Obtención de una velocidad de onda superficial de $2031 \mathrm{~m} / \mathrm{s}$ para una longitud de onda de $5 \mathrm{~cm}$, un valor aceptable para un mortero estructural de buena calidad.

Curva global de dispersión mediante promediado de curvas y considerando desviación estándar.

Evolución velocidades de onda vs Edad curado [En este caso, las distancias mayores ofrecen mayor dispersión de datos, y es debido a que separaciones del orden de 30-40cm se alejan del 
Figura 108

Figura 109

Figura 110

Figura 111

Figura 112

Figura 113

Figura 114

Figura 115

Figura 116

Figura 117

Figura 118

Figura 119

Figura 120

Figura 121

Figura 122

Figura 123

Figura 124

Figura 125

Figura 126

Figura 127

Figura 128 criterio de filtrado establecido]. Recordemos que un ensayo AEOS es válido mientras $d_{2} \leq \lambda$.

Comparativa resultados a la edad final de $120 \mathrm{~h}$ para cada técnica reservada para validación del método AEOS.

Modelo de tabla para procesado de datos del método AEOS. [Incluye rutina desarrollada para cálculo automatizado de los ensayos mediante FFRC, I-ECO y ensayo de resistencia a rotura]. Velocidades de fase para Losa e.20cm.

Similitud de espectros de fase y fase desplegada para 4 registros diferentes para un mismo ensayo.

Tabla de normativa ASTM de aplicación y consulta para morteros.

Tabla de normativa ACI Codes de aplicación y consulta para morteros y hormigón estructural.

Tabla de normativa UNE de aplicación y consulta para cemento, áridos y morteros.

Determinación de resistencias mecánicas en un cemento mediante ensayo UNE EN 196/1.

Parámetros de configuración de ensayos en prensa hidráulica.

Tabla de resistencias y edades para cada mezcla de mortero de ensayo.

Resultados obtenidos en los ensayos de compresión de las probetas 40x40x160mm correspondientes a los morteros de mezclas $A, B$ y $C$.

Relación existente entre las resistencias de los tres morteros referenciadas al valor máximo.

Comparativa de resistencias mecánicas mediante rotura de probetas a flexo/compresión frente al método FFRC (Frecuencia Resonancia).

Tabla de constantes elásticas de un material. Relación entre magnitudes.

Tablas de Correlación entre el módulo dinámico de elasticidad y resistencia a compresión.

Características del aditivo superplastificante GLENIUM ACE 324 proporcionadas por el fabricante.

Tablas de características técnicas de aditivo empleado en las mezclas. Ficha técnica AENOR del tipo de cemento suministrado.

(Izq). Amasadora empleada para fabricar las pastas de cemento. (Der). Determinación de la consistencia normal de la pasta. Dispositivo de los tiempos de fraguado (UNE-EN 196-3).

Tiempos de fraguado para el cemento combinado con diferentes dosis de aditivo.

Gráfica de evolución del fraguado del mortero tipo (1/0,5/3) [c/c;a/c;f/c] amasada Noviembre 2011 con el principio y final de fraguado marcados.

Gráfica de evolución del fraguado del mortero tipo (1/0,5/2,25) [c/c;a/c;f/c] amasada Abril 2012 con el principio y final de fraguado marcados.

Desarrollo de los experimentos en modelos de losa tricapa donde la superficie del espécimen muestra esa baja relación agua/cemento determinante en las resistencias finales del modelo tipo (1/0,5/2,25) [c/c;a/c;f/c]- Amasada Abril 2012. 


\section{Agradecimientos.}

Este estudio ha sido financiado por el Programa de Fondos Tecnológicos del Centro para el Desarrollo Tecnológico Industrial (CDTI) para financiación de proyectos $\mathrm{I}+\mathrm{D}+\mathrm{i}$, mediante el proyecto integrado T3CI “Tecnología para el control del curado del hormigón en la construcción de infraestructuras” (Empresas participantes: Azvi, Geolen Ingeniería y Aertec).

Durante el tiempo de desarrollo de este estudio han sido muchas las personas que han contribuido a que se desarrollara satisfactoriamente. Principalmente a mi tutor D. Rafael Gallego Sevilla, excelente en trato y profesionalidad, quiero agradecerle la oportunidad que me ha dado al confiarme este trabajo; a su vez, a los miembros del grupo de investigación de Mecánica de Sólidos y Estructuras, y a los componentes del Laboratorio de Materiales de la ETSICCP bajo la dirección del estimado Prof. José R. Montero, por su acogida, apoyo diario y por su paciencia en los avances desarrollados para la redacción de este trabajo.

$Y$, gracias también, a todas las personas con las que he mantenido contacto durante estos meses, porque todas ellas han contribuido a que esta etapa de mi vida sea muy satisfactoria tanto desde el punto de vista profesional como personal.

Por último, agradezco de manera especial el apoyo de mi pequeña familia ... a Rebeca, por tu paciencia depositada en mí, que a pesar de los malos momentos y dificultades que pasamos juntos, conseguiste que no perdiera la confianza en mí mismo... a mi hijo Daniel, por todo, porque su forma de ser, su espontaneidad, cimentan mi afán de superación...y mi hija Zoila, porque llegaste cuando más lo necesitábamos.

\section{UgV Universidad} de Granada 
RESUMEN.

\section{ANÁLISIS EXPERIMENTAL DE LA CURVA DE DISPERSIÓN MEDIANTE PROPAGACIÓN DE ONDAS SUPERFICIALES EN MORTEROS A EDADES TEMPRANAS MEDIANTE MÉTODO AEOS.}

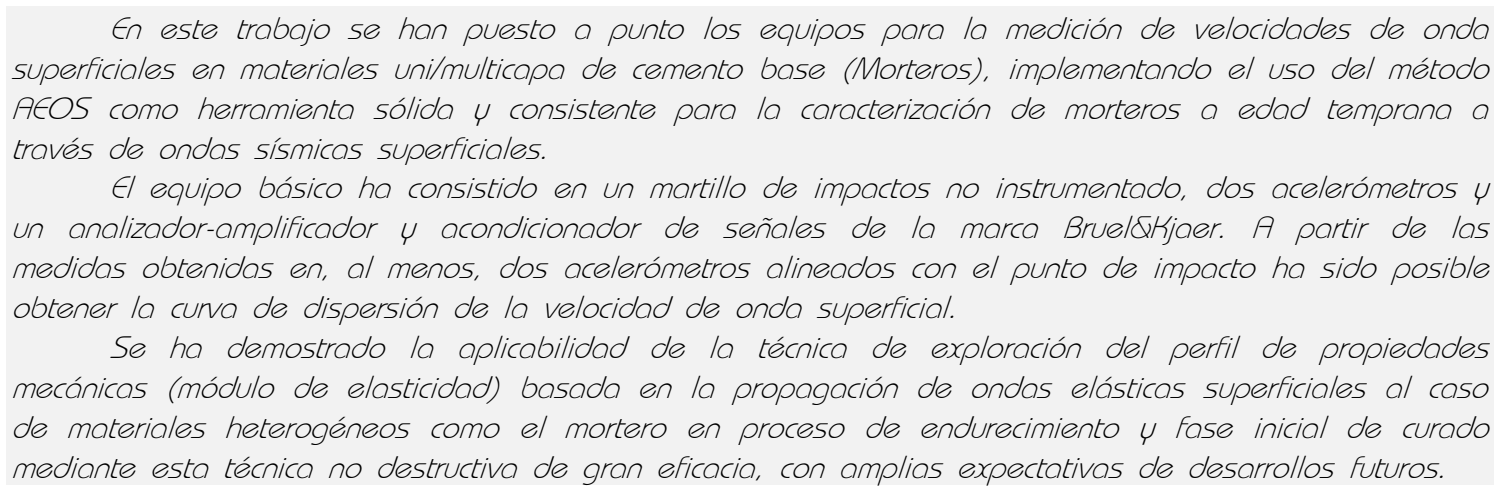

En este trabajo se han puesto a punto los equipos para la medición de velocidades de onda superficiales en materiales unilmulticapa de cemento base (Morteros), implementando el uso del método AEOS como herramienta sólida y consistente para la caracterización de morteros a edad temprana a través de ondas sísmicas superficiales.

El equipo básico ha consistido en un martillo de impactos no instrumentado, dos acelerómetros $y$ un analizador-amplificador y acondicionador de señales de la marca Brueldkjaer. A partir de las medidas obtenidas en, al menos, dos acelerómetros alineados con el punto de impacto ha sido posible obtener la curva de dispersión de la velocidad de anda superficial.

Se ha demostrado la aplicabilidad de la técnica de exploración del perfil de propiedades mecánicas (módulo de elasticidad) basada en la propagación de ondas elásticas superficiales al caso de materiales heterogéneos como el mortero en proceso de endurecimiento $y$ fase inicial de curado mediante esta técnica no destructiva de gran eficacia, con amplias expectativas de desarrollos futuros.

El tema central del estudio se presenta como un análisis de la metodología de caracterización mecánica no destructiva de morteros de edad temprana (proceso de endurecimiento), mediante la técnica no destructiva, flexible y rentable, de Análisis Espectral de Ondas Superficiales (Código ACl 228.2R-98 "Nondestructive Test Methods for Evaluation of Concrete in Structures") que recurre al estudio de la curva de dispersión para obtener las velocidades de fase en función de la longitud de onda, mediante el procesamiento de señales generadas por impacto a bajas frecuencias con martillos calibrados, dos transductores piezoeléctricos y un equipo de vibración analizador de Brüel\&Kjaer adquirido y puesto a punto para el desarrollo del método AEOS en morteros a edad temprana.

Como objetivo principal del trabajo se ha determinado la información necesaria de modelos estructurales de morteros dosificados de distinta forma (simulando perfiles heterogéneos y dispersivos debido a la diferente forma de curado de los especímenes), mediante el citado método de ensayo no destructivo de propagación de ondas superficiales [AEOS o SASW]: técnica idónea para definir directamente la curva de dispersión proporcionando la velocidad de onda superficial en función de la longitud de onda, variable valiosa dentro del perfil de capas de un material, ya que a través de este valor se derivan parámetros importantes estructurales (resistencias, módulos...) en morteros a edad temprana, presentando sus propiedades según proceso de curado, espesor y profundidad desde la superficie.

Conocido como método de caracterización no invasivo, desarrollado por Jones (1958) y evolucionado por Stokoe \& Nazarian (1980) en geotecnia y pavimentos en su origen, hoy día, debido a sus posibilidades, se constituye como una alternativa significativa, más rápida, limpia y económica por su naturaleza no destructiva, en comparación a otras metodologías normalmente utilizadas.

La investigación se ha centrado principalmente en la aplicación de la teoría de propagación de la onda Rayleigh en un medio heterogéneo viscoelástico lineal basado en modelos reales tipo placa de morteros fabricados en laboratorio con diferentes dosificaciones para determinar mediante impactos a bajas frecuencias (alta longitud de onda y alcance en profundidad) la velocidad de onda en cada capa interna a diferentes edades de fraguado. Basado en el principio de que los diversos componentes de la longitud de onda en la superficie de impacto penetran a diferentes profundidades en un medio dispersivo de ondas R, las frecuencias de la onda se propagan a diferentes velocidades de fase.

Por tanto, se analizan y discuten las diferentes bases/etapas/resultados experimentales, del método explorando en detalle, su alcance, limitaciones, desarrollo computacional e implementación de la rutina como programa con aplicabilidad próxima a hormigones. Para validar el método los resultados se contrastaron con otras dos metodologías complementarias no destructivas, las técnicas de Frecuencia-Resonancia (FFRC) y de Impacto-Eco (IE). 


\section{ÍNDICE DE CONTENIDOS}

- LISTADO DE SÍMBOLOS. TERMINOLOGÍA.

- AGRADECIMIENTOS.

- RESUMEN.

- INTRODUCCIÓN, DESCRIPCIÓN, JUSTIFICACIÓN Y OBJETIVIDAD.

Introducción. Justificación y objetivos pags.1-4

Objetivos principales. Metodología aplicada.

Avance en ensayos y desarrollo experimental previsto.

Planteamiento y organigrama del trabajo.

- ESTADO DEL CONOCIMIENTO (Materiales y Teoría de Ondas).

(I). Materiales y métodos: TECNOLOGÍA DEL MORTERO pags. $5-14$

Antecedentes de la mezcla. Factores y diseño.

Proceso inicial de dosificación en morteros de edad temprana.

Secuencia de amasado para la fabricación del mortero. Normativa.

Dosificación de la pasta de cemento y del mortero.

Justificación del mortero.

Observaciones a los componentes del mortero para ensayos.

Plan de Trabajo.

Dosificaciones iniciales y ensayos previos adoptados a normativa.

(II). Materiales y métodos: TECNOLOGÍA DEL CEMENTO pags.15-18

Curado e hidratación del Cemento Portland.

Secuencia y tiempo de curación. Operaciones de acabado.

Necesidad y preparación del curado. Control de humedad y Ta.

Procedimientos de curado. Condiciones. Secuencia y tiempos.

Trabajos de acabado. Requerimientos mínimos. Desencofrado.

(III). Teoría de propagación de ondas: Metodología.

pags.19-26

Antecedentes teóricos de Onda Rayleigh.

Tipos de cargas dinámicas. Naturaleza de las cargas impulsivas.

Principios de Ondas elásticas: definiciones y terminología.

Naturaleza de las cargas impulsivas. Ondas Rayleigh.

Formulación teórica. Análisis de la onda R.

Velocidad de propagación de la onda. Reflexión y Refracción.

- METODOLOGÍA. Desarrollo analítico.

(IV). Antecedentes teóricos e históricos. pags. $27-30$

Precedentes del método de ensayo. 
(V). Desarrollo básico [Análisis Espectral de Ondas Superficiales]

pags.31-43

Una visión general del método por impacto. Caracterización.

Etapas del método. Criterios de filtrado.

Efecto del impacto sobre el tiempo de contacto.

Función de fase. Efecto de campo-cercano.

Aproximación a las propiedades elásticas.

(VI). Desarrollo avanzado del método "AEOS"

pags. $44-60$

Caracterización mecánica en morteros frescos a edad temprana.

Criterios para la interpretación de ensayos AEOS.

Fundamentos teóricos del método.

Evaluación computacional de la curva de dispersión. Ejemplo.

Factores que han influido en el desarrollo del método. Problemática.

Posición relativa de los acelerómetros en los ensayos.

Dispersión y atenuación de onda.

Caracterización de la absorción. Defectos internos. Relación a/c.

Tamaño del árido. Ruido coherente y aleatorio.

(VII). Metodología de análisis. Técnicas paralelas END previstas....... pags. 61-70

Determinación de parámetros elásticos del material ( $E, G, \mu, \rho)$.

* Impacto-Eco (ASTM [1383/2010) *

* Frecuencia-resonancia (FFRC ASTM C215/2002) *

- PROCEDIMIENTO DE ANÁLISIS EXPERIMENTAL.

(VIII). Ensayos, aproximaciones y resultados experimentales pags. $71-84$

Desarrollo experimental.

Adquisición de datos. Equipo B\&K captador de señales.

Justificación de los instrumentos para medición.

Análisis integral del mortero a edad temprana mediante la aplicación de

Ios 3 métodos [FFRC+I_E+SASW]. Ensayos a Losas $40 \times 40 \mathrm{~cm}$ y Probetas.

Ejemplos Losa unicapa/bicapa/tricapa.

Configuración de los ensayos. Parámetros. Procedimientos.

Obtención de la curva de dispersión. Comparativa de resultados.

Resultados, recomendaciones y análisis posterior. Validación.

- CONCLUSIONES

pags. $85-91$

C 01. Comportamiento dispersivo del mortero.

C 02. Método de propagación de ondas superficiales. Otras técnicas END.

C 03. Ventajas e inconvenientes del método AEOS.

C 04. Aspectos clave del método.

C 05. Discusión de variabilidad en resultados.

C 06. Experiencias propias en los ensayos experimentales.

C 07. Conclusiones en el desarrollo de la rutina computacional del método.

- FUTURAS LÍNEAS DE INVESTIGACIÓN. pags. $92-93$

Objetivos, aplicaciones en desarrollo y trabajos futuros. 
Recomendaciones de estudio a largo plazo.

- REFERENCIAS A NORMATIVA. APLICACIÓN ACTUAL

pags. $94-95$

ASTM Standards. Códigos ACI. Normativa UNE.

- BIBLIOGRAFÍA (CATEGORÍAS)

pags. 96-104

Artículos en periódicos y revistas científicas.

Documentos, tesis y trabajos de investigación.

Libros y capítulos bibliográficos.

Normativas y Reglamentos.

Congresos, conferencias y webs específicas.

- ANEXOS

pags. $105-123$

Anexo 01. Características mecánicas del mortero. Resistencia a flexión/compresión.

Anexo 02. Parámetros elásticos en material elástico, lineal, isótropo y homogéneo.

Anexo 03. Materiales, medios, equipos e instrumentos de ensayo.

Anexo 04. Herramientas de procesamiento de señales.

Anexo 05. Ensayos paralelos. Observaciones del curado del mortero.

Anexo 06. Tablas de resultados en morteros uni/bi/tri-capa a edades tempranas. 


\section{Análisis Espectral de Ondas Superficiales (AEOS)}

INTRODUCCIÓN, DESCRIPCIÓN, JUSTIFICACIÓN Y OBJETIVOS DEL ESTUDIO

Durante la etapa de construcción o el ciclo de vida de un mortero o un hormigón estructural, necesita ser evaluada la integridad del modelo. Una inspección visual sólo proporciona información sobre lo que ha ocurrido en la superficie. Para controlar la calidad de las estructuras nuevas o evaluar el deterioro de las existentes, se utilizan métodos destructivos de extracción de muestras de laboratorio difíciles de adquirir y perjudiciales debido a los daños causados.

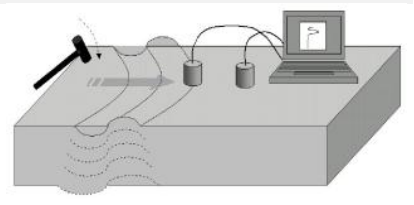

Introducción.

El ciclo de vida y capacidad de carga del mortero, como material de matriz de cemento, depende en gran parte de su espesor, mezcla original, condiciones de curado, vertido y colocación... La práctica común de evaluación es la aplicación de técnicas invasivas destructivas. El mortero, por su heterogeneidad, es un material particular del que se desconocen sus propiedades reales en estado fresco, siendo preciso evaluar con relativa fiabilidad sus parámetros elásticos a edades tempranas:

- Por la seguridad de las estructuras ya que se evitarían colapsos a la hora de descimbrar determinados elementos constructivos y, si se conociera el nivel de resistencia alcanzada a edades tempranas, se podría disminuir ese riesgo.

- Por el rendimiento de la obra puesto que se pueden acortar los plazos de desencofrado y, por tanto, los plazos de ejecución, disminuyendo así los costes de producción.

Normalmente las propiedades resistentes de un mortero se estiman por defecto a los comúnmente utilizados, en la mayoría de las ocasiones no se determinan con precisión las propiedades a edades tempranas ni los parámetros elásticos del material en los primeros días, ya que se suele hacer sobre probetas que no reproducen con la suficiente fiabilidad las condiciones que pueden presentarse en los elementos constructivos. Por ello, este trabajo evalúa la aplicabilidad del método no destructivo de ondas superficiales a las estructuras de mortero actuales, mediante la técnica AEOS, utilizada con difusión en el análisis de pavimentos desde los años 80 .
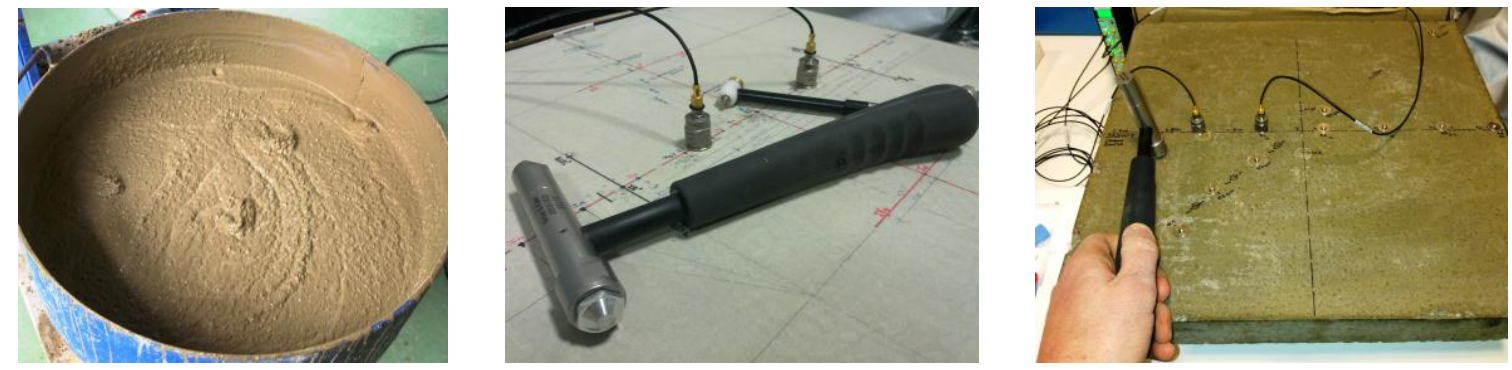

(Fig. 1). Fabricación de mortero durante la preparación de los modelos de ensayo. Modelos finales. 
Demostrar la aplicabilidad de la técnica de exploración del perfil de propiedades mecánicas basada en la propagación de ondas elásticas superficiales al caso de morteros en proceso de endurecimiento. La descripción de éste método involucra las siguientes etapas fundamentales:

- Calibración experimental de equipos de captación y procesamiento de señales.

- Fabricación de modelos estructurales propios en laboratorio, determinación de largos períodos de ensayos para obtener una técnica fiable de cálculo de la curva de dispersión, las propiedades del material y sus resistencias mecánicas.

- Método directo y análisis posterior. Validación con otras técnicas.

Metodología aplicada.

Para verificar el método se exponen las mediciones reales experimentales sobre especímenes de mortero fabricados en el Laboratorio de Materiales [ETSICCP Granada] y ensayados con un equipo de vibraciones de la marca Brüel\&Kjaer de reciente adquisición.

En particular se ha desarrollado la posibilidad de obtener de los ensayos realizados la curva de dispersión de velocidad de onda para rangos de frecuencias $1 \mathrm{~Hz}$ a $60 \mathrm{KHz}$ en modelos estructurales de diferentes espesores y estratigrafía por su edad de curado [la necesidad de un enfoque estacional para determinar la curva experimental de dispersión esencialmente está relacionada con la variación espacial de velocidad de fase frente a la longitud de onda, ya que no depende sólo de las propiedades mecánicas del medio].

En el presente trabajo, se analizan y discuten las diferentes bases y etapas del método explorando cada una de ellas en detalle y profundidad, sus alcances y aplicaciones, además, se desarrollan metodologías paralelas de comprobación de los resultados, que parten de una extensa bibliografía asociada al empleo de técnicas no destructivas en ingeniería, permitiendo comprender cómo implementar este método de caracterización a morteros estratificados. El estudio desarrolla las siguientes actividades:

- Determinación de parámetros elásticos mediante aplicación END con propagación de ondas por impacto superficial de morteros usuales en ingeniería, para diferentes dosificaciones y modelos estructurales. Correlación de los ensayos realizados cuestionando la fenomenología del mortero a edad temprana y sus consecuencias en estructuras reales.

- Cálculo de la curva de dispersión en morteros a edad temprana mediante análisis espectral de ondas superficiales de baja frecuencia. Validación con métodos de FrecuenciaResonancia e Impacto-Eco mediante ensayos a probetas 40x40x160mm y modelo unicapa/bicapa/tricapa de losas de $40 \times 40 \mathrm{~cm}$ y espesores 5 a $20 \mathrm{~cm}$.

- Determinación del módulo de elasticidad estático y dinámico, rigidez transversal, coeficiente de Poisson, resistencias y densidad sobre las probetas mediante la técnica no destructiva de impactos en superficie del material. 
Esta tecnología, basándose en sus ideales iniciales (Jones 1958), abre una nueva rama de investigación desarrollando una metodología muy avanzada con nuevos desarrollos para caracterizar de manera no intrusiva las estructuras en cuanto a precisión, para calcular globalmente los parámetros del material e inferir su perfil de velocidades. Por lo tanto, sí es posible obtener la curva de dispersión (la relación velocidad de fase vs frecuencia) experimentalmente y, los parámetros mecánicos del medio esencialmente con tres pasos: ensayo experimental, análisis de los registros temporales y curva de dispersión global de velocidades de fase. Posteriormente el método deja abierta una vía futura de validación mediante la aplicación del proceso de inversión.

Ensayos previstos. Desarrollo experimental.

Se describen los conceptos básicos relacionados con la respuesta sísmica y el comportamiento ante cargas impulsivas y la evolución de los parámetros elásticos del material, directamente asociados a la propagación de ondas superficiales de tipo Rayleigh, en un espacio infinito, isótropo, elástico, lineal y homogéneo. Se explican los conceptos asociados al análisis de señales, ya que permiten entender el procedimiento para desarrollar las curvas de dispersión.

Para ensayar la variación de las propiedades en todo el espesor del modelo, se utilizan modelos de probetas prismáticas $40 \times 40 \times 160 m m$ y modelos uni/bi/tri-capas, variables en dosificación y espesor, fabricados en el Laboratorio en tiempo y condiciones diferentes, de especímenes tipo losa-placa de $\mathbf{4 0 0 x 4 0 0 m m}$ para simular efectos reales en estructuras de mayor escala (ASTM C192). Se aplican además del método AEOS, las técnicas impacto-eco (IE), y frecuencia-resonancia (FFRC).

Inicialmente, partiendo de artículos asociados al empleo del SASW en geofísica, permitieron comprender cómo implementarlo en morteros como método de caracterización de un material estratificado a edad temprana, logrando los parámetros elásticos del material con tan solo un "par de receptores y un martillo". De ésta manera, en la medida que el trabajo ha ido evolucionando, los conceptos de desfase, velocidad de onda, coherencia, dispersión... del tratamiento de señales, fueron adaptados gradualmente, implementados como parte de la rutina computacional del AEOS.

Cabe destacar que el objetivo principal del trabajo no es sólo descifrar de manera detallada y minuciosa los procesos del método, sino a partir del completo entendimiento del fenómeno y su metodología, plantear una alternativa para calcular globalmente uno/varios parámetros, implementando rutinas que utilizan dos acelerómetros monoaxiales y un martillo equipado para generar bajas/altas frecuencias, y planteando una línea futura de trabajo en el uso de varios sensores de señales (SASW/MASW). 
a) Puesta a punto de equipo de vibraciones Brüel\&Kjaer, calibrado de acelerómetros, preparación de materiales y equipos de laboratorio, montaje de bandas extensométricas y fabricación de morteros para probetas de ensayo y encofrado de losas a mayor escala en molde de polietileno reticulado e.2,5mm de dimensiones max. 400x400x200mm.

b) El trabajo se centrará en el empleo de un mortero plástico con cemento común que suele emplearse con frecuencia: CEM-I 42,5N. (UNE-EN 196-1/2005; 197-1/2000; 1015-2/99). Composición: Cemento Portland tipo I, árido fino normalizado suministrado con un tamaño máximo de 4 mm y alto contenido en filler, y aditivo con plastificante $(0,25$ a 0,9\%).

c) Asignación de árido específico mediante análisis granulométrico en laboratorio de muestras disponibles. Se propone un árido tamizado de Ø2,6-4mm (UNE 146901/2002) utilizado para la composición de morteros específicos de diferentes dosificaciones.

d) Fabricación de morteros con diferentes relaciones a/c; fino/c... recomendadas para mejor trabajabilidad (a/c: 0,4-0,5-0,6) según métodos empíricos y puesta en obra (UNE EN196, EN197, EN934-2). La dosificación árido fino/cemento (f/c: 2,25 a 3,25). [Las dosificaciones se justifican respondiendo de forma básica a una serie de mezclas comunes estándar en estructuras reales].

e) Determinación de parámetros relacionados con las propiedades del material, a fin de poder correlacionar en el ensayo SASW posterior las velocidades de propagación de onda mediante formulación específica del método de evaluación.

f) Cálculo de parámetros elásticos de cada muestra (Módulo de Elasticidad, E; coeficiente de Poisson, u; densidad de masa, $\rho$; Módulo de Elasticidad dinámico, Ed; coeficiente de Poisson dinámico, ud; Módulo de rigidez transversal, G), que permitan correlacionar los resultados AEOS por medio de dos técnicas adicionales conocidas, Frecuencia de resonancia e Impacto-Eco. Los parámetros del material se determinarán mediante tests a intervalos regulares (1-1,5h) desde las 7 horas de su fabricación hasta los 28 días (curado de probetas: 1-2 días fraguando en molde a $T^{\underline{a}} 20^{\circ} \pm 2{ }^{\circ} \mathrm{C}$ y Hr: $65 \% \pm 5 \%$ y 21 días restantes desmoldado en cámara húmeda al aire; normas ASTM C192/2006, UNE EN 1015-11/1999, ACI 318M-08, ACI 228.2R 98 y ACI 308R 01).

g) Para analizar y comparar los resultados obtenidos de cada mortero, se fabrican 3 modelos de losas uni/bi/tri-capas de morteros diferentes, y un amplio $n^{\circ}$ de probetas $4 \times 4 \times 16 \mathrm{~cm}$ para la realización de ensayos paralelos a edades tempranas. Se tomarán registros desde las 7 , 8, 9, 10, 11, 12, 13, 14, 16, 18, 21, 24, 48horas , y a 3, 4, 5, 6, 7, 14, 21 hasta 28 días.

h) Elaboración de rutina computacional que implemente el método para el análisis de todos los registros temporales para cada modelo ensayado mediante el método AEOS.

i) Registrados los ensayos para cada modelo uni/bi/tri-capas, y comprobados los parámetros elásticos del material deducidos con las técnicas auxiliares de I-E / FFRC, se extraen las conclusiones del AEOS a edades tempranas. Comparativa de gráficos resultantes. 


\section{Análisis Espectral de Ondas Superficiales (AEOS)}

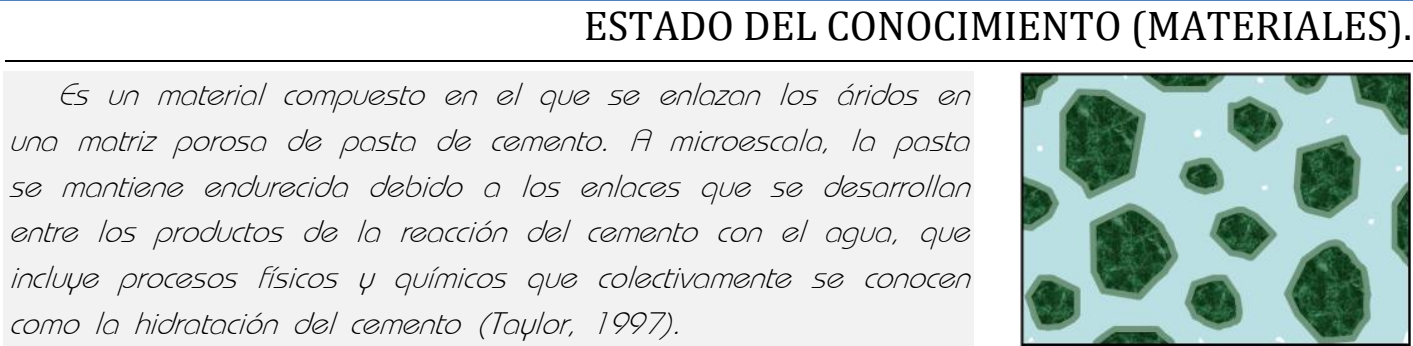

\section{Materiales y métodos (I): TECNOLOGÍA DEL MORTERO}

Antecedentes de la mezcla. Factores y diseño.

La fabricación del mortero con cemento Portland, en condiciones climáticas normales, ha influido de manera directa en las características y en las propiedades físicas y mecánicas, para cualquier etapa del mismo: amasado, enmoldado, vertido, vibrado y curado, así como cuando es mezclado con agua se libera calor de hidratación, que es el resultado de la reacción química exotérmica incrementando la temperatura del mortero. El efecto conjunto de las condiciones térmicas ambientales y el calor de hidratación del cemento podía agravar la resistencia final del material, principalmente a compresión. Existen métodos de actuación para minimizar este efecto perjudicial, destacando aquellos que han sido referentes en los morteros fabricados en este trabajo:

- Actuaciones sobre los áridos.- El mayor volumen del mortero lo constituyen los áridos, requieren de más tiempo y de más recursos energéticos que el resto de componentes.

- Actuaciones sobre el agua de amasado.- La temperatura del agua tiene la ventaja de poder ser controlada (calor específico=1), y a pesar de que se emplea en menores cantidades que los otros constituyentes, el uso de agua fría efectuó una reducción en la $T^{a}$ del amasado.

- Actuaciones sobre los aditivos.- Retrasando el fraguado (retardadores) o reduciendo la cantidad del agua (plastificantes), evitaron una reacción exotérmica de hidratación durante el fraguado, compensando la manejabilidad, fisuración, tiempo de fraguado y a/c.

- Actuaciones sobre la dosificación del cemento.- Se ha evitado utilizar cementos de rápido endurecimiento y controlar cualquier sobredosificación común en una amasada de la cantidad de cemento que modificase la dosificación y las resistencias mecánicas.

- Actuaciones sobre el curado.- como garantía de las prestaciones de ejecución del mortero, es la etapa más crítica para las posteriores propiedades físicas y mecánicas.

El inicio del trabajo parte de un desarrollo experimental del tipo de mortero que debía utilizar, previamente a la realización de los morteros de ensayo se estudiaron los materiales de composición, las dosificaciones deseadas, optando por aquellas que ofrecían mayor compactación, mejora de aspecto, color... se realizaron varias proporciones con finalidades similares en el estudio de las propiedades de morteros a edad temprana.

Se citan a continuación algunas referencias que sirvieron de punto de partida: 


\begin{tabular}{|c|c|c|}
\hline \multirow{7}{*}{ 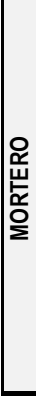 } & Artículo: & $\begin{array}{l}\text { Nondestructive evaluation of in-place cement mortar } \\
\text { compressive strength using SASW }\end{array}$ \\
\hline & Año: & 2000 \\
\hline & Autores: & Young S. Cho, Feng-Bao Lin \\
\hline & Dosificación & Losa A > 1: 0,5: 2,25 \\
\hline & (c/c;a/c;finos/c;grava/c) & Losa B > 1: 0,6: 3,25 \\
\hline & $\begin{array}{c}\text { Clase cemento (UNE-EN } \\
197-1: 2000)\end{array}$ & CEM I \\
\hline & $\begin{array}{l}\text { Dimensiones modelo } \\
\text { ensavo: }\end{array}$ & $\begin{array}{c}\text { Losas } 900 \times 900 \times 100 \mathrm{~mm} \\
\text { Ensayo fcd: } 101,6 \times 101,6 \times 305 \mathrm{~mm} / \varnothing 76 \times 150 \mathrm{~mm}(\mathrm{ACl})\end{array}$ \\
\hline
\end{tabular}

\begin{tabular}{|c|c|}
\hline Artículo: & $\begin{array}{c}\text { EFFECT OF AGGREGATE SIZE ON ATTENUATION } \\
\text { OF RAYLEIGH SURFACE WAVES IN CEMENT- } \\
\text { BASED MATERIALS }\end{array}$ \\
\hline Año: & 2000 \\
\hline Autores: & Laurence J. Jacobs, Joseph O. Owino \\
\hline \multirow{2}{*}{$\begin{array}{c}\text { Dosificación } \\
\text { (c/c;a/c;finos/c;grava/c) }\end{array}$} & capa $A \gg>1: 0,4: 2,0(\varnothing 0,25 \mathrm{~mm})$ \\
\hline & capa B > 1: 0,4: $2,0(\varnothing 3,5 \mathrm{~mm})$ \\
\hline $\begin{array}{c}\text { Clase cemento (UNE-EN } \\
197-1: 2000)\end{array}$ & CEM I \\
\hline $\begin{array}{c}\text { Dimensiones modelo } \\
\text { ensavo: }\end{array}$ & Cilindros $\emptyset 75 \times 125 \mathrm{~mm}$ \\
\hline
\end{tabular}

\begin{tabular}{|c|c|c|}
\hline \multirow{8}{*}{ 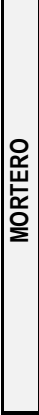 } & Artículo: & $\begin{array}{l}\text { NDE of two-layered mortar samples using high- } \\
\text { frequency Rayleigh waves }\end{array}$ \\
\hline & Año: & 2004 \\
\hline & Autores: & M. Goueygou, B. Piwakowski \\
\hline & Dosificación & сара $A \gg>1: 0,5: 3,0(\varnothing 3 \mathrm{~mm})$ \\
\hline & (c/c;a/c;finos/c;grava/c) & сара $B \gg>1: 0,8: 4,0(\varnothing 5 \mathrm{~mm})$ \\
\hline & $\begin{array}{c}\text { Clase cemento (UNE-EN } \\
197-1: 2000)\end{array}$ & CEM I \\
\hline & Dimensiones modelo & $300 \times 150 \times 40 \mathrm{~mm}$ \\
\hline & ensavo: & $300 \times 150 \times 50 \mathrm{~mm}$ \\
\hline
\end{tabular}

\begin{tabular}{|c|c|}
\hline Artículo: & $\begin{array}{c}\text { Nondestructive Analysis of a Concrete Tunnel Model } \\
\text { Using a Newly Proposed Combined Stress Wave } \\
\text { Propagation Method }\end{array}$ \\
\hline Año: & 2009 \\
\hline Autores: & S. D. Boone, P. J. Barr, J. A. Bay \\
\hline \multirow{2}{*}{$\begin{array}{c}\text { Dosificación } \\
\text { (c/c;a/c;finos/c;grava/c) }\end{array}$} & $A \gg 1: 0,54: 3,41: 3,87 ; B \gg>1: 0,46: 2,48: 2,91$ \\
\hline & Mortero POBRE > 1: 0,73: 11,25 \\
\hline $\begin{array}{c}\text { Clase cemento (UNE-EN } \\
197-1: 2000)\end{array}$ & --- \\
\hline \multirow{2}{*}{$\begin{array}{c}\text { Dimensiones modelo } \\
\text { ensavo: }\end{array}$} & Losas $500 \times 200 \times 60 \mathrm{~mm}$ \\
\hline & $\emptyset 100 \times 200 \mathrm{~mm}$ (ASTM C192) \\
\hline
\end{tabular}

\begin{tabular}{|c|c|c|}
\hline \multirow{7}{*}{ 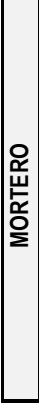 } & Artículo: & $\begin{array}{l}\text { Experimental study of wave dispersion and } \\
\text { attenuation in concrete }\end{array}$ \\
\hline & Año: & 2004 \\
\hline & Autores: & D.G. Aggelis, T.P. Philippidis \\
\hline & $\begin{array}{c}\text { Dosificación } \\
\text { (c/c;a/c;finos/c;grava/c) }\end{array}$ & $\begin{array}{c}A>1: 0,375: 1,5(\varnothing 4,75 \mathrm{~mm}) ; B>1: 0,4: 3,0 ; C>1: 0,5: \\
4,0\end{array}$ \\
\hline & $\begin{array}{c}\text { Clase cemento (UNE-EN } \\
197-1: 2000)\end{array}$ & CEM I \\
\hline & \multirow{2}{*}{$\begin{array}{c}\text { Dimensiones modelo } \\
\text { ensayo: }\end{array}$} & $50 \times 30 \times 40 \mathrm{~mm}$ \\
\hline & & Hormigón: 150x150x150mm \\
\hline
\end{tabular}

\begin{tabular}{|c|c|}
\hline Artículo: & $\begin{array}{c}\text { Ultrasonic Wave Reflection and Resonant Frequency } \\
\text { Measurements for Monitoring Early-Age Concrete }\end{array}$ \\
\hline Año: & 2009 \\
\hline Autores: & J. Hong Kim, S. P. Shah, Zhihui Sun \\
\hline $\begin{array}{c}\text { Dosificación } \\
\text { (c/c;a/c;finos/c;grava/c) }\end{array}$ & A > 1: 0,5: 1,0: 1,0 \\
\cline { 2 - 2 } $\begin{array}{c}\text { Clase cemento (UNE-EN } \\
\text { 197-1:2000) }\end{array}$ & B > 1: 0,5: 2,5: 2,5 \\
\hline $\begin{array}{c}\text { Dimensiones modelo } \\
\text { ensayo: }\end{array}$ & CEM I \\
\cline { 2 - 2 } & $\varnothing 100 x 200 m m(A S T M$ C39) \\
\hline
\end{tabular}

\begin{tabular}{|c|c|c|}
\hline \multirow{6}{*}{$\begin{array}{l}\text { 암 } \\
\text { 崖 } \\
\text { 일 }\end{array}$} & Artículo: & $\begin{array}{l}\text { Wave dispersion and attenuation in fresh mortar: } \\
\text { theoretical predictions vs. experimental results }\end{array}$ \\
\hline & Año: & 2005 \\
\hline & Autores: & D.G. Aggelis, D. Polyzos, T.P. Philippidis \\
\hline & $\begin{array}{c}\text { Dosificación } \\
\text { (c/c;a/c;finos/c;grava/c) }\end{array}$ & 1: $0,525: 4,75(\varnothing 4 \mathrm{~mm})$ \\
\hline & $\begin{array}{l}\text { Clase cemento (UNE-EN } \\
\text { 197-1:2000) }\end{array}$ & CEM II 32,5 (Arena limestone $\emptyset 1-4 \mathrm{~mm}$ ) \\
\hline & $\begin{array}{c}\text { Dimensiones modelo } \\
\text { ensayo: }\end{array}$ & --- \\
\hline
\end{tabular}

\begin{tabular}{|c|c|}
\hline Artículo: & $\begin{array}{c}\text { Determination of Early Age Mortar and Concrete } \\
\text { Strength by Ultrasonic Wave Reflections }\end{array}$ \\
\hline Año: & 2003 \\
\hline Autores: & T.Voigt, Yilmaz Akkaya, S.P. Shah \\
\hline $\begin{array}{c}\text { Dosificación } \\
\text { (c/c;a/c;finos/c;grava/c) }\end{array}$ & Mortero > 1: 0,5: 2,42 (aireante 0,26) \\
\cline { 2 - 2 } $\begin{array}{c}\text { Clase cemento (UNE-EN } \\
\text { 197-1:2000) }\end{array}$ & CEM I ,arena río; cenizas volantes F \\
\hline $\begin{array}{c}\text { Dimensiones modelo } \\
\text { ensavo: }\end{array}$ & $\begin{array}{c}\text { Losas 100x410x80mm } \\
\text { Ensavo fcd: } \varnothing 76 \times 150 \mathrm{~mm}\end{array}$ \\
\hline
\end{tabular}

(Fig. 2). Tabla de dosificaciones analizadas correspondientes a estudios previos relacionados.

\section{Proceso inicial de dosificación en morteros de edad temprana.}

Los materiales necesarios para la fabricación del mortero fueron almacenados en la cámara húmeda 3 días antes de ejecutar las amasadas, para estar sometidos a los ciclos térmicos y reproducir así lo mejor posible las condiciones de contorno reales. El tiempo total de amasado fue de 4 a 8 minutos por regla general en las dosificaciones de prueba realizadas.

El diseño de la mezcla inicial utilizada corresponde a un mortero de endurecimiento normal, fabricado con componentes adecuados y puesto en obra correctamente, cuyo cemento común es de resistencia 42,5MPa, con relación agua/cemento (a/c:0,5), fino/cemento (f/c:2,25) y árido Ø4mm. 
El contenido de agua corresponde al contenido total corregido que considera la necesaria para el mezclado, hidratación y absorción de los áridos. Cabe mencionar que la humedad de los áridos es prácticamente despreciable por lo que no ha sido considerada en las dosificaciones.

Secuencia de amasado para la
fabricación del mortero.

Esta secuencia trata de reflejar las condiciones de producción reales de un mortero común, con el objeto de reproducir al máximo las condiciones a nivel industrial o a pie de obra. En el amasado se siguió la

(Fig.3). Características del CEMENTO CEM I 42,5R (Especificaciones según UNE EN 197-1/2000)

\begin{tabular}{|c|c|}
\hline Componentes. & \\
\hline 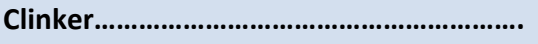 & 95 a $100 \%$ \\
\hline Componentes adicionales............................. & 0 a $5 \%$ \\
\hline Características químicas. & \\
\hline Pérdida por calcinación................................. & $<5,0 \%$ \\
\hline Residuo insoluble........................................... & $<5,0 \%$ \\
\hline \multicolumn{2}{|c|}{ Anhídrido sulfúrico (SO3) ............................<4,0\% } \\
\hline \multicolumn{2}{|c|}{ 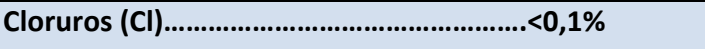 } \\
\hline Características físicas. & \\
\hline Principio de fraguado....................................... & $>60 \mathrm{~min}$ \\
\hline Expansión Le Chatelier................................... & $<10 \mathrm{~mm}$ \\
\hline Resistencias a compresión. & \\
\hline 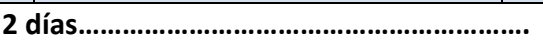 & $>20,0 \mathrm{MPa}$ \\
\hline 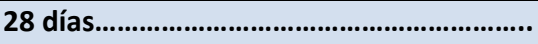 & $>42,5 \mathrm{MPa}$ \\
\hline
\end{tabular}
siguiente secuencia de materiales:

1. Agua (inicialmente se mezclaron $2931 / \mathrm{m} 3$ con un 0,6\% de aditivo).

2. Áridos de tamaño fino 0-4mm.

3. Cemento $(586 \mathrm{~kg} / \mathrm{m} 3$ amasado durante 90 segundos $)$.

4. Adicionado de plastificante $3,5 \mathrm{~kg} / \mathrm{m} 3$ diluido en agua (amasado durante 120 segundos).

5. Se extrae la proporción de mortero necesario para la realización de ensayos y fabricación de probetas $40 \times 40 \times 160 \mathrm{~mm}$, recomendadas para test en laboratorio.

Fabricación de las probetas para ensayos.

El volumen de fabricación de la amasada prevista para los ensayos clave del método AEOS fue de 20-40 litros, en función de la capacidad de la amasadora eléctrica utilizada y las necesidades de mortero según características de espécimen a modelar. Se elaboraron moldes triples de probetas prismáticas RILEM 40x40x160mm [ASTM C192/C192M-00] en torno a 30 probetas elaboradas por amasada principal, para ser ensayadas por las técnicas que validaron los ensayos AEOS, que son el método de Impacto-Eco [I-E] y Frecuencia-Resonancia [FFRC] (métodos no destructivos) y finalmente, para rotura de piezas para determinación de las resistencias a flexión/compresión, con medición mediante bandas extensométricas de 20-30mm [ASTM C39/C39M-01]. Se realizan los ensayos en $n^{\circ}$ de 3 probetas, dejando una de reserva para ensayos posteriores. Las condiciones de conservación y fabricación son esenciales para mantener la fidelidad con los resultados del Análisis Espectral, por lo que una vez enmoldadas y enrasadas en su fabricación, se protegen mediante cubrición con bolsas de plástico para reducir la tasa de evaporación del agua de constitución. 
Los objetivos específicos de cada serie experimental son los siguientes:

- Simular las condiciones climáticas mediante la cámara húmeda, asimismo tener una condición de referencia de su resistencia para ensayos posteriores de I-E, FFRC y SASW.

- Fabricar probetas de idéntico mortero que el constituyente de los modelos a mayor escala reproducidos, que permiten someterlas a ensayos no destructivos, pruebas varias y posteriormente rotura para caracterización mecánica mediante ensayos a flexo/compresión.

- Analizar los resultados obtenidos en función de su naturaleza mecánica y microestructural y, compararlos con las tendencias observadas en la realidad.

- Formular las conclusiones pertinentes en función de las tendencias principales observadas.

Dosificación de la pasta de cemento y mortero.

Las proporciones para la fabricación de la pasta se han determinado siguiendo las proporciones de la mezcla base restando a la cantidad de agua total la absorción de los áridos, tal y como se detalla a continuación: $\boldsymbol{W}=164,9-\boldsymbol{A}_{I} \cdot \boldsymbol{a}_{A I}$, donde:

$W=$ cantidad de agua correspondiente a la pasta

$A 1=$ es la cantidad de arena $0-4 m m$

$a_{A l}=$ coeficiente de absorción de la arena $0-4 m m=1,60 \%$

Los valores de absorción de los áridos han sido tomados de resultados experimentales y ensayos de estudios previos en Laboratorio, como se ha mencionado anteriormente. En la tabla se muestra la dosificación inicial, así como las cantidades utilizadas en su fabricación:

\begin{tabular}{|c|c|c|}
\hline Material & $\begin{array}{c}\text { Teóricas para } \\
1 \mathrm{~m}^{3} \text { de hormigón }\end{array}$ & $\begin{array}{c}\text { Fabricación de } \\
\text { muestra 401 }\end{array}$ \\
\hline Cemento & $586 \mathrm{~kg}$ & $23,44 \mathrm{~kg}$ \\
\hline Agua & $293 \mathrm{lt}$ & $11,72 \mathrm{lt}$ \\
\hline Aditivo & $3,52 \mathrm{~kg}$ & $140 \mathrm{gr}$ \\
\hline
\end{tabular}

Materiales y dosificación para la fabricación de la pasta

\begin{tabular}{|c|c|}
\hline Material & $\begin{array}{c}\text { Dosificación } \\
\text { (gr) }\end{array}$ \\
\hline Cemento & $2342 \pm 2$ \\
\hline Agua & $1172 \pm 1$ \\
\hline Arena normalizada & $5270 \pm 5$ \\
\hline
\end{tabular}

Materiales y dosificación para la fabricación del mortero

(Fig. 4). Tablas de dosificación y componentes de la fabricación de la pasta de cemento y del mortero.

Conjuntamente a la pasta de cemento, se fabricó el mortero con arena normalizada según las condiciones climáticas de fabricación y conservación a primeras edades. En este sentido se han seguido los procedimientos descritos en la siguiente normativa de referencia:

- ASTM C305-99e1 “Practice for Mechanical Mixing of Cement Pastes \& mortars".

- ASTM C348 “Standard Test Method for Flexural Strength of Hydraulic-Cement Mortars".

• ASTM C349 “Test Method for Compressive Strength of Cement Mortars".

\section{Secuencia y procedimiento de amasado}

$\mathrm{Al}$ igual que para el caso de la fabricación de un hormigón, los materiales utilizados para la fabricación del mortero fueron almacenados en la cámara húmeda por espacio de 72 horas con el objeto de someterlos a las condiciones óptimas de curado según normativa. Dado que se pretende determinar la resistencia a edades tempranas hasta los 28 días, se realizaron amasadas continuas con el objeto de reducir al máximo la dispersión de los resultados. 
La secuencia de amasado se realizó mediante vertido del agua y del cemento dentro del recipiente de la amasadora. Se inicia el amasado a velocidad lenta y a 30 seg se introduce de forma regular la arena durante 30 seg, momento en el cual se pasa a velocidad rápida durante otros 30 seg. Se detiene el amasado y mediante una espátula de goma se retira el mortero adherido a la pala de la amasadora y se devuelve a la mezcla. Continúa el amasado durante 1 minuto más a velocidad rápida.
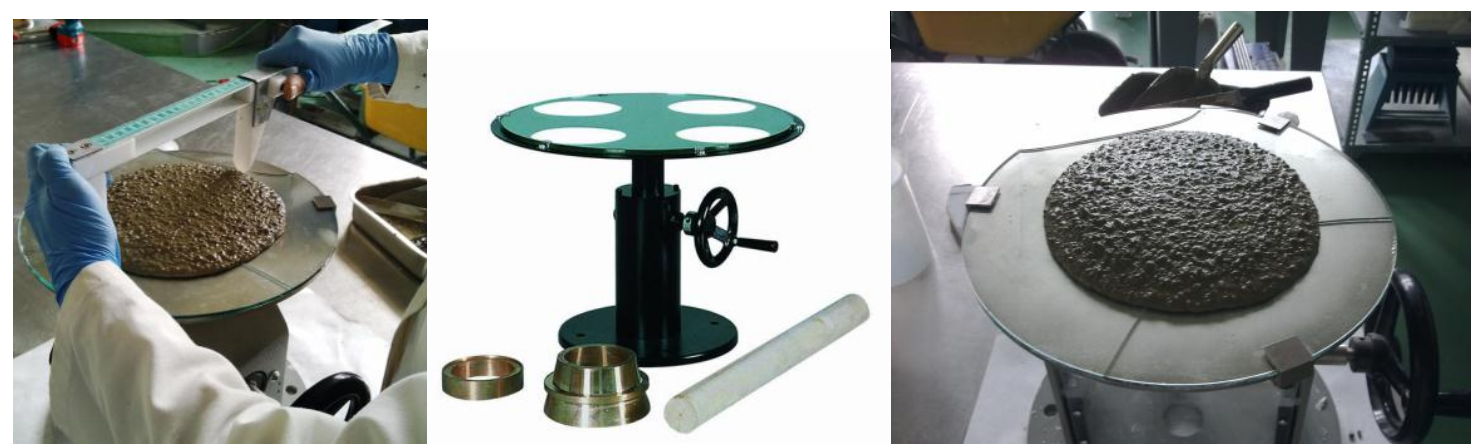

(Fig. 5). Ensayos de consistencia del mortero en la mesa de sacudidas. Muestra de mortero.

Una vez finalizado el amasado del mortero se determina su grado de fluidez por medio del ensayo de consistencia mediante la mesa de sacudidas definido en la norma ASTM C305-99e1,

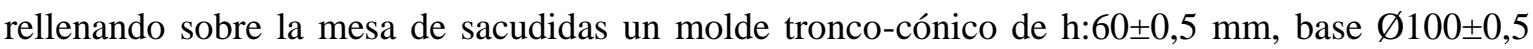
mm mediante dos capas compactadas con 10 golpes de pisón. Inmediatamente después de la preparación del mortero se fabricaron las series de probetas de 40x40x160mm, enrasadas con una espátula y conservadas en cámara húmeda, durante 48h, para su curado hasta el ensayo.

Justificación del mortero.

La buena calidad del material tiene una influencia decisiva para conseguir los resultados deseados del mortero, dependiendo de las materias primas, la dosificación, la correcta ejecución y el posterior curado. La dosificación del mortero (cemento, áridos, agua y aditivos) será la adecuada para obtener las características y propiedades exigidas: resistencia mecánica y durabilidad. Atendiendo especialmente a la dosificación debemos cumplir las limitaciones de la máxima relación agua/cemento $(\mathrm{a} / \mathrm{c})$ y el contenido mínimo de cemento $\left(\mathrm{kg} / \mathrm{m}^{3}\right)$.

Una relación $\boldsymbol{a} / \boldsymbol{c}:$ 0,25 será suficiente para hidratar el cemento Portland, pero se necesita más cantidad para poder amasar el alto contenido en áridos con la pasta hidratada para facilitar una adecuada distribución interna de la interfaz del mortero así como su puesta en obra. Esto se consigue si se aumenta la relación a/c: 0,4-0,5. Cuando el mortero fragua, el agua sobrante se evapora al exterior (sangrado) dejando atrás una red de poros que se debe limitar ante la entrada de agua externa o aire que lo debilite. Con una relación a/c: 0,7 los poros se hacen demasiado grandes, hasta $\varnothing 1 \mathrm{~mm}$, además de numerosos. Además, una relación a/c grande hace disminuir drásticamente la resistencia del mortero (aumentar un 10\% la cantidad de agua hace disminuir un $20 \%$ la resistencia), por lo que se seleccionaron morteros con relaciones $\mathbf{a} / \mathbf{c}: \mathbf{0 , 5 - 0 , 6 5}$. 
El contenido mínimo de cemento es importante por su alcalinidad, debiendo dosificarlo con una cantidad mínima de $250 \mathrm{~kg}$ de cemento por $\mathrm{m}^{3}$ de mortero $\left(\boldsymbol{m i n} .200 \mathrm{~kg} / \mathrm{m}^{3} ; \boldsymbol{m a x} .500 \mathrm{~kg} / \mathrm{m}^{3)}\right.$. La puesta en obra, es decir, su vertido, colocación y compactación, deberá cuidar aspectos como el límite de tiempo del que dispone desde la fabricación hasta su colocación $(\approx 1,5$ horas en condiciones normales); la disgregación de la mezcla o separación de los áridos al compactarlo de forma inadecuada; el principio de fraguado, y la reducción del aire ocluido que tiene la masa (teniendo un mortero más denso, y por lo tanto, más impermeable y más resistente al agua, será menos vulnerable a la intemperie y con mayor resistencia característica a edades tempranas).

Un aspecto importante del cemento en el presente estudio fue la velocidad de desarrollo de la hidratación en las primeras edades. Para evaluar este aspecto resultó útil conocer el tiempo de principio y final de fraguado del cemento empleado. (Ver Anexo 05).

La norma seguida para la determinación del tiempo de fraguado ha sido la UNE-EN 196-3:2005.

\begin{tabular}{|c|c|c|}
\hline $\begin{array}{c}\text { Agua para consistencia } \\
\text { normal }(\mathrm{g})\end{array}$ & Principio de fraguado (min.) & Final de fraguado (min.) \\
\hline $\mathbf{1 4 7}$ & 198 & 250 \\
\hline
\end{tabular}

(Fig. 6). Agua para consistencia normal y tiempos de fraguado del cemento CEM I 42,5 R

Los ensayos de control de producción y de contraste para el cemento facilitado arrojan los siguientes resultados experimentales de tiempos de curado y fraguado indicados:

\begin{tabular}{|c|c|c|}
\hline Tipo de lote & Principio de fraguado (min.) & Final de fraguado (min.) \\
\hline Control de producción & 207 & 289 \\
\hline Muestras de contraste & 179 & 234 \\
\hline
\end{tabular}

(Fig. 7). Control de producción y muestras de contraste.

\begin{tabular}{|c|c|c|}
\hline & Curado en cámara húmeda Ta20ㄷ & Curado en exterior TạoC \\
\hline Principio de fraguado (min.) & 394 a 845 & 1240 \\
\hline Final de fraguado (min.) & 484 a 945 & 1860 \\
\hline
\end{tabular}

(Fig.8). Principio y final de fraguado para el CEM I 42,5 R determinado por el organismo certificador (AENOR).

El objetivo era mantener el mortero húmedo y a temperatura adecuada, para que la hidratación del cemento desarrollase la resistencia final del mortero. Durante el fraguado y el primer periodo de endurecimiento (48h.) se alcanzaron temperaturas apreciables produciéndose evaporaciones, desecación de la masa e interrupción de la hidratación del cemento, creándose poros y posibles faltas de fraguado. Por tanto, se comprobó que un correcto curado consigue que la impermeabilidad sea la mayor posible, reduce poros, aumenta su durabilidad y resistencia (3050\%), mejorando considerablemente la apariencia externa del mortero. 

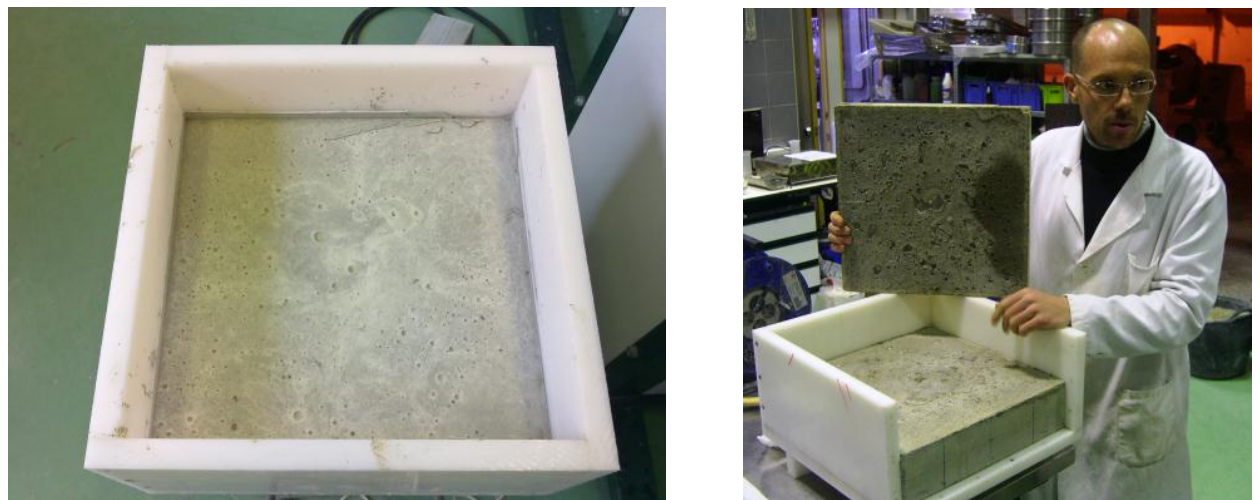

(Fig. 9). Ejemplos de oquedades presentes en los primeros modelos de losas realizados para ensayo AEOS

Observaciones a los componentes del mortero para ensayos.

El cemento seleccionado respondía a una clase resistente mínima de $42,5 \mathrm{~N} / \mathbf{m m} \mathbf{2}$ (cemento común de endurecimiento normal). Tanto para el amasado como para el curado se utilizó un agua sancionada por la práctica como aceptable, sin componentes dañinos que afectasen a las propiedades del mortero, con unas condiciones mínimas ( $p h>5$; sustancias disueltas $<15 \mathrm{~g} /$; hidratos de carbono 0), y evitando la presencia de cloruros que provoquen eflorescencias.

Los áridos finos eran de naturaleza y preparación tales, que garantizasen la adecuada resistencia y durabilidad del mortero: fíller y arenas finas procedentes de yacimientos naturales, machaqueo, escorias estables sin silicatos ni compuestos ferrosos. Los áridos naturales de forma redondeada, fueron idóneos porque dejan menores huecos internos siendo de más fácil puesta en obra y ahorran cemento por su granulometría más perfecta.

El árido utilizado procedente de la cantera de El Purche (Granada) y de naturaleza mineralógica dolomítica, compuesto por dos fracciones. La fracción 1 comprende los tamaños $\varnothing 0$ $4 \mathrm{~mm}$ y la fracción 2 (reservada para hormigones futuros) de $\varnothing 5-15 \mathrm{~mm}$. La granulometría del árido se ha determinado siguiendo la norma UNE-EN 933-1. La densidad real y la absorción de los áridos se ha determinado basandose en la norma UNE-EN 1097-6 y se muestran en la tabla:

\begin{tabular}{|ccc|}
\hline Fracción & Densidad real $\left(\mathrm{kg} / \mathrm{m}^{3}\right)$ & Absorción (\%) \\
\hline 1 & 2.480 & 0,285 \\
\hline 2 & 2.854 & 0,372 \\
\hline
\end{tabular}

(Fig. 10). Densidad real y porosidad del árido.

El aditivo incorporado en el amasado del mortero en proporción de 0,3-0,6\% del peso del cemento, produce la modificación deseada de alguna de las características en estado fresco del material, enfocadas a aumentar la trabajabilidad sin aumentar la relación a/c, influir en los tiempos de fraguado y aumentar tanto las resistencias mecánicas como la durabilidad. 
Puesto que buscábamos determinar las características del mortero a edad temprana, debíamos aditivar con reductores de la cantidad de agua de amasado, siendo de aplicación los plastificantes por su efecto dispersante sobre las partículas de cemento. Aumenta la resistencia con necesidad de menor cantidad de cemento y la mínima agua posible retrasando el fraguado. También podíamos aplicar aditivos aireantes (mayor resistencia a las heladas) al amasado en una cantidad determinada de pequeñas burbujas de aire, uniformemente repartidas, que permanecían después del endurecimiento. Con ello se conseguía interrumpir la red de microgrietas por la que entra el agua al llegar a una de las burbujas. No obstante, en aplicación de los métodos de impacto-eco, frecuenciaresonancia y análisis espectral de ondas superficiales, se deben evitar posibles huecos en la interfaz interna del material que puedan distorsionar la propagación de las ondas atenuando su velocidad. Además tienen el inconveniente de reducir la resistencia del mortero.

\section{PLAN DE TRABAJO EXPERIMENTAL: Dosificaciones y resistencias.}

El presente apartado tiene por objeto definir el programa para la realización de los ensayos al mortero, en el que se han simulado las condiciones para un amasado convencional.

\section{Dosificaciones iniciales y ensayos previos.}

A lo largo del desarrollo de la memoria del trabajo se expondrán los modelos estructurales de mortero diseñados con diferentes tamaños y composiciones, con el objetivo de validar las técnicas de propagación de ondas superficiales y la determinación de los datos necesarios para identificar los parámetros que caracterizan a cada material ensayado.

El estudio preciso se extiende a "Morteros de edad temprana" en condiciones normales. Para analizar las mediciones de las probetas de mortero a edad temprana, se experimenta con moldes prismáticos de 3 probetas \#40x40x160mm, a edades 7h, 8h, 9h, 10h, 11h, 12h, 13h, 14h, 16h, 18h, 21h, 24h, 48h, 60h, 72h, 4, 5, 6, 7, 14, 21 y 28 días.

La dosificación, especímenes y ensayos desarrollados, han sido concluyentes del método, tras varias amasadas y modelos descritos más adelante realizados desde Noviembre 2011. La amasada principal responde a una dosificación tipo (C/C : A/C : F/C) $\rightarrow(1: 0,5: 2,25) ~ \gg$ CEMENTO: 586kG/M3 ; AGUA: 293L/M3 ; ÁRIDOS: $1318 \mathrm{KG} / \mathrm{M} 3$; ADITIVO (0,3\%): 1,75KG/M3

\begin{tabular}{|c|c|c|c|c|c|c|c|}
\hline \multirow{2}{*}{$\begin{array}{c}\text { MORTERO Dosificación } \\
\text { (Pruebas 2011): }\end{array}$} & CEM 42,5N & \multicolumn{2}{|c|}{ ARENA FINOS 0/4 } & \multicolumn{2}{|c|}{ AGUA } & \multicolumn{2}{c|}{ ADITIVO } \\
\cline { 2 - 8 } & $\mathrm{kg}$ & $\mathrm{kg}$ & $\boldsymbol{f} / \boldsymbol{c}$ & $\mathrm{L}$ & $\boldsymbol{a} / \boldsymbol{c}$ & $\mathrm{KG}$. & $\boldsymbol{A d} / \boldsymbol{c}$ \\
\hline Mezcla A & 571 & 1496.6 & $\mathbf{2 . 6 2}$ & 290 & $\boldsymbol{0 . 5 1}$ & 3.43 & $\boldsymbol{0 . 6}$ \\
\hline Mezcla B & 492 & 1554.2 & $\mathbf{3 . 1 6}$ & 295.17 & $\boldsymbol{0 . 6}$ & 2.95 & $\boldsymbol{0 . 6}$ \\
\hline Mezcla C & 613 & 1491.7 & $\mathbf{2 . 4 3}$ & 275.83 & $\boldsymbol{0 . 4 5}$ & 1.84 & $\boldsymbol{0 . 3}$ \\
\hline
\end{tabular}



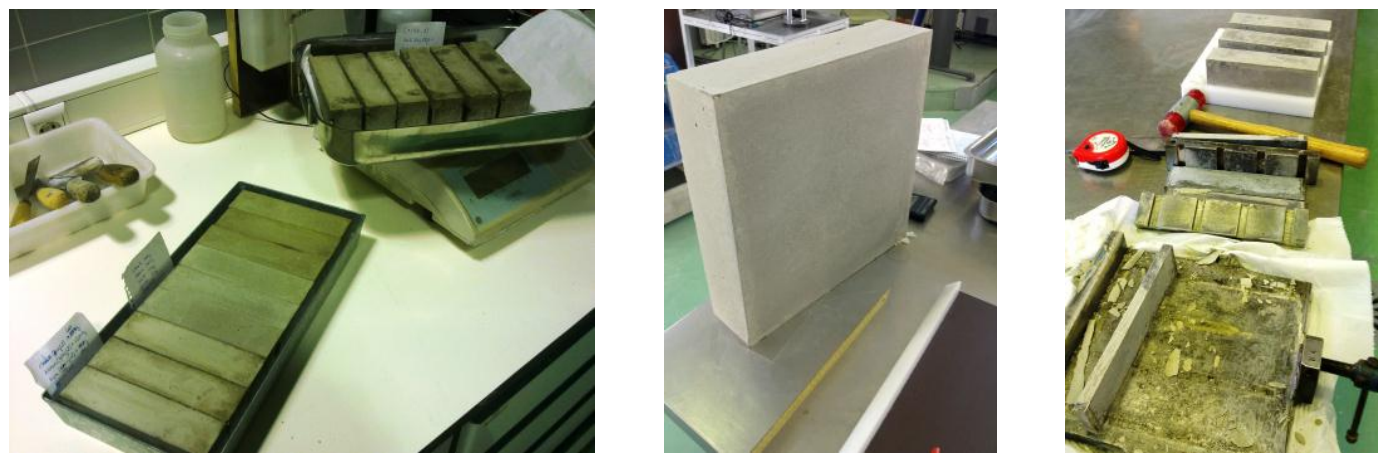

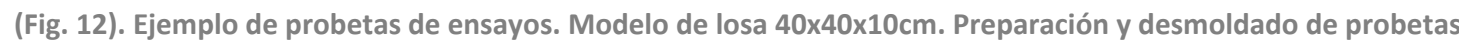
$40 \times 40 \times 160 \mathrm{~mm}$ para ensayos varios.

Inicialmente, se ensayaron otras dosificaciones citadas a continuación para estudiar los efectos de la dispersión de onda, la atenuación, la absorción del árido, la relación a/c.... aspectos que han proporcionado resultados con conclusiones que validan las técnicas adoptadas.

- DOSIFICACIÓN No 1: Amasada mortero teórica de partida (ASTM C469):

CEM $42,5 \mathrm{~N}=350 \mathrm{Kg} / \mathrm{m}^{3}$.

Árido fino $=851,76 \mathrm{Kg} / \mathrm{m}^{3}$.

Agua $=175 \mathrm{~L}$.

Aditivo $=\mathbf{2 , 1 0} \mathrm{Kg} / \mathrm{m}^{3}$.
RELACIÓN (c/c;a/c ; f/c ; \%adit.) $>(1 ; 0,5 ; 2,5 ; 0,6 \%]$

- DOSIFICACIÓN No 2: Amasada para 3 probetas 40x40x160mm. (UNE EN 196-1/2005):

CEM 42,5N $\rightarrow 450 \pm 2 \mathrm{~g}$.

Árido $\rightarrow 1350 \pm 5 \mathrm{~g}$.

Agua $\rightarrow 225 \pm 1 g$.

- DOSIFICACIÓn No 3: Amasada de 3 probetas 40x40x160mm: 768 $\mathrm{cm}^{3}$. (ASTM C318M):
Peso dosificación: $2,025 \mathrm{Kg}$.

$$
\rho_{\text {teórica }}: 2200 \mathrm{Kg} / \mathrm{m}^{3} . \quad \rho_{2200}=P / V=2,025 / V \rightarrow V=0,964 K g
$$

$\begin{array}{ll}\text { CEM } 42,5 \mathrm{~N}=350 \times 0,768 / 587,24 \rightarrow 458 \pm 2 g . & \text { Agua }=175 \times 0,768 / 587,24 \rightarrow 229 \pm 1 g . \\ \text { Árido fino }=851,76 \times 0,768 / 587,24 \rightarrow 1110 \pm 5 g . & \text { Aditivo }=2,10 \times 0,768 / 587,24 \rightarrow 2,7 g .\end{array}$

Inicial (3 probetas). Peso dosificación: 1799,7g. Volumen: $768 \mathrm{~cm} 3$. Densidad $2343 \mathrm{~kg} / \mathrm{m}^{3}$.

- DosifiCACIÓN No 4: Amasada (1:0,5:2,25) para probetas 40x40x160mm: (UNE EN 196-1):

\begin{tabular}{|c|c|c|c|c|c|c|c|}
\hline Dosificación MORTERO 3 probetas 40x40×160mm. & CEM 42,5N & \multicolumn{2}{|c|}{ ARENA 0/4 } & \multicolumn{3}{|c|}{ AGUA } & \multicolumn{3}{|c|}{ PLASTIFICANTE } \\
\cline { 2 - 8 } & $\mathrm{kg}$. & $\mathrm{kg}$. & $\mathrm{f} / \mathrm{c}$ & $\mathrm{L}$ & $\mathrm{a} / \mathrm{c}$ & $\mathrm{g}$. & $\%(\mathrm{ad} . / \mathrm{c})$ \\
\hline CEM EN 197-1/ I 42,5N & 0,458 & 1,11 & 2,45 & 0,229 & 0,5 & 2,75 & 0,6 \\
\hline
\end{tabular}

- Se realizaron ensayos con bandas extensométricas para comprobación de módulos determinados por el método de Frecuencia-resonancia (ASTM C215). Los resultados determinaron las amasadas para desarrollo del método AEOS en losas uni/ bi/ tricapa.

- La realización de esta primera fase de trabajo fue determinante para establecer una variabilidad necesaria en las mezclas finales realizadas conforme a tamaño de especímenes deseado, cantidad de probetas para ensayos y modelización de un perfil dispersivo heterogéneo multicapa a edades tempranas: 


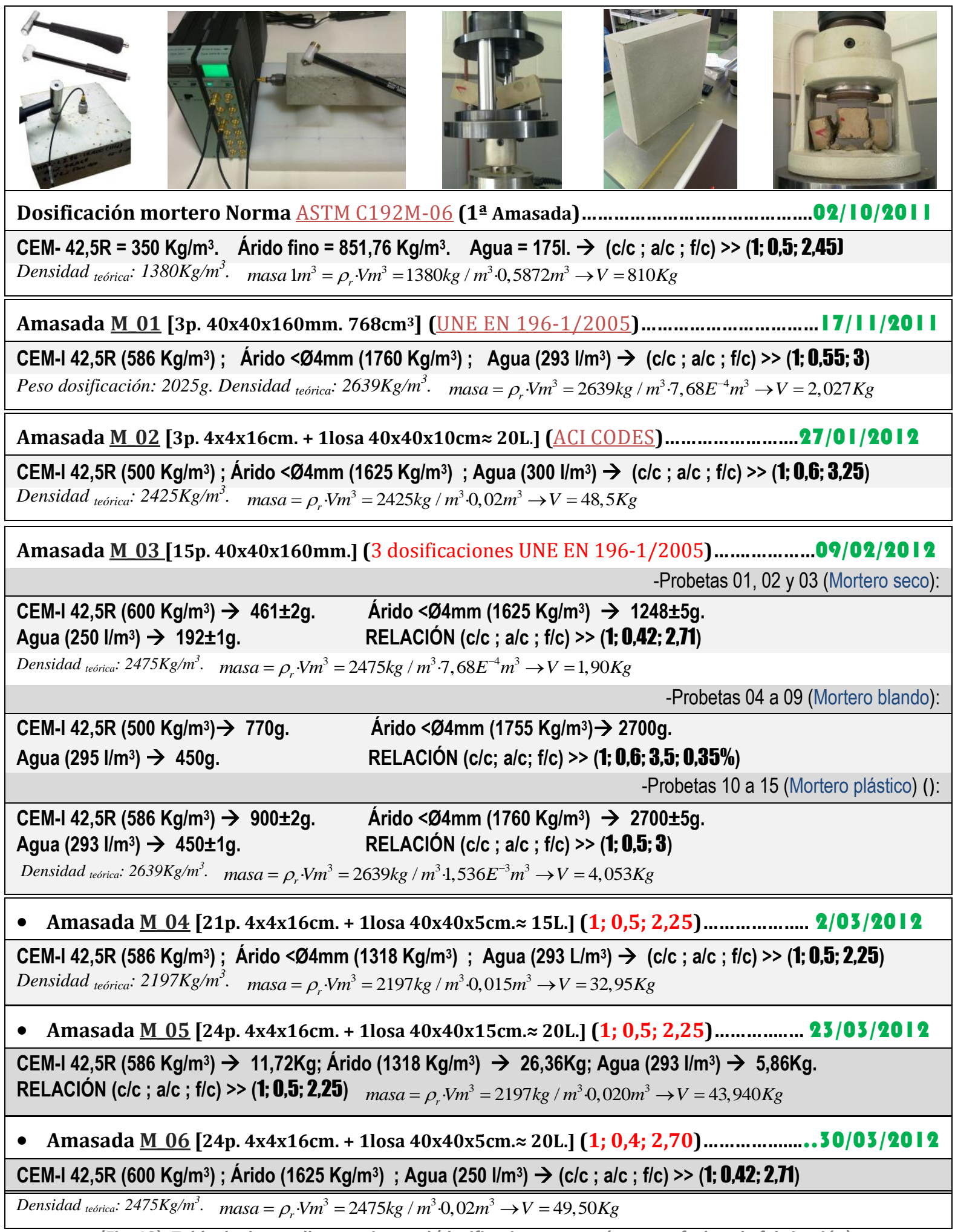

(Fig. 13). Tabla de desarrollo experimental (dosificaciones, especímenes y fechas de fabricación).

Las probetas restantes se ensayaron con galgas mediante equipo Model P3 de Vishay, con intervalos de tiempo de 1 msegundo. Los valores obtenidos en prensa se contrastan con las resistencias determinadas mediante FFRC. Se comprobaron las deformaciones registradas mediante software Labview Signal Express v.2009. 


\title{
Análisis Espectral de Ondas Superficiales (AEOS)
}

MATERIALES Y MÉTODOS (II): TECNOLOGÍA DEL CEMENTO.

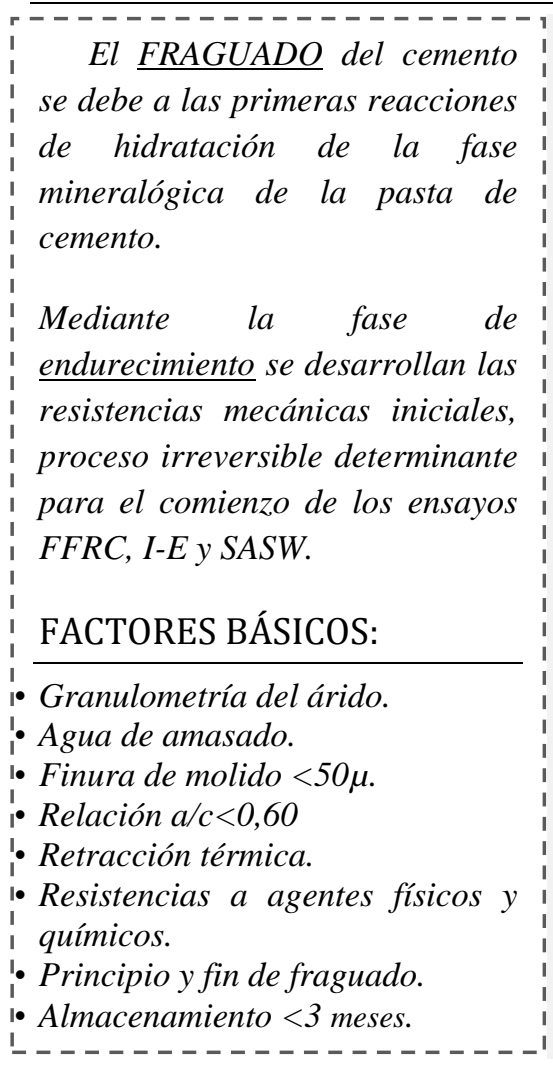

\section{Naturaleza del cemento con clínker pórtland}

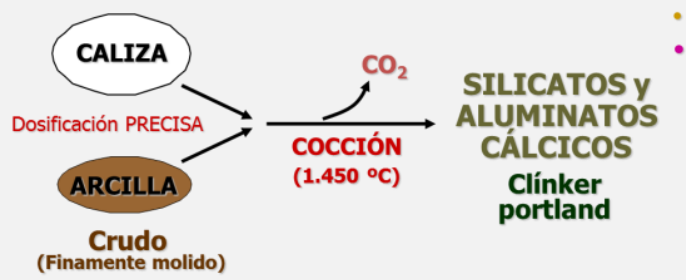

Regulador de fregnede

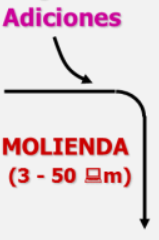

CEMENTO de CLÍNKER PORTLAND

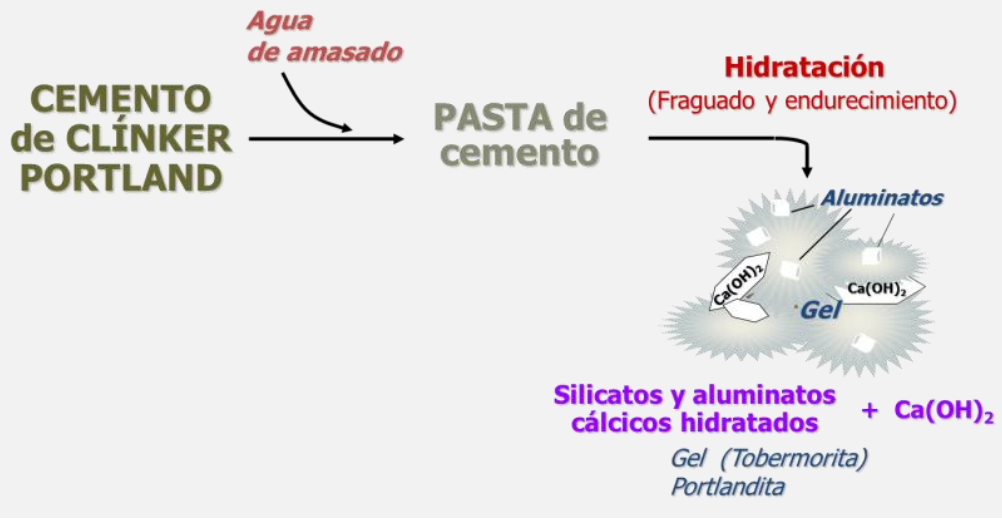

(Fig. 14). Naturaleza del cemento con clínker Portland.

\section{Recomendaciones de curado y conservación del mortero.}

CURADO E HIDRATACIÓN DEL CEMENTO PORTLAND.

Conforme a exigencias del Comité ACI 308R-2001

\begin{abstract}
Se utiliza el término "curado" para describir el proceso por el cual el mortero de cemento madura y desarrolla propiedades reforzadas con el tiempo como resultado de la continua hidratación en presencia de suficiente agua y calor, que depende del entorno natural $\psi$ las medidas adoptadas para modificarlo al limitar la pérdida de agua o proporcionando externamente humedad y calor, para permitir la hidratación hidráulica y, si procede, las reacciones de adtivos que pueden desarrollar las posibles propiedades de la mezcla.
\end{abstract}

El período de curado se define como el comienzo del tiempo puesto en servicio, mediante la consolidación, acabado y extendido, hasta que se han desarrollado las propiedades que se deseen, con el objetivo de evitar la pérdida de humedad y mantenimiento a temperatura favorable. En la capa superficial del mortero, el curado tiene una influencia significativa en las propiedades como fuerza, permeabilidad, resistencia a la abrasión, estabilidad, y por supuesto en el correcto desarrollo del método AEOS por la cuidada colocación de los acelerómetros requerida.

En la microescala, la pasta se mantiene endurecida debido a los enlaces que se desarrollan entre los productos de la reacción del cemento con el agua. La reacción de cemento-agua incluye 
procesos físicos y químicos que colectivamente se conocen como la hidratación del cemento (TAYLOR, 1997). Conforme el proceso de hidratación continúa, la fuerza del enlace entre las partículas internas aumenta, y disminuye la porosidad del medio. La superficie de la partícula se cubre con una masa densa, aleatoriamente orientada, conocida como gel de cemento, necesaria para el llenado de los microporos.

Por lo tanto, para los procesos de curado se requiere suficiente agua disponible para el cemento para mantener el tipo y grado de hidratación necesaria para lograr las deseadas propiedades del mortero en el tiempo requerido. El agua que se consume en la formación de los productos de gel es conocida como agua químicamente dependiente o hidrato de agua y su cantidad varía con la composición del cemento y las condiciones de hidratación. Un valor promedio es de 0,25 (Kosmatka \&y Panarese 1988). Se presenta en condiciones ambientales secas y para su eliminación requiere calentar la pasta de cemento endurecido a $105^{\circ} \mathrm{C}$ (NEVILLE 1996).

La hidratación del cemento es posible "sólo cuando el agua está disponible tanto para las reacciones químicas como para cubrir los poros de gel" (NEVILle 1996; TAYLOR 1997). La clave para el desarrollo de la fuerza y durabilidad en el mortero, no es tanto el grado al que el cemento ha hidratado sino el grado al que se han llenado los poros entre las partículas de cemento con productos de hidratación (Powers \& Brownyard 1947). Sin embargo, el grado de relleno de los poros, depende no sólo de que el cemento haya hidratado, sino también del volumen inicial de poros en la pasta, de ahí, la importancia combinada de la disponibilidad de curar el agua y la relación agua-cemento $(\mathrm{a} / \mathrm{c})$.

Por un lado, es importante reducir al mínimo el volumen de agua para reducir el espacio de poros entre partículas de cemento de la mezcla (a/c baja). Por otra parte, es necesario proporcionar al cemento agua suficiente para sostener el relleno de los poros con productos de hidratación. Aunque una a/c alta puede proporcionar suficiente agua y promover un alto grado de hidratación, el resultado sería un bajo grado de poros rellenos debido a la porosidad de la pasta inicial alta.

Secuencia y tiempo de curación. Operaciones de acabado.

El curado debe iniciarse cuando la superficie del mortero comienza a secar, momento en el que expulsa el agua intersticial por evaporación.

Se describen las etapas de curado, técnicas utilizadas y el momento en que se inician:

- El curado inicial se refiere a los procedimientos entre la colocación y el acabado final del mortero para reducir la pérdida de humedad de la superficie (Ej: fogging...).

- El curado intermedio, procedimientos antes de que el mortero alcance el estado final.

- El curado final, su tiempo de aplicación varían dependiendo del secado de la superficie. 


\section{* Curado inicial.}

La velocidad y duración depende de la mezcla de mortero, la profundidad o espesor del mortero y el método de consolidación. Aunque también influye la relación a/c, los contenidos de cemento, agregados, aditivos y aire ocluido. Mezclas con una tasa baja de expulsión del agua interior son particularmente susceptibles de acelerar el secado, ya que incorporan humo de sílice, cementos finos, baja a/c, alto contenido de aire o reducción de agua (ACI 302.1R).

\section{* Curado intermedio.}

Se requieren medidas de curación intermedias cuando la textura deseada se logra rápidamente. La necesidad de proteger contra la pérdida de humedad puede entrar en conflicto con la necesidad de evitar daños a la superficie después de terminar.

\section{* Curado final.}

La superficie debe protegerse contra la pérdida de humedad inmediatamente después de la máquina de acabado, ya que la tasa máxima de evaporación se produce inmediatamente después de la última pasada por la presión que se ejerce llevando el agua a la superficie, así ocurre en la ejecución de las losas de mortero. Un retraso en la curación definitiva puede resultar perjudicial.

\section{Necesidad y preparación del curado. Control de humedad y T⿳a.}

Debía iniciarse tan pronto como era posible cuando la superficie comenzaba a secar. Agua, aditivos, adiciones, cubrición, equipo de aplicación y accesorios debíann estar preparados cuando las condiciones ambientales extremas requerían una acción rápida.

Se comprobó en el desarrollo de los ensayos que en aquellos morteros dosificados como de baja permeabilidad, el secado de la superficie pudo inhibir el desarrollo de sus propiedades exteriores, mientras que las propiedades interiores se desarrollaron plenamente.

El agua para el curado debía proporcionar una cobertura completa y liberación continua de impurezas agresivas que fuesen capaces de causar el deterioro del mortero (manchas, decoloración....). En general, el agua potable era aceptable como agua de curado (ASTM C94).

\section{Procedimientos de curado. Condiciones. Secuencia y tiempos.}

Independientemente de los materiales o métodos utilizados para curar el mortero, debía mantenerse un grado de humedad y temperatura óptimas. Los dos sistemas generales para el mantenimiento adecuado de la humedad varían en eficacia dependiendo de la mezcla de mortero, método de curado, materiales utilizados, los detalles de las operaciones de construcción y las condiciones atmosféricas. Estos sistemas son la aplicación continua o frecuente de agua a través de inmersión en cámara húmeda, fogging o vaporización, y la minimización de la pérdida de agua del cemento mediante el uso de láminas de plástico de retención de humedad (ASTM C309/C1315).

Inmersión: es el método más completo de curado; se utilizó en los modelos de losas de 40x40 mediante traslado a cámara húmeda en Pl.-3 ETSICCP. 
Trabajos de acabado del curado. Requerimientos mínimos.

Durante el período de curación, no se dejó absorber agua de los materiales saturados en superficie. Al utilizar agua para el curado, el mortero debía secar al menos 8 h para minimizar la probabilidad de congelación y rotura.

El clima frío durante el desarrollo de la parte experimental del trabajo, expuso al mortero inmaduro en peligro, especialmente cuando el mortero estaba caliente y la humedad era baja. Si la temperatura del mortero disminuía, podía congelar el agua de los poros provocando daños por heladas, ya que la temperatura fría disminuye la tasa de hidratación y las propiedades del cemento. La tasa de evaporación de la superficie recién colocada fue un aspecto presente que hubo que minimizar debido a que surgieron agrietamientos de contracción plástica, por lo que para mantener la hidratación del cemento, debía mantenerse un nivel alto de humedad en la superficie hasta que se desarrollase una resistencia a la compresión de al menos 3,5MPa. Para permitir pruebas experimentales debíamos mantener la temperatura por encima de $10^{\circ} \mathrm{C}$ (ACI 305R).

\section{Requerimientos mínimos de curado y desencofrado.}

El curado debía continuar lo suficiente para asegurar que el 100\% del valor especificado para las propiedades del mortero como fuerza o módulo de elasticidad (ACI 301), se desarrollaran en un período de tiempo razonable después del cese de las medidas deliberadas de curación.

En las dosificaciones mencionadas anteriormente, cuando el rendimiento de la estructura requería que la fuerza alcanzase el 100\% del valor especificado, el curado se amplió hasta que se había alcanzado la propiedad especificada [penetrómetro, (ASTM C 803) y rebote (ASTM C 900)].

La duración necesaria para alcanzar los niveles deseados de fuerza, durabilidad o ambos, dependían de la composición química, la finura del árido, relación a/c, proporciones de mezcla, aditivo y la eficacia del método de curado en retención de humedad superficial. Este complejo conjunto de factores es difícil de afirmar con confianza en el tiempo mínimo necesario para alcanzar el nivel deseado de rendimiento de curado en cuestión.

Para un mortero normal de los realizados, una duración mínima de 7 días de curado fue suficiente para alcanzar aproximadamente el $70 \%$ de la resistencia a la compresión especificada.

$>$ En el mortero fabricado pudo retirarse el encofrado de probetas y de losas de $40 \times 40 \mathrm{~cm}$ cuando, no mostrando grandes daños superficiales ni deterioro, se puso en servicio sin necesidad de una protección adicional ni de enfriamiento gradual.

Como en mi caso no había una experiencia previa experimental, los consejos del profesor D. José R. Montero fueron muy valiosos para garantizar la curación mínima. 


\title{
Análisis Espectral de Ondas Superficiales (AEOS)
}

\author{
ESTADO DEL CONOCIMIENTO (Teoría de propagación de ondas [I]). \\ El método de onda superficial explora la naturaleza dispersiva de las andas de \\ Rauleigh. La velocidad de propagación de dichas ondas en la superficie del modelo \\ heterogéneo depende de su longitud de anda asi como las propiedades del material.
}

Metodología de ondas superficiales. [Antecedentes teóricos].

RAYLEIGH en 1885 demostró, dentro del marco de la teoría de la Elasticidad, que además de las ondas P y S, podía existir un tercer tipo de onda en la superficie libre de un sólido que motivaba el que sus partículas tuvieran el movimiento elíptico levógiro. Se sabía que la vibración de un medio elástico, homogéneo, isótropo e infinito se propagaba en forma de ondas esféricas con dos velocidades: una velocidad tangencial o transversal, Vs (onda $S$ ), y una velocidad longitudinal, Vp $($ onda $P): V_{S}=\sqrt{G / \rho} \quad V_{P}=\sqrt{2 G(1-v) / \rho(1-2 v)}$

Este tipo de onda (Rayleigh), tiene una velocidad de propagación $V_{R}$ inferior a las de las ondas transversales, $V_{S}$, que no dependen más que de las propiedades elásticas y de la densidad del material: $\boldsymbol{V}_{\boldsymbol{R}}=\boldsymbol{K} \cdot \boldsymbol{V}_{\boldsymbol{S}}$; donde $K$ es una función que sólo depende del coeficiente de Poisson v y varía entre 0.874 para $v=0$ hasta 0.955 para $v=0.5$. La representación de la velocidad en función de la frecuencia (f) o de la longitud de onda $(\boldsymbol{\lambda})$ es lo que se conoce como curva de dispersión, relacionadas por la siguiente ecuación: $V_{R}=f \cdot \lambda$

La existencia de las ondas superficiales fue demostrada, al considerar la propagación de ondas en un medio semi-infinito limitado por una superficie plana libre.

LAMB (1904) demostró que una excitación puntual de corta duración en la superficie de un medio elástico produce ondas Rayleigh además de ondas P y S. Posteriormente, Mitler y Pursey (1955) encontraron que la distribución de energía en el campo lejano debido a la vibración vertical de una placa circular rígida colocada en la superficie de un medio elástico, homogéneo e isótropo es un 67\% en forma de onda Rayleigh; $26 \%$ onda $S ; 7 \%$ onda $P$.

El hecho de que 2/3 de la energía producida por una vibración vertical se propague en el campo lejano en forma de ondas Rayleigh y que estas ondas superficiales se atenúen con la distancia a la fuente vibratoria mucho más lentamente que las ondas internas, indica que las ondas $\mathrm{R}$ son de máximo interés para el tipo de ensayo no destructivo objeto de este estudio.

En medio homogéneo, isótropo y elástico, la velocidad de onda de Rayleigh no varía con la frecuencia, pero sí en un medio heterogéneo de varias en capas cuando hay una variación de rigidez en profundidad. Este fenómeno de dispersión donde la frecuencia depende de la velocidad de onda de Rayleigh y la capacidad de detectar y evaluar la profundidad del medio, está influenciada por la longitud de onda y la frecuencia generada. La menor longitud de onda penetra 
en la zona menos profunda de la superficie y la longitud de onda más larga de baja frecuencia penetra más profundo en el medio.

Referente al análisis de las ondas superficiales, destacan los trabajos citados en la bibliografía referente a ondas de Rayleigh [HERTwIG, 1931; JoNES, 1958; HEUKоLOM \& FOSTER, 1962; ABbiSS, 1981; BALLARD \& MCLEAN (1975), NAZARIAN \& STOKOE (1984); ROBERTSON (1992); MATTHEWS (1996)].

Cualitativamente, los ensayos experimentales realizados en este trabajo se basaron en el supuesto demostrado de que el mortero, como material con baja relación a/c exhibe mayor velocidad de pulso, así como mayor amplitud [GRoSSE \& REINHARDT 1994; REINHARDT 2000; BOUMIZ 1996; CASSON \& DOMONE 1982; BOUTIN \& ARNAUD, 1995; ARNAUD \& THINET, 2003$].$

\section{- ESTADO DEL CONOCIMIENTO (TEORÍA DE PROPAGACIÓN DE ONDAS [II]).}

Se presenta una revisión del Método END de Análisis Espectral de Ondas Superficiales (SASW) para evaluación de morteros en edad temprana [conceptos básicos, principios, procedimientos de prueba, procesamiento de la señal y aplicaciones representativas], cuya característica común con otros métodos es que las condiciones internas de la estructura están basadas en el efecto de la propagación de ondas sísmicas.

Exceptuando inspección visual, el uso del método de onda de impacto es la forma más antigua de las pruebas no destructivas.

Golpear el modelo con un martillo y escuchar el sonido "resonante" es una manera común de detectar la presencia de defectos y anomalías cerca de la superficie.

Requiere precisión en el manejo del equipo utilizado, y a pesar de estas limitaciones, es un método útil y una técnica estándar disponible.

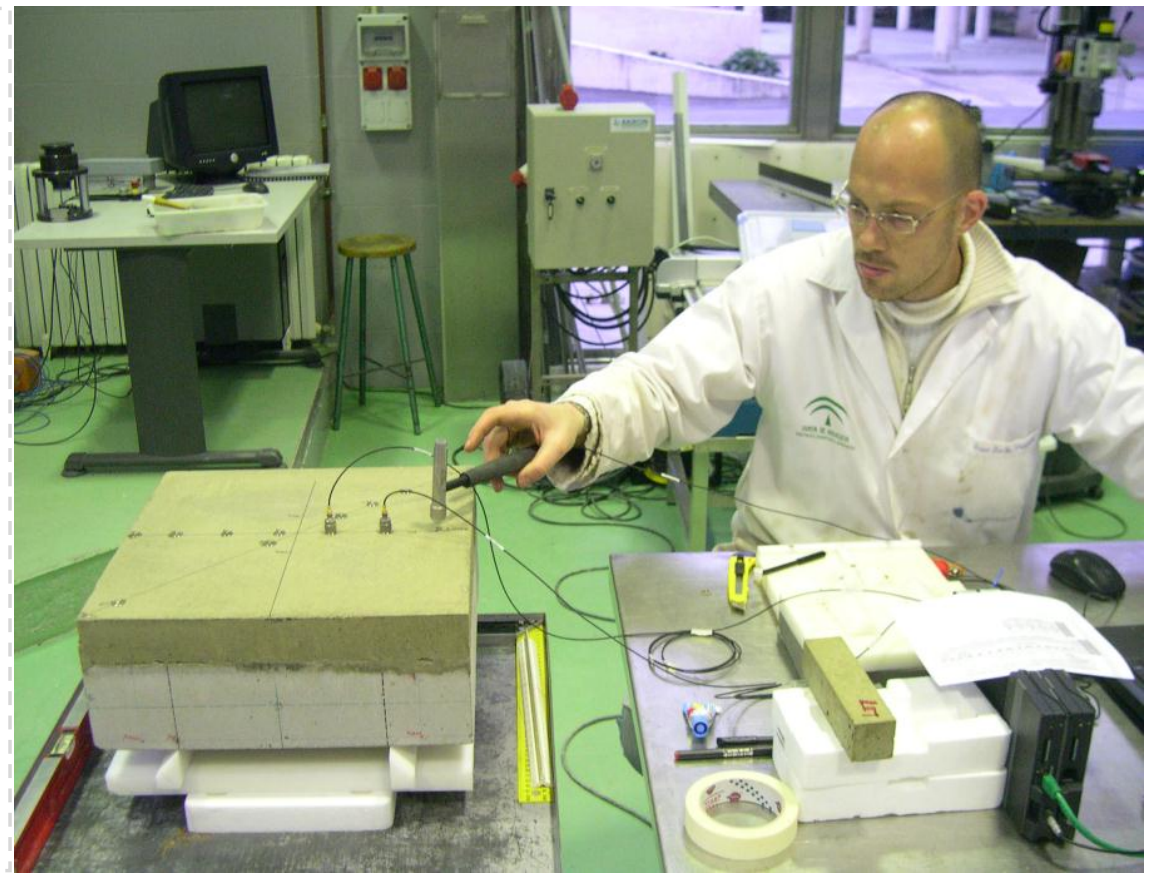

(Fig.15). Ensayo de propagación de ondas superficiales en modelo tricapa de losa de mortero 40x40×20cm. Por tANTO, SE DESCRIBE LA TEORÍA DE PROPAGACIÓN DE ONDAS SUPERFICIALES, EL DESARROLLO ACTUAL DEL MÉTOdO SASW, EL ENSAYO EXPERIMENTAL, INTERPRETACIÓN DE DATOS, REDUCCIÓN DE REFLEXIONES EN EL CONTORNO CON EL OBJETIVO dE CORRELACIONAR LA RESISTENCIA A LA COMPRESIÓN EN MORTEROS DE EDAD TEMPRANA Y LA VELOCIDAD DE ONDA SUPERFICIAL.

Tipos de cargas dinámicas. Naturaleza de las cargas impulsivas.

Las cargas dinámicas se clasifican en función de cómo varía dicha carga $\mathrm{P}(\mathrm{t})$ en el tiempo t, siendo deterministas y aleatorias. Las señales deterministas, expresadas mediante una relación matemática explícita, son periódicas (sucesivos ciclos que se repiten de forma armónica simple o en forma no armónica) y transitorias (cargas que no se repiten con las mismas características en el tiempo, 
siendo de corta duración o IMPULSIVAS, objeto de este estudio). En este caso, el impacto que se introduce al modelo mediante Análisis Espectral de Ondas Superficiales, consiste en una carga impulsiva forzada, de forma arbitraria, cuya principal característica es que el tiempo de duración es muy corto comparado con el periodo de vibración de la estructura sobre la que se aplica.

Consiste en un único impulso de corta duración cuya respuesta máxima suele darse antes de que la estructura o modelo ensayado pueda desarrollar fuerzas de amortiguamiento significativas, por lo que pueden despreciarse. Si tomamos el valor máximo de respuesta de la señal, al procesarla obtenemos el espectro de Fourier y el autoespectro de energía, la base del análisis espectral.

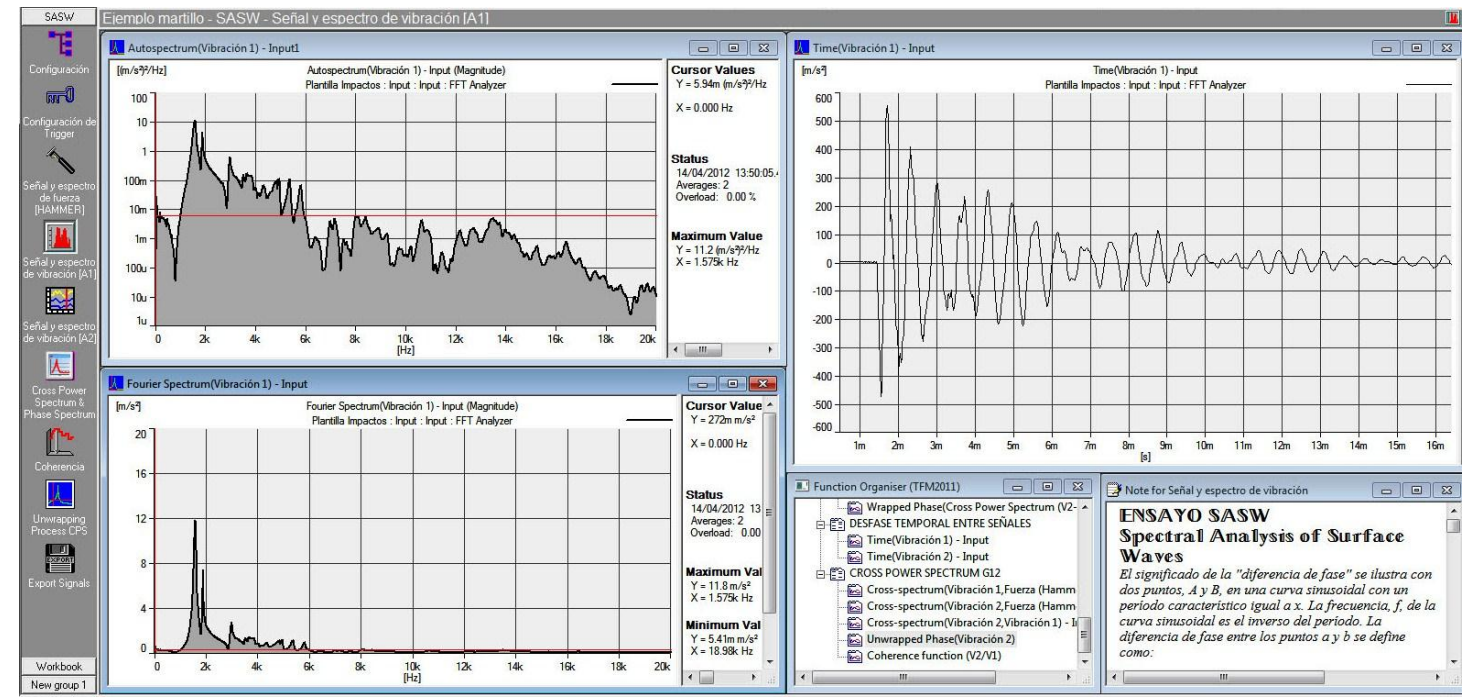

(Fig.16). Ejemplo en PULSE v.16 de una señal temporal, espectro de Fourier y autoespectro.

El amortiguamiento es una propiedad de cada modelo de ensayo experimental que se traduce en el efecto de atenuación de la onda de propagación, y que más adelante se justifica su presencia en la dispersión de la onda. Influyen otros parámetros del material que hacen que si el sistema se deja vibrando libremente después de aplicarle el impacto impulsivo inicial, acabe por detenerse la propagación trascurrido un tiempo determinado (régimen transitorio).

Principios de Ondas elásticas: definiciones y terminología.

El objetivo es adquirir datos de onda Rayleigh (superficial) utilizando una fuente por impacto (carga por caída de martillo, etc.) y un par de acelerómetros para ondas de baja frecuencia, que mediante un transductor de señales se procede al procesamiento de datos, análisis de Fourier, tratamiento de la curva de dispersión y obtención de las velocidades de fase para cada espécimen de mortero.

Las ondas producidas por un impacto se transmiten desde el foco, a velocidades que dependen de la elasticidad de los materiales, la naturaleza de las capas del mortero que atraviesan, las trayectorias de propagación y el tiempo mínimo en recorrerlas. Las ondas directas se propagan en los sólidos elásticos de tres maneras diferentes:

1) Ondas longitudinales (de compresión) u ondas $\boldsymbol{P}$ (primarias). El movimiento de vibración de las partículas se produce en la misma dirección de propagación. Son las primeras en registrarse y tienen una amplitud pequeña y periodo corto. Su movimiento es irrotational y la onda se propaga con velocidad $\mathbf{V p}$. 
2) Ondas transversales (de cizallamiento) u ondas $S$ (secundarias). El movimiento se produce normal rotatorio a la dirección de propagación. Se registran con posterioridad a las ondas $P$ e indican un movimiento de amplitud algo mayor y periodo semejante al de aquellas ondas.

3) Ondas superficiales (de largo periodo). Las ondas Rayleigh existen únicamente en la superficie libre de un medio elástico, son las últimas en registrarse en el punto de observación y presentan amplitudes y periodos grandes. Las ondas son mucho más complejas ya que éstas pueden reflejarse y refractarse pudiendo cambiar la forma de onda de manera que la complejidad del registro puede ser muy grande.

La onda Rayleigh.

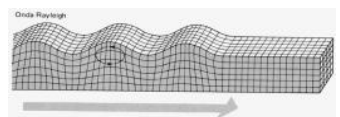

Propagación en $x_{1}$

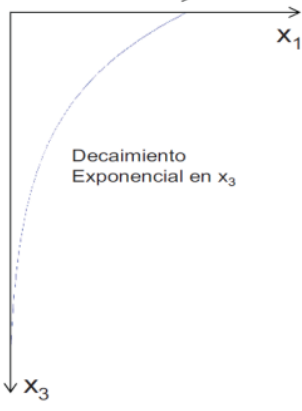

En un medio uniforme sólo aparecen ondas P y S. Si el medio es limitado (mortero) aparecen las ondas superficiales, cuya profundidad de penetración depende de su longitud de onda. En este medio no uniforme, la onda Rayleigh viaja a velocidad dependiente de su frecuencia, de amplitud decreciente exponencialmente en el eje z, cuyas partículas se mueven en planos verticales de eje 1,5 veces el horizontal, describiendo elipses verticales retrógradas (movimiento opuesto a la dirección de avance de la onda) de velocidad menor a las ondas P y S. El carácter superficial de esta onda hace que el tiempo de recorrido dependa de las irregularidades de la superficie que sigue la onda. Se engendran por acción de las ondas longitudinal y transversal en el interior del sólido y la discontinuidad que representa la cara limite superficial.

Si examinamos la superficie del solido, los ejes mayor y menor de la elipse van cambiando hasta 0,2ג de la superficie, donde el movimiento vertical de la partícula de la onda Rayleigh decrece rápidamente en profundidad (decaimiento exponencial de la amplitud), por lo cual se asume que el movimiento asociado a ésta onda está confinado a la zona más superficial del medio. Así, la propagación está determinada por las características mecánicas a una profundidad no mayor a una longitud de onda.

Considerando el esquema inferior de vibración armónica a baja frecuencia, se demuestra que 2/3 de la energía total de entrada son ondas Rayleigh y $1 / 3$ de ondas P y S. Añadiendo el fenómeno de la atenuación, se concluye que a cierta distancia de la fuente, la influencia de la onda está dominada por 0 . Rayleigh.
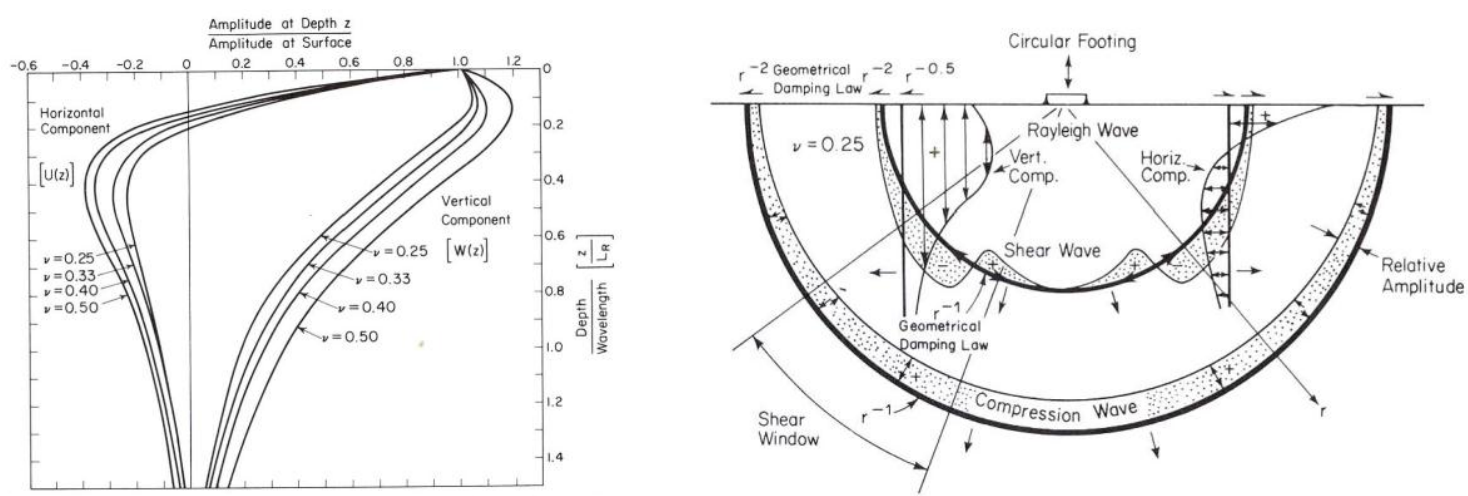

(Fig. 17). Decaimiento amplitud de onda R en profundidad. Esquema medio lineal homogéneo [Richart \& Woods 1970]. Relación entre coeficiente de amplitud vs profundidad en función de la longitud de onda en un medio lineal elástico. 
Las ecuaciones de Navier de equilibrio dinámico en la formulación del vector se pueden expresar como: $(\lambda+\mu) \nabla \nabla \cdot u+\mu \nabla^{2} u+\rho f=\rho \ddot{u} \quad$ Donde $\boldsymbol{u}$ es el desplazamiento de la partícula, $\rho$ la densidad media, $\lambda, \mu$ las constantes de Lamé y flas fuerzas de ondas $P$ y $S$.

La solución se encuentra usando la descomposición de Helmholtz y asumiendo una forma exponencial, siguiendo la definición de una onda superficial que decae rápidamente conforme aumenta su profundidad. Así, la solución que satisface la velocidad de propagación de la onda R es:

$$
\begin{aligned}
& K^{6}-8 K^{4}+\left(24-16 \gamma^{2}\right) \cdot K^{2}+16\left(\gamma^{2}-1\right)=0 \quad K=\frac{V_{R}}{V_{S}} \quad \gamma=\frac{V_{S}}{V_{P}} \quad \gamma^{2}=\frac{1-2 v}{2(1-v)} \quad 0<v<0,5 \\
& K=\frac{0,87+1,12 v}{1+v} \quad 0,87<\frac{V_{R}}{V_{S}}<0,96
\end{aligned}
$$

Se observa que en un medio homogéneo lineal y elástico el único factor que lo caracteriza es la velocidad de la onda Rayleigh.
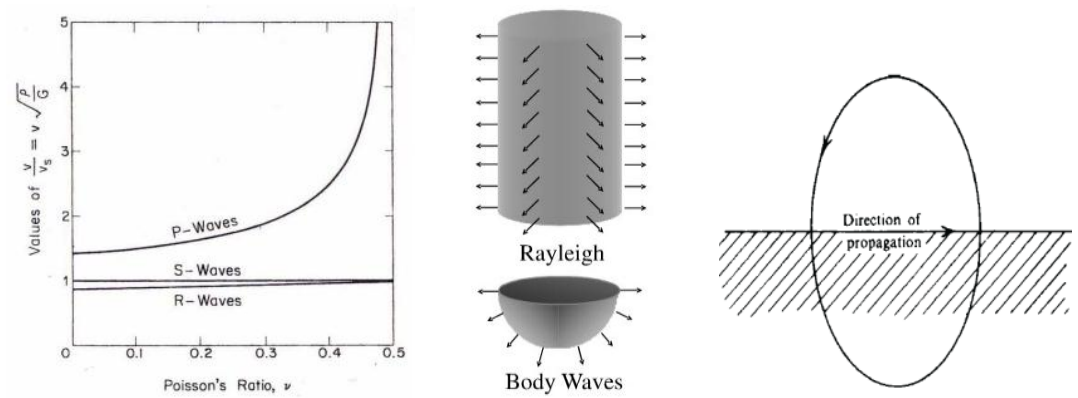

(Fig. 18). Relación entre coeficiente de Poisson y las velocidades de propagación de ondas (P), (S) y (R) en un medio lineal y homogéneo elástico. Desplazamiento de la partícula [RICHART, HALL, WoOdS 1970]

Análisis de la señal.

FUnCIONES PERIÓdICAS, SERIES DE FOURIER, INTEGRAL DE FOURIER, FFT y DFT.

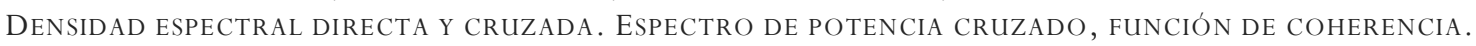

Los parámetros para caracterizar una señal son dos: Fase y Amplitud. Estos parámetros se definen a partir de la transformada de Fourier, y el espectro de potencia cruzado, $\mathbf{S}_{\mathbf{x y}}$ :

$$
\text { FASE }: \varnothing=\operatorname{tg}^{-1}\left[\frac{\operatorname{Im}\left(S_{x y}\right)}{\operatorname{Re}\left(S_{x y}\right)}\right] \quad \text { AMPLITUD }: \mathrm{A}=\sqrt{\left(\operatorname{Re}\left(S_{x y}\right)\right)^{2}+\left(\operatorname{Im}\left(S_{x y}\right)\right)^{2}}
$$

Una vez expresadas las señales como funciones periódicas de una serie de Fourier en el dominio del tiempo, necesitamos comprender las características que presenta el proceso registrado en el espacio de la frecuencia, por lo que debemos analizar la función de autocorrelación $R \boldsymbol{x}(\boldsymbol{t})$, de la señal $\mathrm{x}(\mathrm{t})$. Esta función otorga información sobre las frecuencias presentes en un proceso aleatorio de manera indirecta, por lo que resulta ventajoso; se define como:

$$
\left.\begin{array}{l}
\text { Autocorrelación }: R_{x}(\tau)=E[x(t) \cdot x(t+\tau)]=f(\tau) \rightarrow F F T \rightarrow \\
\text { Densidad espectral directa }: S_{x}(\omega)=\frac{1}{2 \pi} \int_{-\infty}^{+\infty} R_{x}(\tau) \cdot e^{-i \omega t} d \tau \rightarrow
\end{array}\right\} R_{x}(\omega)=\int_{-\infty}^{+\infty} S_{x}(\omega) \cdot e^{i \omega t} d \omega
$$


Siendo $\operatorname{Sx}(\omega)$ la densidad espectral directa o espectro de potencia directo, función de la frecuencia angular $\omega$. Así, el valor medio del cuadrado de un proceso aleatorio $\mathrm{x}(\mathrm{t})$ es el área bajo la curva de la densidad espectral, $\operatorname{Sx}(\omega)$ en el espacio de la frecuencia. De esta forma, la densidad espectral cruzada es la transformada de Fourier de la función de correlación cruzada:

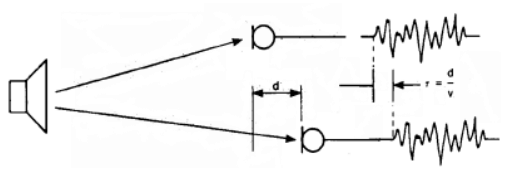

$$
\begin{aligned}
& S_{x y}(\omega)=\frac{1}{2 \pi} \int_{-\infty}^{+\infty} R_{y x}(-\tau) \cdot e^{-i \omega \tau} d \tau \quad \text { Dónde d es la distancia entre } \\
& T_{|(a b)|}(\tau)=\lim _{\tau \rightarrow \infty} \int_{0}^{T} a(t) \cdot(t+\tau) d t
\end{aligned}
$$

receptores; $\boldsymbol{\tau}$ es el periodo; $\mathbf{v}$ es la velocidad de propagación de las ondas.

La evaluación del espectro cruzado de potencia permite evaluar sistemas dinámicos determinando parámetros como la fase y razones espectrales, en función de la frecuencia. Mediante la DFT podemos calcular la densidad espectral de un proceso aleatorio.

La señal registrada por los acelerómetros, se analiza mediante la función de correlación cruzada, que muestra la similitud entre las dos señales de tiempo $a(t)$ y $b(t)$ para diferentes periodos de tiempo. A partir de la correlación cruzada, conociendo la distancia entre los receptores, puede determinarse el tiempo de llegada de las ondas P y S a cada uno de los acelerómetros y de este modo determinar los parámetros del modelo de mortero.

Velocidad de propagación de la onda.

A partir del análisis de las señales, puede relacionarse la velocidad de propagación de las ondas con las constantes elásticas del medio. Se puede adquirir una comprensión básica de la relación entre las propiedades físicas de los materiales y la velocidad de onda de la teoría de propagación de ondas en medio isótropo y elástico, la velocidad de onda $P, V_{p}$, es función del módulo de Young, $\boldsymbol{E}$, la densidad, $\boldsymbol{\rho}$, módulo de corte, $\boldsymbol{G}$ y el coeficiente de Poisson, $\boldsymbol{v}$ :

$$
\begin{aligned}
& \frac{V_{P}}{V_{S}}=\sqrt{\frac{1-v}{0,5-v}} \quad v=\frac{\left[0,5 \cdot\left|\frac{V_{P}}{V_{S}}\right|^{2}\right]-1}{\left(\frac{V_{P}}{V_{S}}\right)^{2}-1}=0,1857 \approx 0,2 \quad V_{P}=\sqrt{\frac{E(1-v)}{\rho(1+v) \cdot(1-2 v)}} \\
& V_{S}=\sqrt{\frac{E}{2 \rho(1+v)}}=\sqrt{\frac{G}{\rho} \rightarrow G=\rho\left(V_{S}\right)^{2}} \quad V_{R}=\frac{0,87+1,12 v}{1+v} \cdot \sqrt{\frac{1-2 v}{2(1-v)}} \cdot V_{P} \\
& G(\text { módulo corte })=E / 2(1+v) \quad v=0,5\left|V_{L} / V_{T}\right|^{2}-1 /\left|V_{L} / V_{T}\right|^{2}-1 \quad 0<v<0,5
\end{aligned}
$$

En elementos lineales de contorno, como las placas delgadas de mortero que se estudiaron para ensayos AEOS en modelos unicapa, la velocidad puede variar en función de las dimensiones laterales de la sólida relación con la componente longitud de onda $(\lambda)$ de la onda de propagación. En este caso, la velocidad se determina así: $C_{B}=\sqrt{E / \rho}$ para un coeficiente de Poisson típico v=0,2. La velocidad de onda $\mathrm{S}, \mathrm{C}_{\mathrm{S}}$, se expresa así: $C_{S}=\sqrt{G / \rho}$ donde $G=E / 2(1-v)$. Es usual 
expresar la velocidad de onda P y onda S por la anterior relación de parámetros: $\alpha=\frac{C_{s}}{C_{p}}=\sqrt{\frac{(1-2 v)}{2(1-v)}}$.

Para un coeficiente de Poisson $v \approx 0.61$, la propagación de onda Rayleigh, $\mathrm{C}_{\mathrm{R}}$, se expresa con la formula: $C_{R}=[(0,87+1,12 v) /(1+v)] C_{S}$

Reflexión y Refracción.

La propagación de ondas de tensión transitoria a través de un sólido acotado heterogéneo, como un elemento placa de mortero, es un fenómeno complejo.

Cuando un frente de onda es incidente en un límite o contorno entre diferentes medios de comunicación, se produce el reflejo "especular" (similar a la reflexión de la luz por un espejo), las ondas sísmicas pueden propagarse en la dirección del rayo. En un límite entre dos medios diferentes se refleja sólo una parte de onda. El resto penetra en el medio subyacente (refracción).

El ángulo de refracción, $\beta$, es función del ángulo de incidencia, $\Theta$, y la relación de velocidades de onda $\mathrm{C}_{2} / \mathrm{C}_{1}$, está dada por la ley de Snell: $\sin \beta=\left(C_{2} / C_{1}\right) \sin \theta$

Las ondas sísmicas pueden cambiar su modo de propagación al golpear un límite en ángulo oblicuo. Según el ángulo de incidencia, una onda puede reflejar/refractar parcialmente dos ondas $P$ y $S$.

Cuando $C_{s}<C_{P}$ se reflejarán y se refractarán en ángulos $\theta$ s y $\beta$, menores que los ángulos de onda $P$ (ley de Snell):

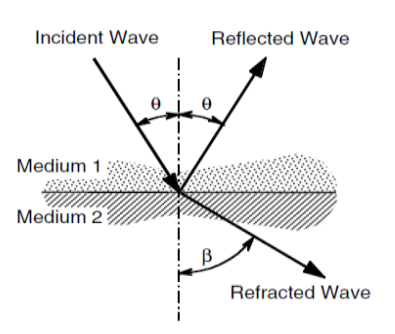

$$
\begin{gathered}
\qquad \frac{\sin \theta}{\mathrm{C}_{1}}=\frac{\sin \beta}{\mathrm{C}_{2}} \\
\text { A Reflection and Refraction }
\end{gathered}
$$

(Fig. 19). El comportamiento de una onda $P$ en una interfaz entre dos medios diferentes: A). Reflexión y refracción; (B) Conversión

Las amplitudes relativas de las ondas reflejadas dependen de la incompatibilidad en impedancias acústicas específicas en la interfaz, el ángulo de incidencia, la distancia de la fuente de impacto y la atenuación de onda.

La porción de un rayo incidente de una onda $\mathrm{P}$ que se refleja en una interfaz entre dos medios depende de las impedancias acústicas específicas de cada medio. La impedancia acústica específica es: $Z=\rho \cdot C p$ (MORTEROS: $\left.\rho=2300 \mathrm{~kg} / \mathrm{m}^{3} ; C p=3000-4500 \mathrm{~m} / \mathrm{s} ; Z=6,9-10,4 \times 10^{6} \mathrm{~kg} / \mathrm{m}^{2} \mathrm{~s}\right)$.

La amplitud de un rayo reflejado es máxima cuando el ángulo de incidencia del rayo es normal a la interfaz. Para incidencia normal, se determina la amplitud del rayo reflejado respecto a la amplitud del rayo incidente como: $R=\left(Z_{2}-Z_{1}\right) /\left(Z_{2}+Z_{1}\right)$ donde $R n=$ coeficiente de reflexión para incidencia normal; Z1,Z2 = impedancias acústicas específicas de los medios 1 y 2. Si Z1>Z2, Rn es negativa, indicando que la onda reflejada tendrá el signo opuesto, es decir, ocurre un cambio de fase. 
Ideas principales de Ondas Superficiales.

Para un sistema homogéneo, se destaca:

- Su velocidad de propagación es similar a la de las ondas S. La relación entre ambas es función del coeficiente de Poisson $(0,87$ a 0,96$)$.

- El movimiento de la partícula asociada es elíptico y retrógrado con el eje vertical.

- La propagación implica una parte superficial del sólido, de grosor similar a la longitud de onda.

- La atenuación geométrica desde la fuente está relacionada con la raíz cuadrada de la distancia y por lo tanto es menos sensible que en ondas de cuerpo.

- En un modelo vibrando a baja frecuencia (probeta de mortero), 2/3 de la energía de entrada va en ondas superficiales y la parte restante en ondas $S$.

Para un sistema heterogéneo, se destaca:

- La velocidad de fase depende de la frecuencia en medio elástico (dispersión geométrica).

- El movimiento en la superficie es elíptico pero no es necesariamente retrógrada.

- Existen varios modos de vibración libre, caracterizados por una longitud de onda y una velocidad de fase propias, lo que implica diferente desplazamiento con la profundidad.

- La atenuación geométrica es una función compleja de las propiedades mecánicas del sistema.

- Debido a la diferencia entre la velocidad de fase y velocidad de grupo, la separación entre modos tiene lugar fuera de la fuente y el pulso cambia de forma.

Finalmente cabe mencionar las principales lecciones de ensayos y simulaciones:

> Para un perfil normalmente dispersivo (capas más rígidas en profundidad), la velocidad de fase efectiva es prácticamente coincidente con el $1^{\circ}$ modo fundamental.

$>$ Para un perfil inversamente dispersivo (ej: pavimentos) es muy importante tener en cuenta la superposición modal. 


\section{Análisis Espectral de Ondas Superficiales (AEOS)}

\section{ANTECEDENTES TEÓRICOS E HISTÓRICOS DEL MÉTODO.}

La técnica de propagación de ondas superficiales tiene su origen en Alemania (1930) bajo el método geotécnico SWM (Spectral waveform method) como herramienta de uso geofísico para estimar la respuesta de efectos de sitio, poniendo el énfasis en la construcción de una curva de dispersión asegurando su fiabilidad frente a otros métodos del momento.

Análisis espectral de ondas superficiales
(AEOS) es el nombre dado al eficiente
método no destructivo para determinación
in-situ de las velocidades de fase
mediante la curva de dispersión de las
ondas mecánicas cuando viajan a través
de un medio heterogéneo como es el
mortero. Desde diferentes longitudes de
onda la técnica se verá afectada por las
condiciones a distintas profundidades de
la superficie.

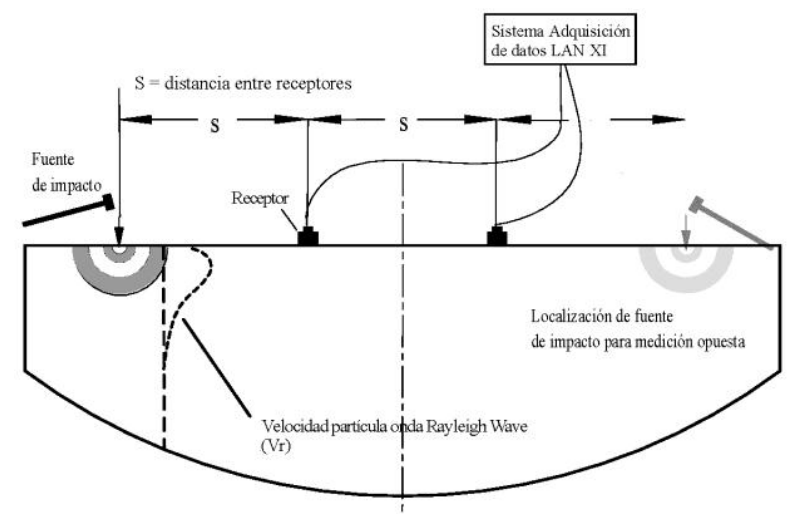

(Fig. 20). Esquema experimental de los ensayos AEOS con equipo B\&Kjaer.

Precedentes del método de ensayo.

La primera contribución importante al estudio de ondas superficiales en el terreno fue realizada por LORD RAYLEIGH (1885). El primer estudio de la propagación de ondas P en un medio elástico de espesor uniforme fue realizado por ВRомwicH (1898) suponiendo ondas estacionarias de longitud de onda superior al espesor de la capa. Posteriormente Love (1911) analizó el mismo caso para ondas S. Además, encontró que, para longitudes de onda pequeñas comparadas con el espesor de la capa, podía existir la onda $\mathrm{R}$ cuya velocidad dependía de las propiedades del medio y no del espesor de la capa. StoneLeY (1924) completó esta investigación al estudiar el efecto producido por la superficie de separación entre dos medios elásticos. A partir de entonces han sido varios los estudios realizados con el fin de demostrar la influencia que tiene la estratificación en la propagación de ondas [SEZAWA (1927), KANAI (1941), SATO (1949-1954), EWING Y PRESS (1950)].

En las primeras aplicaciones que se remontan a la década de 1930, las ondas superficiales eran inducidas por un generador de estado estacionario de vibración armónica colocado en la superficie de un pavimento.

En la década de 1960-1970, el interés en el método disminuyó por las limitaciones de la instrumentación y las capacidades de análisis.

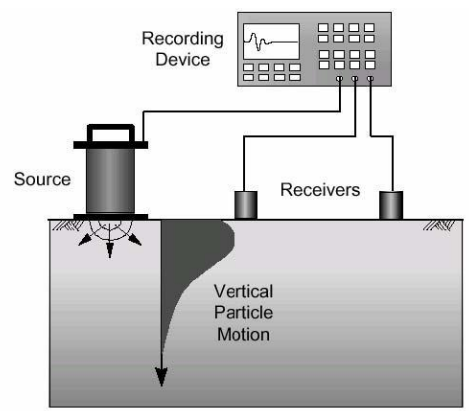

(Fig.21). La velocidad de propagación de las ondas tipo Rayleigh o velocidad de fase de cada componente armónica, depende de la frecuencia, debido a lo cual las ondas de distinto período viajan con distinta velocidad, por lo que la señal se extiende en el tiempo al aumentar la distancia recorrida. 
El primero en formular la propagación de ondas planas en sistemas multicapas matricialmente de manera adecuada para tratamiento computacional fue THомSON (1950). Posteriormente HASKELL (1953) sugiere el «Método de la Matriz de Transferencia» para hallar la curva de dispersión. Sin embargo, tuvieron que pasar varios años para que este método fuera programado por ordenador (DORMAN 1960, KAUSEL\& ROESSET 1981).

Los primeros ensayos conocidos de auscultación vibratoria por ondas superficiales fueron realizados en carreteras (perfiles geofísicos, evaluación de suelos, detección de anomalías de compactación de rellenos, balasto en ferrocarriles...) y tuvieron lugar en los Estados Unidos (BERNHARD, $1939 \&$ LONG, 1945), cuyos precedentes experimentales se remontan a 1965 por la Sociedad Germana del estudio de la Mecánica de los suelos, además del Ejercito de Ingenieros de EEUU (FRY, 1965) y los métodos analíticos para reducción de datos (JONES, 1958). Posteriormente, en el Road Research Laboratory de Inglaterra se efectuó el desarrollo de esta técnica que haría posible la obtención de las curvas de dispersión (JONES 1955-1962). En la década de los sesenta el Laboratoire Central des Ponts et Chaussées de Francia inicia los estudios de esta técnica continuando su desarrollo (Dosso 1968 \& GUILLEMIN 1971). Es en la década siguiente cuando el Laboratorio del Transporte y Mecánica del Suelo (actual Laboratorio de Geotecnia del CEDEX) introduce esta técnica en España (SANTAMARía 1973).

En otros trabajos (HEUKELOM 1962 \& BALLARD 1973), ensayaron en la superficie de terrenos, vibraciones senoidales permanentes dentro de una amplia gama de frecuencias buscando los puntos de la superficie que estaban en fase con el vibrador. De esta forma, multiplicando la longitud de onda por la frecuencia se obtenía la velocidad de onda Rayleigh, pero el tiempo de ejecución del ensayo era excesivo; por ello, su difusión fue limitado. Sin embargo, en las últimas décadas, se ha mejorado con el desarrollo de los equipos electrónicos digitales y las nuevas fuentes de vibración utilizadas: impacto (NIELSEN Y BAIRD 1977; HEISEY 1982; NAZARIAN 1984; CÚELLAR, 1988); aleatorias (WILLIAMS 1981; DMEVICH 1985); barrido lineal en frecuencias (VALERIO 1990; MUÑOZ 1991).

En 1980, investigadores de la UNIVERSIDAD DE TEXAS EN AUSTIN comenzaron los estudios de la técnica ("análisis espectral de ondas superficiales") que implicaba un impacto mecánico en lugar de una vibración de estado estacionario, un procesamiento digital de señales que relacionaba longitud de onda y velocidad de fase. Los avances y la modificación del método alcanzaban en la década de 1980 un nuevo auge, se reducía significativamente el tiempo de análisis. En la década de 1990 se introdujo el concepto de curva de dispersión "aparente" para describir la superposición de modos fundamentales.

El método SASW se ha utilizado en diferentes aplicaciones después de la mejora de la técnica (JONES 1958-1962; MEYER 1982; NAZARIAN 1983; STOKOE, WRIGHT, BAY \& ROESSET 1994). En resumen, los mayores aportes vinieron de la mano de las siguientes investigaciones: 
- E. Poggiagliolmi (1982): estudia las posibilidades y limitaciones del proceso de despligue de los ángulos de fase de los espectros de amplitud entre señales temporales, aspecto clave que será determinante en el método AEOS.

- Nazarian (1984): determinó el método de estudio in situ y desarrolló un algoritmo para conocer la rigidez desde la curva de dispersión.

- N. J. Carino \& SAnsalone (1984): se aplicó la teoría del impacto-eco al estudio de la propagación de ondas con un equipo similar al utilizado en geofísica y en metales.

- DRNEVICH (1985): recurre a un vibrador conectado a una función aleatoria generadora del impacto como fuente experimental.

- Sтокое (1986): desarrolló los aspectos teórico-experimentales del método SASW como aplicación en el campo de la geotecnia y la ingeniería de pavimentos.

- SÁNCHEZ-SAlinero (1987): estudió la configuración analítica más fiable recomendada entre fuente-receptor, indicando que la distancia deseable entre fuente y primer receptor (más cercano) debe ser igual a la separación entre los receptores $(D \approx X)$. Se supone que sólo participan las ondas de Rayleigh. Se ignora el efecto de ondas P y S.

- Shever (1987): añade que en el método SASW no se deben considerar longitudes de onda superiores a 3 veces la distancia de separación entre receptores $\left(\lambda<3 d_{2}\right)$.

- Hiltunen (1988): confirma experimentalmente estas recomendaciones.

- Rix (1988): basándose en la investigación experimental, se concluye que la energía de ondas superficiales en SASW se asocia con los modos fundamentales de vibración.

- Hossain \& DRnevich (1989): aportan un algoritmo para determinar el perfil de rigidez. Aparece el método de inversión asociado a técnicas de optimización y algoritmos de aplicación para el estudio de la dispersión de onda.

- Young CHO (1990): aplica la técnica tradicional del método AEOS en modelos delgados de cemento tipo placa para determinar la velocidad de onda $P$.

- GuCUNSKI \& Woods (1991): añaden un estudio analítico para la cuantificación de los problemas asociados con la heterogeneidad de los materiales de varias capas.

- Barker \& SteVEns (1991): reportan algunas de las preocupaciones del procesamiento de la señal en la obtención de datos mediante SASW.

- SAтон (1991): describe un método aproximado para la reducción de datos experimentales, con las limitaciones aceptables en el perfil de suelos uniformes.

- Dessai (1991): propone un método rápido para la construcción de curvas de dispersión a partir de la medición de datos en el campo.

- RIX \& LEIPSKI (1991): proponen un método de inversión al tratamiento de datos para suelos, mediante simplificación de mínimos cuadrados para invertir los datos de ondas.

- Folnquinos (1992): aporta mejoras a los estudios de Rix mediante la comparación experimental de la solución de varias capas de suelos en SASW con ondas de cuerpo.

- Tokimatsu \& Tamura (1993): aportaron nuevos avances en los efectos de los modos de vibración sobre la dispersión de la onda Rayleigh, así como de nuevos criterios de filtrado en la construcción de la curva de dispersión. 
- Cheng \& Sansalone (1994): estudian la técnica en pavimentos junto al método I-Eco para determinar la velocidad de onda P y la existencia de defectos internos en el material.

- M. Osama Al-HunaIDI (1995): analiza el efecto de la dispersión de onda en el método AEOS usando la técnica de filtrado múltiple y correlación cruzada en pavimentos.

- M. Osama Al-Hunaidi (2000): propone un método de inversión para determinar el perfil de rigidez a partir de curvas de dispersión basado en los coeficientes de máxima flexibilidad en el dominio de la frecuencia. 


\section{Análisis Espectral de Ondas Superficiales (AEOS)}

(V). DESARROLLO BÁSICO DEL MÉTODO.

El análisis espectral de ondas superficiales es un método no destructivo para determinar perfiles de velocidad de onda, comúnmente utilizado para determinar la rigidez de pavimentos. Los pasos clave involucrados son la construcción de una curva experimental de dispersión de los datos y la inversión de dicha curva. Al conocer la distancia entre receptores y la fase, se puede calcular la velocidad de fase $\psi$ la longitud de anda asociadas.
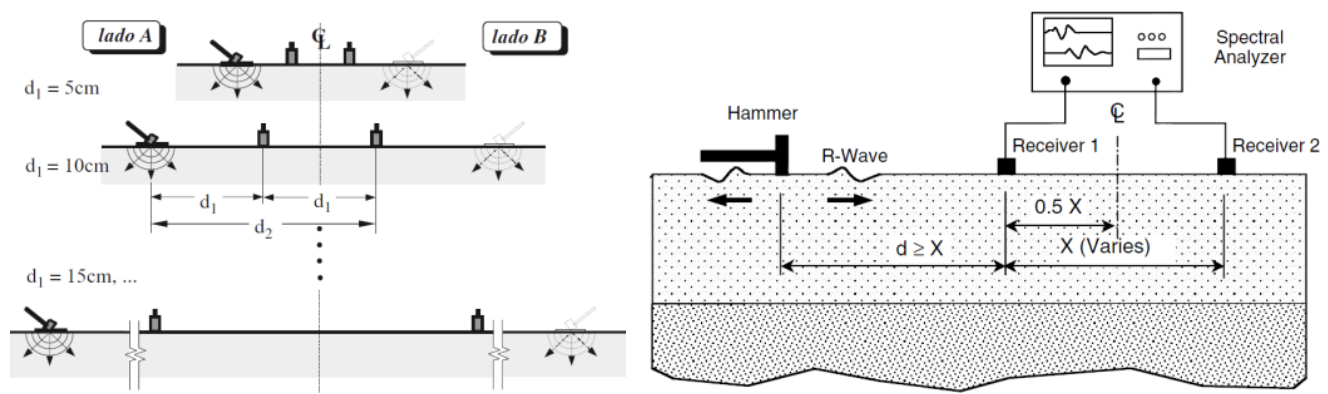

(Fig. 22). Esquema general de la configuración de un ensayo AEOS (Fuente: "NDT Methods in concrete" Malhotra,2005).

Una visión general del método por impacto. Caracterización.

El análisis espectral de ondas superficiales SASW (Spectral Analysis of Surface Waves) como ensayo NDT (no destructivo) en el que se miden las ondas de Rayleigh generadas por un impacto en la superficie del mortero, se desarrolló originalmente para la evaluación de las propiedades elásticas de suelos geotécnicos. Más tarde aplicado en pavimentos para determinar el espesor y la rigidez elástica de las capas subyacentes. Se propone en este estudio como aplicación en especímenes estructurales de mortero con ondas de baja frecuencia (Rayleigh).

De manera simplificada, el concepto asume que la vibración superficial está determinada por la rigidez y espesor de las diferentes capas en un mortero fresco a edades tempranas de curado. Entonces, si se mide la respuesta del material a un impacto controlado se puede llegar a determinar sus propiedades mecánicas. Los dos parámetros básicos son la velocidad y la atenuación de la onda. La velocidad se mide por esta técnica, conocida originalmente como SASW (Spectral analysis of surface waves) mientras que la transmisión de energía se entiende como la opuesta de la atenuación, de la cual se hablará más adelante.

En un medio continuo compuesto en capas que varían sus propiedades elásticas con la profundidad de alcance de la onda (ej., el mortero en estado fresco), la velocidad de onda superficial se propaga afectada para cada componente de frecuencia (dispersión). Una curva de dispersión muestra la velocidad de fase frente a la longitud de onda.

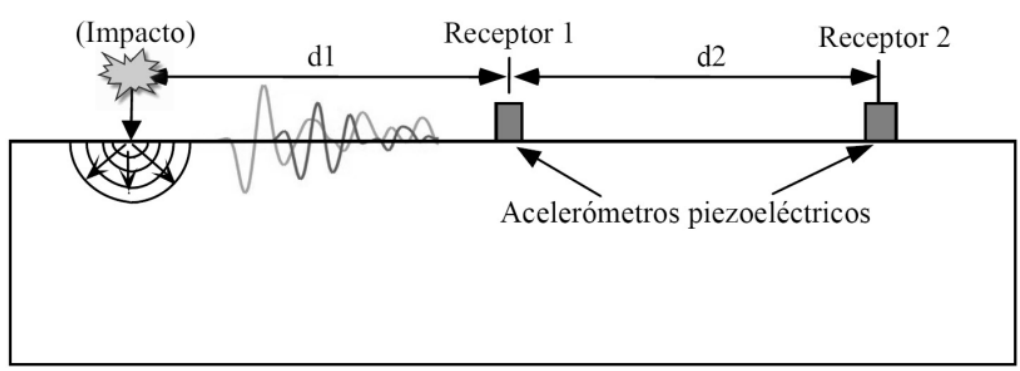

(Fig. 23). Montaje típico del ensayo AEOS. 
El enfoque básico del método AEOS es medir la curva experimental de dispersión y determinar un perfil de velocidades $\boldsymbol{V}_{\boldsymbol{S}}$-Alcance de onda donde converja la curva de dispersión teórica con la curva experimental. El propósito principal en este trabajo se basa en determinar la curva experimental y su validez para la obtención las propiedades mecánicas del material.

El proceso puede dividirse en tres pasos generales:

[1]. Captura de Datos (Data Collection): En el paso de recopilación de datos, las mediciones se realizan para determinar la diferencia de fase en función de la frecuencia entre los dos acelerómetros receptores situados en la superficie.

[2]. Procesamiento de las señales (Data Processing): El tratamiento de datos mide la diferencia de fase entre receptores y las velocidades de onda.

[3]. Análisis Posterior (Data ANAlysis): El análisis resultante establece una curva de dispersión experimental para cada modelo real fabricado en este estudio.

Un siguiente paso para desarrollos futuros es el proceso de inversión, que permitirá encontrar la mejor coincidencia entre las curvas de dispersión teórica y experimental.

\section{Data Collection (Captura de datos)}
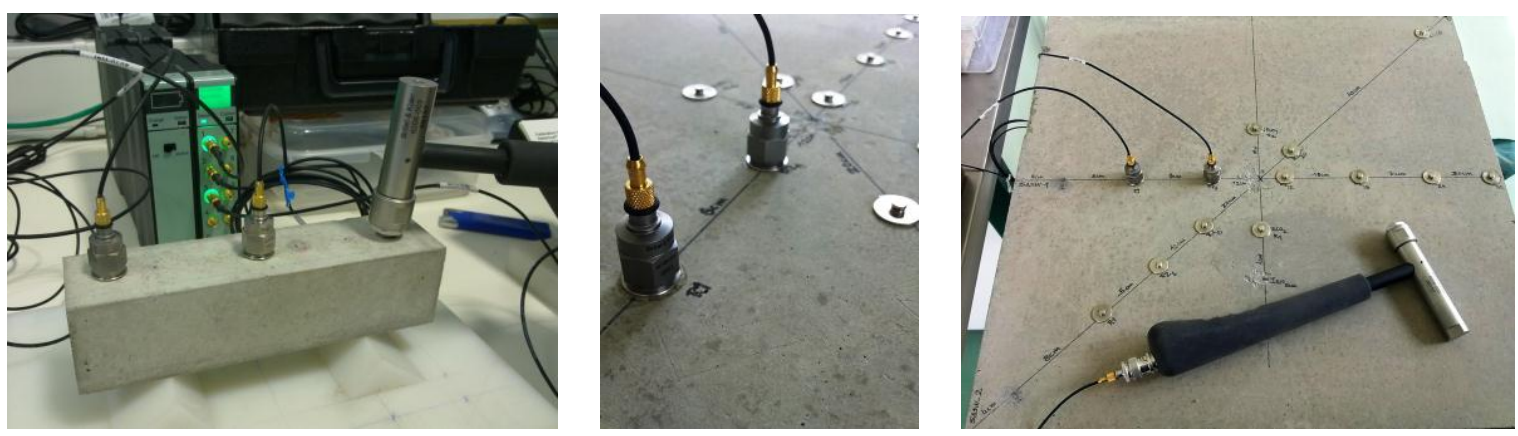

(Fig. 24). Ejemplo de captura de señales mediante ensayos AEOS. Detalle colocación de acelerómetros y configuración para la realización de mediciones en probetas y losas de mortero.

El proceso de adquisición y procesamiento de datos, interesa por:

- el cálculo de la longitud de onda para cada frecuencia, como la distancia entre dos máximos consecutivos de vibración.

- cálculo de velocidad de fase para cada frecuencia, $f$, de la relación $\boldsymbol{V}_{\boldsymbol{R}}=\boldsymbol{f} \cdot \boldsymbol{\lambda}$

- la construcción de la curva de dispersión, $\boldsymbol{V}_{\boldsymbol{R}} \boldsymbol{v} \boldsymbol{f}$.

El objetivo de las mediciones utilizando el método SASW es medir la diferencia de fase entre receptores sobre una amplia gama de frecuencias. Los dos acelerómetros generalmente están dispuestos sobre un punto medio común con la fuente a distancia igual a la separación entre ambos. Mantener una distancia suficiente entre el origen y el receptor más cercano a la fuente permite a la onda superficial estabilizarse minimizando el error significativo debido al efecto de campocercano (SÁNCHEZ SALINERO, 1987), que provoca la pérdida de resolución del espectro de fases, precisando del empleo de funciones ventana tipo Hanning. Para reducir los efectos de inhomogeneidades laterales del modelo (Aliasing, Leakage, efecto Picket fence, ruido...) o 
minimizar el efecto de atenuación de la onda en profundidad, las mediciones AEOS se repiten de 3 a 5 veces variando la fuente a una localización simétrica inversa (S. Ho JOH, 1996; HOLLRAH, 2005).

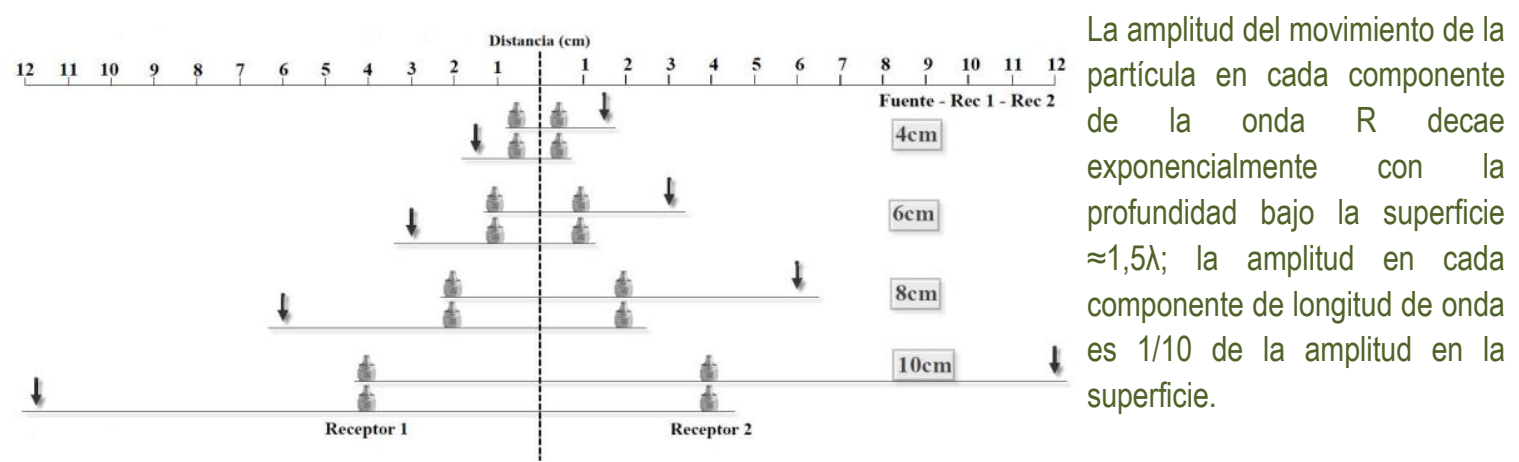

(Fig. 25). Montaje superficial y distanciamientos de acelerómetros.

La onda $\mathrm{R}$ producida por el impacto contiene un rango de frecuencias dependiente del tiempo de contacto del impacto; cuanto menor sea el tiempo de contacto, más amplio será el rango de frecuencias o longitud de onda $(\lambda)$.

Efecto del impacto sobre el tiempo de contacto (Force-time contact).

Conforme aumente la profundidad de ensayo, también aumentará la distancia entre receptores y se requiere un impacto con mayor energía a frecuencias bajas.

Un sistema de ensayo experimental se compone de una fuente de impacto, un transductor de los registros temporales captados por dos acelerómetros (receptores) y un sistema de adquisición de datos con el software adecuado para la gestión de datos y el posterior análisis de las señales. La selección de la fuente de impacto (tamaño de martillo, tipo de punta...) es un aspecto crítico justificado de forma empírica en base a los ensayos realizados.

El tiempo de contacto determina el contenido de la frecuencia del impulso generado por el impacto, siendo el más corto el de menor tiempo de contacto cuanto mayor sea el rango de frecuencias contenidas. Por lo tanto, el tiempo de contacto determina los resultados AEOS.

Disminuir el tiempo de contacto implica que la onda contenga componentes de frecuencia superiores (longitud de onda corta), efecto que más adelante nos servirá para localizar con precisión los defectos superficiales, determinar inhomogeneidades internas al material y encontrar la frecuencia de resonancia de cada modelo de mortero.

Por ejemplo, para un tiempo de contacto de $100 \mu$ s, la frecuencia máxima con amplitud significativa es de $10 \mathrm{kHz}$. Para una velocidad de onda, $C_{p}=4000 \mathrm{~m} / \mathrm{s}$, se necesitaría un pulso con un tiempo de contacto $<100 \mu$ s para alcanzar la profundidad de ensayo de espesor $20 \mathrm{~cm}$ correspondiente al espesor de la placa de mortero experimental (40x40x20cm). ((ASTM C1383 $\left.\left.\rightarrow t_{c}=1 / f_{\max } ; C_{P}=2 \cdot f_{\max } \cdot e_{\text {spesor }}\right)\right)$.

Por lo tanto, para estructuras tipo placa o losa, son preferibles impactos de corta duración. Así, se recurre al martillo adquirido para este trabajo, modelo $B \& K 8204$ de $\emptyset 3-11 \mathrm{~mm}$ para inducir un impacto que provoque un $\boldsymbol{t}_{\boldsymbol{c}} \approx \mathbf{1 5 - 1 0 0 \mu s}$. Es decir, el diámetro del impacto está relacionado con el 
tiempo de contacto y de forma inversa con la frecuencia máxima detectada en el espectro de amplitud o autoespectro de cada registro (SANSALONE \& STREET, 1997).

El tiempo de contacto (tc) debido al impacto de la punta de aluminio del martillo con la superficie afecta a la validez de la medición de la velocidad de onda. La relación del tiempo de contacto, $t_{c}$ (seg.) y el diámetro de la punta, $\varnothing$ (m.) es: $t_{c}=0,0043 \varnothing$ (TA PENG CHANG, 2005).

Debido a que la frecuencia es inversamente proporcional al espesor del elemento, un impacto más grande (frecuencias bajas) detectará el contorno inferior del elemento atravesando todo el espesor del modelo, y la velocidad de propagación se verá afectada por sus diferentes propiedades (módulo de elasticidad, densidad, rigidez y coeficiente de Poisson). Así, las ondas de mayor longitud de onda penetran más profundamente [MALHOTRA \& CARINo, 2004], y esta es la clave para obtener las propiedades del material.

La correcta selección de factores básicos como la separación entre receptores, distancia al impacto, tipo de fuente, intervalo de frecuencias y sensibilidad del equipo de medición, debe considerarse para la profundidad deseada del análisis.
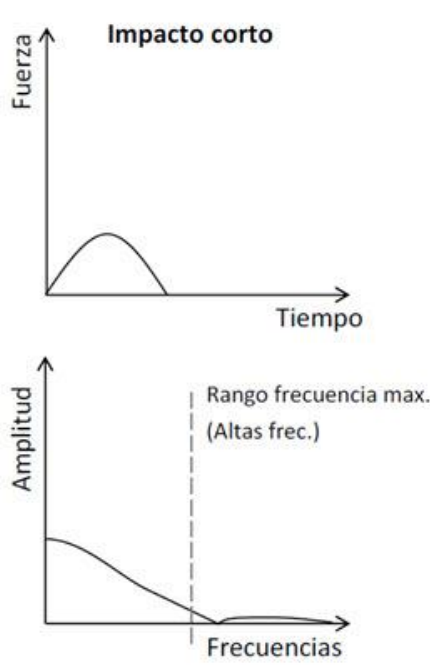
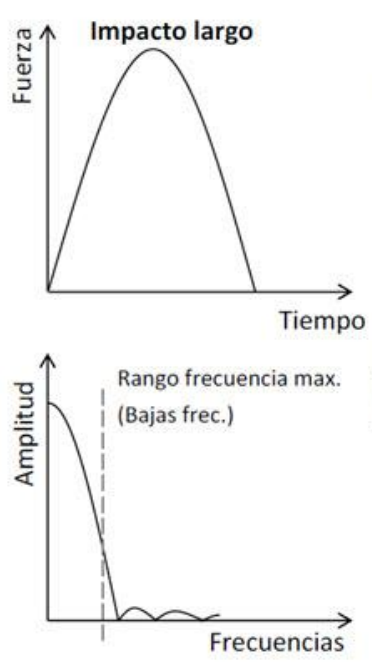
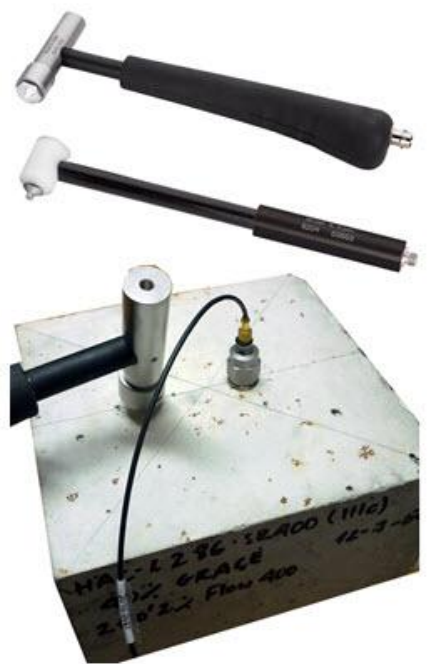

Se considera oportuno puntualizar las conclusiones experimentales que se obtienen:

- Martillo pequeño $(B \& K$ 8204) $\gg$ Punta acero $-0 \mathrm{~mm} \gg$ Impacto corto $=$ Frecuencias altas $\gg-$ Amplitud de onda $\left(\mathrm{m} / \mathrm{s}^{2}\right) \gg-$ Longitud de onda $(\lambda) \gg-$ Velocidad de onda $\left(C_{R}\right)$ $\gg-$ Alcance en profundidad.

- Martillo grande $(B \& K 8206$ 003) $\gg$ Punta goma $+0 \mathrm{~mm} \gg$ Impacto largo $=$ Frecuencias bajas $\gg+$ Amplitud de onda $\left(\mathrm{m} / \mathrm{s}^{2}\right) \gg+$ Longitud de onda $(\lambda) \gg+$ Velocidad de onda $\left(C_{R}\right) \gg+$ Alcance en profundidad.

(Fig. 26). Esquema y conclusiones derivadas del proceso experimental desarrollado en este trabajo. Tipos de martillos empleado en las mediciones AEOS en este trabajo (modelos 8206/8204 Brüel\&Kjaer).

El efecto de campo-cercano es la distancia (desde la fuente) a partir de la cual se puede considerar que la onda generada es exclusivamente Rayleigh. Su determinación es uno de los mayores problemas del método, logrando en base a experimentaciones, un criterio aproximado que mitigue en parte la existencia de ondas de cuerpo, utilizando los criterios de filtrado. 
Así, para construir una curva de dispersión fiable sobre una amplia gama de longitudes de onda, las pruebas se repiten con separaciones diferentes entre receptores. Las características necesarias de la fuente de impacto dependen de la rigidez de capa, las distancias entre los dos receptores y la profundidad a investigar (NAZARIAN 1983). En este caso, se requiere un pequeño martillo que produzca un pulso de corta duración con suficiente energía a frecuencias $\approx 10$ a $20 \mathrm{kHz}$.

Criterios de filtrado (Filtering criterion).

El tipo de acelerómetro o receptor, el ángulo de fase y el agente de acoplamiento se deben escoger cuidadosamente logrando la menor atenuación, el mayor ancho de banda (Bandwith), la frecuencia de muestreo $(F s)$ más alta que proporcione el equipo de medición y el $n^{o}$ de puntos $(N)$ que proporcionen un muestreo de frecuencias en detalle $(\Delta f)$. Recurriendo a los ensayos realizados con el equipo adquirido Lan XI de Bruel\&Kjaer, debido a la atenuación del material, la distancia emisor-receptor variable no se puede aumentar indefinidamente. El efecto de atenuación de la señal se produce de manera que nos impide colocar receptores en el campo lejano.

\begin{tabular}{|c|c|c|c|c|}
\hline \multicolumn{5}{|c|}{ SASW Criterios configuración ensayos ((Filtering criterion)) } \\
\hline Referencias & \multicolumn{2}{|c|}{$\begin{array}{c}\mathrm{d} 1=\mathrm{distancia} 1^{\circ} \text { receptor- fuente impacto ; } \mathrm{d} 2= \\
\text { separación entre acelerometros ; } \lambda=\text { longitud onda ; } \\
\mathrm{h}=\text { espesor capa (profundidad) }\end{array}$} & \multirow{2}{*}{$\begin{array}{l}\text { Criterio } 1 \\
2,5 \Lambda \leq \mathrm{d} 1\end{array}$} & \multirow{2}{*}{ Criterio 2} \\
\hline H. Bolton Seed \& J. Lysmer & న్ำ & $\begin{array}{c}\text { Soil-structure interaction analyses by finite } \\
\text { elements }\end{array}$ & & \\
\hline G.P.Ahiss & 要 & $\begin{array}{l}\text { Shear-wave measurements of the elasticity of the } \\
\text { ground }\end{array}$ & $h \approx \lambda$ & $0,3 \lambda \leq h<0,5 \lambda$ \\
\hline E. Kausel \& J.M. Roesset & 覃 & Stiffness matrices for layered soils & $0,5 \lambda \leq d_{1}<2 \lambda$ & $0,5 \lambda \leq d_{2}<\lambda$ \\
\hline J. S. Heisey \& K.H. Stokoe II & 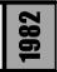 & $\begin{array}{c}\text { Determination in situ shear wave velocities from } \\
\text { SASW }\end{array}$ & $\mathrm{d}_{1}=\mathrm{d}_{2}$ & $0,33 \lambda \leq d_{2}<2 \lambda$ \\
\hline W. Heukelom \& CR. Foster & 兽 & Dynamic testing of pavement & $\mathrm{d}_{1}=\mathrm{d}_{2}$ & $0,33 \lambda<h \leq 0,5 \lambda$ \\
\hline Sanchez-Salinero I. & 鱼 & Analytical investigation of seismic methods & $\mathrm{d}_{1}=\mathrm{d}_{2}$ & $2 \lambda \leq d_{2}$ \\
\hline N. Gucunski \& RD. Woods & 尽 & Numerical simulation of the SASW test & - & $0,5 \Lambda \leq d_{2}<4 \lambda$ \\
\hline K. Tokimatsu \& S. Tamura & 옹 & $\begin{array}{c}\text { Effects of multiple modes on Rayleigh wave } \\
\text { dispersion }\end{array}$ & $0,25 \lambda \leq d_{1}+0,5 d_{2}$ & $0,0625 \lambda \leq d_{2}<\lambda$ \\
\hline S. Foti & 总 & $\begin{array}{c}\begin{array}{c}\text { Multi-station method for characterization surface } \\
\text { waves }\end{array} \\
\end{array}$ & $d_{1} \approx 2 \lambda$ & $d_{2} \approx 2,5 \lambda$ \\
\hline \multirow{3}{*}{ TFM_SASW } & \multirow{3}{*}{ กั่ } & \multirow{3}{*}{\begin{tabular}{|c|} 
Análisis experimental del perfil de velocidades de \\
ondas en mortero/hormigón mediante Análisis \\
Espectral de Ondas Superficiales (SASW)
\end{tabular}} & $d_{1} \geq 0,5 d_{2} \approx h_{\left(S A S W_{\text {ideal) }}\right)}$ & $0,5 h<d_{2} \leq 1,5 h$ \\
\hline & & & $\lambda_{\max } \leq h$ & $0,4 h \leq d_{1}<2 \lambda$ \\
\hline & & & $d_{1} \geq \lambda_{\min } \approx d_{2 \min }$ & $d_{1 \max } \approx d_{2} \leq 1,5 h-2 h$ \\
\hline & & Ejemplo: $\mathrm{d} 1 \approx 4 \mathrm{~cm}$ & $\mathrm{~d} 2_{\mathrm{cmp}} \approx 4 / 6 / 8 / 10 / 12 \mathrm{~cm}$ & $\mathrm{~d} 2_{\mathrm{cs}} \approx 4 / 8 / 16 / 32 \mathrm{~cm}$ \\
\hline
\end{tabular}

(Fig. 27). Ficha principal de aplicación del filtrado de datos en la curva final de dispersión. Aporta además las recomendaciones básicas de distancias para obtener un ensayo AEOS ideal.

La fuente de impacto generada en este trabajo corresponde a un impacto de respuesta transitoria (martillo instrumentado de bajas frecuencias y larga longitud de onda) capaz de producir una energía que cubra el rango de frecuencias de salida de la señal "FREQUENCY SPAN". 
Otros conceptos de procesamiento de señales necesarios son la frecuencia de muestreo (SAMPLING FREQUENCY), intervalo temporal (SAMPLING INTERVAL) y tiempo de contacto (CONTACT TIME).

Para un perfil homogéneo, normalmente, se consideran profundidades de aproximadamente la mitad de la longitud de onda máxima medida $(Z \approx \lambda / 2)$. La mínima separación entre receptores debe ser de 1 a 3 veces la mínima longitud de onda medida, y la máxima distancia la mitad de la longitud de onda esperada (aprox. el espesor de la capa de interés). Algunos autores ya mencionados han propuesto sus criterios en función de los resultados coherentes. Se aporta un esquema añadiendo los criterios propios deducidos de los estudios experimentales realizados en este trabajo:

Data Processing (Procesamiento de las señales).

En este punto, comienza un complejo proceso de análisis de las señales para determinar la curva de dispersión de velocidad de fase del medio de ensayo [ZHU, 2005]. Es prioritario conocer los conceptos de FFT (fast Fourier transform), diferencia de fase, espectro cruzado de energía, coherencia y velocidad de fase para entender el procesamiento de las señales requerido.

La información de fase necesaria para construir la curva de dispersión experimental se puede obtener mediante el procesamiento digital de señales. El primer paso es calcular el promedio del espectro de potencia cruzado de los dos frentes de onda, a partir de las transformadas de Fourier de ambas señales. Para mejorar la calidad de los datos, suele repetirse el test de 3-5 veces, y en los siguientes pasos se utiliza el espectro cruzado de energía (cross power spectrum) representado por su amplitud y el espectro de fase, que ofrece la diferencia de fase entre los dos receptores para cada componente de frecuencia (BRACEWELL, 2000).

El espectro de potencia cruzado, $\mathrm{G}_{12}$, de las dos ondas, se teoriza así: $\mathrm{G}_{21}=\left(\mathrm{S}_{2}\right) \cdot\left(\mathrm{S}_{1} *\right)$

- $\quad S 2$ = la transformada de Fourier de la forma de onda grabada en el canal 2.

- $\quad S 1$ = el complejo conjugado de la transformada de Fourier de la onda grabada en el canal 1 .

Aplicando la formulación vista, la diferencia de fase para cada componente de frecuencia se utiliza para calcular la velocidad de fase y la longitud de onda. Es importante señalar que la función de coherencia se utiliza para seleccionar el rango de frecuencias en las que se aplica el proceso de cálculo. La función de coherencia valdrá:

- $\boldsymbol{O}$ cuando las señales $\boldsymbol{X}_{\boldsymbol{I}}(\boldsymbol{t})$ y $\boldsymbol{X}_{2}(\boldsymbol{t})$ no estén relacionadas entre sí. (Los valores de coherencia baja $<90 \%$ se descartan de la construcción de la curva de dispersión).

- 1 cuando haya una dependencia lineal entre ellas, indica una correlación perfecta entre las señales por los receptores (lo que equivale a una relación señal-ruido de valor infinito).

La coherencia se calcula como un medio de evaluación de la calidad de los datos de fase de las señales observadas. El espectro de la función de coherencia se define:

$$
\begin{array}{lll}
\gamma^{2}=\frac{G_{21} \cdot G_{21}^{*}}{G_{11} \cdot G_{22}^{*}} & \bullet G_{21}=\text { complejo conjugado del espectro de potencia cruzado promediado. } \\
& \text { - } G_{11}=\text { el promedio del autoespectro de potencia }(S 1) \cdot(S 1 *) \text { de la onda } 1 . \\
&
\end{array}
$$


Un valor de coherencia cercano a 1 indica buena correlación entre las frecuencias de la señal de entrada y de la onda medida. Se considera que una coherencia baja $(<0.90)$ puede indicar la presencia de ruido, ecos en la señal, leakage, retraso en la respuesta, no linearidad u otros problemas en la señal.

En la construcción de la curva de dispersión experimental, las frecuencias (longitudes de onda) con valores bajos de coherencia no se han considerado, por lo que se descartan del resto del proceso.

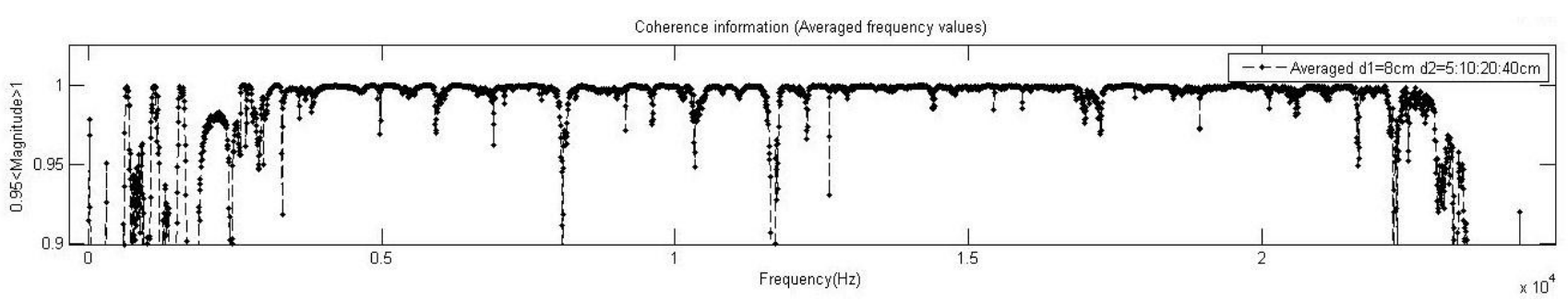

(Fig. 28). Ejemplo gráfico de coherencia en Matlab. Obsérvese como se consideran todos los registros en frecuencia y mediante una rutina implementada se filtran aquellas que no cumplen con una coherencia $>0.95$

Cada una de las frecuencias $f$ contenidas en la señal generada por la fuente se propaga por la superficie del sistema con una determinada velocidad de fase que sólo depende de las características elásticas de las distintas capas y de la geometría del modelo, provocando un cambio de forma o "dispersión" del frente de ondas generado a medida que se aleja de la fuente.

Función de Fase.

El concepto de función de fase, $\boldsymbol{\theta}_{12}(f)$ se deriva de que a cada valor de frecuencia le corresponde un valor de desfase $\emptyset(f)$ entre los puntos de colocación de los acelerómetros (1 y 2), relacionándolo con el tiempo de recorrido, $\boldsymbol{t}_{12}$ ( $\mathrm{seg}$.) de una onda entre ambos transductores mediante: $t_{12(f)}=\theta^{\mathrm{o}}{ }_{12(f)} / 360^{\circ} \cdot f_{(H z)}$. Este paso es importante ya que debemos seleccionar con cuidado el ángulo de fase, mediante el "unwrapping process" y el filtrado previo de la señal mediante "paso-banda".

Una vez conocido es inmediato determinar la velocidad de fase: $C_{R(f)}=X / \Delta t_{12(f)}$ siendo $X$ la distancia entre ambos receptores. Finalmente se establece que la velocidad de onda superficial calculada corresponde a una longitud de onda: $\lambda=V_{R} / f$ Repitiendo este proceso para varias frecuencias, se puede obtener la velocidad vs frecuencia o en función de la longitud de onda. Esta variación de la velocidad con la frecuencia es lo que se conoce como «curva de dispersión».

La diferencia de fase se determinó mediante la transformada rápida de Fourier (FFT).

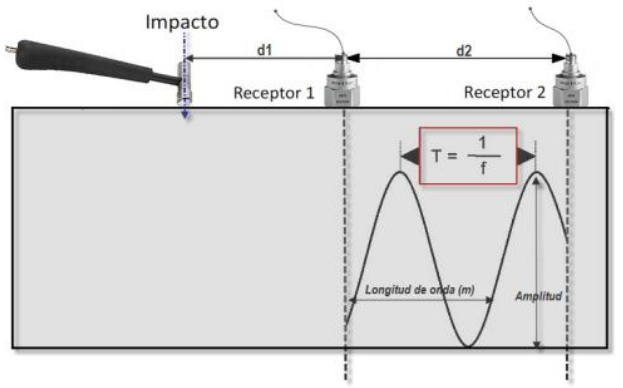

(Fig. 29). Esquema del periodo característico de la señal en una configuración típica AEOS y definición de diferencia de fase entre dos puntos en una onda periódica. 


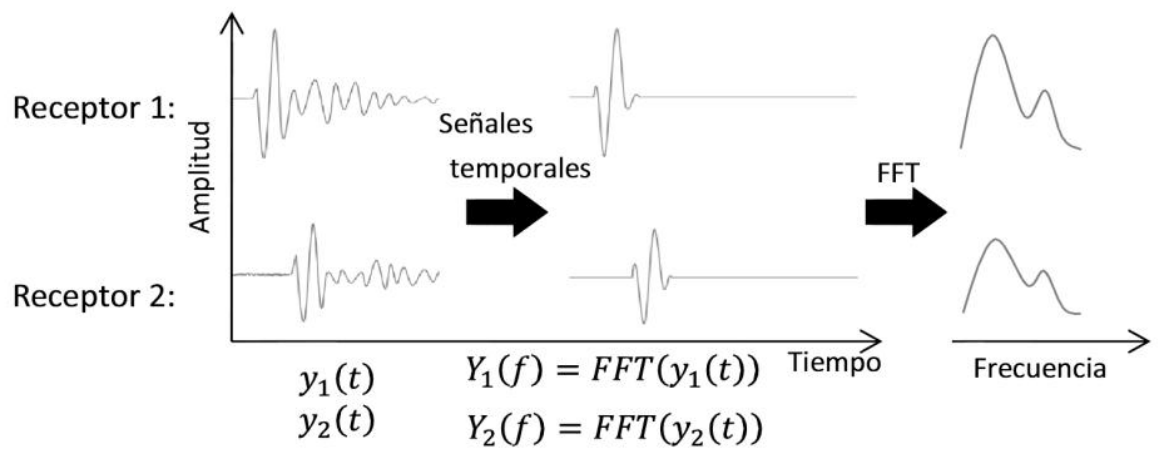

"Espectro cruzado de energía":

(Nota: La barra superior indica el complejo conjugado)

$$
\begin{array}{ll}
G_{11}(f)=Y_{1}(f) * \overline{Y_{1}(f)} \\
G_{22}(f)=Y_{2}(f) * \overline{Y_{2}(f)} \\
G_{12}(f)=Y_{1}(f) * \overline{Y_{2}(f)}
\end{array} \quad \begin{aligned}
\text { Diferencia de fase: } \\
\Delta \varphi(f)=\frac{G_{12}(f)}{G_{11}(f)} \\
\text { Velocidad de fase: } \\
C_{R}(f)=\frac{2 \pi f * d 2}{\Delta \varphi(f)}
\end{aligned}
$$

(Fig. 30). Esquema de interpretación del análisis espectral de ondas superficiales

El espectro cruzado de potencia muestra el retardo de fase $\left( \pm 180^{\circ}\right)$ entre los dos receptores en función de la frecuencia:

$$
S_{x y}(\theta)=\frac{1}{2 \pi} \int_{-\infty}^{+\infty} R_{x y}(\tau) \cdot e^{-i \theta \tau} d \tau=H(\theta) * S_{x}(\theta)
$$

- El significado de "diferencia de fase" entre dos puntos, en una curva sinusoidal con un período característico $\tau$, frecuencia, $f$, se define como: $\varnothing=(\Delta t / \tau) \cdot 360^{\circ}=\Delta t \cdot f \cdot 360^{\circ}$, donde $\Delta t$ es la diferencia de tiempo de viaje entre receptores para cada frecuencia entre los receptores: $\Delta t_{f}=\varnothing / 360^{\circ} \cdot f$

- La velocidad de una componente de frecuencia, $C_{R}(f)$, puede determinarse a una distancia $X$, entre los dos receptores: $C_{R(f)}=X / \Delta t_{f}=X \cdot\left(360^{\circ} / \varnothing\right) \cdot f$

- La longitud de onda, correspondiente a una frecuencia, puede determinarse a una distancia $X$ entre receptores, siendo: $\lambda_{f}=C_{R(f)} / f=X \cdot\left(360^{\circ} / \varnothing\right)$

El ángulo de fase $(\varnothing)$ es la fase acumulada entre las ubicaciones de los dos receptores. Para obtener este valor de cálculo de la fase experimental debemos hacer el proceso de despliegue de fase (unwrapping phase method). Este proceso implica identificar el número de ciclos o "intervalos de salto" en el espectro de fase obtenido de promediar los espectros cruzados de potencia de los registros medidos, y la necesidad de filtrado previo para evitar "saltos ficticios" o erróneos. 


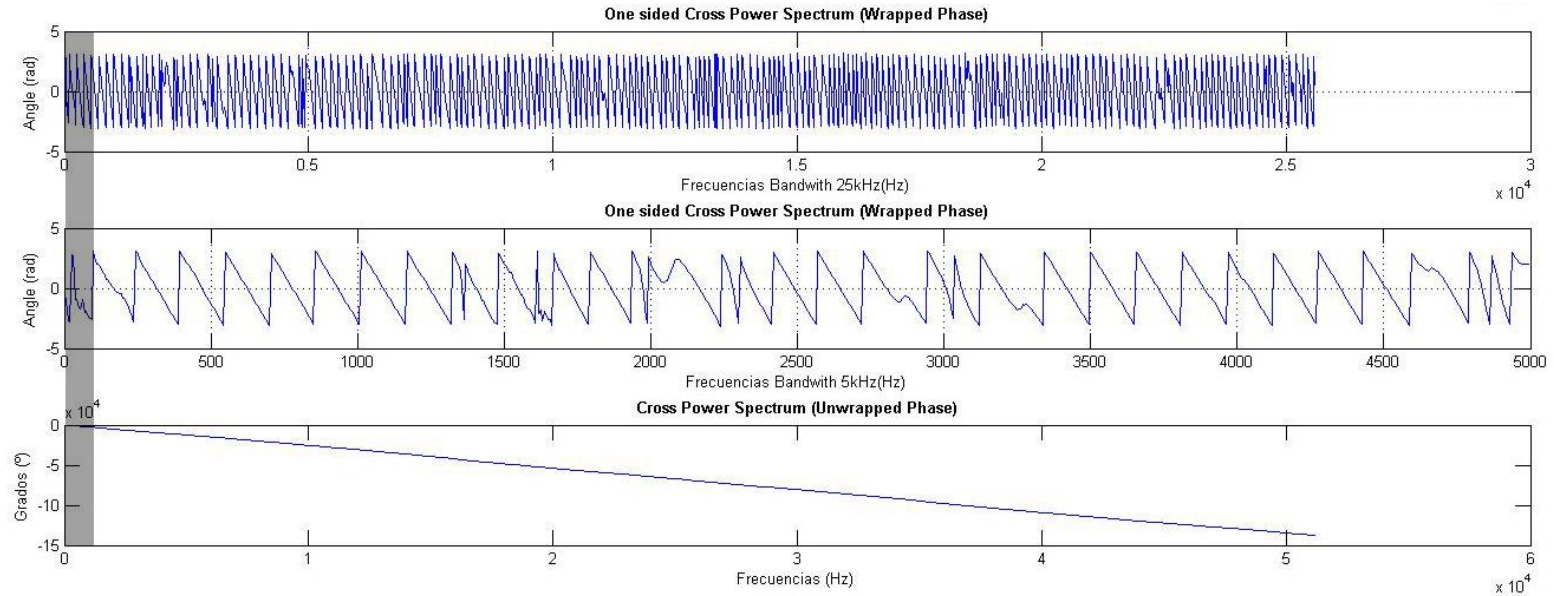

(Fig. 31). Salida gráfica de la rutina implementada en Matlab para un mortero bicapa (fase del espectro cruzadowrapped phase- y despliegue de ángulos de fase-unwrapped phase-).

El procedimiento también implica el desenmascaramiento de aquellos datos que no deberían incluirse en el cálculo de la curva de dispersión debido a que presentan una coherencia baja entre las señales. Esto incluye la información afectada por el efecto de campo-cercano (longitudes de onda mayores a 2 veces el espaciado fuente-receptor $[\lambda>2 d])$ y con $\underline{\text { baja }}$ relación señal-ruido.

(Fig. 32). Efecto de campo cercano en transductor.

La parte sombreada muestra los datos que estarían descartados de la construcción de la curva de dispersión, por esta razón se requiere el promediado de varias señales que permitan albergar un amplio contenido en frecuencias válidas:

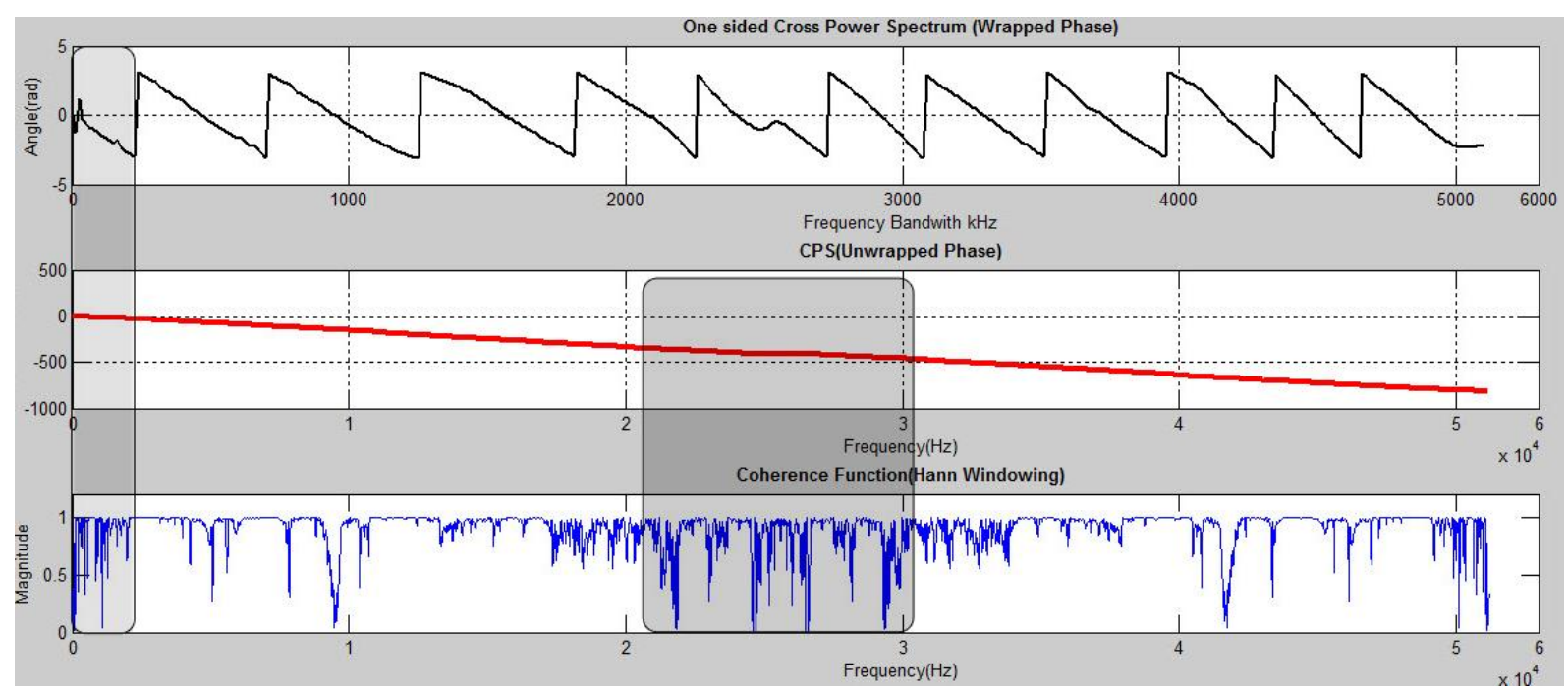

(Fig 33). Ejemplo de despliegue de ángulos de fase (radianes) en modelo de una losa de $40 x 40$ de mortero tricapa: fase del espectro cruzado de energía (arriba), unwrapped phase (centro), coherencia (abajo). 
La curva de dispersión experimental configurada mediante la medición unitaria de todos los datos recopilados de varias pruebas a distintas separaciones entre receptores, se generó a través de los datos del ángulo de fase y la velocidad calculada utilizando la diferencia de fase. En respuesta a las fórmulas citadas para cada componente de frecuencia y usando el diagrama de fase "desplegada", se obtiene la curva individual bruta para cada ensayo registrado, que promediadas en el dominio de la frecuencia, determinan la curva de dispersión global del análisis.
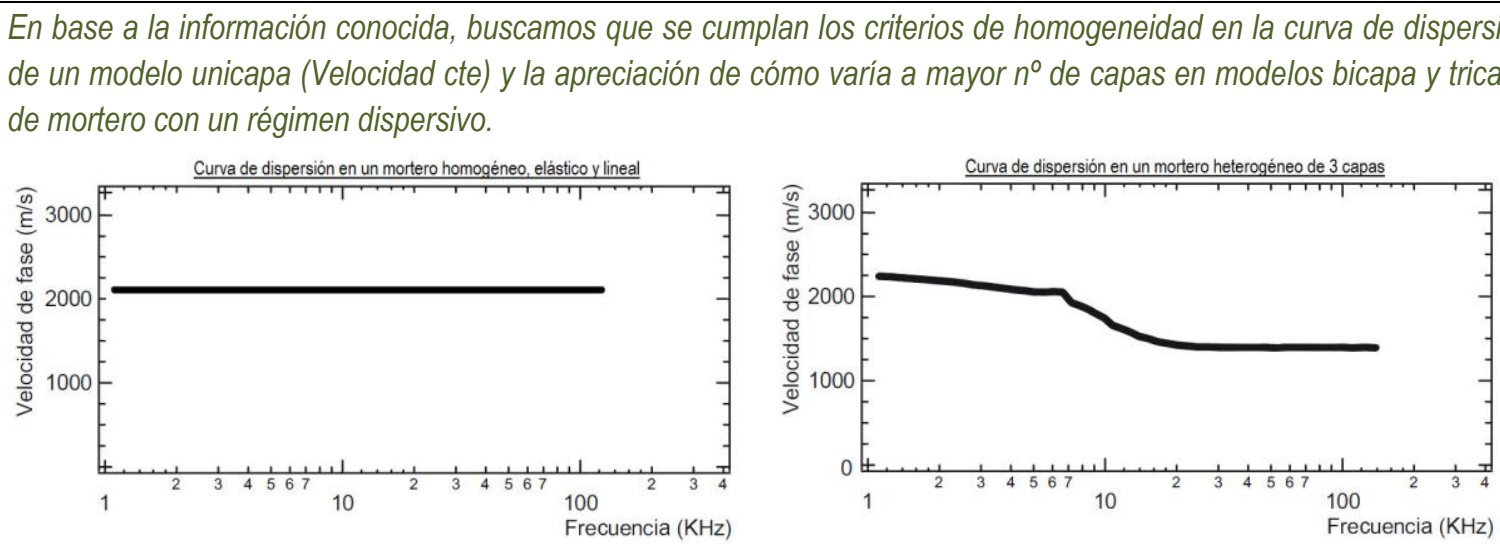

(Fig. 34). Ejemplos de curvas de dispersión individual en modelos de morteros unicapa homogéneo y tricapa heterogéneo.

Para ello, se desarrolló un análisis espectral inicial en modelos unicapa y bicapa teniendo en cuenta sólo ondas Rayleigh, acelerómetros colocados a intervalos regulares de la fuente en la misma superficie libre y los siguientes parámetros de adquisición de señales:

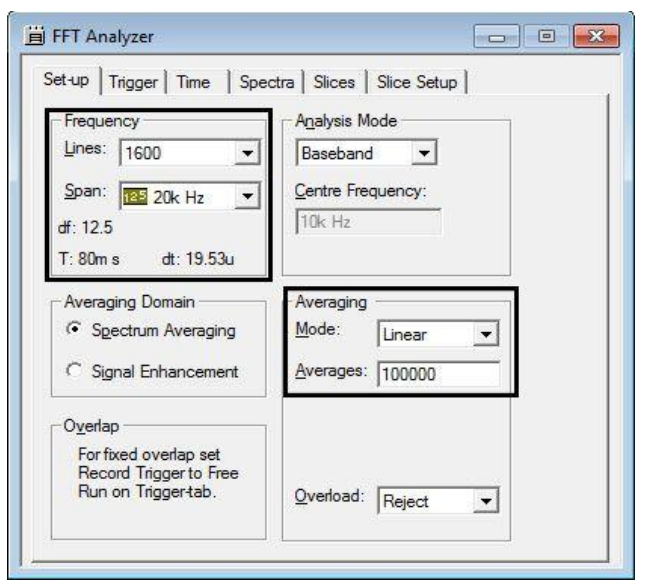

(Fig. 35). Configuración de análisis FFT en módulo de señales. En particular teniendo en cuenta la gama habitual de frecuencias de interés en las pruebas de SASW, la frecuencia de muestreo fue $\boldsymbol{F}_{\mathrm{s}}=51,2 \mathrm{Khz}$ (frecuencia Nyquist 25,6Khz, que estaba por encima de las frecuencias más altas que se necesitaban para la caracterización del mortero); el intervalo de muestreo en el tiempo $\delta_{t}=\mathbf{1} / \boldsymbol{F}_{s}=\mathbf{1 9}, \mathbf{5 3} \boldsymbol{\mu s}$. Para obtener una resolución suficiente en el dominio de la frecuencia se habían elegido $N=4096$ muestras $(\Delta T=N \cdot \delta t=0,008 s)$, que correspondian a una resolución de frecuencia igual a ( $d f=1 / \Delta T=12,5 \mathrm{hz}$ ).

Con esos datos de muestreo se ensayaron modelos de losa de mortero fabricados. Así se adelanta en el siguiente ejemplo correspondiente al modelo de losa bicapa $40 \times 40 \times 15 \mathrm{~cm}\left(d_{2}: 5 \mathrm{~cm} ;\right.$ edad $\left.8 \mathrm{~h}\right)$ : 

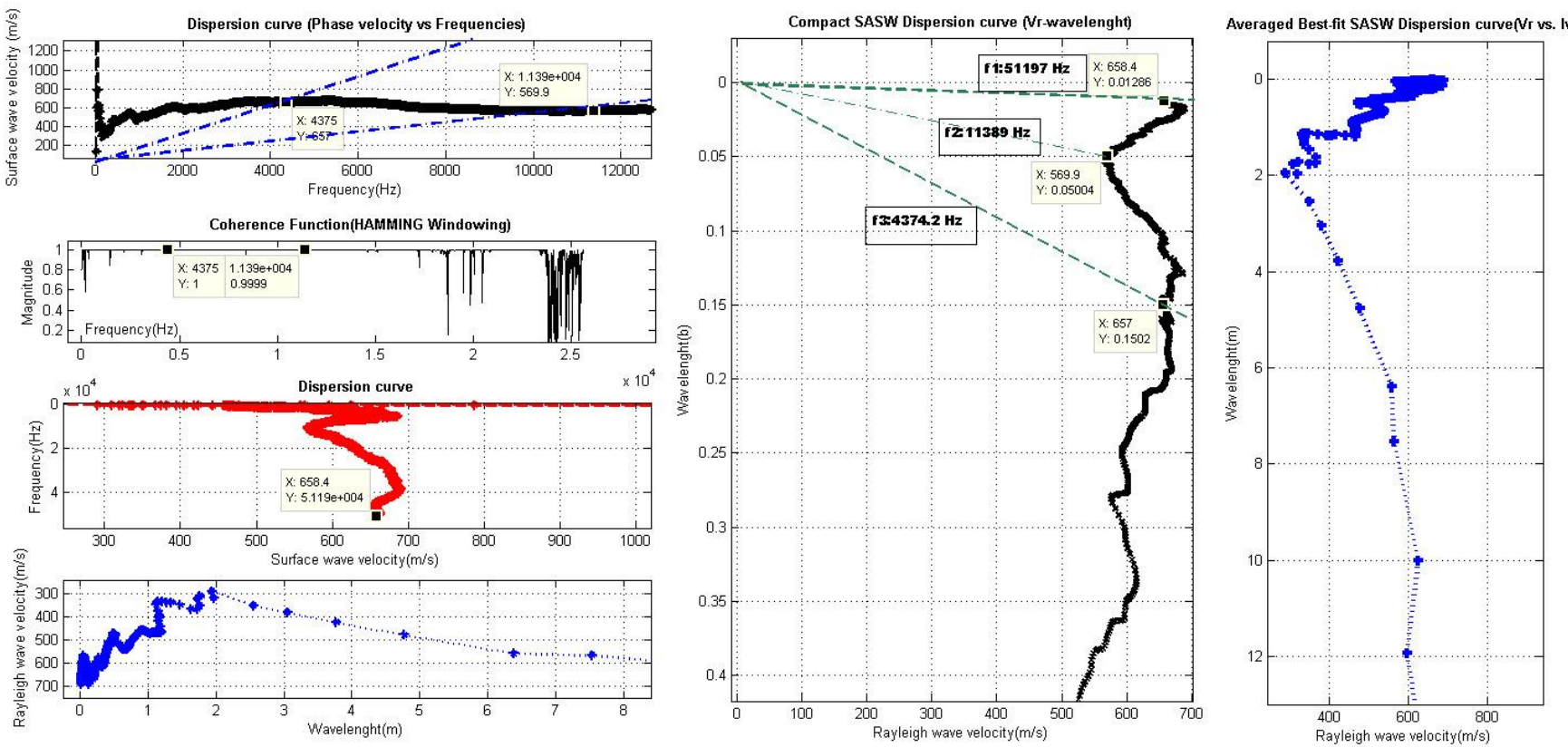

(Fig. 36). Ejemplo de curvas de dispersión en función de la velocidad de fase frente al contenido de frecuencias (izq) o frente a la longitud de onda (der). Coherencia de las señales con filtro de ventana Hamming.

\section{Data Analysis (Análisis posterior).}

Esta parte del método AEOS se encarga de generar una curva de dispersión experimental convencional ("global analysis") de dispersión global que se obtiene de promediar los diferentes espectros cruzados de energía para cada test realizado.
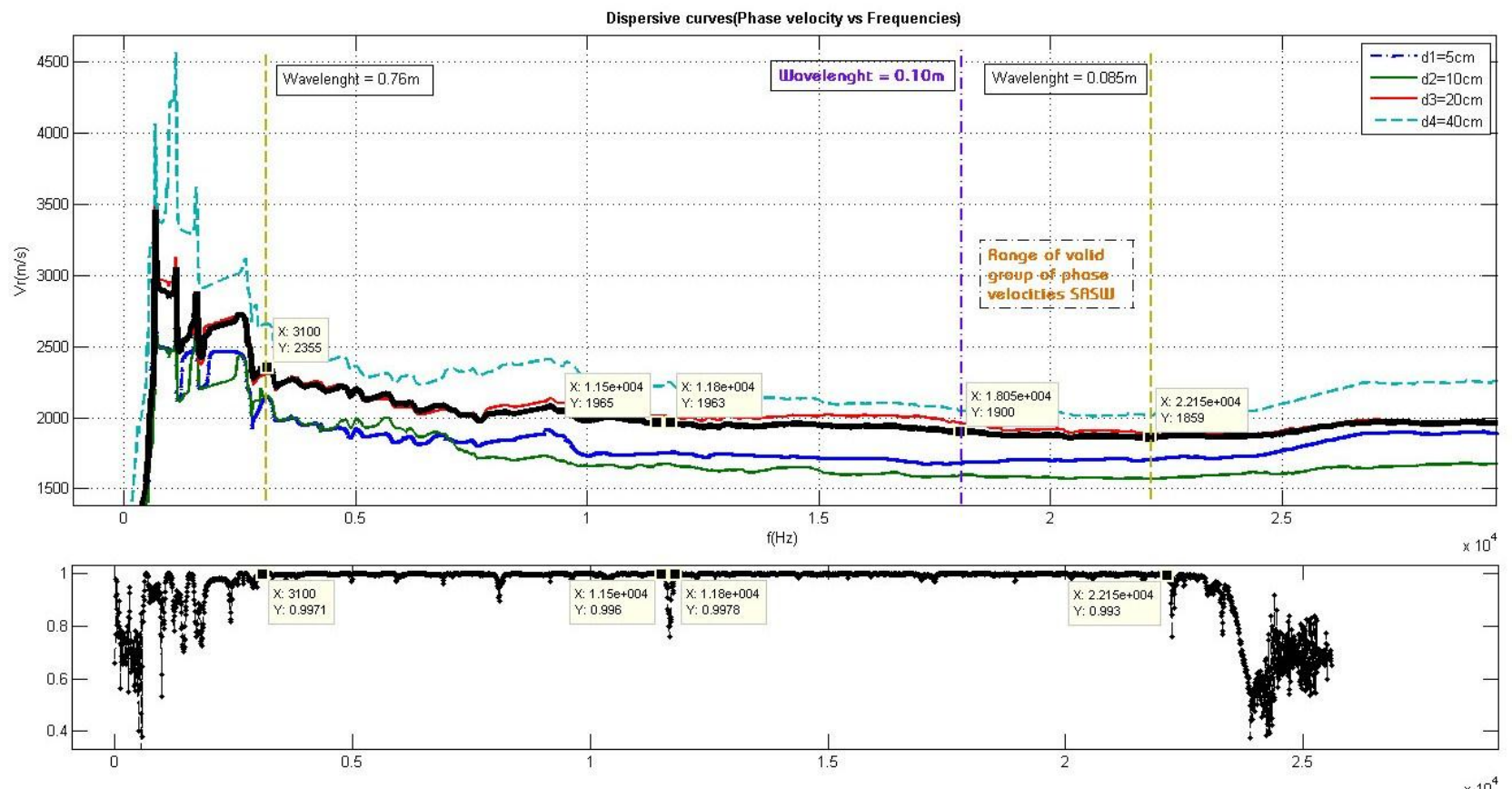

(Fig. 37). Promedio de curvas de dispersión (velocidad fase vs frecuencias) identificando el intervalo de datos con coherencia válida. Representación de curva global mediante tendencia lineal.

- Las curvas de dispersión experimentales se calculan desarrollando análisis espectral en señales de registros del movimiento vertical de partículas. La obtención depende de la 
correcta determinación de la fase, no siendo suficiente aplicar criterios basados en longitud de onda y coherencia, sino también criterios adicionales, como la experiencia del operador.

El segundo enfoque implica generar un promedio individual de todas las curvas de dispersión experimentales (INDIVIDUAL DISPERSION CURVE) para cada espaciado entre receptores, cuyas frecuencias representen una idea general del trazado de la dispersión y, que una vez promediadas entre sí, generen una curva de tendencia final o curva global de dispersión (AVERAGE DISPERSION CURVE). Se suele representar aplicando desviación standard, criterio aceptado por su eficacia y resolución, válida para modelos sencillos de pocas capas:
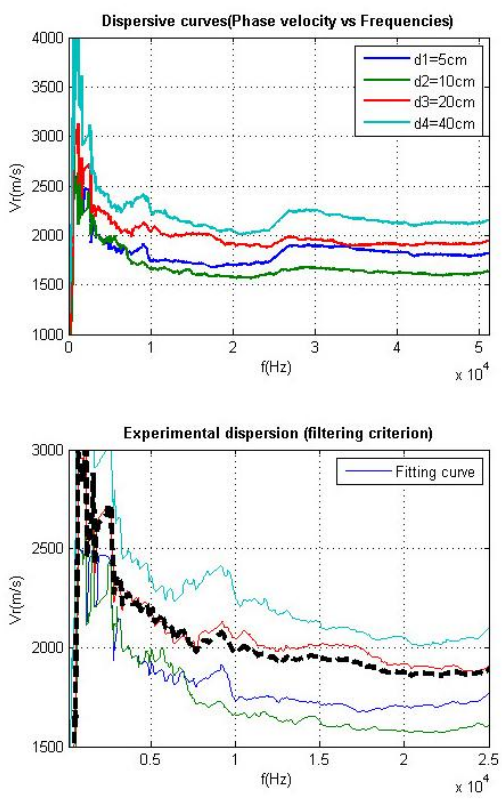
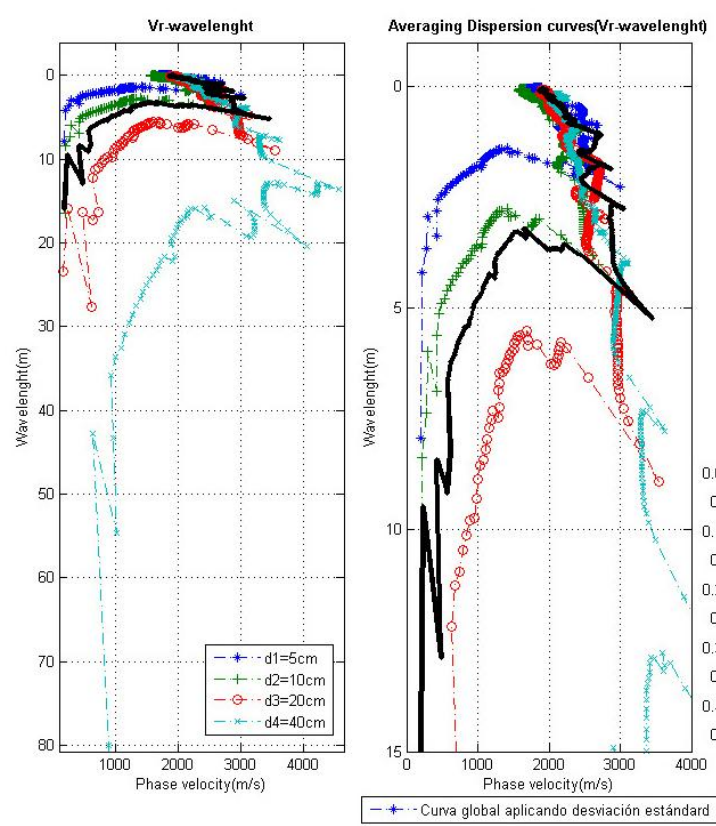

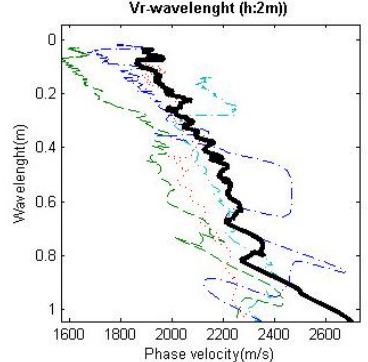

Averaged Best-fit SASW Dispersion curve $(\mathrm{V} r$ vs. Iw

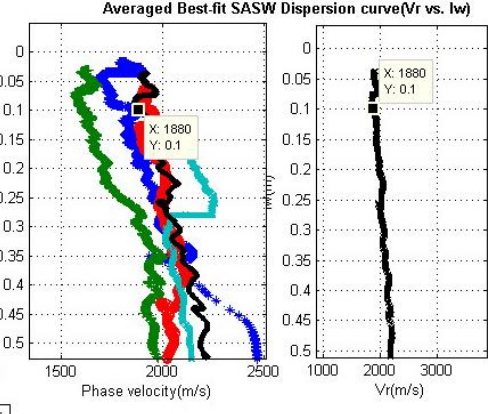

(Fig. 38). El espectro de fase se representa en frecuencias (eje horizontal) y como ángulo de fase en radianes (eje vertical). Obsérvese que el espectro de fase muestra una gráfica en diente de sierra característica de alcanzar los valores mínimos de fase en - $\pi$. Ejemplo de promedio de curvas de dispersión en losa de 40x40cm.

La forma de la curva de dispersión indica el tipo de medio: una recta indica un medio no dispersivo - rigidez constante con la profundidad - mientras que una curva cóncava o convexa indica un medio normal o inversamente dispersivo, respectivamente. Es decir, corresponde con el planteamiento de trabajo propuesto, ya que se fabricaron modelos de losas de 1,2 o 3 capas para simular cada estado de dispersión y comprobar la veracidad de los ensayos AEOS realizados, y los resultados reflejan que en cada espécimen de varias capas a edades tempranas la velocidad de onda $\underline{\text { se atenúa, de manera que a mayor profundidad (longitud de onda) la velocidad decrece. Este perfil }}$ inv. Dispersivo se invierte a partir de las 11 horas del fraguado. Así se observa en la siguiente curva de dispersión, para el mismo modelo con $\mathrm{d}_{2}: 10 \mathrm{~cm}$ y edad 11 horas: 

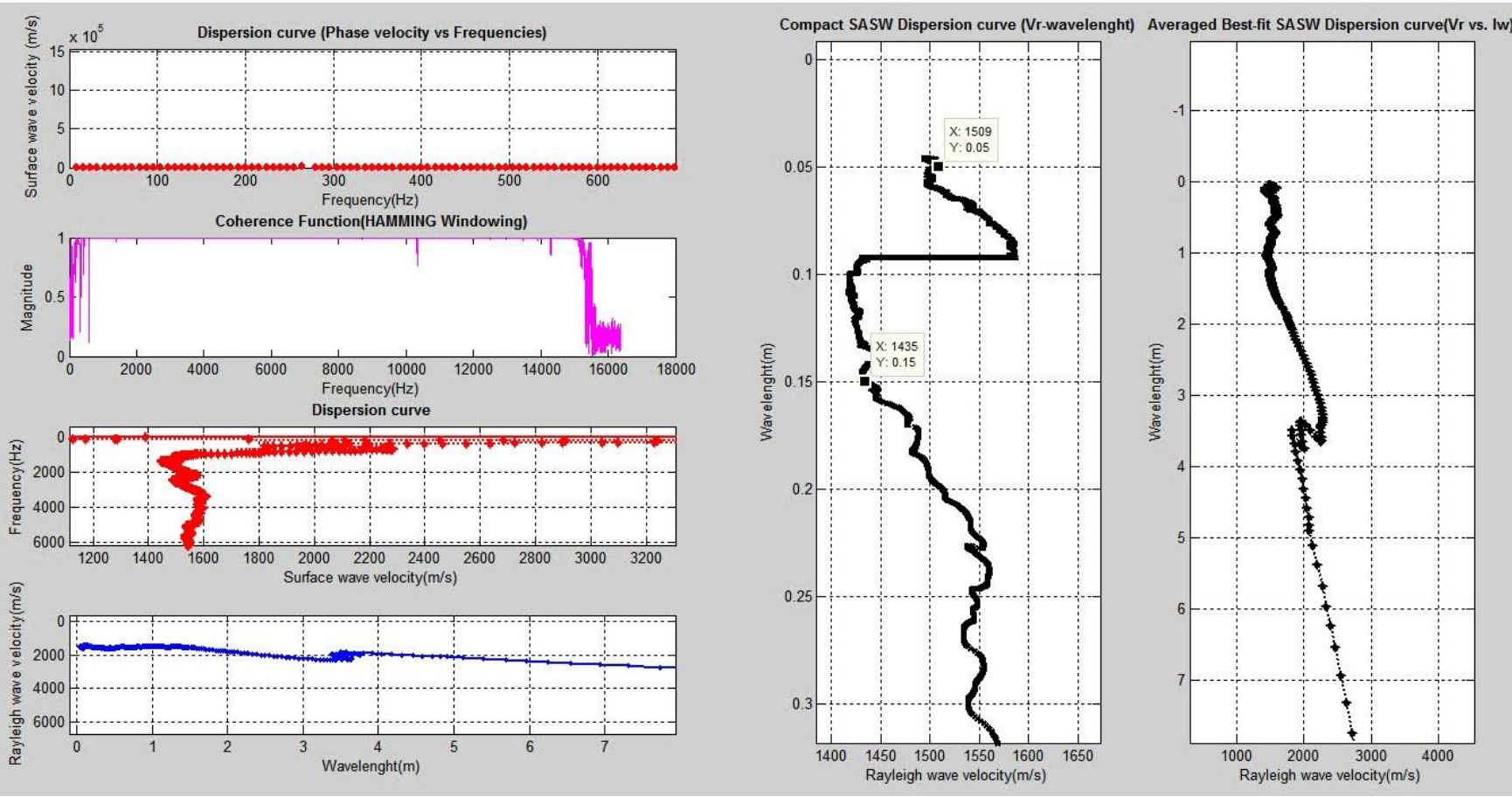

(Fig. 39). Coherencia, curva de dispersión experimental y curva global promediando registros a d:5,10 y $18 \mathrm{~cm}$ para losa $40 \times 40 \times 15 \mathrm{~cm}$ a la edad de 11 horas. Obsérvese como se invierte el perfil aumentando la velocidad proporcional a la longitud de onda.

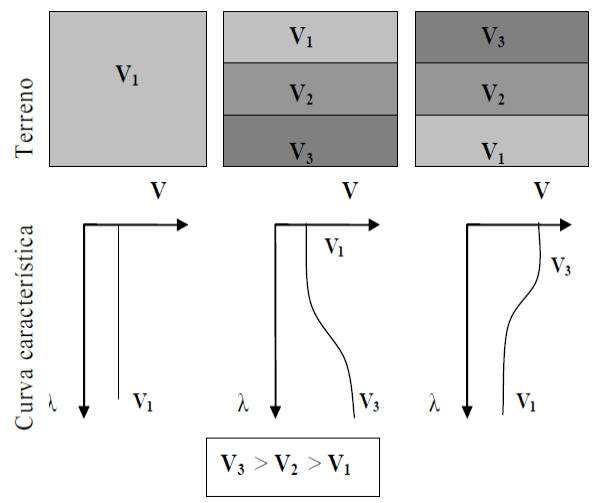

\begin{abstract}
[NOTA: Las curvas experimentales, en los primeros modelos de mortero, presentaron dificultades de identificación por la heterogeneidad de las capas, el efecto de reflexión y el uso del filtrado como reducción del ruido ambiental o incoherente.
\end{abstract}

Es importante saber que en este caso, las condiciones de prueba mostraron limitaciones, debido a los breves márgenes de medición en edad temprana (duración de la medida) y los posibles ruidos causados por fuentes externas de vibración que podían alterar los resultados].

(Fig. 40). Criterios de dispersión de velocidad.

\title{
Aproximación a las propiedades elásticas del material.
}

La velocidad de onda Rayleigh $\left(\mathrm{V}_{\mathrm{R}}\right)$ está relacionada con la velocidad de onda de corte $\left(\mathrm{V}_{\mathrm{S}}\right)$ :

$$
V_{R} \simeq \frac{0,87+1,12 v}{1+v} V_{S} \rightarrow V_{S} \approx 1,1 V_{R} \quad G=\frac{E}{2(1+v)}=\left(1,1 V_{R}\right)^{2} \cdot \rho \quad V_{P}=\frac{1+v}{0,87+1,12 v} \sqrt{\frac{2(1-v)}{1-2 v} V_{R}} \simeq 1,79 V_{R}
$$

siendo G el módulo de rigidez transversal, v el coeficiente de Poisson, E el módulo de Young y $\rho$ la densidad del medio. Los parámetros necesarios para definir las propiedades de cada capa son: espesor $(h)$, velocidad de onda $\left(V_{R}\right)$, coeficiente de Poisson (v) y densidad ( $\rho$ ). Entre estos parámetros, $V_{R}$ tiene el efecto dominante en dispersión de onda superficial y los efectos de la densidad de masa y coeficiente de Poisson son más bien pequeños. Por lo tanto, debemos asumir que $(\rho)$ y (v) se conocen a través de las otras técnicas no destructivas de validación del trabajo. 


\section{Análisis Espectral de Ondas Superficiales (AEOS)}

\section{(VI). DESARROLLO AVANZADO DEL MÉTODO.}

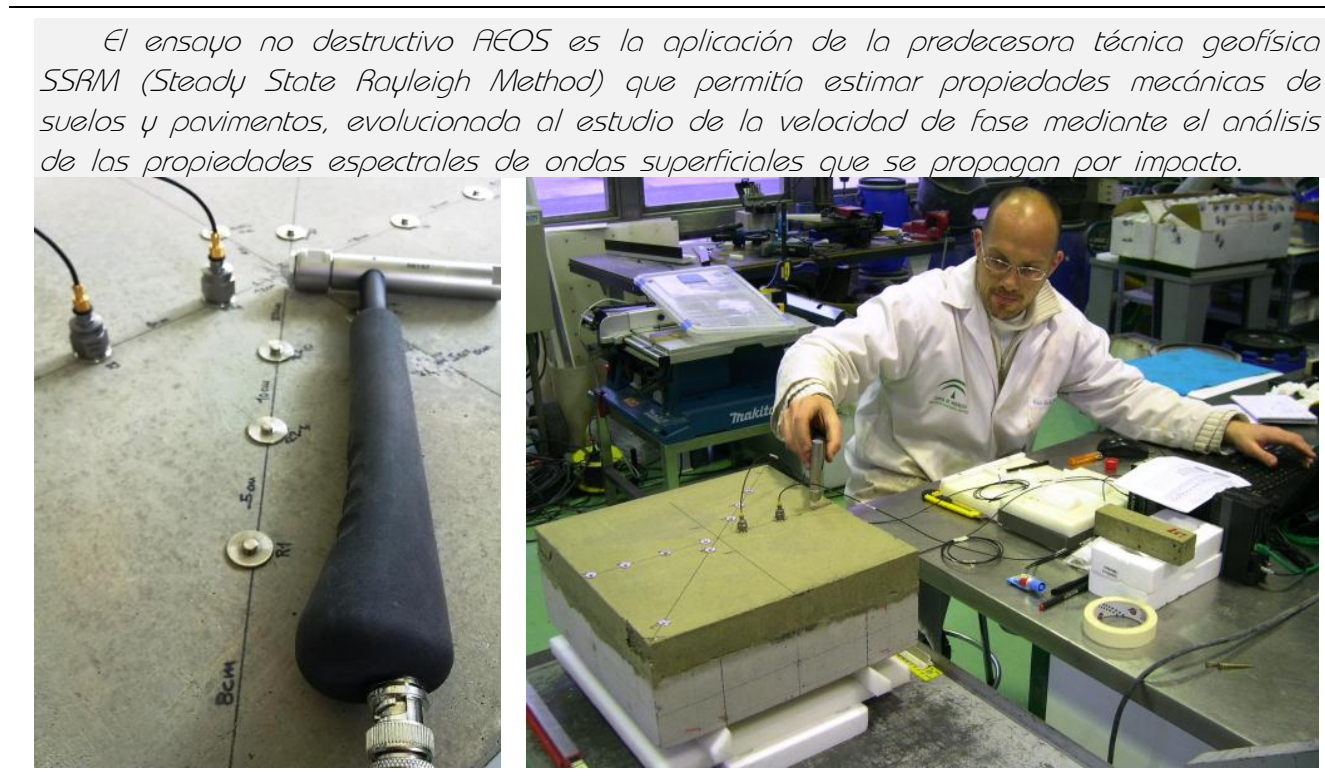

(Fig. 41). Equipo de ensayo superficial. Ejemplo ensayo AEOS a losa bicapa 40x40x(10+5)cm con impacto largo.

Caracterización mecánica en morteros frescos a edad temprana.

La aplicación de técnicas de velocidad de onda superficial que ganó popularidad a finales del s. XX en el terreno de la caracterización de materiales geofísicos, se recupera ahora para elaborar el estudio aplicado a morteros, mediante la propagación de ondas Rayleigh en la superficie libre de un medio vertical heterogéneo. Esta técnica activa, denominada originalmente "SPECTRAL ANALYSIS OF SURFACE WAVES" [SASW] destaca por:

- Las ondas Rayleigh se generan en una gama amplia de frecuencias mediante la aplicación de un impacto mecánico vertical en la superficie del espécimen de ensayo.

- Como regla general, si uno está interesado en las propiedades del material a una profundidad $h$, entonces la superficie del ensayo debe extenderse en una línea de receptores a distancia igual a $0,5 \mathrm{~h}$.

- Altas frecuencias o longitudes de onda corta penetran a poca profundidad, mientras que bajas frecuencias o longitudes de onda largas penetran a mayor profundidad en el material.

- La distancia conocida entre los receptores y la diferencia de fase medida entre las ondas superficiales en los dos receptores se utilizan para determinar la curva de dispersión.

- Los parámetros determinados por las mediciones SASW representan el comportamiento a pequeñas tensiones, así, el módulo de elasticidad $E$, coeficiente de Poisson $\mu$, módulo de rigidez transversal $G$ y velocidad de onda superficial $V_{r}$ representan las propiedades físicas del material.

- El uso del espectro de fase relativa para la construcción de la curva experimental de dispersión es adecuado porque domina el $1^{\circ}$ modo de vibración, caso presente donde la rigidez de capa cambia gradualmente con la profundidad (mortero a edades tempranas). 
La ventaja del método es la medición de la velocidad de fase mediante la curva de dispersión con una técnica no destructiva superficial, por lo que la onda es hasta 3 veces mayor que la onda P. Esta energía superior permite que la onda Rayleigh penetre más profundo en la estructura y logre datos físicos del material, incluso en condiciones extremas de accesibilidad donde técnicas de extracción de testigos son imposibles.

\section{Criterios para la interpretación de ensayos AEOS.}

Como método de ensayo no destructivo basado en la propiedad de dispersión de las ondas superficiales, incluye errores asociados para cada etapa del ensayo: i) obtención de la respuesta insitu mediante ensayos; ii) determinación de la curva de dispersión. Desde el punto de vista físico, la existencia de diferentes modos de propagación - a una frecuencia dada - puede explicarse por las interferencias entre ondas. Cuando la rigidez varía en profundidad, las trayectorias de los rayos son curvilíneas y por lo tanto interfieren entre sí.

Para hacer que el método SASW funcione, se hacen dos suposiciones de simplificación:

- Se supone que la estructura del medio puede aproximarse por varias capas horizontales y que las propiedades de los materiales de cada capa son constantes.

- Se supone que sólo el plano de las ondas Rayleigh participa. Se ignora el efecto de ondas de cuerpo (SÁNCHEZ-SALINERO, 1987; RIX, 1991), ya que dicha simplificación no altera los resultados experimentales al mantener la geometría fuente-receptor respecto a la longitud de onda dentro de ciertos límites.

Existen 2 configuraciones típicas en el método con distintas separaciones entre acelerómetros: fuente moviéndose respecto al centro simétrico (common mid point) entre receptores o fuente de impacto fija variando la distancia interna de los acelerómetros (common source):
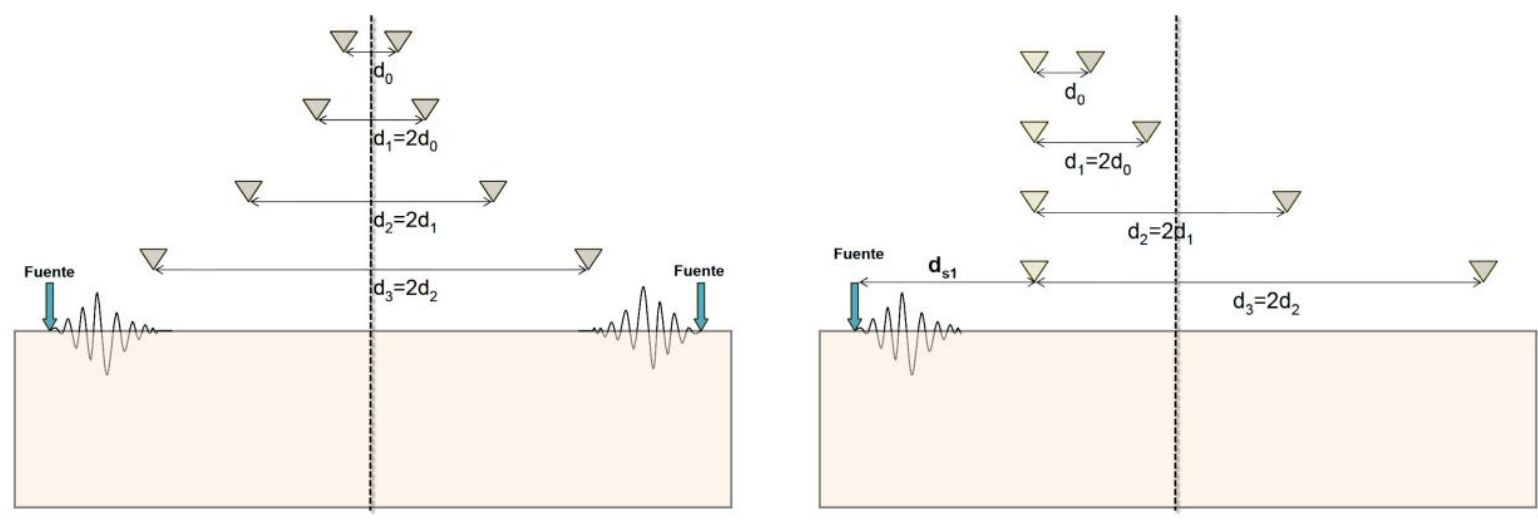

(Fig. 42). Configuraciones típicas para la realización de ensayos AEOS.

- Para maximizar la calidad de la curva de dispersión experimental, la colocación equidistante entre receptores es la más adecuada. Los dos receptores se mueven fuera de la línea imaginaria central a un ritmo igual, y la fuente tal que la distancia entre el origen y el receptor más cercano es igual a la distancia entre los dos receptores. Aumentando simultáneamente la distancia de impacto y la separación entre receptores, se obtiene la curva de dispersión que la caracteriza (NAZARIAN Y STOKOE, 1986).

- El mortero presenta heterogeneidades internas que pueden distorsionar el resultado. Por esta razón puede ser útil realizar mediciones en varias posiciones cuyas diferencias permitan evaluar la eficacia de la hipótesis del plano y de las capas paralelas. 

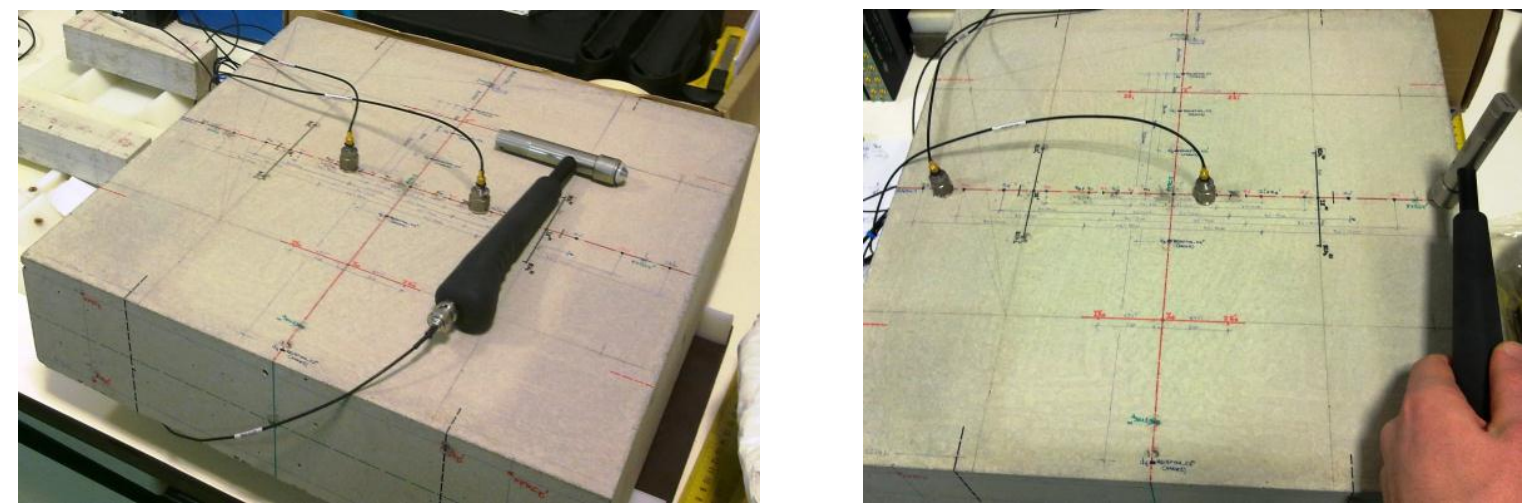

(Fig. 43). Realización de ensayos AEOS con las dos configuraciones típicas con fuente común (der) y con punto central (izq) en modelo de losa de mortero $40 \times 40 \times 10 \mathrm{~cm}$.

- Espaciamientos (D) cortos y fuente débil generan altas frecuencias, longitud de onda corta $(\lambda)$, y poco alcance en profundidad.

- Mayor separación (D) y fuente energética generan bajas frecuencias, mayor longitud de onda y mayor alcance en profundidad.

Hormigón maduro $\rightarrow+V \rightarrow+\lambda \rightarrow+$ Profundidad $\leftarrow$-tiempo impacto $\leftarrow+D \leftarrow+$ densidad $\leftarrow-a / c$

El método analiza la velocidad de onda de diferentes contenidos de frecuencia en el tiempo. La caracterización del registro de impacto pretende caracterizar la información del espectro de fase de la función de transferencia con la FFT para obtener el cambio de fase relativa entre las dos $\underline{\text { señales en el rango de frecuencias que se generan del movimiento de la onda que recorre la }}$ superficie. Por el ángulo de fase, se genera la curva de dispersión experimental compuesta de todos los datos registrados de diversas separaciones entre receptores. La velocidad de fase determina el tiempo de viaje necesario entre receptores, dependiente de la frecuencia $[c=c(\omega)]$.

Se establece la importancia de las dos funciones siguientes del dominio de la frecuencia:

- El espectro de potencia cruzado (cross power spectrum) entre los dos receptores (utilizado en la preparación de la curva experimental de dispersión), que describe la distribución de la energía entre ambos sensores con la frecuencia y además, está asociado a la transformada de Fourier de la correlación temporal cruzada entre ambas señales. (Cross power spectrum) : $G_{X 1 X 2}=X_{1}(f) \cdot X^{*}{ }_{2}(f)$

(Auto power spectra): $G_{X 1}=X_{1}(f) \cdot X^{*}{ }_{1}(f) \quad G_{X 2}=X_{2}(f) \cdot X^{*}{ }_{2}(f)$

- Las señales pueden estar contaminadas con ruido de fondo. Es necesario identificar los datos de fase dentro del rango de frecuencias afectadas antes de representar la curva de dispersión. Para ello se utiliza la función de coherencia (asegura la recopilación de datos válidos entre el registro señal temporal - ruido incoherente o ambiental y examina visualmente la calidad de las señales que se registran in situ). Un valor 1 indica perfecta correlación entre señales mientras que un valor 0 no representa correlación debido al ruido. Coherencia: $\quad \gamma^{2}(f)=\frac{G_{X 1 X 2}^{2}}{G_{X 1} \cdot G_{X 2}}$ 
La fuente vibratoria aplicada en la superficie genera dos señales temporales: $x_{1}(t)$ y $\boldsymbol{x}_{2}(t)$. Si se quiere obtener la velocidad de fase $\boldsymbol{c}=\boldsymbol{c}(\boldsymbol{\omega})$ de un registro $\boldsymbol{u}(\boldsymbol{x}, \boldsymbol{t})$, entre dos puntos $\mathrm{x}_{1} \mathrm{y} \mathrm{x}_{2}$, es necesario hacerlo a través de la transformada de Fourier, y obtener la fase en función de la frecuencia, $\varphi=\varphi(\omega)$. La diferencia de fases, está dada por: $\Delta \varnothing=\varnothing_{2}(\omega)-\varnothing_{1}(\omega) \pm 2 n \pi$. Así, para una onda con período $\boldsymbol{T}_{\boldsymbol{0}} \mathrm{y}$ frecuencia $\omega_{\boldsymbol{0}}$ la velocidad de fase es: $c\left(\omega_{0}\right)=\Delta d / \Delta t \pm n T_{0}$

Para esta onda sinusoidal la diferencia de fase entre ambos puntos no es exacta, dependiendo de la incerteza que se tenga del término $n T_{0}$. El término $2 n \pi$ debe incorporarse para evitar ambigüiedades de la fase (Unwrapped Phase). Es posible obtener la velocidad de fase a partir de dos señales por medio del análisis de Fourier a través de la formulación:

$$
\begin{aligned}
& \omega=\frac{2 \pi}{T}=\frac{\Delta \varnothing}{\Delta t} \quad c=\frac{\Delta x}{\Delta t} \rightarrow \Delta t=\frac{\Delta x}{c} \quad \omega=\frac{\Delta \varnothing \cdot c}{\Delta x} \rightarrow c=\frac{\omega \cdot \Delta x}{\Delta \varnothing} \quad \text { Así }: c=\frac{\omega \cdot\left(x_{2}-x_{1}\right)}{\varnothing_{2}(\omega)-\varnothing_{1}(\omega) \pm 2 n \pi} \\
& \text { AMPLITUD : } \mathrm{A}=\sqrt{\left(\operatorname{Re}\left(S_{x y}\right)\right)^{2}+\left(\operatorname{Im}\left(S_{x y}\right)\right)^{2}} \quad S_{x y}=G_{X 1 X 2}
\end{aligned}
$$

Se forma el promedio de los receptores A y B, precisando para cada frecuencia la diferencia de fase relativa $\Delta \varnothing_{A B(f)}$ y absoluta $\varnothing_{(f)}: \quad \Delta \varnothing_{A B(f)}=\tan ^{-1}\left[\frac{\operatorname{Im}\left(S_{x y(f)}\right)}{\operatorname{Re}\left(S_{x y(f)}\right)}\right] \quad \varnothing(f)=\Delta \varnothing_{(f)}+$ cte

El numerador y denominador de la fase relativa corresponden a la parte imaginaria y real de las componentes del espectro cruzado en función de la frecuencia.

Podemos relacionar la fase con el tiempo de viaje de la onda (t) y obtener la velocidad de la onda

El espectro de potencia cruzada (Cross Power Spectrum) se utiliza para obtener el cambio de fase relativa (retardo de la onda en el medio o tiempo de viaje dependiente de la frecuencia entre dos receptores).

El espectro de energía estima la distribución de frecuencias para las señales cuyos valores altos prevalecen sobre el ruido aleatorio. Los resultados fiables se consiguen con un filtrado previo a fin de mitigar los efectos de deterioro de la señal causado nor la atenuación. superficial y la longitud de onda:

$t=\frac{\varnothing}{360^{\circ} \cdot \omega}=\varnothing / 2 \pi \omega \rightarrow \quad V_{R}(\omega)=D / t=\frac{2 \pi D}{\varnothing(\omega)} \omega \rightarrow \lambda(\omega)=\frac{V_{R}(\omega)}{\omega} \quad$ (KRAMER, 1996)

Con la función densidad espectral cruzada, podemos analizar la coherencia y la fase, $\theta_{12(\mathrm{f})}$.

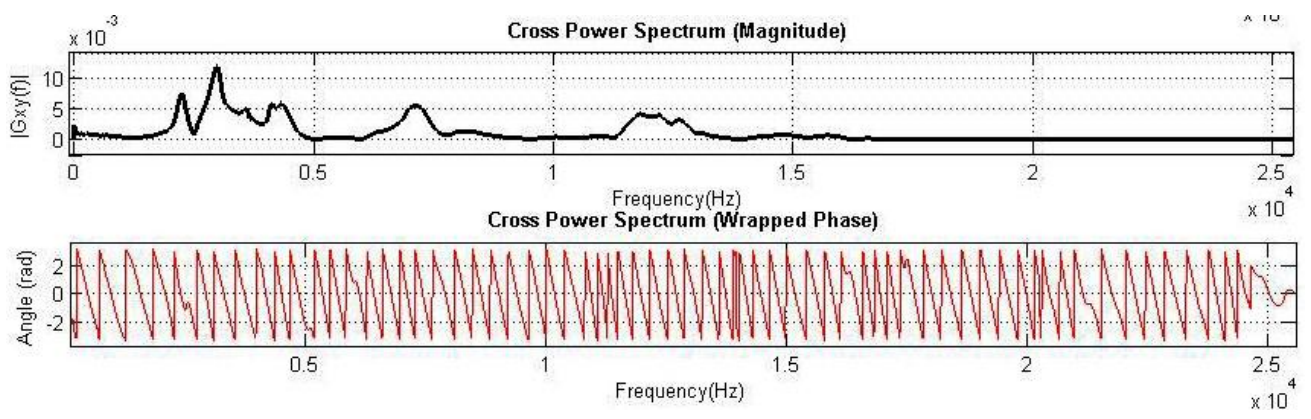

(Fig. 44). Ejemplo de espectro de potencia cruzado (magnitud y fase). 


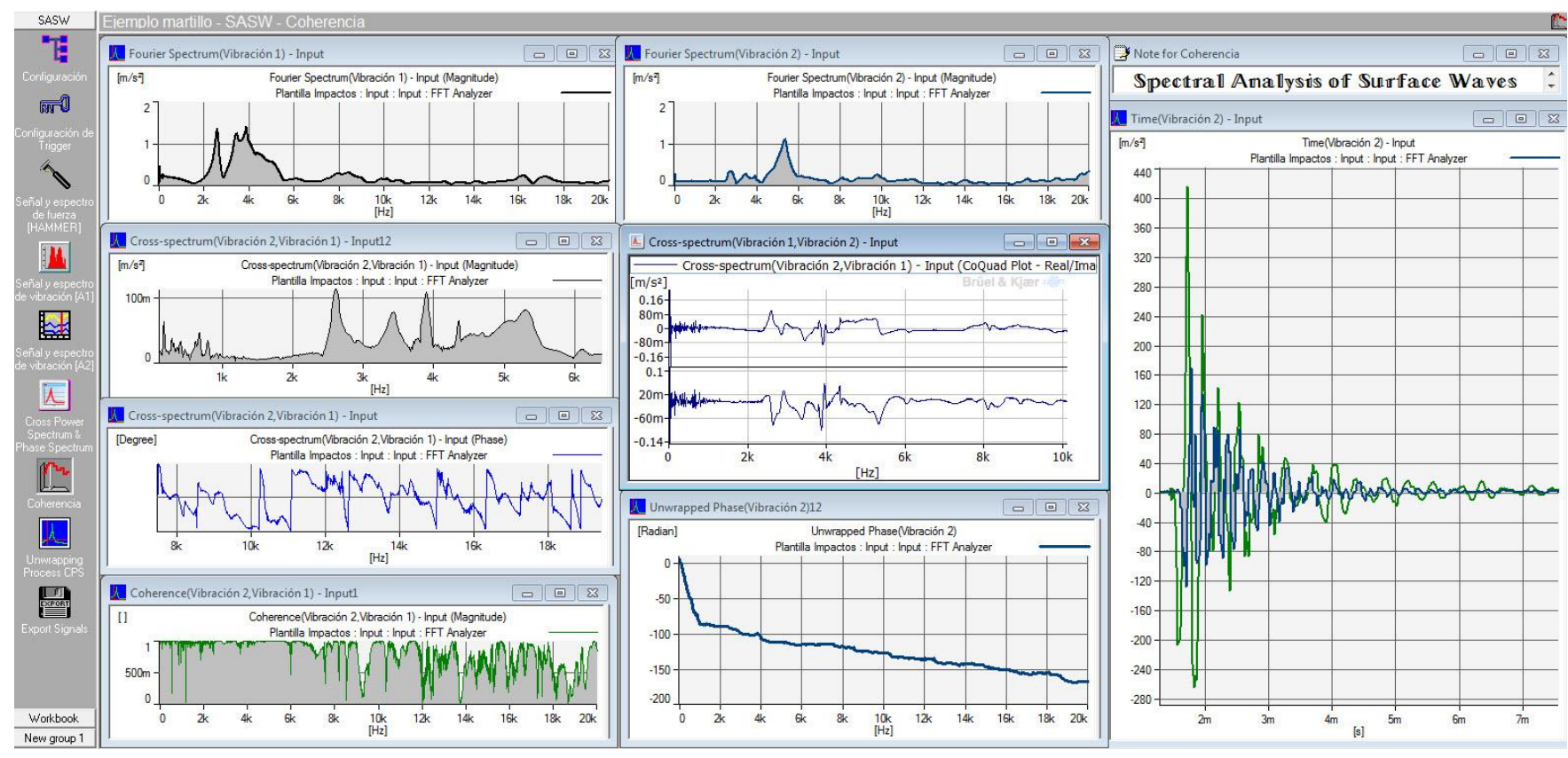

(Fig. 45) Ejemplo análisis AEOS mediante software de adquisicón de datos PULSE v.16 (Brüel\&Kjaer). (Izq/Der.) Desfase entre señales (der.); Autoespectros de energía (arriba); densidad espectral cruzada, fase del espectro cruzado, partes real e imaginaria espectro cruzado (centro); coherencia entre señales, unwrapped phase (abajo).

Evaluación computacional de la curva de dispersión mediante Método AEOS.

Se presenta el procesamiento de datos para la obtención de las curvas de dispersión según dos modalidades, implementando las herramientas conocidas:

1. Desarrollo a partir de un registro individual en el dominio de la frecuencia.

2. Desarrollo a partir del promedio de las estimaciones espectrales.

La diferencia entre ambas modalidades es que al utilizar un solo registro para el cálculo de la función de coherencia, se produce el efecto leakage o fuga de frecuencias de los espectros de potencia, lo que básicamente implica promediar el mismo espectro de potencia varias veces.

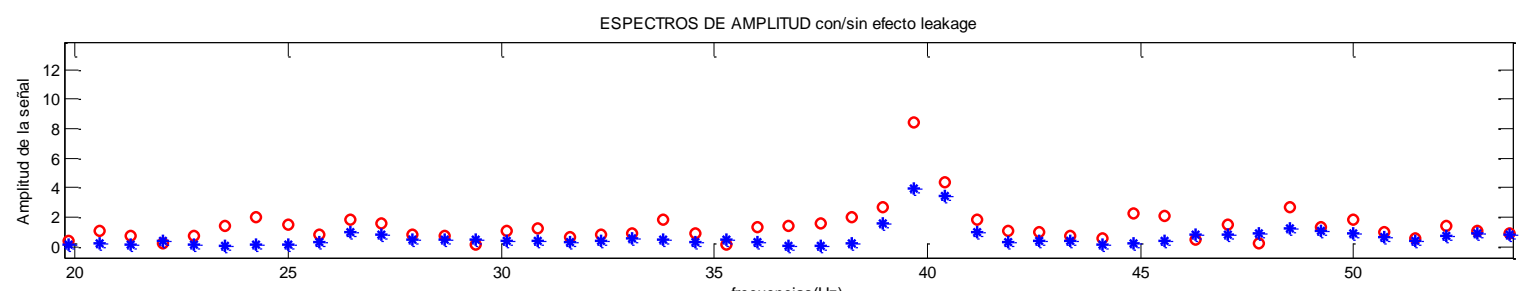

(Fig. 46). Detalle del efecto leakage en el espectro de Fourier de un registro temporal.

Por otra parte, utilizando varios registros, $\underline{\text { la función de coherencia y la fase se definen a }}$ partir del promedio de los espectros de potencia (directo y cruzado).

Respecto al fenómeno del aliasing, el equipo adquirido de Bruel\&Kjaer tiene un filtro anti-alias integrado que se establece automáticamente al fijar el intervalo de muestreo en el tiempo. Una vez 
que se define el par de receptores, se procede al cálculo de las estimaciones espectrales teniendo las siguientes consideraciones en la manipulación de los registros correspondientes a cada sensor:

- Definimos parámetros de ensayo 》 Frecuencia de muestreo $51.2 \mathrm{KHz} ; \mathrm{N}$ 4096puntos; Duración registros $80 \mathrm{~ms}$; Intervalo muestreo $19.53 \mu$ s y Resolución en frecuencia de $12.5 \mathrm{~Hz}$.

- Se estudia la necesidad del filtrado del leakage. Se utilizó como máximo, $n=5$ (promedios).

- Resta del promedio de los registros a los registros mismos.

- Realización del zero padding y aplicación de FFT. Procesamiento de señales.

- Definición de autoespectros, espectros de potencia, directo y cruzado, densidad cruzada de potencia, correlación cruzada, covarianza, espectro de fase, función de transferencia... considerando $f_{\text {Nyquist. }}$

- Cálculo de la fase y posterior desempaquetamiento de ésta (Unwrapping phase).

- Aplicación del smoothing (suavizado espectral) a las estimaciones espectrales, éste se realizó con 10 puntos, dado que el $n$ definido como máximo es 5.

- Efecto de ventana "Hamming" aplicada a la coherencia para filtrado de frecuencias $<0,95$.

- Una vez realizado el smoothing, aplicábamos la coherencia entre señales para filtrado de frecuencias válidas para la construcción de la curva de dispersión.

- Desarrollo empírico y determinación de velocidades de fase para cada frecuencia.

- Representación de la curva experimental de dispersión (Vr vs $\lambda$ ). La curva global se obtiene de promediar un min.3-5 registros con separaciones entre receptores equidistantes.

Ejemplo: Losa 3 capas de mortero de dimensiones $40 \times 40 \times(10+5+5) \mathrm{cm}$.

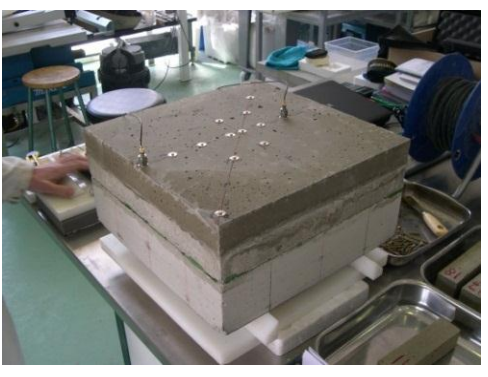

Dosificaciones y edades de cada capa (c/c ; a/c ; f/c):

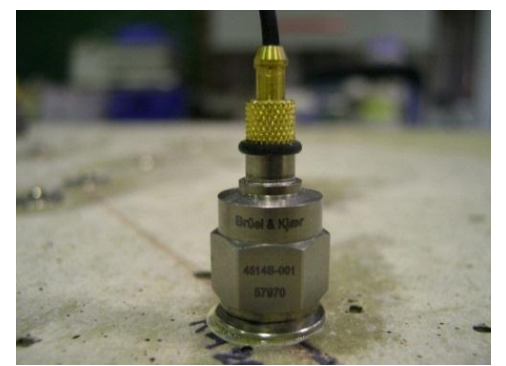

Losa superior e.5cm (1/0,4/2,70): 24horas. Losa central e.5cm (1/0,5/2,25): 28 días. Losa inferior e.10cm (1/0,6/3,25): 96 días.

El espécimen de mortero que se presenta para descripción del procedimiento de análisis espectral de ondas superficiales (AEOS) simula una placa tricapa en perfil dispersivo (+ rígidez en profundidad), con adquisición de señales de 2 acelerométros piezoeléctricos espaciados entre sí mediante la posición de montaje de fuente común "Common source" a $d: 5,10,20,40 \mathrm{~cm}$ (contorno-fuente: $4 \mathrm{~cm}$; impacto-receptor 1: $8 \mathrm{~cm}$ ) en diagonal y un segundo test a distancias $d: 6$, 12, 18, 24, 30cm (contorno-fuente:4cm; impacto-receptor 1: 6cm.) en paralelo. Los resultados corresponden a la EDAD DE $\underline{\mathbf{1 2} \text { HORAS }}$ de su fabricación. El mortero se fabricó el día 30/03/2012.

NOTA: Se escogió el modelo de losa debido a que sus propiedades mecánicas son más homogéneas que en piezas con otras geometrías. Además, en función de cumplir las relaciones propuestas para cada método por la normativa particular en cuanto a sus proporciones (Iong/espesor) podíamos aplicar posteriores técnicas de Frecuencia resonancia e Impacto Eco. 
1). ADQUISICIÓN DE DATOS. Configuración del equipo captador de vibraciones "Lan Xl" de Brüel\&Kjaer y el software comercial "PULSE v.16". Se muestra el ejemplo para una distancia entre acelerómetros $d=12 \mathrm{~cm}$ y a $6 \mathrm{~cm}$ de la fuente de impacto. La fuerza se genera con un martillo calibrado de punta de acero de Ø12mm creando un impacto de fuerza $1500 \mathrm{~N}$ en un intervalo <200 $\mu$ s:

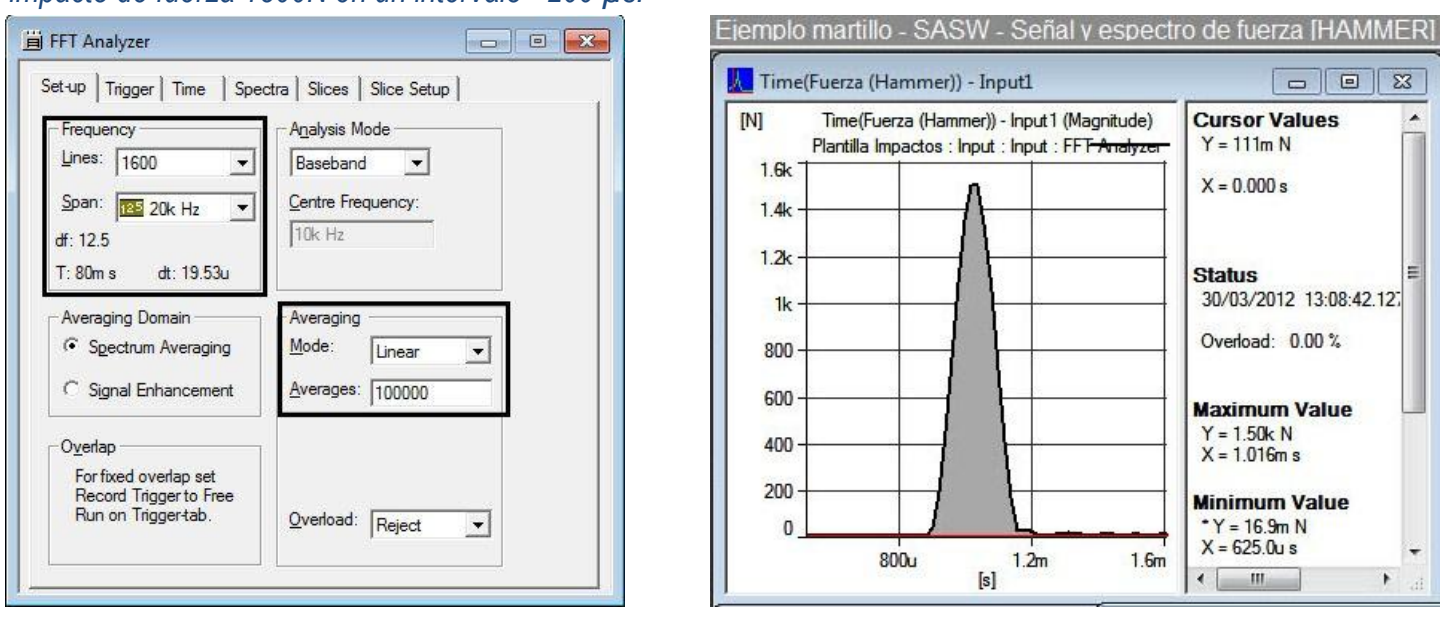

(Fig. 47). Detalle de la configuración del módulo de adquisición de datos (FFT Analyzer). Ejemplo de disparo o impacto en la superficie de un mortero, generado como una función escalón.

2). Procesamiento de LAS SeÑAleS: Captación de los registros temporales de cada acelerómetro. Como el ensayo se realizó en zona carente de ruidos externos y el acoplamiento de los receptores a la superficie del mortero fue mediante placas adheridas mediante adhesivo, se garantizó la calidad de ausencia de ruido o efectos de distorsión. No obstante, a edades tempranas menores a 24horas el análisis AEOS requiere un filtrado del efecto leakage mediante funciones ventana tipo Hanning:

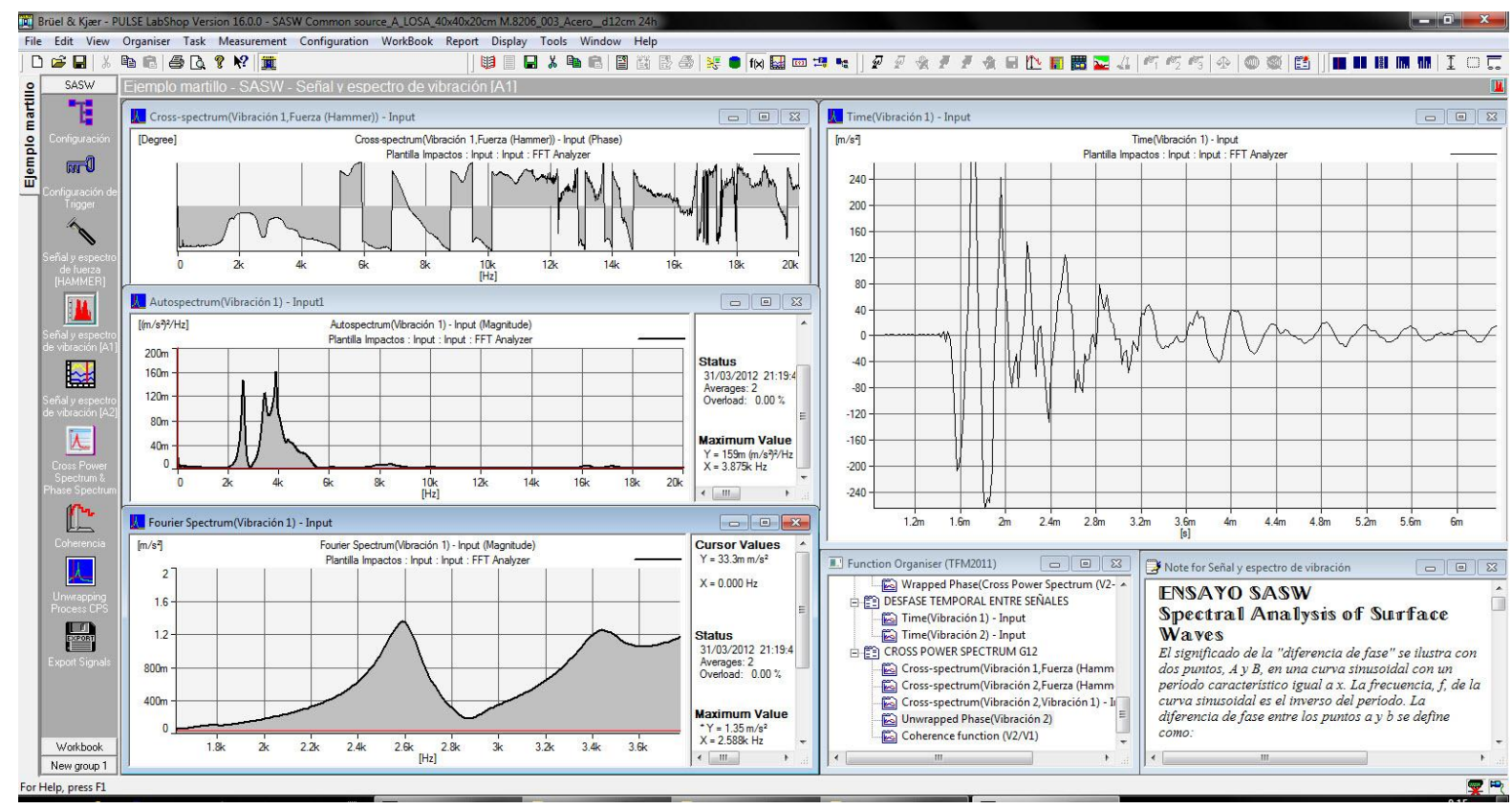

(Fig. 48). Detalle de adquisición del registro correspondiente al primer receptor debido al impato anterior que provoca la propagación de la onda.

3). ANÁLISIS DE DATOS: Una vez procesados los registros en el dominio del tiempo, se exportaron a Matlab@ para desarrollo de la rutina computacional creada para el desarrollo del método AEOS, y poder comprobar los resultados paralelos en PULSE para validación del proceso. Paralelamente se determinaron los parámetros elásticos del mismo mortero mediante ensayos Impacto Eco y Frecuencia Resonancia a probetas 4x4x16cm: 


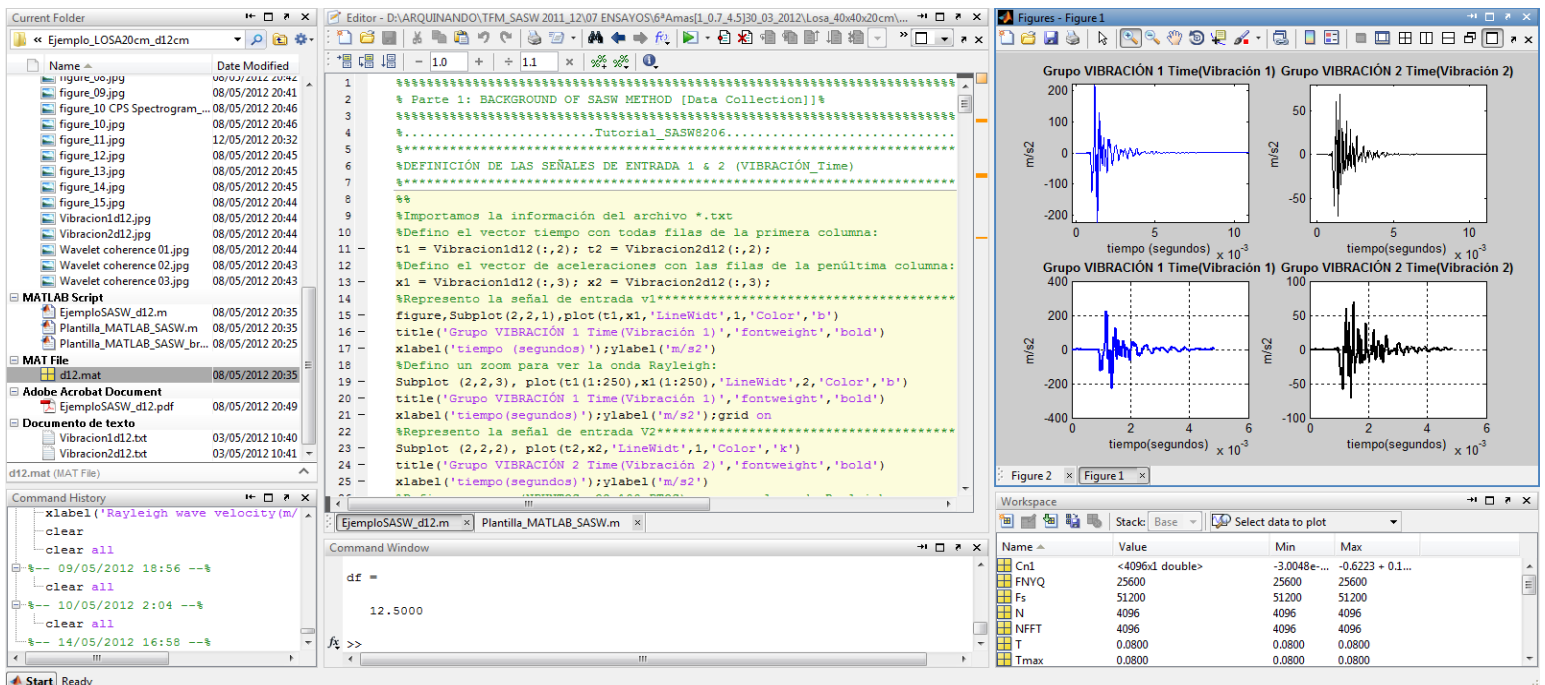

(Fig. 49). Definición de señales en el dominio del tiempo. Introducción de datos FFT Analyzer.

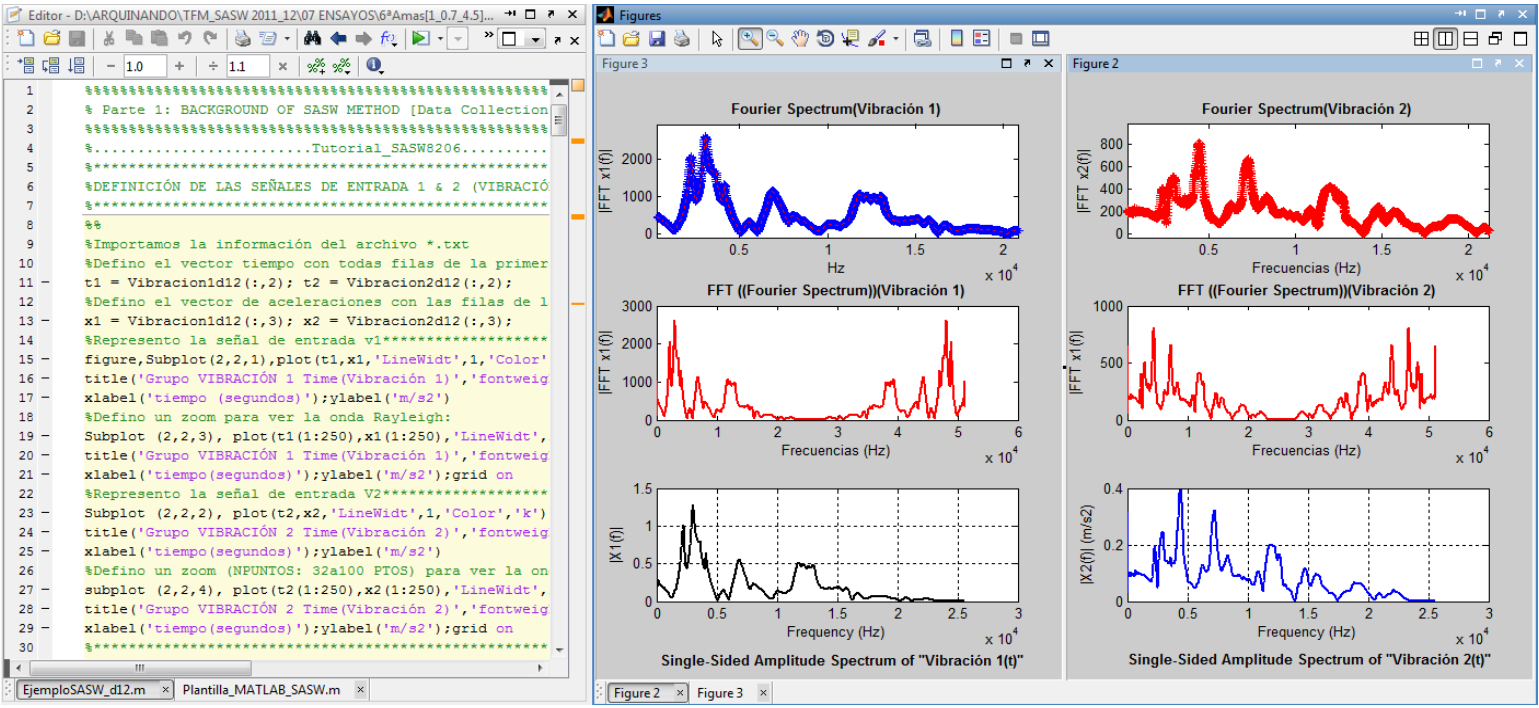

(Fig. 50). Definición de espectros de Fourier y autoespectros de energía de cada registro.
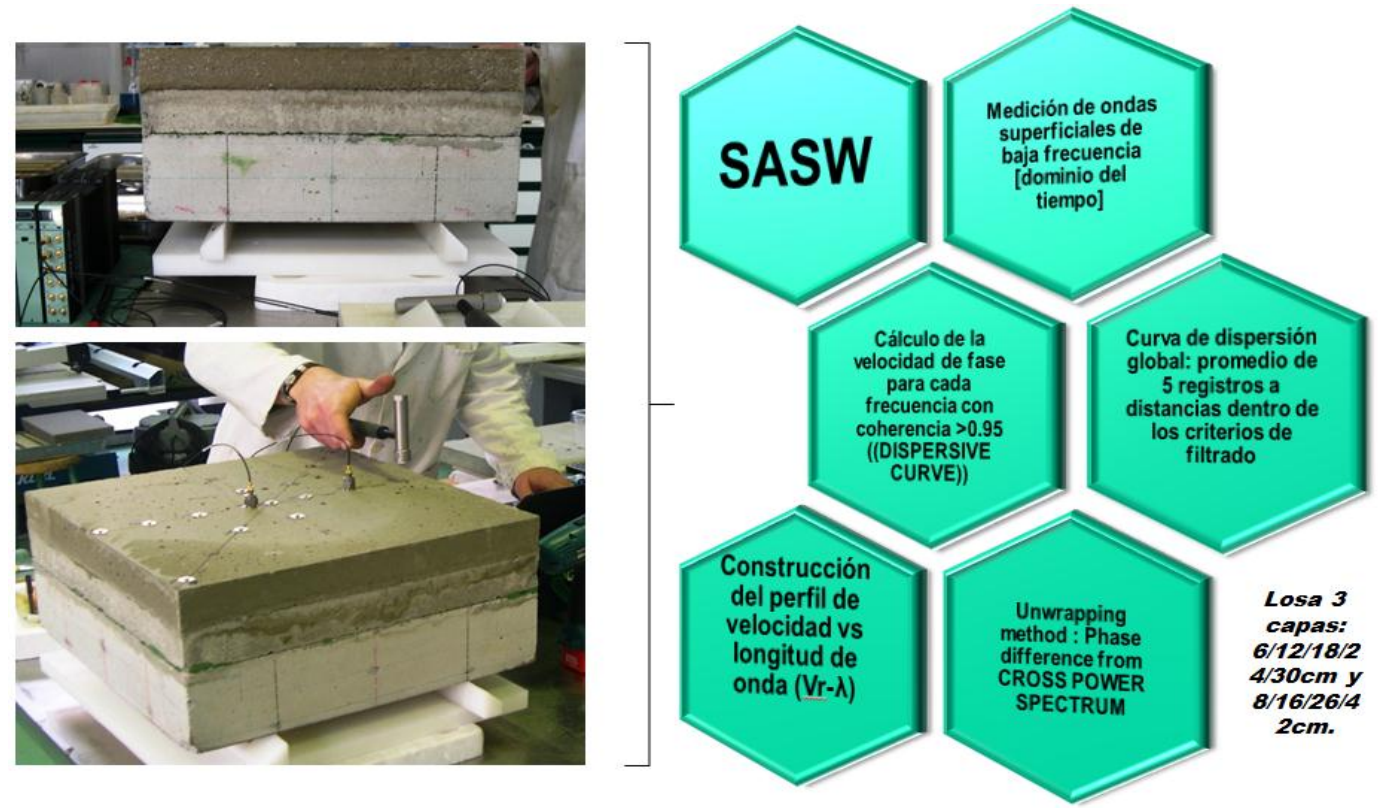

(Fig. 51). Desarrollo de los pasos a seguir en el método AEOS. Detalle de su aplicación en modelo tricapa. 


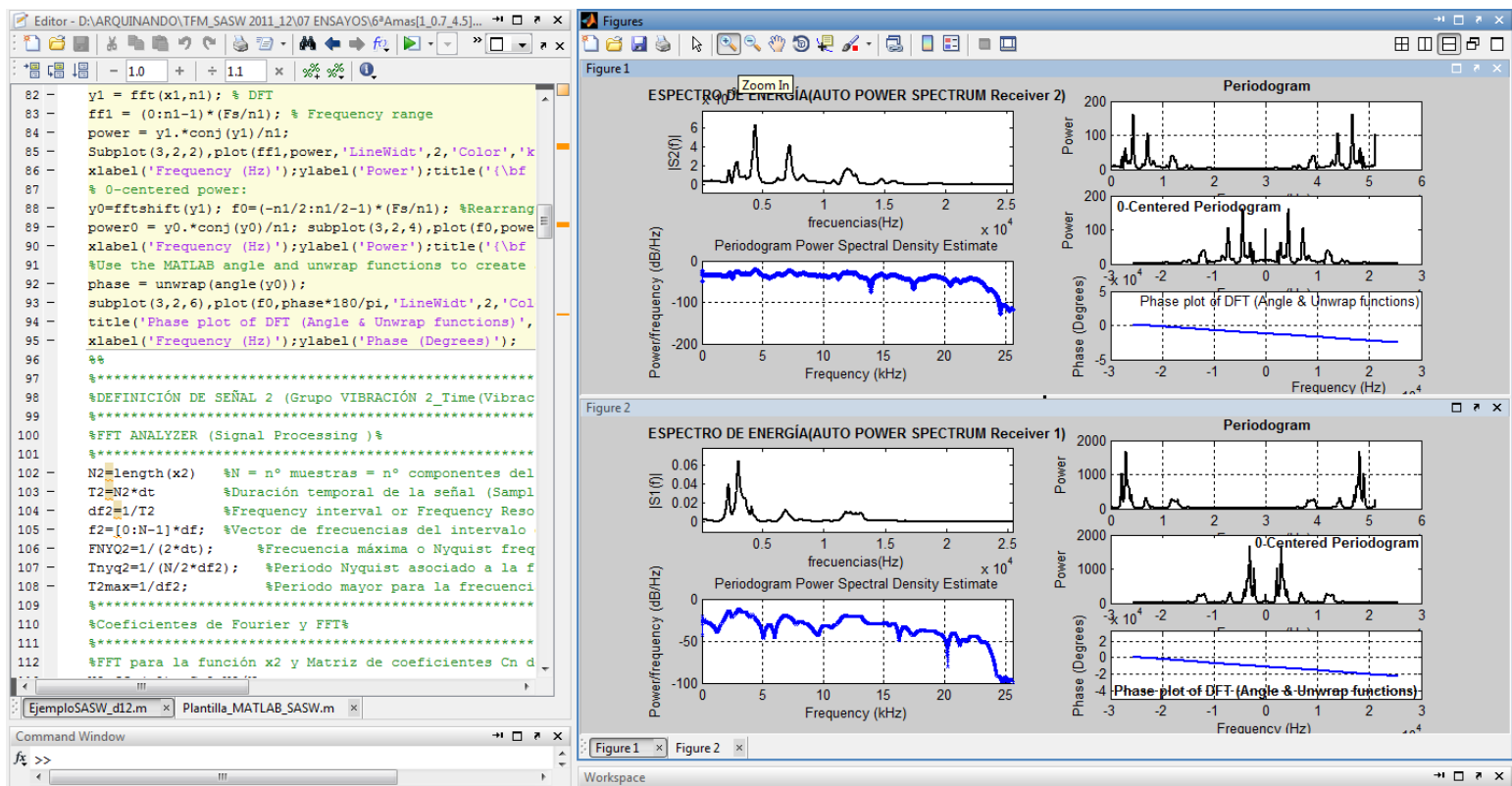

(Fg. 52). Determinación de espectros de energía, la densidad espectral cruzada y el periodograma de ambas señales.

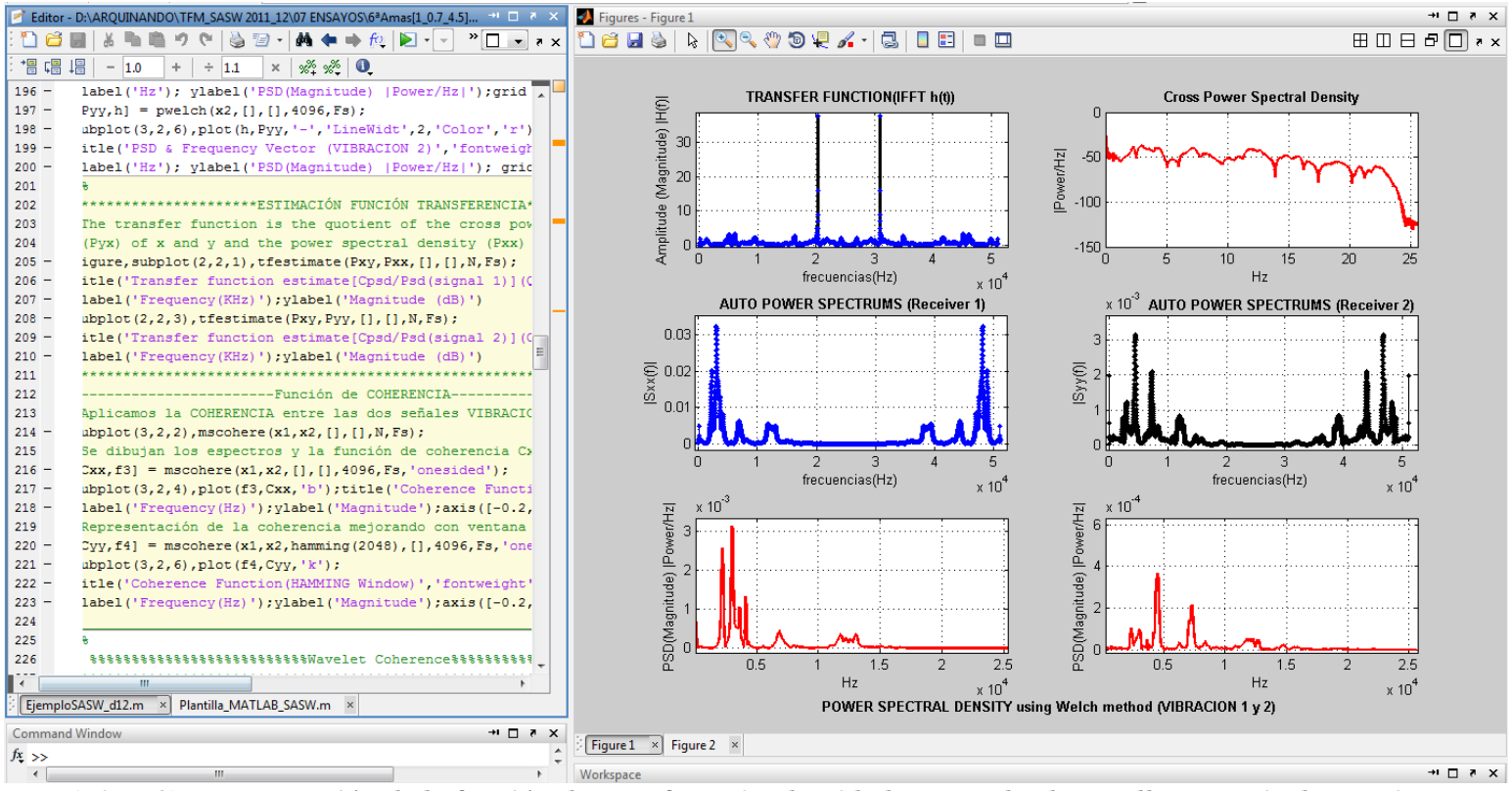

(Fig. 53). Interpretación de la función de transferencia, densidad espectral y desarrollos en serie de Fourier.

4). ANÁLISIS EN EL DOMINIO DE LA FRECUENCIA: El espectro de energía nos proporciona información visual del contenido energético del fenómeno para cada una de las frecuencias en las que descomponemos la señal de estudio. En este punto podemos diseñar filtros para eliminar de nuestra señal los contenidos de frecuencias que no nos interesen en un momento dado (ruido). La Función de Transferencia nos proporciona la respuesta en el dominio de la frecuencia de un sistema lineal invariante en el tiempo cualquiera que sea la señal de entrada. De este modo, en la siguiente gráfica se muestra el cálculo de la Función de Transferencia del sistema que estamos analizando en esta práctica. En ella podremos comprobar cuales son las frecuencias más problemáticas o si tenemos algún fenómeno de resonancia que debamos tener en cuenta. 


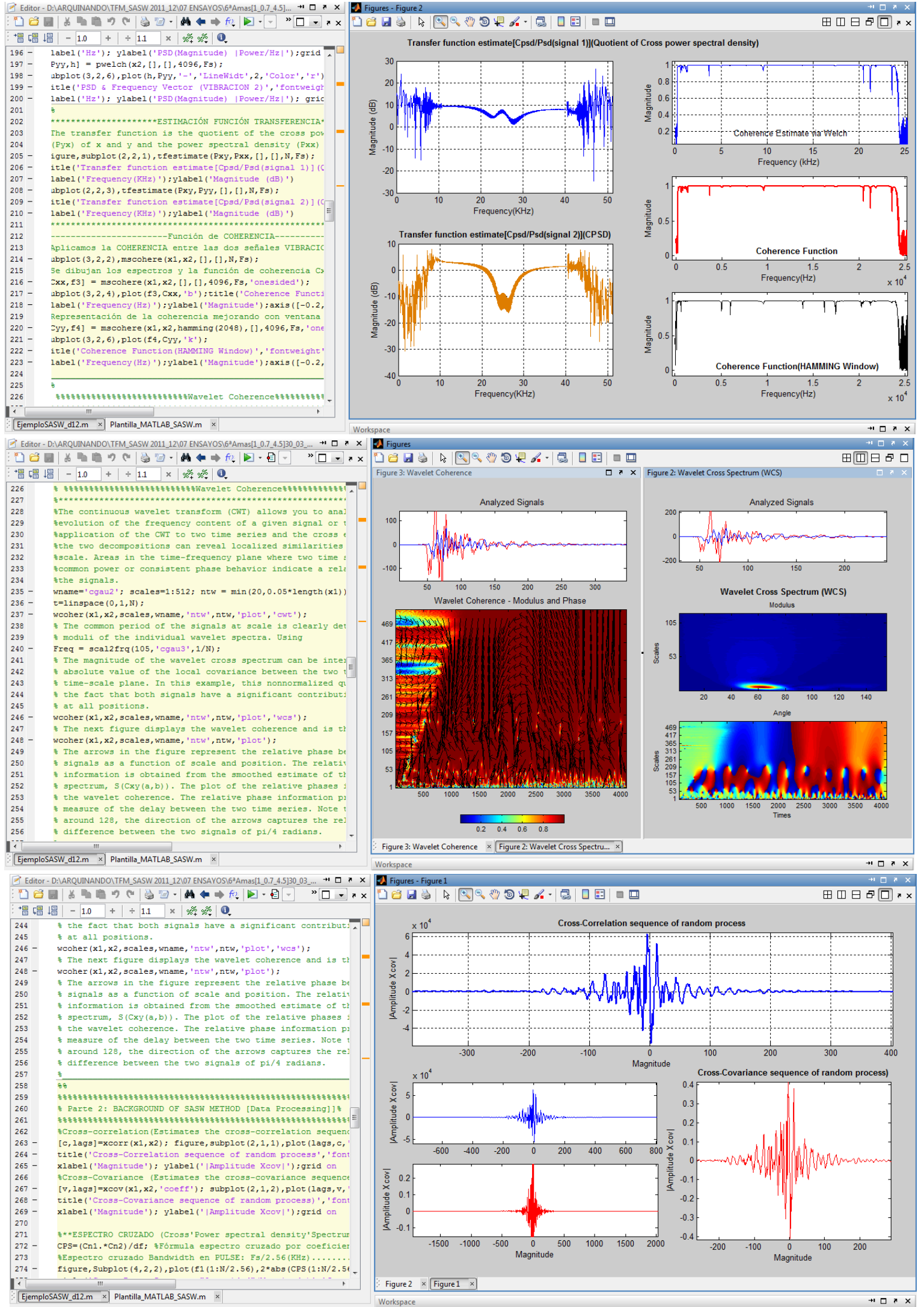

(Fig.54). Estimación de la cuota de densidad espectral cruzada entre señales, función de coherencia, "wavelet coherence method" y corrección de leakage mediante función ventana Hamming, correlación cruzada y co-varianza. 

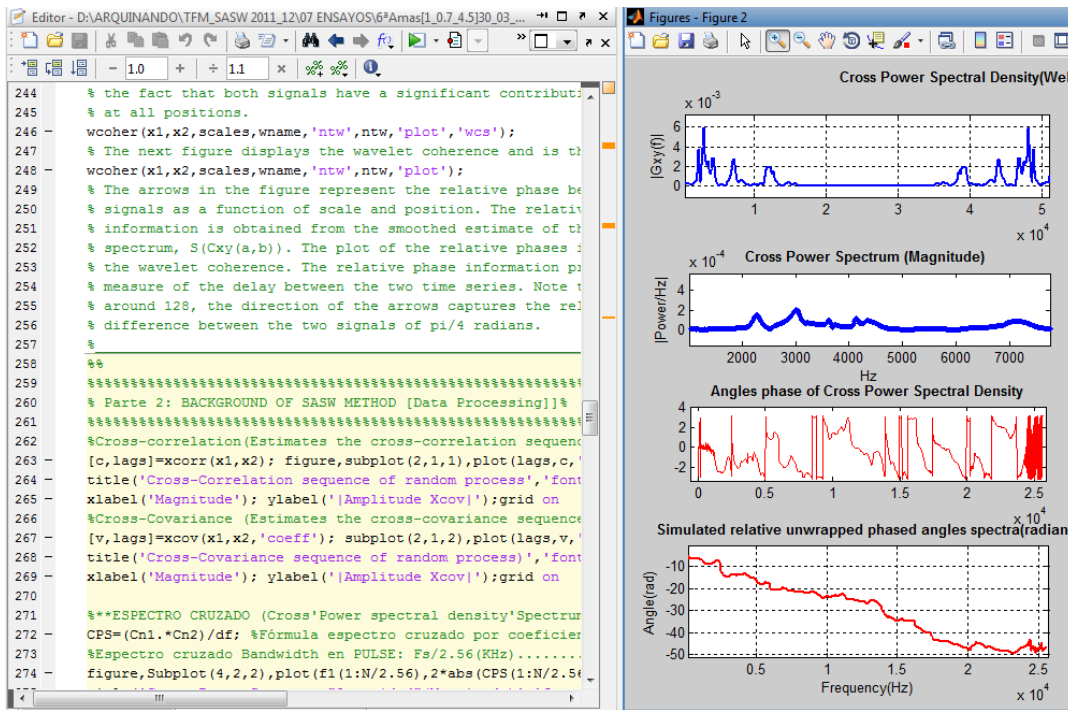
Tutor: RAFAEL GALLEO SEVILLA

(Fig.55): Espectro cruzado de potencia (magnitud, fase, partes real e imaginaria). Unwrapping method.

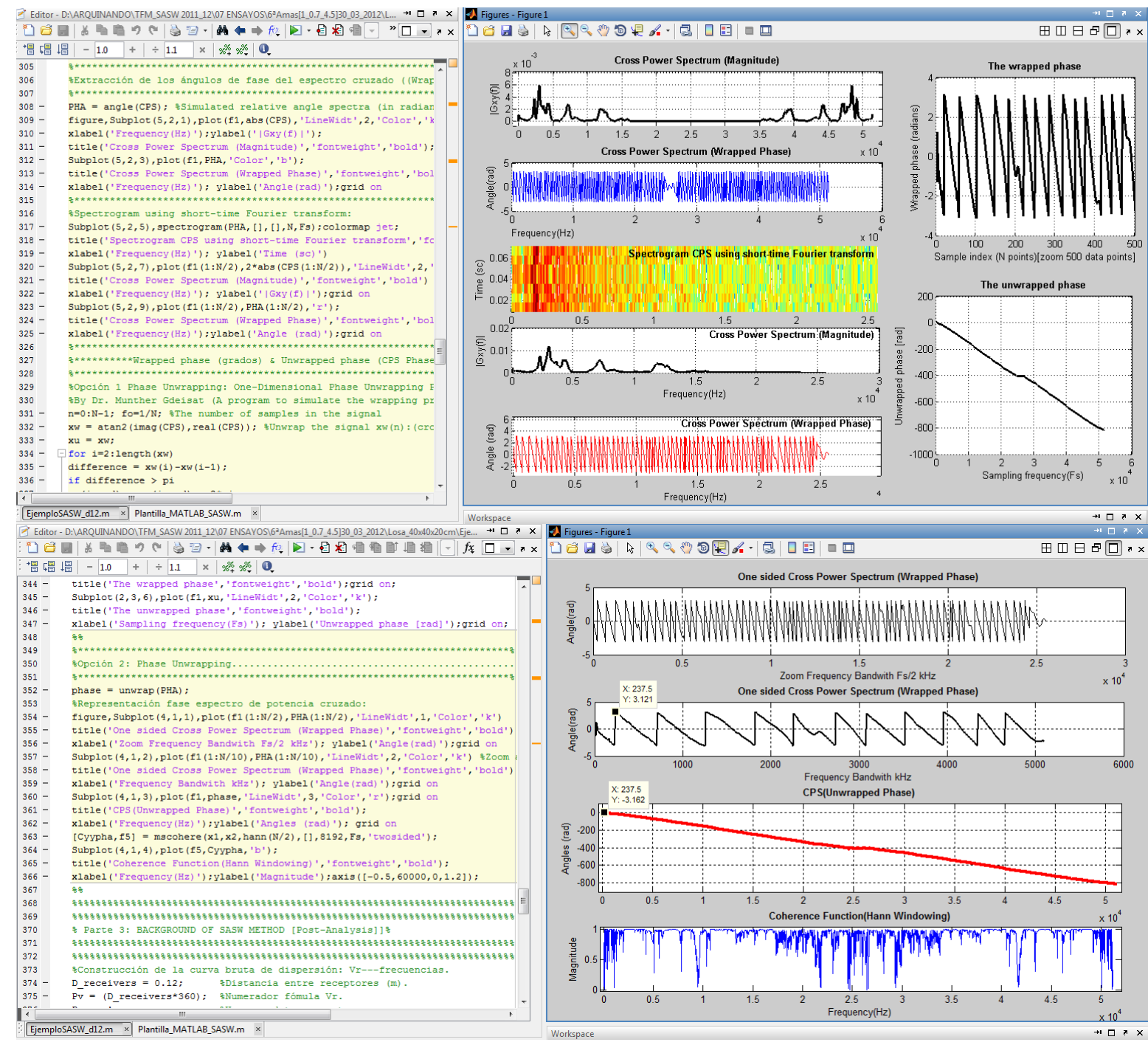

(Fig.56): Espectograma de Fourier del espectro cruzado de energía, espectro de fase. Desenmascaramiento de ángulos de fase para obtener los ángulos de fase reales previos a la obtención de las velocidades de fase. 
4). CONSTRUCCión DE LA CURVA DE DISPERSIÓN: Hasta aquí, se han definido todos los parámetros espectrales fundamentales para la definición de la curva de dispersión. Con la fase y la coherencia definidas, sabiendo la distancia entre receptores, es posible definir la velocidad de fase y obtener su curva de dispersión asociada.

Esta curva de dispersión incluye tanto la información de alta calidad, así como la de mala calidad. A esta curva se le denomina dispersión bruta. Así, es necesario aplicar criterios de validación (filtering criterion) para separar ambas clases de datos. Se definen los datos válidos de la curva de dispersión, eligiendo estos ya sea por criterio propio (este criterio se aplica picando la señal entre aquellos rangos de frecuencia que el operador considera válido), o bien por los criterios automatizados propuestos en base a longitud de onda y función de coherencia.
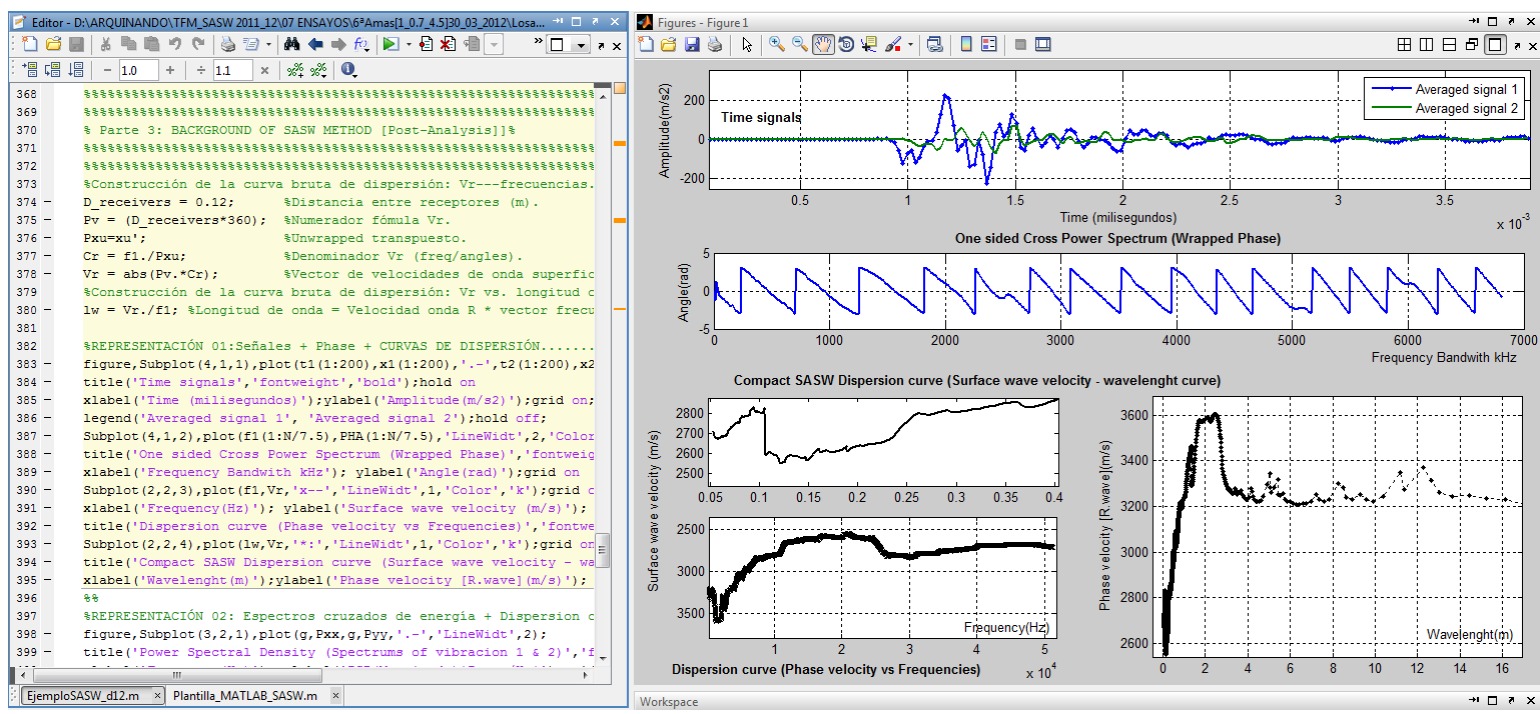

(Fig.57): “Time histories" entre señales. Curva de dispersión bruta (sin promediar) Vr vs $\lambda$.

El rango válido según el criterio con que el operador de la señal define los intervalos de frecuencia con la información más confiable se desarrolla en base al estudio de la teoría de curvas de dispersión de ondas Rayleigh en medios estratificados y el análisis de estudios destacados realizados a partir de mediciones de ondas superficiales. Como se observa en el ejemplo, el rango de frecuencias fiables de la curva de dispersión es entre $612,5 \mathrm{~Hz}$ a $24 \mathrm{KHz}$, coincidiendo en parte con el rango en que la fase y la coherencia se desarrollan correctamente.

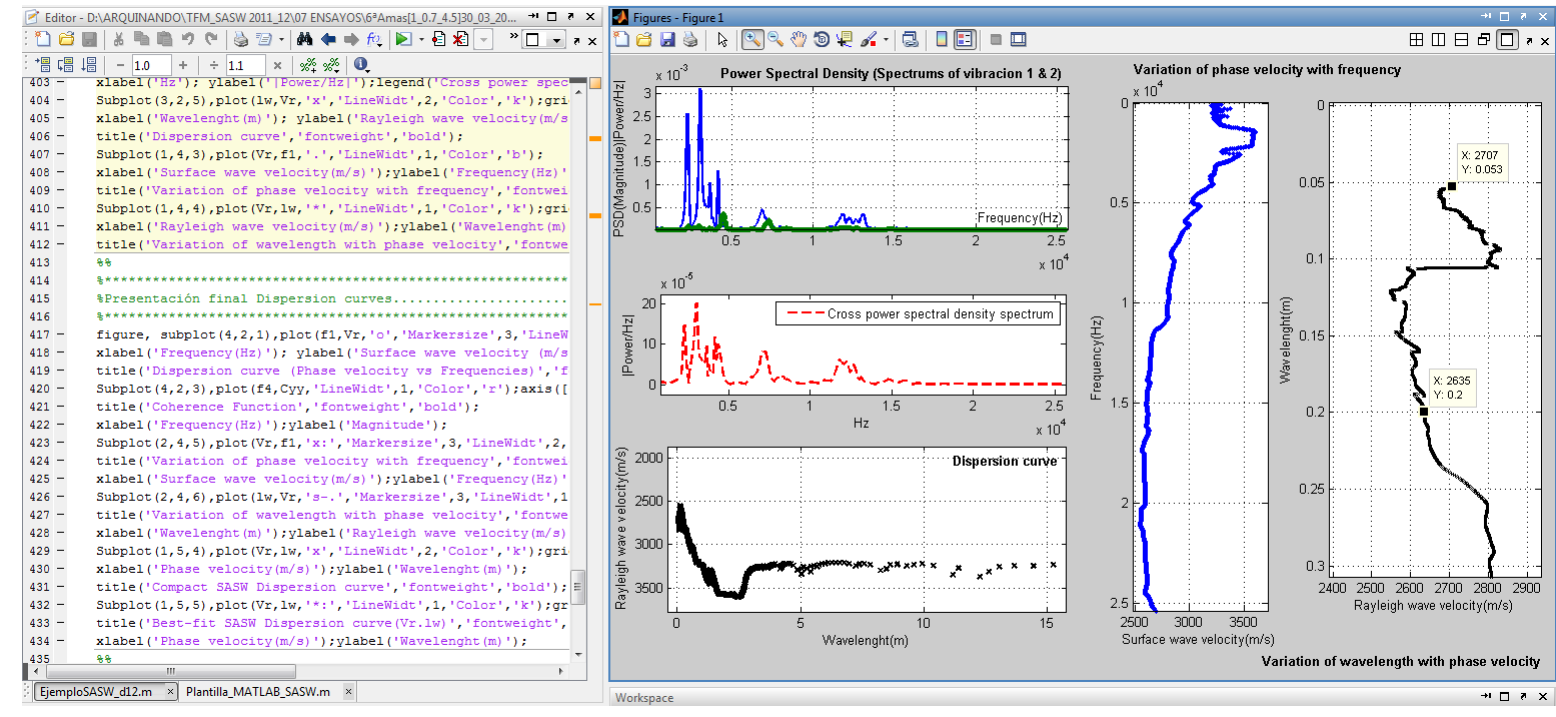

(Fig. 58). Construcción de la curva de dispersión aplicando rangos de frecuencias válidas.

Una vez que el par de acelerómetros han sido procesados para componer la curva de dispersión total, nos encontramos con una gran cantidad de información representada por todos los puntos de cada ensayo, a través de una curva de 
dispersión gruesa. De esta curva de dispersión robusta, es preciso minimizar la mayor cantidad de puntos, cuidando de no perder la información relevante del terreno que subyace a las mediciones.

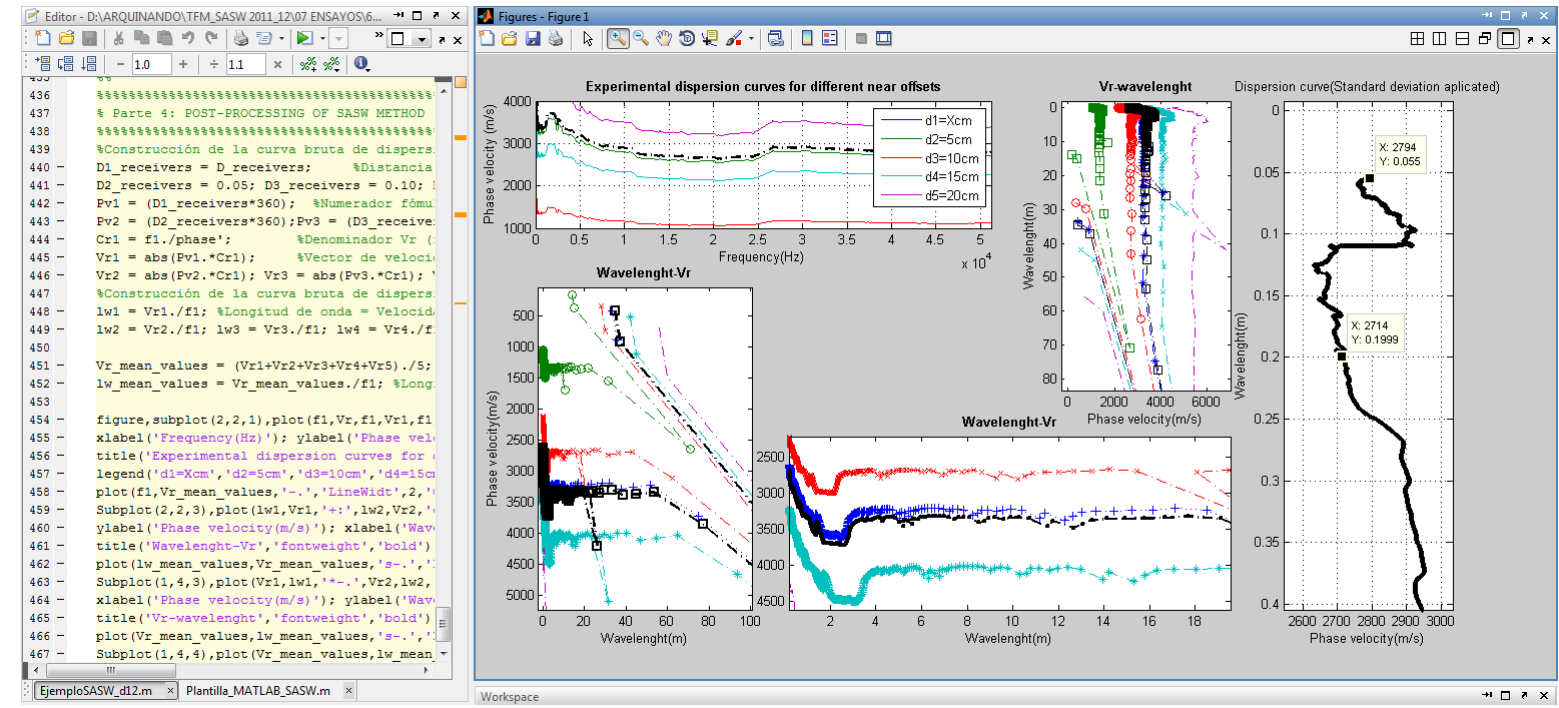

(Fig. 59). Curvas de dispersión globales. Promedio de ensayos a diferentes separaciones entre acelerómetros.

Algunas peculiaridades de la curva de dispersión final deben ser comentadas. En primer lugar, que la desviación estándar suele variar con las frecuencias, debido a la información procedente de las diferentes configuraciones de posición de los receptores, porque la velocidad de fase es función de la frecuencia. Además, la falta de continuidad en la información dada por la colocación de los receptores respecto a la fuente de impacto, puede causar la presencia de deficiencias en algunas zonas y, por tanto, pequeños cambios ficticios de pendiente en la curva de dispersión. Para este caso, la velocidad de onda superficial corresponde al valor asignado en la curva para una longitud de onda equivalente al espesor de la capa nueva $(e .5 \mathrm{~cm})$ superior.

Finalmente, presento la tabla creada para la captación de resultados del ensayo AEOS para la edad de 12horas:

\begin{tabular}{|c|c|c|c|c|c|c|c|c|c|c|c|c|c|c|}
\hline & $40 \times 40 \times 20 \mathrm{~cm})$ & \multicolumn{13}{|c|}{ SPECTRAL ANALYSIS OF SURFACE WAVES Method (ACI 228.2R 98 Nondestructive Test Methods for Evaluation of Concrete) } \\
\hline \multirow{2}{*}{\multicolumn{2}{|c|}{$\begin{array}{l}\text { Edad: [8h-28dias] } \\
\text { Fabricación: } \\
\text { V23/03/2012; 23:00h }\end{array}$}} & \begin{tabular}{|c} 
Sample \\
points (N)
\end{tabular} & \begin{tabular}{|c} 
Span \\
(Bandwidth) \\
{$[\mathrm{Hz}]$}
\end{tabular} & $\begin{array}{l}\text { Sampling } \\
\text { frequency } \\
\text { (Fs) }[\mathrm{Hz}] \\
\end{array}$ & $\begin{array}{c}\text { Nyquist (Fs/2) } \\
{[\mathrm{Hz}]}\end{array}$ & $\begin{array}{c}\text { Sampling } \\
\text { Interval (ot) [s] }\end{array}$ & \begin{tabular}{|c|} 
Sampling \\
Period $(\Delta t)[s]$
\end{tabular} & \begin{tabular}{|c|}
$\begin{array}{c}\text { Frequency } \\
\text { interval }(\Delta f) \\
{[H z]}\end{array}$ \\
\end{tabular} & $0,5 \mathrm{~h}<\mathrm{d}_{2} \leq 1.5 \mathrm{~h}$ & $\lambda_{\max } \leq h$ & $d_{1 \max } \leq 1,5 h$ & \multirow{3}{*}{\multicolumn{3}{|c|}{$\begin{array}{c}\text { Resultados a partir de datos obtenidos } \\
\text { mediante SASW }\end{array}$}} \\
\hline & & 1600 & 20000 & 51200 & 25600 & $1.953 \mathrm{E}-05$ & 0.080 & 12.50 & $0,4 h \leq d_{1}<2 \lambda$ & $d_{1} \geq \lambda_{\min }$ & $d_{1} \geq 0,5 d_{2} \approx h$ & & & \\
\hline Pro & betas $4 \times 4 \times 16 \mathrm{~cm}$ & \multicolumn{7}{|c|}{ Material properties of mortar \& concrete ((EXPERIMENTAL RESULTS)). } & $\mathrm{d} 2_{\mathrm{cs}} \approx 6 / 12 / 18 / 24 / 30 \mathrm{~cm}$ & $\mathrm{~d} 2_{\mathrm{cs}} \approx 8 / 16 / 26 / 42 \mathrm{~cm}$ & $d_{1} \approx 6-8 \mathrm{~cm}$ & & & \\
\hline $\begin{array}{l}\text { Eda } \\
\text { des }\end{array}$ & $\begin{array}{c}\text { Resistencia maxima } \\
\text { a compresion (Mpa) } \\
\text { [ENSAYO UNE EN 196/1- } \\
\text { EN 1015/11] }\end{array}$ & Masa $(g)$ & V. (cm3) & $\begin{array}{c}\text { Densidad } \\
(\mathrm{g} / \mathrm{cm} 3)\end{array}$ & $\begin{array}{l}\text { Resonant } \\
\text { frequency } \\
\text { (CPSpectrum) }\end{array}$ & $\begin{array}{l}\text { Poisson's } \\
\text { ratio }(\mu) \\
{[(E R G)-1]}\end{array}$ & $\begin{array}{l}\text { Young's } \\
\text { Modulus } \\
\text { Elasticity } \\
\text { (Ed) [Pa] }\end{array}$ & $\begin{array}{c}\text { Modulus } \\
\text { Rigidity (Gd) } \\
\text { [Pa] }\end{array}$ & $\begin{array}{c}\text { SASW_01: Velocidad onda } \\
\text { superficial [Rayleigh Wave] } \\
\text { Im/sI }\end{array}$ & $\begin{array}{l}\text { SASW_02: Velocidad } \\
\text { onda superficial Im/sI }\end{array}$ & $\begin{array}{c}\text { Averaged } \\
\text { SASW_Phase } \\
\text { velocity Im/sl }\end{array}$ & $\begin{array}{c}\text { Velocidad } \\
\text { Onda S } \\
\text { [m/s] }\end{array}$ & $\begin{array}{l}\text { Coeficiente } \\
\text { relacion } \\
V_{r} V_{s}\end{array}$ & $\begin{array}{c}\text { Averaged } \\
\text { Phase } \\
\text { velocity_IECO } \\
\text { (ASTM C1383 } \\
\text { Proc.A) }[\mathrm{m} / \mathrm{s}] \\
\end{array}$ \\
\hline 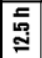 & 18.901 & 19080 & 8000 & 2.385 & 3200 & 0.13 & $2.30 \mathrm{E}+10$ & $1.02 \mathrm{E}+10$ & 1748.1 & 1442.0 & 1595.05 & 1769.57 & 0.9014 & 1962.81 \\
\hline
\end{tabular}

(Fig. 60). Tabla tipo ensayos AEOS y almacenamiento de resultados para la edad de 12 horas.

En el capítulo de resultados experimentales se corroboran estos resultados, ya que se procesaron 3 modelos de mortero (1, 2 y 3 capas) con una media de 24 ensayos AEOS para cada modelo.

Considerando que el ensayo es doble por tener los registros simétricos conforme al método, y que cada ensayo conlleva un mínimo de 3 a 5 registros variando la separación entre acelerómetros, podemos decir que el método se ha validado para unas 600 señales aproximadamente, sin considerar los ensayos realizados a otros modelos previamente para adquirir destreza en el método. 


\section{Factores que han influido en el desarrollo del método. Problemática.}

El mortero, como material heterogéneo cuyas propiedades evolucionan con el tiempo, adaptado al método de ondas superficiales determina un frente de onda de baja nitidez, dependiendo de la capacidad para evaluar el nivel de influencia de algunos factores como la presencia de defectos o humedad interna. Para un correcto análisis experimental, la propagación de la onda en un mortero unicapa puede entenderse como una fase homogénea constituida por la pasta de cemento y la fase constituida por los áridos. Influyen otros factores: trabajabilidad, propiedades reológicas, tixotropía, tiempo de fraguado, sangrado, segregación, viabilidad, y cuestiones prácticas relacionadas con el enmoldado y desencofrado.

Posición relativa de los acelerómetros en los ensayos.

En la transmisión superficial se disponen en la misma cara del elemento que se ensaya. Al estar la superficie del mortero rugosa e irregular, puede variar el espesor de acoplamiento entre receptores generando difracción o reflexión de onda. Debemos considerar el fenómeno de dispersión y atenuación a causa de las discontinuidades locales del material que reducen el impulso recibido. Estas medidas dependen mucho del estado superficial (grietas, heterogeneidad, coqueras) de la probeta o del elemento estructural de mortero a ensayar.

\section{DISPERSIÓN y ATENUACIÓN de onda en morteros frescos.}

La atenuación y la dispersión de onda se estudian con el objetivo de caracterizar de forma más precisa el daño interno de la estructura y la caracterización del tamaño del árido empleado.

La evaluación de técnicas comúnmente utilizada en ingeniería, no es apta para caracterizar la curva de dispersión en aquellos casos que sólo se puede acceder a una cara de la estructura, siendo la técnica AEOS más adecuada. [Por dispersión se entiende la variación de la velocidad de onda en función de la longitud de onda. En un medio sólido homogéneo, la velocidad de onda Rayleigh es constante, no varía con la frecuencia. Sin embargo, en un medio formado por varias capas (etapas de fraguado a edad temprana), las ondas superficiales se dispersan].

Se ha observado en morteros con frecuencias más altas $(<\lambda)$ microfisuras, que decrecen la resistencia del mortero siendo débil, provocan una mala calidad del curado, y por tanto, velocidades de onda superficiales más lentas.

$\underline{\text { La longitud de onda debe ser comparable al }}$ espesor de la primera capa, por lo que en este trabajo, implicaba llegar a frecuencias $\approx 50 \mathrm{KHz}$ dependientes de la velocidad de fase.

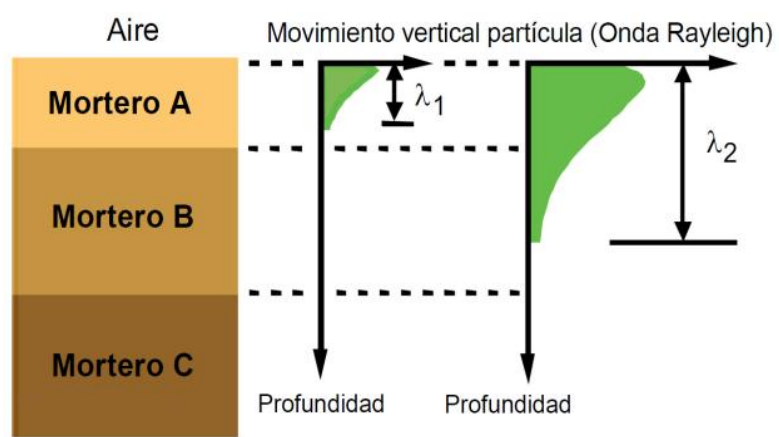

(Fig. 61). Distribución de la dispersión de las partículas con la profundidad de dos ondas de superficie de diferentes longitudes de onda (RIX \& STOKOE, 1989). 
Caracterización de la absorción en el mortero.

El mortero se considera una matriz compuesta de partículas pegadas que exhiben un comportamiento dispersivo, examinado a través del análisis de la onda Rayleigh adquirido en diferentes puntos de la superficie de una muestra ensayada.

* La dispersión se ve influida por el $\varnothing$ árido y por la velocidad. Un mayor contenido de áridos aumenta la velocidad de onda y disminuye las altas frecuencias de la señal en el mortero, mientras que el diámetro de la partícula no parece afectar decisivamente a la velocidad (T.P. PHILIPPIDIS, D.G. AGGELIS, 2005). Así se comprobó en los ensayos realizados que para un árido Ø4mm:

\begin{tabular}{|c|c|c|c|c|}
\hline & Ensayos a 28 días & $\begin{array}{l}\text { LOSA UNICAPA } \\
40 \times 40 \times 10 \mathrm{~cm}\end{array}$ & $\begin{array}{c}\text { LOSA BICAPA } \\
40 \times 40 \times(10+5) \mathrm{cm}\end{array}$ & $\begin{array}{c}\text { LOSA TRICAPA } \\
40 \times 40 \times(10+5+5) \mathrm{cm}\end{array}$ \\
\hline \multirow[b]{2}{*}{ AEOS } & Relación cemento/agua & 0,6 & 0,5 & 0,4 \\
\hline & Relación cemento/árido & 3,25 & 2,25 & 2,70 \\
\hline
\end{tabular}

(Fig. 62). Tabla de resultados para cada espécimen de 1, 2 y 3 capas de losas de mortero.

El mortero muestra un comportamiento dispersivo a través de la transmisión de ondas superficiales, que revelan una tendencia a bajas frecuencias. Aunque el cambio de la relación a/c= 0,50 a 0,6 no afecta demasiado a la velocidad al no mostrar grandes cambios, las diferencias deben buscarse por encima de frecuencias $60 \mathrm{kHz}$ (a frecuencias altas > - velocidad > +dispersión).

Influencia de las partículas de arena y burbujas de aire.

- A bajas frecuencias > se produce dispersión por la presencia de aire ocluido o burbujas de aire en la matriz de la pasta de cemento.

- A altas frecuencias > se produce exclusivamente atenuación por el contenido de arena.

Las mediciones experimentales demostraron el efecto dominante de los granos de arena en la atenuación de altas frecuencias. Del mismo modo, el efecto de distorsión debido a reforzar la matriz de cemento con arena fina parece ser la respuesta a la influencia de las burbujas de aire ocluidas frente a la atenuación a frecuencias bajas.

Detección de defectos internos.
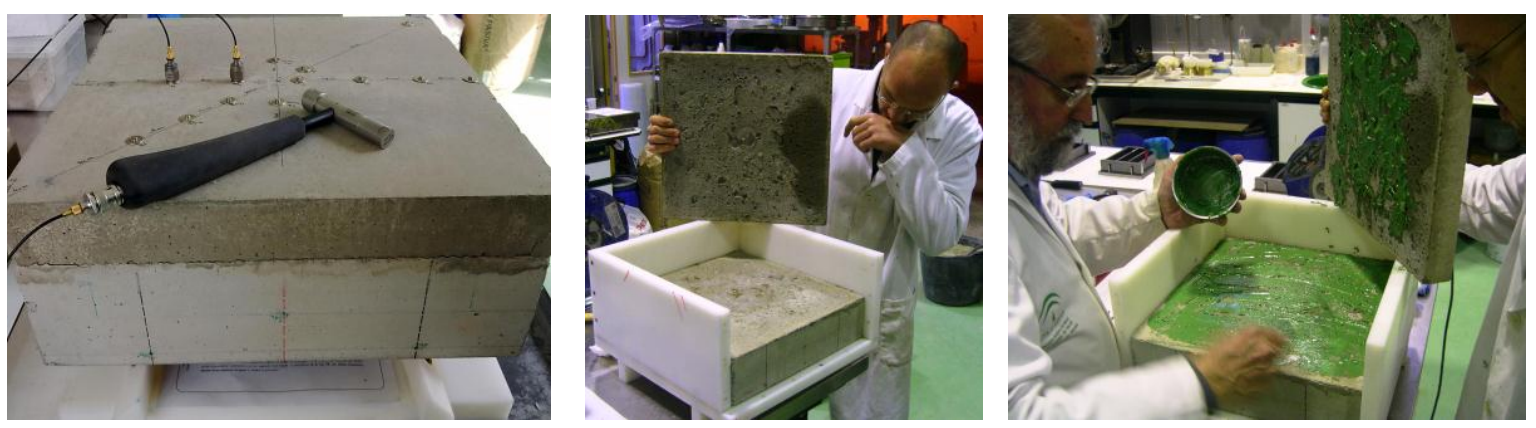

(Fig. 63). Modelo bicapa de mortero. Reparación de oquedades debido al desprendimiento de la nueva capa sobre el modelo de losa unicapa a la edad de 45 días de su curado. Estos defectos fueron apreciables en las pruebas de Impacto Eco. Posteriormente se rigidizó el conjunto.

También puede utilizarse para detectar defectos internos en las estructuras, ya que tienden a frenar la propagación de ondas mediante la atenuación. En este caso la onda viaja hasta chocar 
con el defecto provocando una baja velocidad aparente ya que la componente de frecuencia determinada disminuye en el conjunto de datos en función del tamaño del defecto.
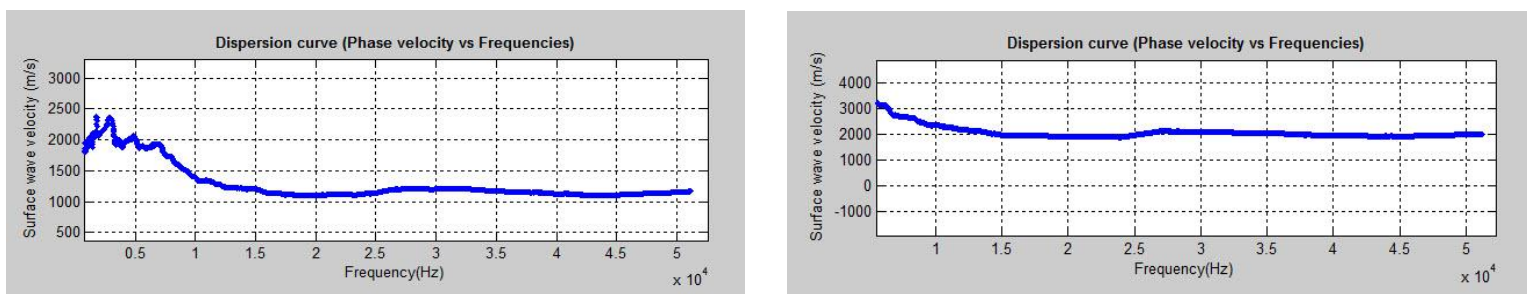

(Fig. 64). Ejemplo gráfico de detección de defectos internos bajo capa de $5 \mathrm{~cm}$. El modelo bicapa es una losa de 40x40x(10+5)cm fabricada para ensayo AEOS a edades tempranas. (Arriba) Espécimen, detección de coqueras y reparación mediante sellado. (Izq.) Curva de dispersión de capa con defecto, menor velocidad y mayor dispersión de onda a bajas frecuencias. (Der.) Curva de dispersión de modelo sin defectos.

Efecto de la relación agua/cemento $(\mathrm{a} / \mathrm{c})$.

La proporción a/c es un factor clave para la resistencia final del mortero y su durabilidad (Abrams 1918; Neville 1995). Una excesiva adición de agua, no mejora la trabajabilidad ya que altera sus propiedades (Bescher 2004).

Los ensayos realizados a cada una de las dosificaciones realizadas de mortero fabricadas para este trabajo mostraron una concordancia en ciertos aspectos a mencionar:

- El módulo de elasticidad del mortero disminuía con el aumento de la proporción a/c.

- Cuando se aumentaba la relación agua/cemento, también aumentaba la porosidad capilar y la interfaz árido/cemento se volvía menos resistente, mostrando microfisuración.

- La mezcla con relación a/c<0,5 exhibía mayor velocidad de onda.

Experimentalmente se resume en la siguiente tabla los valores obtenidos para cada mortero:

\begin{tabular}{|c|c|c|c|c|}
\cline { 2 - 5 } \multicolumn{1}{c|}{} & Ensayo AEOS & $\begin{array}{c}\text { LOSA UNICAPA } \\
40 \times 40 \times 10 \mathrm{~cm}\end{array}$ & $\begin{array}{c}\text { LOSA BICAPA } \\
40 \times 40 \times(10+5) \mathrm{cm}\end{array}$ & $\begin{array}{c}\text { LOSA TRICAPA } \\
40 \times 40 \times(10+5+5) \mathrm{cm}\end{array}$ \\
\hline \multirow{3}{*}{28} & Dosificación & $(1 / 0,6 / 3,25)$ & $(1 / 0,5 / 2,25)$ & $(1 / 0,4 / 2,70)$ \\
\cline { 2 - 5 } días & Velocidad Onda R $(\mathrm{m} / \mathrm{s})$ & $\mathbf{2 2 9 1 , 4 3}$ & $\mathbf{2 2 8 2 , 1 9}$ & $\mathbf{2 2 6 7 , 0 5}$ \\
\cline { 2 - 5 } & Resistencia compresión (MPa) & $\mathbf{4 9 , 8}$ & $\mathbf{5 2 , 2 1}$ & $\mathbf{5 2 , 8 8}$ \\
\cline { 2 - 5 } & Módulo Elasticidad (GPa) & $\mathbf{2 7 , 6 8}$ & $\mathbf{2 8 , 4 6}$ & $\mathbf{2 9 , 3 6}$ \\
\hline
\end{tabular}

(Fig. 65). Tabla a 28 días de los parámetros elásticos relevantes de cada modelo de losa.

Efecto del tamaño del árido.

El mortero es un material de interfaz heterogénea y microestructura crítica para estudiar las pérdidas de atenuación. Las impedancias acústicas (velocidad de onda longitudinal $x$ densidad de masa) de la partículas de arena y la matriz de cemento portland son $9.8 \times 10^{6} \mathrm{~kg} / \mathrm{m}^{2}$ s arena $y$ $8.9 \times 10^{6} \mathrm{~kg} / \mathrm{m}^{2}$ s cemento, con diferencia <10\% (ABRAMS 1918; NEVILLE 1995).

* Se estudiaron dos tipos de árido presentes en el Laboratorio, una arena de $\emptyset 2,5 \mathrm{~mm}$ y un árido de $\emptyset 4 \mathrm{~mm}$ empleado con frecuencia. Se estudiaron probetas de $4 \times 4 \times 16 \mathrm{~cm}$ de morteros con cada árido, extrayendo las siguientes conclusiones:

- Aunque reducir el tamaño total máximo de $\emptyset 4 \mathrm{~mm}$ a $\emptyset 2,5 \mathrm{~mm}$ no afectó sustancialmente al módulo de elasticidad, para un mismo volúmen de áridos, la mezcla con Ø4mm, tenía mayor módulo de elasticidad que la otra mezcla.

- Con Ø2,5mm, aumentaba la relación árido/cemento (que es el eslabón más débil) y como resultado el módulo de elasticidad obtenido era menor. 
Ruido aleatorio y ruido coherente.

Tras los ensayos se demuestra que hay una tendencia decadente de la velocidad con el ruido. Considerado como un efecto indirecto, se impone la atenuación de la onda a frecuencias altas, mientras que para las ondas de baja frecuencia caracterizadas por un pico de amplitud fuerte en el espectro de Fourier, mucho mayor que el nivel de ruido, no se ven afectadas.

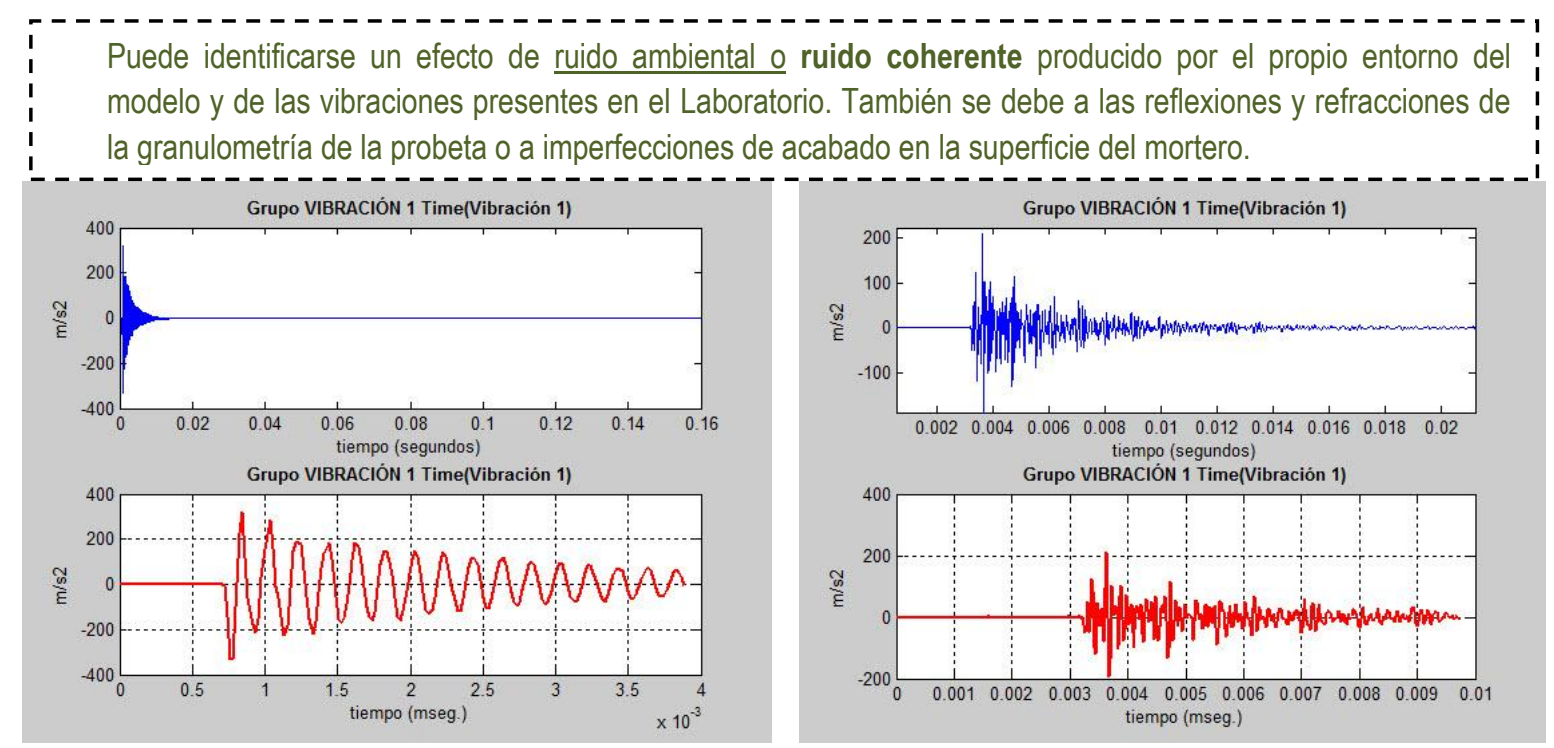

(Fig. 66). (Izq.) Señal captada sin ruido aparente. (Der.) Señal captada con ruido aleatorio de fondo.

La energía coherente del ruido puede distinguirse del ruido aleatorio (el propio aire vibrando en los acelerómetros). El ruido coherente es de baja frecuencia y puede ser filtrado, mientras que el ruido aleatorio es de alta frecuencia debido a la cercanía entre fuente-receptor.

Cuando las señales se transformaron al dominio de la frecuencia (FFT), el ruido disminuía, ya que el contenido de energía que estaba presente no era recogido por el análisis de Fourier. Un enfoque simple para eliminar las distorsiones ruidosas en el espectrograma es el filtrado de ondas.

Significa que la señal de ruido se elimina y permanecen sólo las señales de onda superficial.
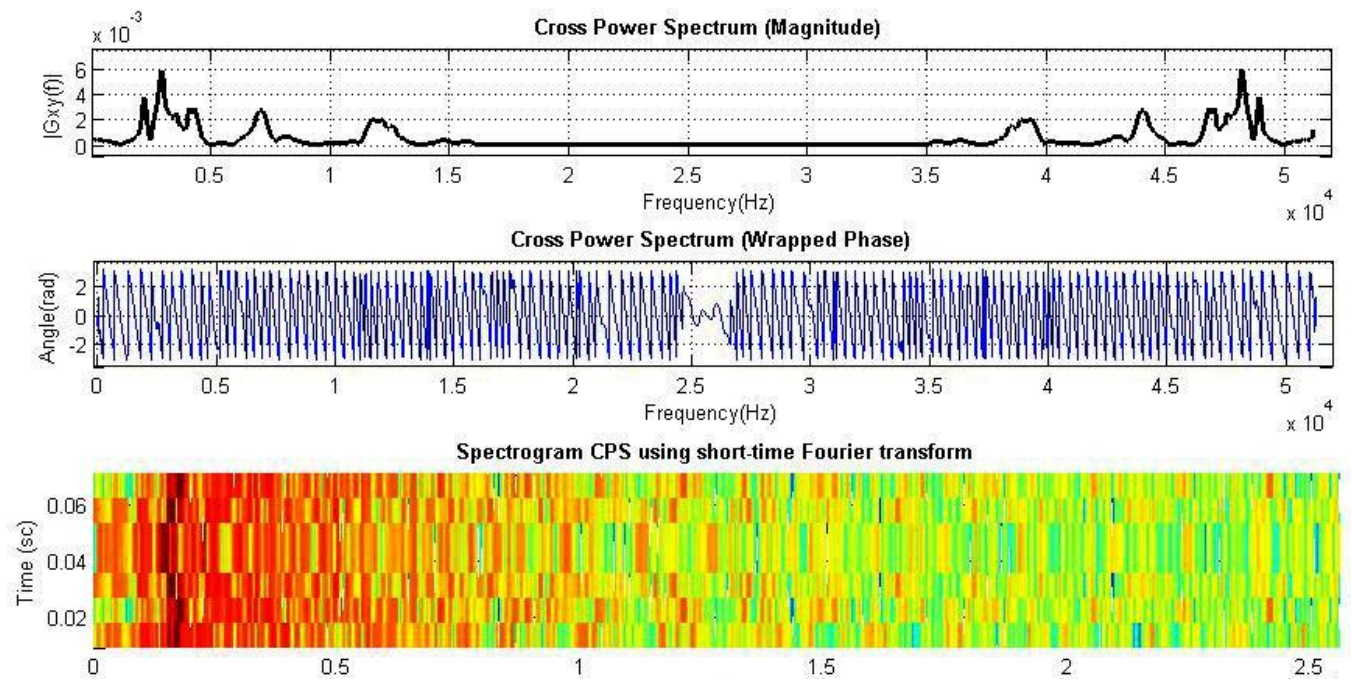

(Fig. 67). Espectro de magnitud y fase de la señal con ruido incoherente. Representación del espectrograma. 


\section{Análisis Espectral de Ondas Superficiales (AEOS)} (VI). METODOLOGÍA DE ANÁLISIS. TÉCNICAS PARALELAS END PREVISTAS.

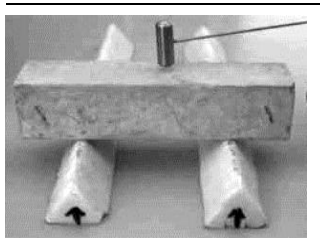

Para abordar el objetivo del trabajo en morteros a edad temprana por la térnica AEOS debemos validar sus resultados $\psi$ los parámetros elásticos del material, para ello, se recurre a dos técnicas paralelas de ensayos no destructivos, aplicadas con eficacio en estructuras reales: el método de Impacto-fco y Frecuencia-Resonancia.

\section{Determinación de parámetros elásticos del material $(E, G, \mu, \rho)$}

El método AEOS (SASW) que determina la velocidad de onda superficial, el tiempo de viaje de la onda y la curva de dispersión del mortero a edades tempranas, se complementa para su validez de resultados y comprobación como técnica de impacto y no destructividad, con la aplicación de las técnicas de IMPACTOECO (I-E) y FRECUENCIA-RESONANCIA (FFRC), que se utilizan para la medición de espesores, detección de defectos y determinación del módulo de elasticidad, Poisson y rigidez transversal del material.

Técnica Impacto-Eco.

(ASTM C13832010 Standard test method for measuring the $P_{-}$Wave speed) La energía se propaga en todas las direcciones, y las reflexiones pueden llegar desde muchas direcciones. En la década de 1980, Sansalone \& CaRino desarrollaron un método impulsivo de pruebas en el campo de la geofísica, con el término "impacto-eco".
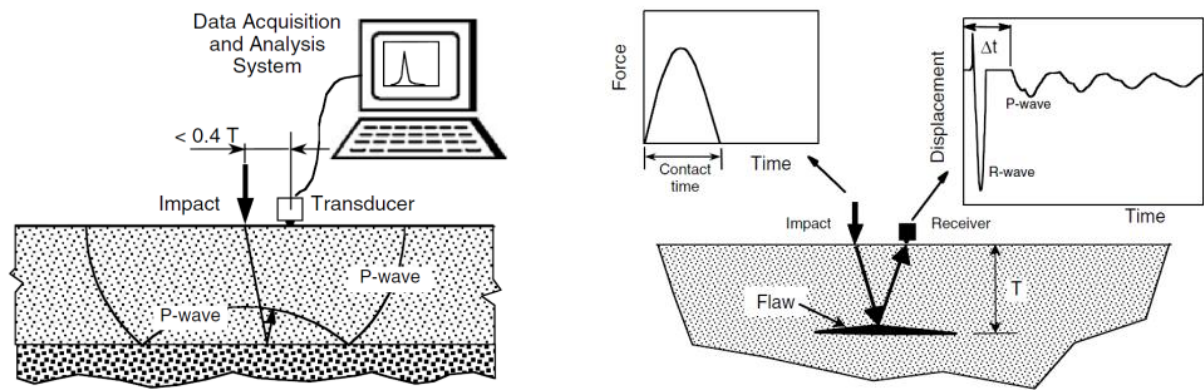

(Fig. 68). Configuración típica del ensayo I-Eco. Distanciamiento, señales de fuerza y desplazamiento.

PRINCIPIO.

El método de impacto-eco es una técnica de detección de defectos internos que se basa en la monitorización de la velocidad superficial resultante de una onda derivada de un impacto mecánico. Uno de los logros del Impacto-Eco es la transformación mediante la FFT que nos proporciona el análisis espectral de señales para convertir el registro del impacto del dominio del tiempo al dominio de la frecuencia.

Un impacto mecánico de altas frecuencias se introduce en el modelo de ensayo propagando frentes de onda esféricos a lo largo de la superficie como una onda superficial. Las reflexiones producen desplazamientos que son medidos por un receptor y grabados por el sistema de adquisición de datos. Al colocarse cercano a la fuente de impacto ( $s<0,4 \cdot e s p e s o r$ capa), predominan los desplazamientos causados por llegadas de ondas $\mathrm{P}$ en el frente de onda, por lo que el éxito del método depende, en parte, de un impacto de duración correcta. 
Análisis: Si el receptor se encuentra cercano a la fuente $(s<0,4 \cdot e s p e s o r$ capa), la respuesta estará dominada por ondas de compresión, a pesar de la presencia de ondas superficiales, siendo apreciable en el espectro de amplitud por un pico de resonancia. Así, la forma de onda es periódica, y el período es igual a la ruta de viaje, $2 \mathrm{~T}$, dividida por la velocidad de la onda primaria (Cp). Debido a que la frecuencia es el inverso del periodo, la frecuencia de resonancia es: $f=\beta C_{p} / 2 T$ (SANSALONE 1997), siendo T el espesor del material o la profundidad a un defecto interno; $\beta$ es un factor dependiente de la sección transversal del espécimen de ensayo (en probetas de $4 \times 4 \times 16 \mathrm{~cm}$ será la sección $4 \times 4 \mathrm{~cm}$ ); así en placas delgadas se considera de valor 1 mientras que en secciones rectangulares oscila de 0,75 a 0,96, como consecuencia del factor de aspecto que considera la siguiente relación:

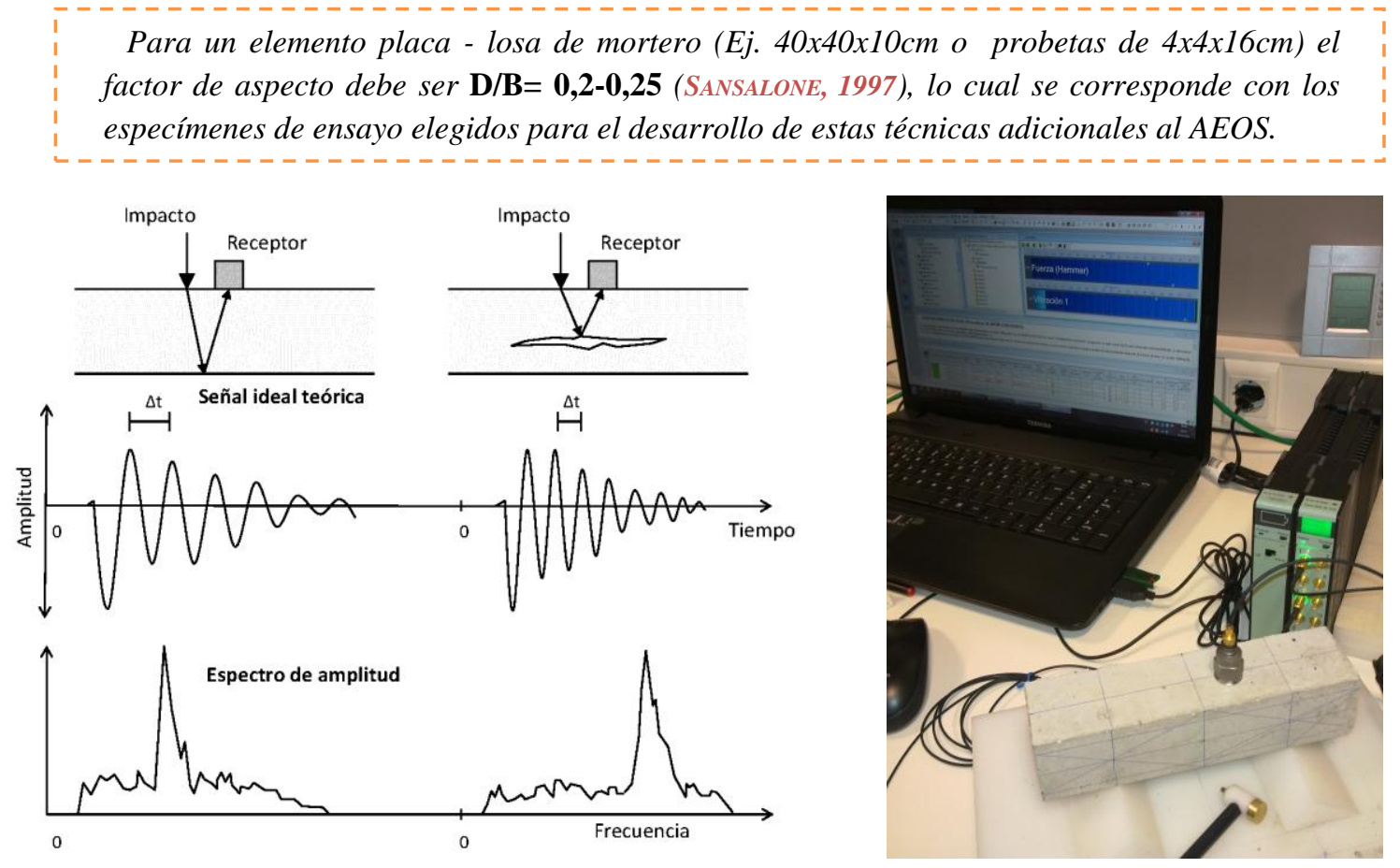

(Fig. 69). Espectros de amplitud en el ensayo I-Eco variando la frecuencia resonante conforme detecta defectos internos. Montaje y equipo para el desarrollo experimental del trabajo con este técnica no destructiva.

El tiempo de contacto determina el contenido en frecuencias debido al impacto. A menor tiempo de contacto mayor será el rango de frecuencias contenidas en el impulso. Para pruebas de impacto-eco de estructuras tipo losa, son preferibles impactos de corta duración. Así, se recurre al martillo B\&K 8204 miniatura de $\emptyset 3-11 \mathrm{~mm}$ para inducir un impacto que provoque un $\boldsymbol{t c} \approx 15-100 \mu \mathrm{s}$ (SANSALONE \& STREet, 1997).

Un menor tiempo de contacto genera un pulso de tensión con una amplia gama de frecuencias. La relación del tiempo de contacto, tc (seg.) y el diámetro de la punta de acero del martillo, Ø(metros), es: tc=0,0043Ø (CHANG, 2005). La norma ASTM C1383 establece en su Procedimiento B que la duración del impacto debe ser al menos: $\mathbf{t}_{\mathbf{C}}<\mathbf{2 T} / \mathbf{C}_{\mathbf{P}}$ 
Ejemplol-ECO: Probeta prismática mortero $40 \times 40 \times 160 \mathrm{~mm}$.

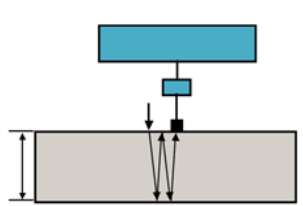

DATOS_FFT_Analyzer_PULSE16:

S.Frequency: $F t=1 / \delta t=20 \mathrm{KHz} \rightarrow \delta t=0,5 \mu \mathrm{s}$

Lines: $N=6400$ ptos.

Sampling_period $: \Delta T=N \cdot \delta t=320 \mathrm{~ms}$

Frequency_interval $: \Delta f=1 / N \cdot \delta t=3,125 \mathrm{~Hz}$

$f=C_{p} / 2 T$

**Fórmulas_básicas**

Time_contact_impact $: t_{c}=0,0043 \cdot \varnothing=0,0043 \cdot 0,005=21,5 \mu \mathrm{s}$

$f_{\max }=290,7 / \varnothing=58 \mathrm{KHz} \rightarrow C_{p}=2 f \cdot e=2 \cdot 58000 \cdot 0,04=4640 \mathrm{~m} / \mathrm{s}($ válida $)$

Resultados_ensayo $(s<0,4 e=1,6 \mathrm{~cm}$. $)$ :

fr $=5,528 \mathrm{KHz} \quad$ Amplitud $=2,06 \mathrm{~m} / \mathrm{s}^{2}$

$f=C_{p} / 2 e \rightarrow C_{p}=5528 \cdot 2 \cdot 0,04 \mathrm{~m}=442,24 \mathrm{~m} / \mathrm{s}$

Time_contact_impact $: t_{c}<\frac{2 e}{C_{p}}<\frac{2 \cdot 0,04 m}{442,24 m / s}<180,9 \mu \mathrm{s}$

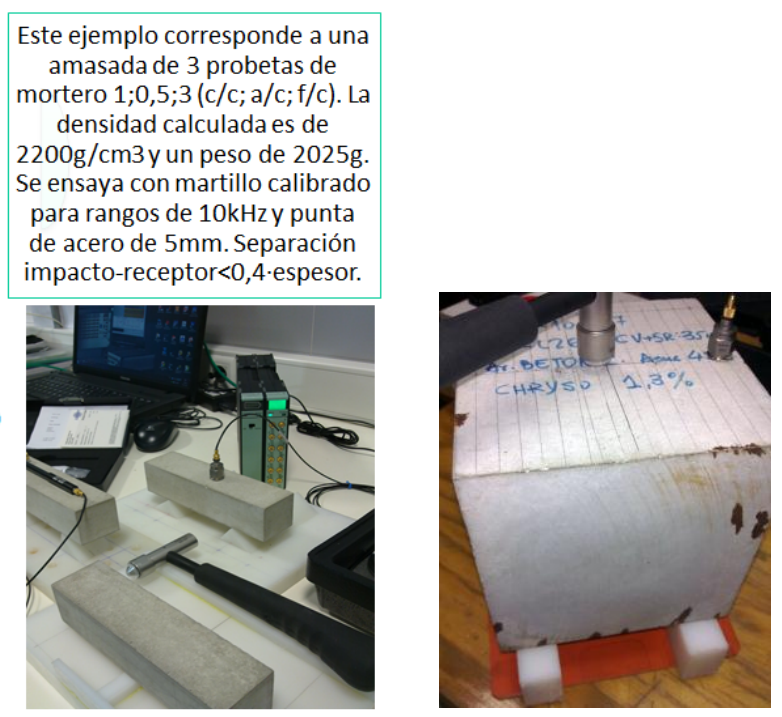

(Fig. 70). Ejemplo de cálculo para una probeta de dim. 40x40x160mm. Detalle de ensayos previos.

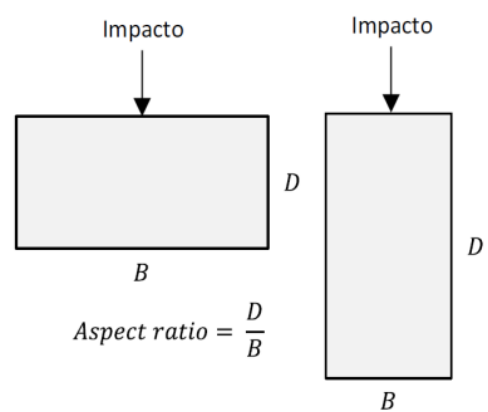

Definición del "Factor de aspecto" en Impacto-Eco.
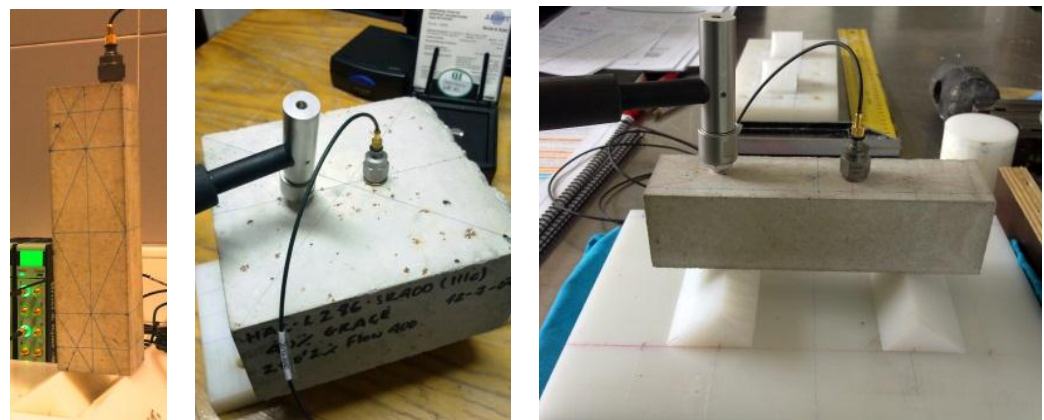

(Fig. 71). Definición del factor de forma indicado en la norma ASTM C1383. Ensayos en probetas de mortero de varias dosificaciones.

La tasa de muestreo del sistema de adquisición de datos debe ser lo suficientemente alta como para medir la frecuencia más alta prevista. El impacto debe ser capaz de generar la frecuencia de resonancia.

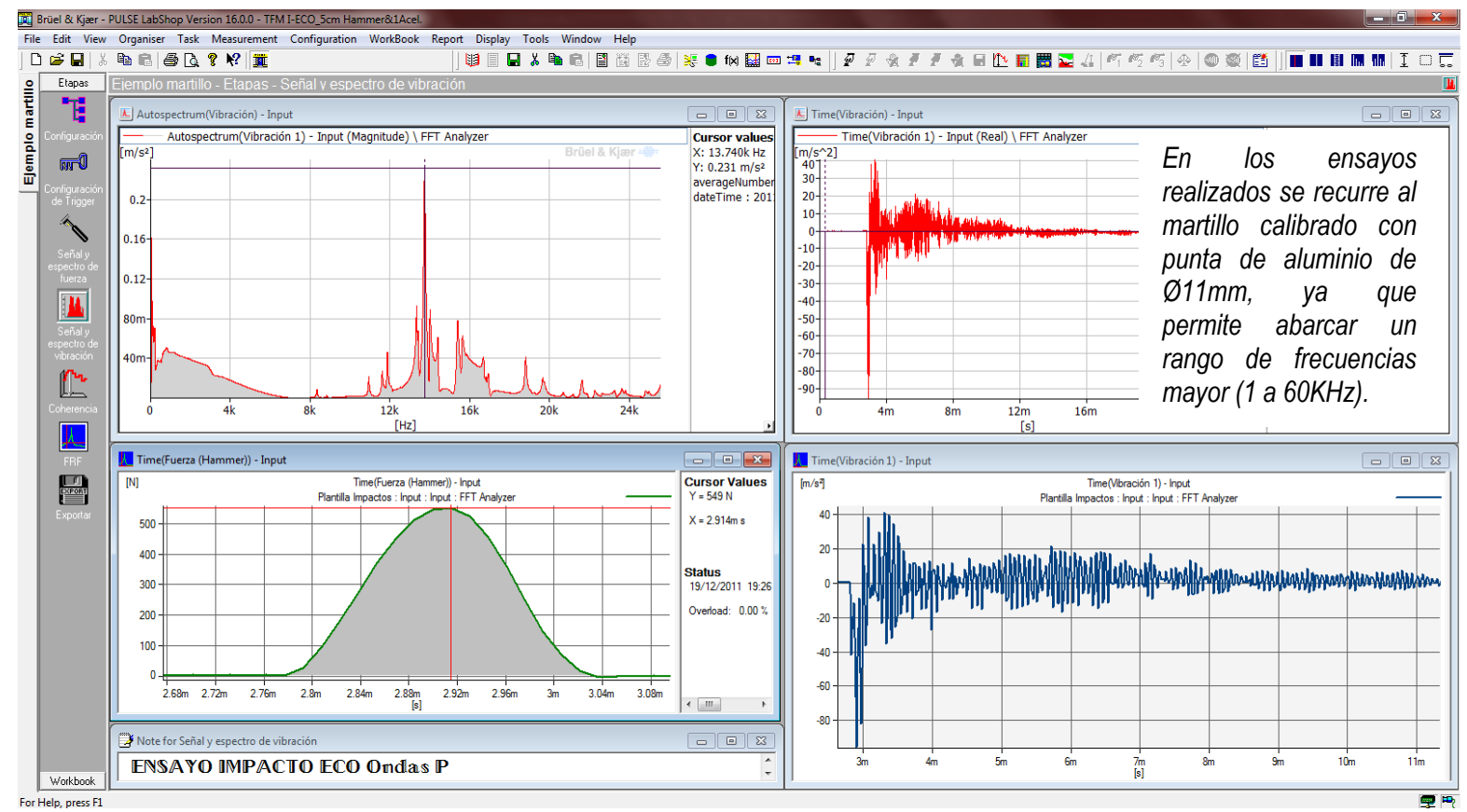

(Fig 72). Espectro de amplitud mostrando la frecuencia pico. Función escalón de impacto generado tc:1ms. Señal temporal generada por el impacto afectada por ruido debido a la heterogeneidad del material a edad temprana. 
El espectro de amplitud resultante muestra las amplitudes de los diversos componentes de frecuencia que componen la forma de onda. En las pruebas de impacto-eco, no se utiliza el espectro de fase. En el método de análisis espectral de ondas superficiales, el espectro de fase se utiliza exclusivamente.

- Ejemplo: Amasada 20/03/2012. Edad: 9h. Dosificación: 1/0,5/2,25. Se fabricaron 8 moldes triples (24 probetas) para ensayos a FFRC, I-E y Rotura.

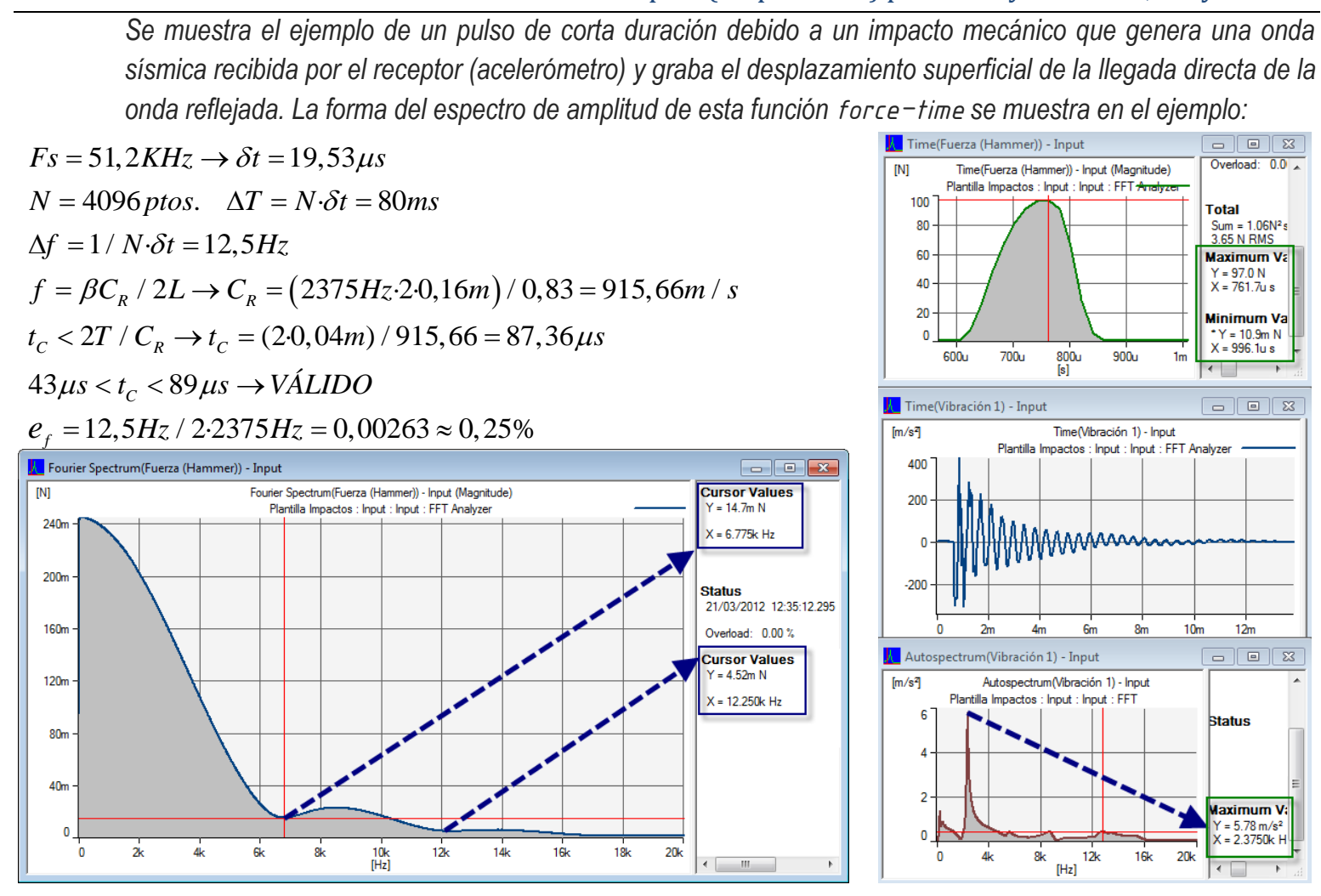

(Fig. 73). Ejemplo de I-Eco en probetas (Detalle de señal de impacto, espectros Fourier, respuesta).

Vemos que el espectro de amplitud se aproxima al eje cero para las frecuencias $6775 \mathrm{~Hz}$ y $12550 \mathrm{~Hz}$. Este espectro representa el contenido de la frecuencia de la fuerza de impacto. Esto significa que si el tiempo de contacto es $\mathbf{8 7 , 3 6 \mu}$ s, la frecuencia máxima utilizable es $1 /\left(\mathbf{4 0} \cdot \mathbf{1 0}{ }^{-6}\right)$ $\approx \mathbf{1 1 , 5} \mathrm{kHz}$. El punto clave es que para excitar la frecuencia predominante en una prueba de impacto-eco, la máxima frecuencia utilizable contenida en el impacto debe ser mayor que la frecuencia del modo de vibración, así el ensayo se hizo con $\mathrm{F}_{\mathrm{NYQ}}$ : 20KHz y N:4096ptos.

Así, a la edad temprana de 8-9horas de su fabricación, se propagaban las ondas superficiales a través del mortero con una velocidad de $915 \mathrm{~m} / \mathrm{s}$. Este ensayo se repite de 2 a 3 veces y se promedian los resultados no sobrepasando el error sistemático permitido. A continuación se muestran los resultados para dicho mortero de $8 \mathrm{~h}$ a 24 horas: 


\begin{tabular}{|c|c|c|c|c|c|c|c|c|c|c|c|c|c|c|c|c|c|c|c|c|c|}
\hline & & & & & & Net & 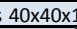 & 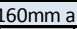 & & artillo & $x<8<0$ & 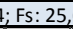 & $\mathrm{KHz} ; \mathrm{N}: 32$ & 200; Proce & edimiento & B (Impac & cto Eco) & & & & \\
\hline & \begin{tabular}{|c|} 
Lines \\
[ptos]
\end{tabular} & \begin{tabular}{|c|} 
Span \\
(Band \\
width) \\
[Hz] \\
\end{tabular} & $\begin{array}{l}\text { Sampling } \\
\text { frequency } \\
\text { (Fs) [Hz] } \\
\end{array}$ & \begin{tabular}{|c|} 
Nyquist \\
frequency \\
(Fs/2) [Hz]
\end{tabular} & $\begin{array}{l}\text { Sampled } \\
\text { points (N) }\end{array}$ & $\begin{array}{c}\text { Sampling } \\
\text { Interval (סt) [s] }\end{array}$ & 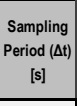 & $\begin{array}{c}\text { Frequency } \\
\text { interval } \\
(\Delta f)[H z]\end{array}$ & $\begin{array}{c}\text { Average } \\
\text { Contact time } \\
\text { (tc) [s] }\end{array}$ & \begin{tabular}{|c|}
$\begin{array}{c}\text { Thickness } \\
\text { mode } \\
\text { frequency }[\mathrm{Hz}] \\
\{\mathrm{f}=\mathrm{V} / 2 \mathrm{~T}\}\end{array}$ \\
\end{tabular} & \begin{tabular}{|c|} 
Round-trip \\
travel time \\
$C \mathrm{Cp}[\mathrm{m} / \mathrm{s}]$ \\
$\{\mathrm{Cp} \leq 2 \mathrm{~T} / \mathrm{tc}\}$ \\
\end{tabular} & \begin{tabular}{|l||} 
Thicknes \\
$s$ (T) [m]
\end{tabular} & \begin{tabular}{|c||} 
Separación \\
impacto- \\
receptor \\
$(X<0,4 T)[\mathrm{m}]$ \\
\end{tabular} & \begin{tabular}{||l||}
$\begin{array}{l}\text { Frecuencia } \\
\text { ECO (Hz) }\end{array}$ \\
\end{tabular} & $\begin{array}{c}\text { Average Eco } \\
\text { frequency } \\
\text { (Hz) }\{f E C O\}\end{array}$ & \begin{tabular}{|l|}
$\begin{array}{r}\text { Frecuencia } \\
\text { resonancia } \\
\text { [Peak][Hz) }\end{array}$ \\
\end{tabular} & \begin{tabular}{|c|} 
Average \\
Resonant \\
frequency \\
(Hz) $\{$ fmax\} \\
\end{tabular} & \begin{tabular}{|c|} 
Systematic \\
error \\
(R.freq.) \\
\{ef=Af/2\} \\
\end{tabular} & $\begin{array}{c}\text { S-Wave } \\
\text { Speed }(C p) \\
{[\mathrm{m} / \mathrm{s}]} \\
\end{array}$ & \begin{tabular}{|c|} 
P-Wave \\
Speed (CP) \\
{$[\mathrm{m} / \mathrm{s}]$} \\
$\{2 \cdot \mathrm{fr} \cdot \mathrm{T} / \mathrm{b}\}$ \\
\end{tabular} & $\begin{array}{c}R \text {-Wave } \\
\text { Speed(Vr) } \\
{[\mathrm{m} / \mathrm{s}]} \\
\{\mathrm{V}=1.79 \mathrm{Vp}\} \\
\end{array}$ \\
\hline$\infty$ & 1600 & 12800 & 32768 & 16384 & 4096 & $3.052 \mathrm{E}-05$ & 0.125 & 8.00 & $2.16 \mathrm{E}-05$ & 46226.24 & 3698.1 & 0.04 & 0.016 & \begin{tabular}{|l|}
1904 \\
1920
\end{tabular} & 1912 & $\begin{array}{l}4336 \\
4368\end{array}$ & 4352 & 2.09E-03 & $\underline{884.7}$ & 1450.43 & $\underline{812.24}$ \\
\hline 郭 1 & 1600 & 20000 & 51200 & 25600 & 4096 & $1.953 \mathrm{E}-05$ & 0.080 & 12.50 & 4.57E-05 & 21864.27 & 1749.1 & 0.04 & 0.016 & $\begin{array}{l}2352 \\
2384\end{array}$ & 2368 & 5280 & 5336 & $2.64 \mathrm{E}-03$ & 1084.81 & 1778.38 & 995.89 \\
\hline$\equiv$ & 1600 & 20000 & 51200 & 25600 & 4096 & $1.953 \mathrm{E}-05$ & 0.080 & 12.50 & 3.97E-05 & 25182.91 & 2014.6 & 0.04 & 0.016 & \begin{tabular}{|l|}
2688 \\
2512 \\
\end{tabular} & 2600 & $\begin{array}{l}6064 \\
6096 \\
\end{array}$ & 6080 & $2.40 \mathrm{E}-03$ & 1236.07 & 2026.34 & 1134.75 \\
\hline : & 1600 & 20000 & 51200 & 25600 & 4096 & | $1.953 \mathrm{E}-05$ & 0.080 & 12.50 & 3.53E-05 & 28292.26 & 2263.4 & 0.04 & 0.016 & $\begin{array}{l}3088 \\
3136\end{array}$ & 3112 & $\begin{array}{l}6992 \\
7200\end{array}$ & 7096 & $2.01 \mathrm{E}-03$ & 1442.62 & 2364.95 & 1324.37 \\
\hline$\Xi$ & 1600 & 20000 & 51200 & 25600 & 4096 & | $1.953 \mathrm{E}-05$ & 0.080 & 12.50 & $3.26 \mathrm{E}-05$ & 30708.88 & 2456.1 & 0.04 & 0.016 & \begin{tabular}{|c|}
3450 \\
3337.5 \\
\end{tabular} & 3394 & $\begin{array}{l}7625 \\
7563\end{array}$ & 7594 & $1.84 \mathrm{E}-03$ & 1543.87 & $\underline{2530.93}$ & $\underline{1417.32}$ \\
\hline 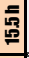 & 1600 & 20000 & 51200 & 25600 & 4096 & $1.953 \mathrm{E}-05$ & 0.080 & 12.50 & 3.12E-05 & 32026.12 & 2562.1 & 0.04 & 0.016 & $\begin{array}{l}3462 \\
3424 \\
\end{array}$ & 3443 & $\begin{array}{l}7632 \\
7872 \\
\end{array}$ & 7752 & $1.82 \mathrm{E}-03$ & 1575.99 & 2583.59 & 1446.81 \\
\hline $\bar{\nabla}$ & 1600 & 20000 & 51200 & 25600 & 4096 & $1.953 \mathrm{E}-05$ & 0.080 & 12.50 & 3.01E-05 & 33237.49 & 2659.0 & 0.04 & 0.016 & $\begin{array}{l}3696 \\
3920 \\
\end{array}$ & 3808 & 8320 & 8288 & $1.64 \mathrm{E}-03$ & 1684.96 & 2762.22 & $\underline{1546.85}$ \\
\hline 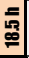 & 1600 & 20000 & 51200 & 25600 & 4096 & $1.953 \mathrm{E}-05$ & 0.080 & 12.50 & $2.78 \mathrm{E}-05$ & 35972.48 & 2871.8 & 0.04 & 0.016 & \begin{tabular}{|c|}
4050 \\
4112.5 \\
\end{tabular} & 4081 & $\begin{array}{l}9138 \\
9200\end{array}$ & 9169 & $1.53 \mathrm{E}-03$ & 1864.07 & 3055.84 & 1711.27 \\
\hline సิ & 1600 & 20000 & 51200 & 25600 & 4096 & $\mid 1.953 \mathrm{E}-05$ & 0.080 & 12.50 & 2.70E-05 & 37072.47 & 2965.8 & 0.04 & 0.016 & $\begin{array}{l}4064 \\
4120\end{array}$ & 4092 & 9256 & 9360 & $1.53 \mathrm{E}-03$ & 1902.90 & 3119.50 & 1746.92 \\
\hline ฟิ & 1600 & 20000 & 51200 & 25600 & 4096 & $1.953 \mathrm{E}-05$ & 0.080 & 12.50 & $2.54 \mathrm{E}-05$ & 39435.00 & 3154.8 & 0.04 & 0.016 & $\begin{array}{l}4250 \\
4313 \\
\end{array}$ & 4282 & \begin{tabular}{|c|}
9912.5 \\
9813 \\
\end{tabular} & 9863 & $1.46 \mathrm{E}-03$ & $\underline{2005.10}$ & 3287.06 & $\underline{1840.75}$ \\
\hline స्ञ & 1600 & 20000 & 51200 & 25600 & 4096 & $1.953 \mathrm{E}-05$ & 0.080 & 12.50 & $2.44 \mathrm{E}-05$ & 41037.81 & 3283.0 & 0.04 & 0.016 & \begin{tabular}{|c|}
4425 \\
4487.5 \\
\end{tabular} & 4456 & $\begin{array}{l}10013 \\
10288 \\
\end{array}$ & 10151 & $.40 \mathrm{E}-03$ & $\underline{2050.71}$ & $\underline{3361.82}$ & $\underline{1882.62}$ \\
\hline
\end{tabular}

(Fig. 74). Resultados I-Eco (mortero a/c:0,5; f/c:2,25 a edades tempranas).

En base a estudios analíticos, se encontró que con espaciados de $0.2<s<0.5$ de la profundidad que queremos analizar se obtuvieron resultados aceptables (N.J. CARINO Y SANSALONE recomiendan $s<40 \%$ de la profundidad).

Como comprobación del método se muestran las gráficas que relacionan los resultados de una losa tricapa por cada una de las técnicas END propuestas de velocidad de fase a edad temprana. Se observa que el ensayo AEOS a edad temprana muestra una curva de crecimiento de la velocidad paralela al resto de métodos, pero con valores ligeramente inferiores, que a partir de las 24 horas empiezan a igualarse, sobre todo en morteros con relaciones a/c $\approx 0,5-0,6$ :
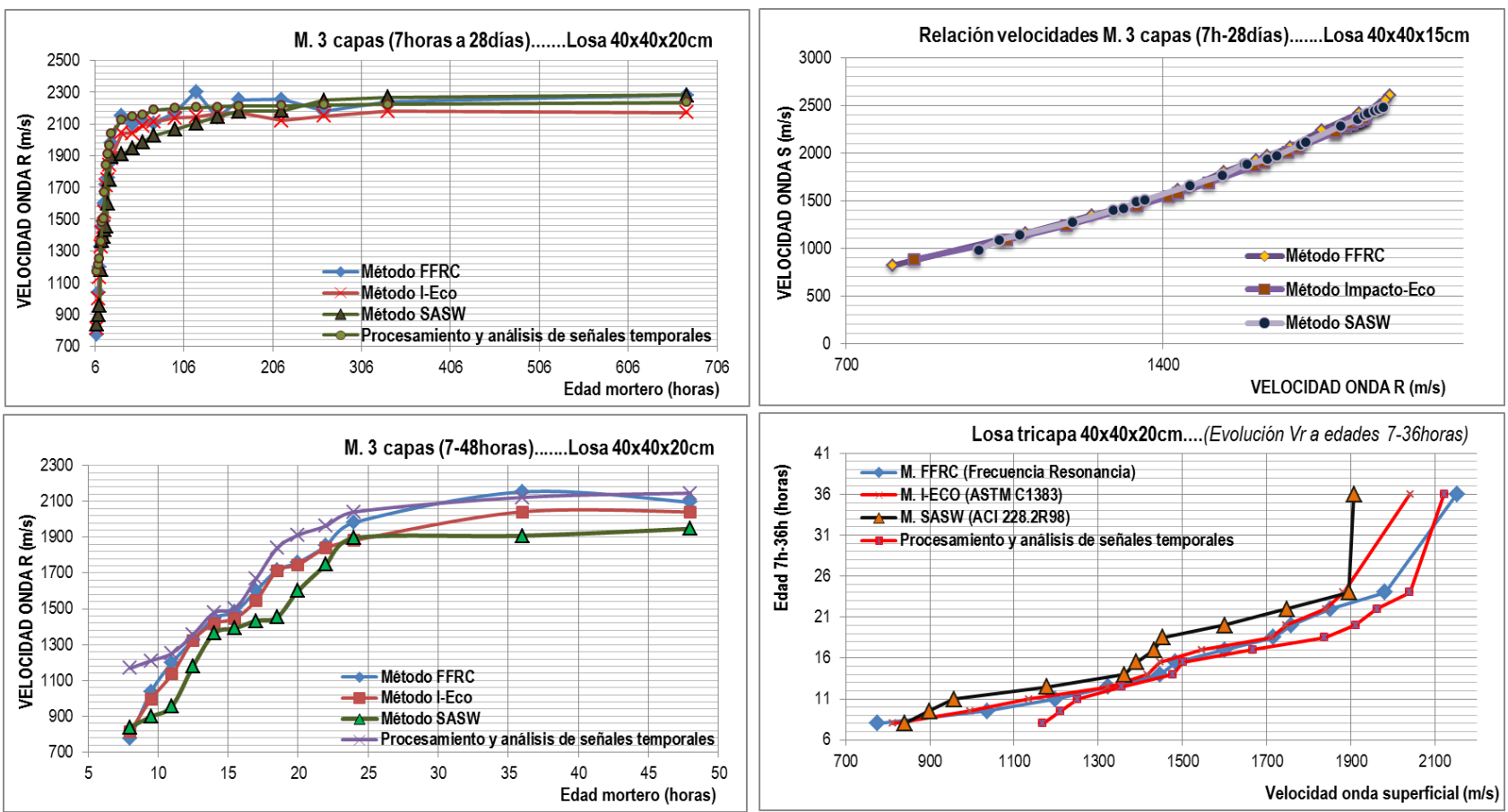

(Fig. 75). Comparativa de métodos AEOS, FFRC e I-Eco para una Losa TRI-capa de 40x40x(10+5+5)cm de mortero inferior

1;0,6;3,25 de 56días; central (1;0,5;2,25) de 14 días; superior de 8horas de dosif. a/c:0,5; f/c:2,25 a edades tempranas. 
Método de la frecuencia de resonancia (FFRC).

(ASTM C215-02 Fundamental Transverse, Longitudinal \& Torsional Resonant Frequencies) (ASTM E1876-09 Dynamic Young's Modulus, Shear Modulus \&Poisson's ratio by Impulse Excitation)

(UNE-EN ISO 12680-1/05. Determinación del modulo de Young dinámico por excitación de la vibración por impulso)

El método de ensayo cubre la medición de las frecuencias fundamentales transversales de los prismas de mortero $40 \times 40 \times 160 \mathrm{~mm}$, a fin de calcular el módulo dinámico de Elasticidad, $\epsilon_{d}$ el coeficiente de Poisson, $v$ y el módulo de rigidez transversal, G. El tamaño de la muestra fue elegido conforme a la norma ASTM C215-02 con una proporción 3<longlespesor 5.

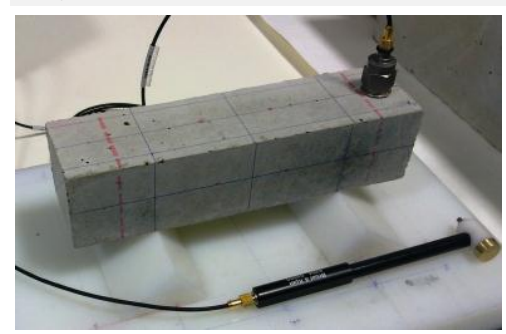

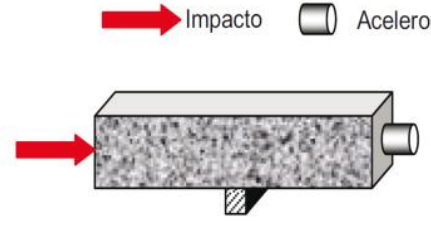

Módulo longitudinal

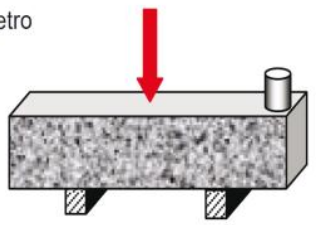

Módulo transversal

(Fig. 76). Configuración de un ensayo típico mediante el método de Frecuencia Resonancia. Detalle equipo.

PRINCIPIO.

Una probeta de geometría adecuada se excita mecánicamente con un solo golpe elástico y su frecuencia de resonancia fundamental se determina. Un acelerómetro de contacto recibe las vibraciones mecánicas de la probeta resultantes de la excitación y las transforma en señales. Los soportes de la probeta, las posiciones del impulso y los puntos de recogida de señal se seleccionan para inducir y medir un modo de vibraciones transitorias específico, es decir, el modo de flexión. Las señales se analizan en el analizador Lan XI B\&K que suministra datos sobre el periodo de vibración de la probeta y determina la frecuencia de resonancia.

Debido a que la frecuencia de resonancia de la vibración está relacionada con la rigidez, aunque la relación no es lineal, una disminución en la frecuencia pico del espectro de amplitud corresponde a una pérdida de rigidez, ya que la estructura proporciona menos resistencia al movimiento.

La frecuencia de resonancia, interesa como parámetro principal en los ensayos de este método, ya que me relaciona las propiedades elásticas y la forma del elemento, con la presencia y la gravedad de defectos internos o la pérdida de velocidad de onda. La ASTM C215 proporciona como determinar las frecuencias fundamentales transversales y longitudinales de los modelos de mortero que se fabrican para cada amasada de mortero propuesta en el trabajo.

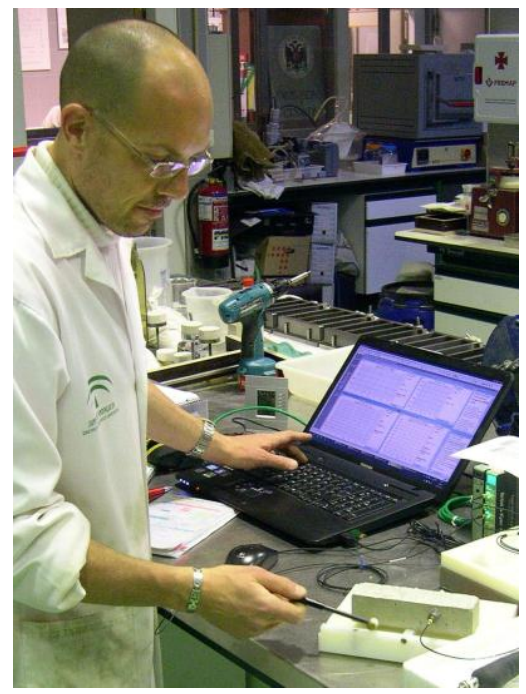

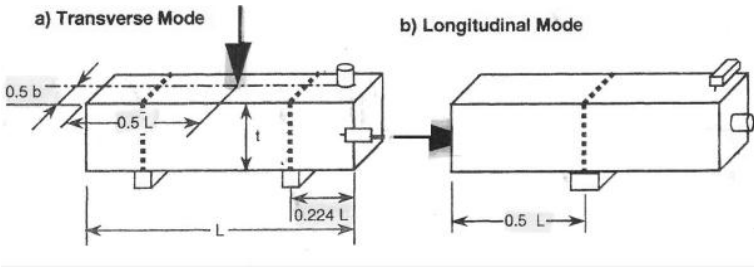

(Fig. 77). Esquema de la disposición FFRC para determinar la $f_{-}$resonancia.

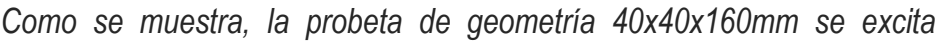
mecánicamente con un golpe elástico del martillo calibrado y su frecuencia de resonancia fundamental se determina como un pico dominante en el espectro de amplitud captado por un acelerómetro variando su posición en los nodos de la estructura (max. Vibración) según el tipo de módulo deseado. 
Los soportes de la probeta, las posiciones del impulso y los puntos de recogida de señal se seleccionan para inducir y medir un modo de vibración transitorio específico. La frecuencia de resonancia, dimensiones y masa cumplen los criterios de la Norma ASTM C215.
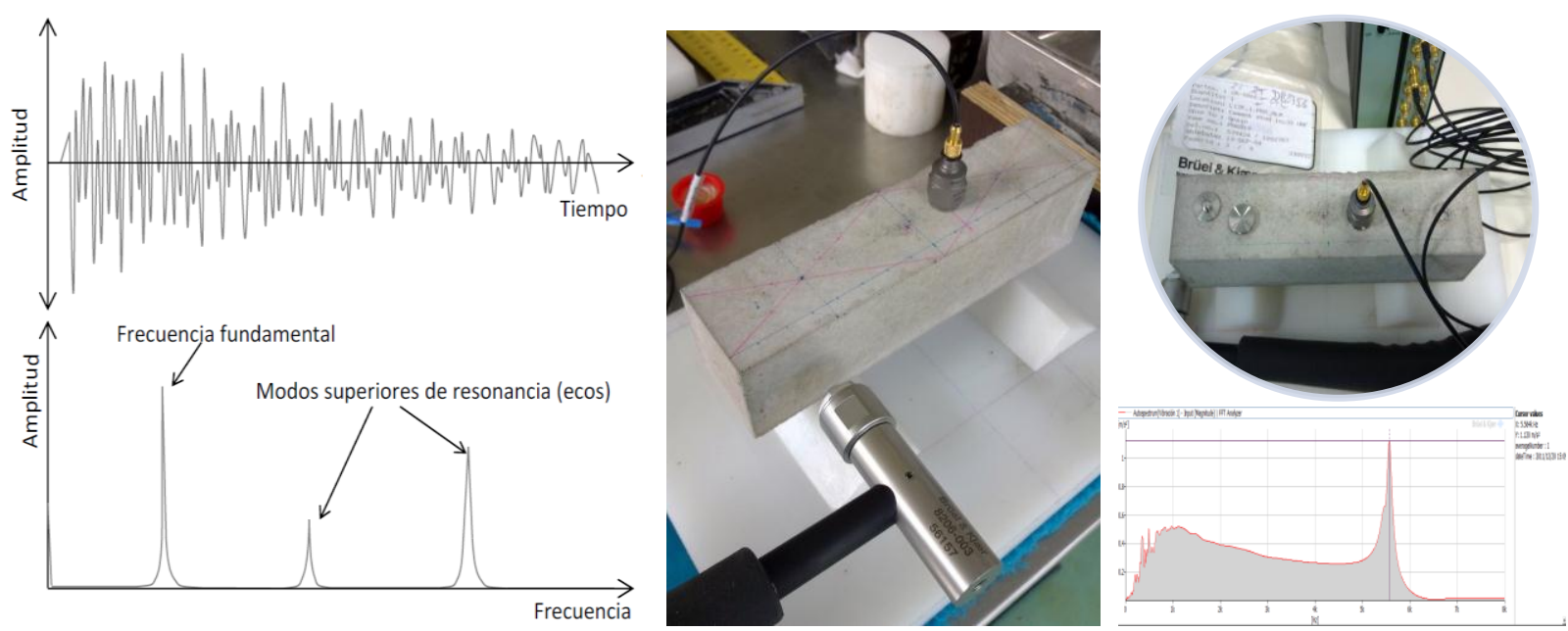

(Fig. 78). Montaje experimental de los ensayos en probetas prismáticas. Ejemplo de espectro y frecuencia de resonancia.

D El espécimen se coloca sobre unos soportes de polietileno blanco o poliestireno extrusionado de $\rho=35 \mathrm{~kg} / \mathrm{m}^{3}$ de lado $3 \mathrm{~cm}$, en forma piramidal para minimizar el punto de contacto como base rígida del mismo material y apoyado el conjunto en su contacto con el entorno sobre una almohadilla de poliuretano expandido por lo que puede vibrar en libertad (condiciones de contorno).

Además de la frecuencia de resonancia, el coeficiente de amortiguación $\eta$ del material y el módulo de elasticidad dinámico se determinan así: $\eta=\left(f_{2}-f_{1}\right) / f \quad ; \quad E_{\text {din }}=C \cdot W \cdot f^{2} \quad ; \quad C=0,965 \cdot 10^{-6} \cdot\left(l^{3} / b \cdot h^{3}\right) \cdot T$ donde Ed=módulo dinámico (MPa); $\mathrm{W}=$ peso del espécimen $(\mathrm{kg}) ; \mathrm{f}=$ frecuencia de resonancia transversal $(\mathrm{Hz}) ; \mathrm{I}=$ longitud; $\mathrm{h}=$ profundidad; $\mathrm{b}=$ ancho del espécimen (m). El factor T=r/I (radio de giro/longitud).

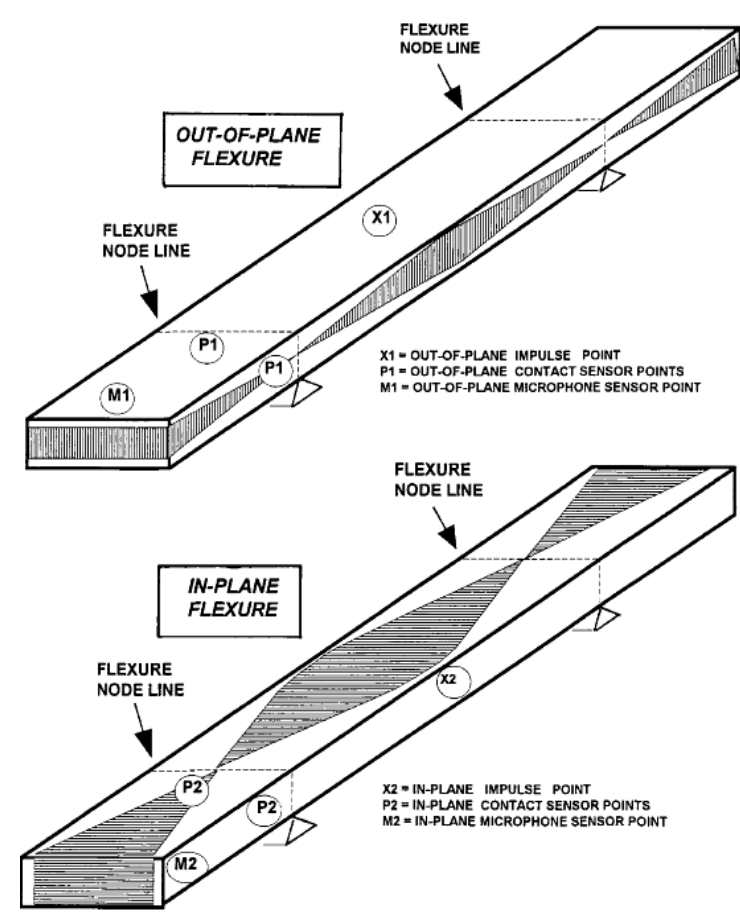

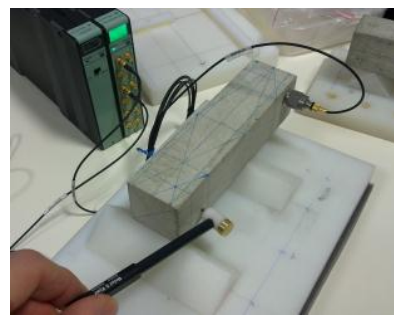

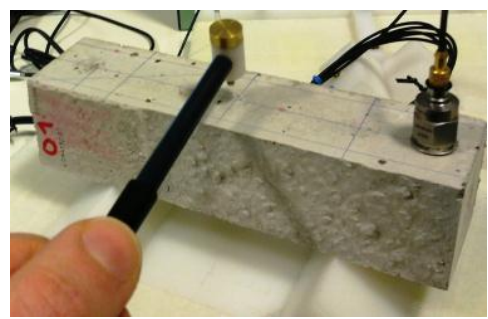

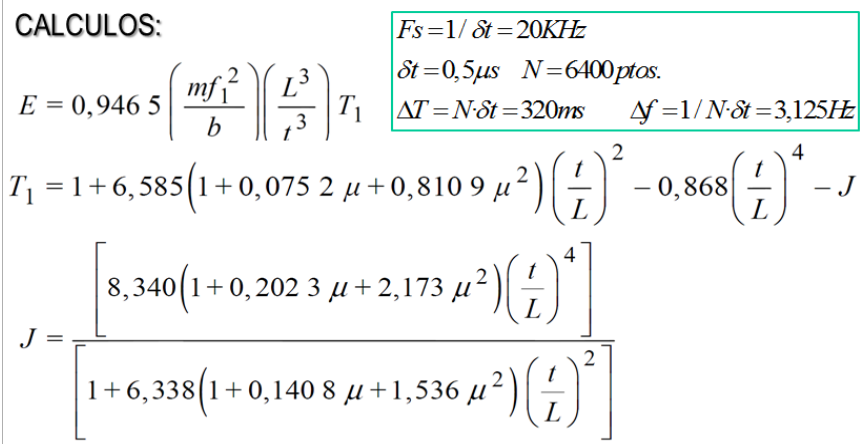

$\boldsymbol{m}$ : masa de la probeta, en gramos; $\boldsymbol{b}$ : anchura $\mathrm{mm} ; \boldsymbol{L}$ : longitud $\mathrm{mm} ; \boldsymbol{t}$. espesor $\mathrm{mm}$; f1: frecuencia de resonancia; T1: factor de corrección del modo fundamental para considerar el espesor finito de la pieza; $\boldsymbol{\mu}$ : Poisson.

(Fig. 79). Detalle de cálculos propuestos en la norma ASTM E1876/09 Dynamic Young's Modulus, Shear Modulus \&Poisson's ratio by Impulse Excitation. 
Metodología. Procedimiento de aplicación.

La ventaja de estas técnicas no destructivas es la facilidad de aplicación sobre probetas normalizadas basadas en el análisis de la frecuencia fundamental de resonancia en el ámbito de los morteros, considerando exclusivamente sus dimensiones y masa previas a la excitación de la vibración por impacto. Una vez finalizados los ensayos se pueden someter a la prueba de rotura conforme dictan las normas UNE EN 196/1:2005 y UNE EN 1015/11:1999 para determinación de la resistencia a flexión/compresión del cemento/mortero endurecido, de manera que estos resultados nuevamente son contrastados y validados. Finalmente se realizaron unas tablas de cálculo que implementan todo el proceso, arrojando los parámetros mecánicos y dinámicos del material y la desviación estándar entre métodos, justificando sólo aquellos con un margen de error sistemático inferior al $2 \%$ con un promedio de 3 a 5 registros por ensayo y método.

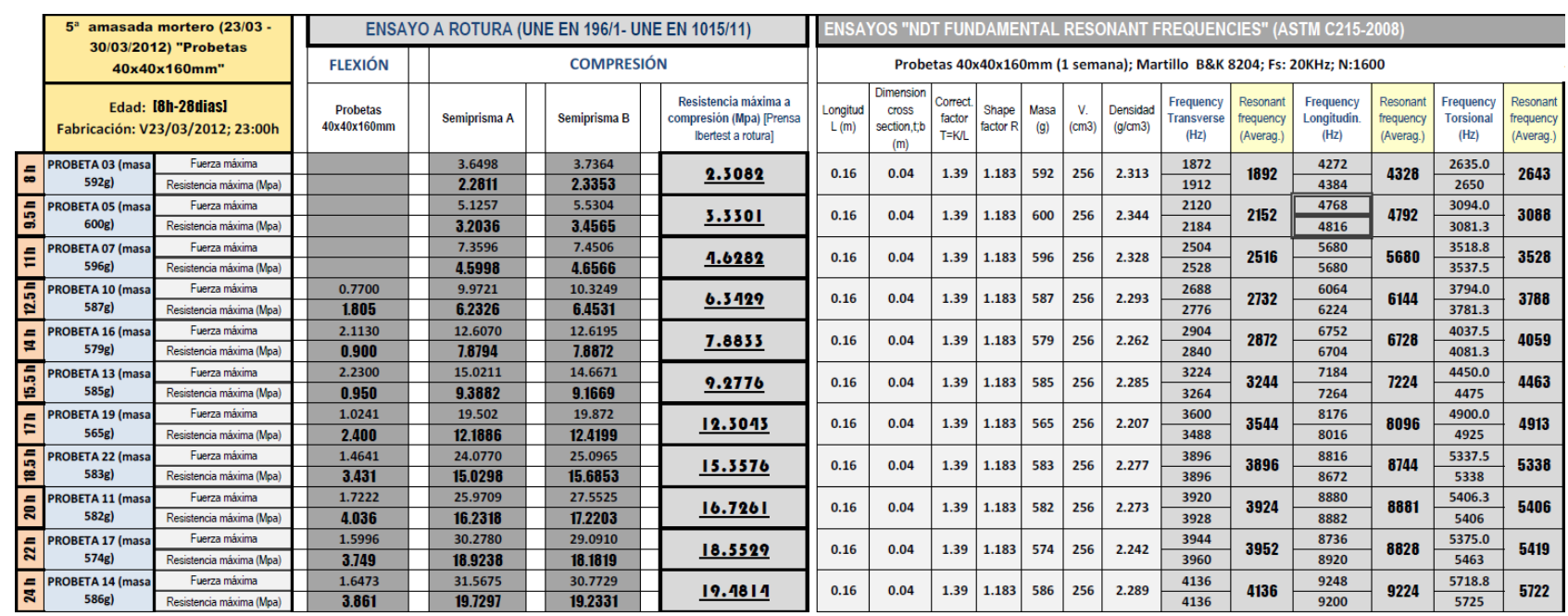

(Fig. 80). Tabla tipo con entrada de datos y salida de resultados de ensayos a rotura y método FFRC en probetas de

mortero.

Se muestra el ejemplo correspondiente a una probeta de $4 \times 4 \times 16 \mathrm{~cm}$ de un mortero fabricado en el laboratorio para la caracterización, desarrollo y control de la calidad del material, determinando sus resistencias mecánicas, módulos de elasticidad estáticos, dinámicos, rigidez transversal, coeficiente de Poisson y velocidad de ondas $P, S$ y Rayleigh, aplicables posteriormente al ensayo AEOS para su verificación.
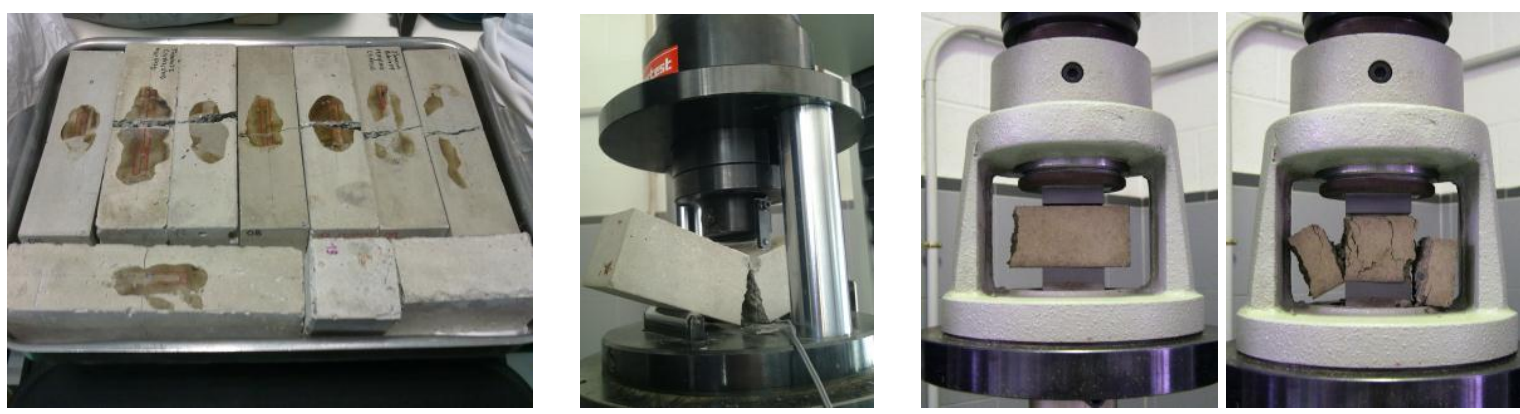

(Fig. 81). Ensayos a rotura posteriores a FFRC e I-ECO en probetas de mortero $4 \times 4 \times 16 \mathrm{~cm}$ a cada edad temprana (7h24h). Amasada (1/0,4/2,70). En cada ensayo se ejecutan 2-3 probetas promediando los resultados. 
(VII). Metodología de análisis. Técnicas paralelas END previstas

Ejemplo: Amasada 30/03/2012. Edades: 8h-24h. Dosificación: 1/0,4/2,70. Se fabricaron 8 moldes triples (24 probetas) para ensayos a FFRC, I-E y Rotura.

\section{* Ensayo Frecuencia-Resonancia (FFRC).}

La tarea principal es la obtención del modo fundamental de la frecuencia propia de resonancia, mediante la aplicación de un impulso instantáneo (golpeo) sobre la probeta y la recogida de la señal o espectro de frecuencias que este golpeo produce. La señal se analiza mediante la transformada rápida de Fourier (FFT):
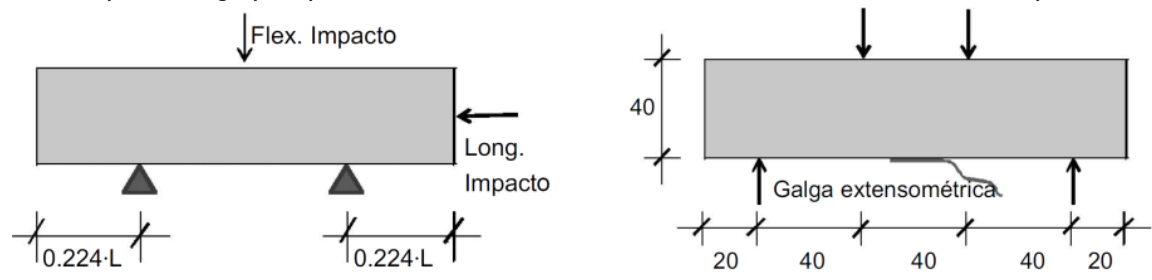

(Fig. 82). (Izq). Esquema de la disposición de apoyos y zonas de impacto en FFRC. (Der.) Esquema en rotura.

Configuración de parámetros del analizador FFTy trigger ("disparo") de impacto superficial.

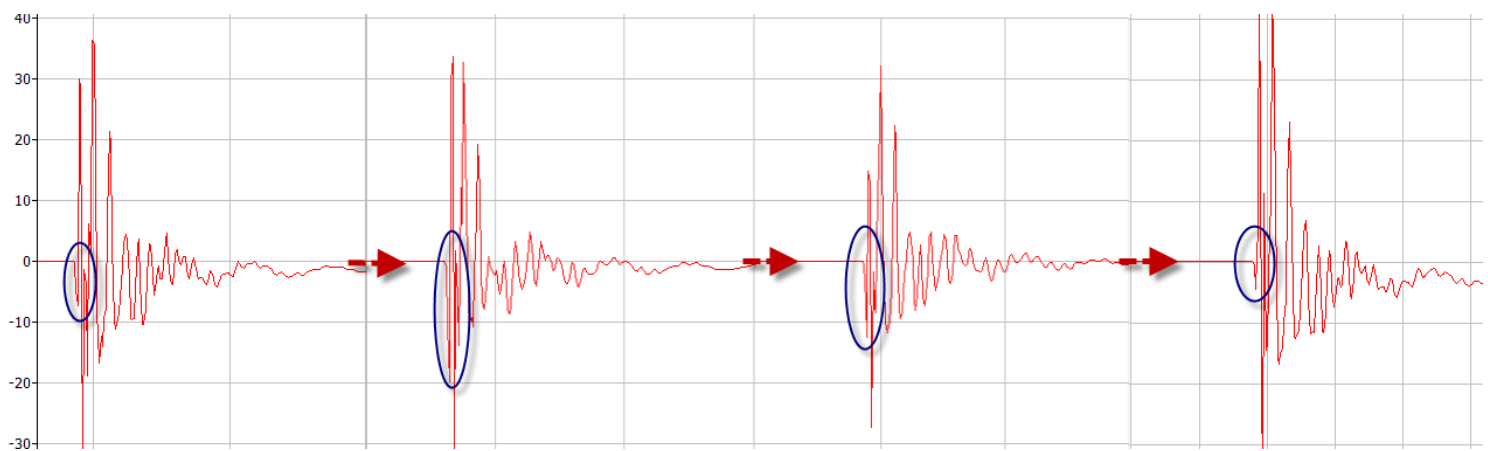

(Fig. 83). Superposición de registros de disparo para configurar la señal de impacto ("triggers")

Análisis del espectro de amplitudes y anotación de la frecuencia pico del autoespectro:
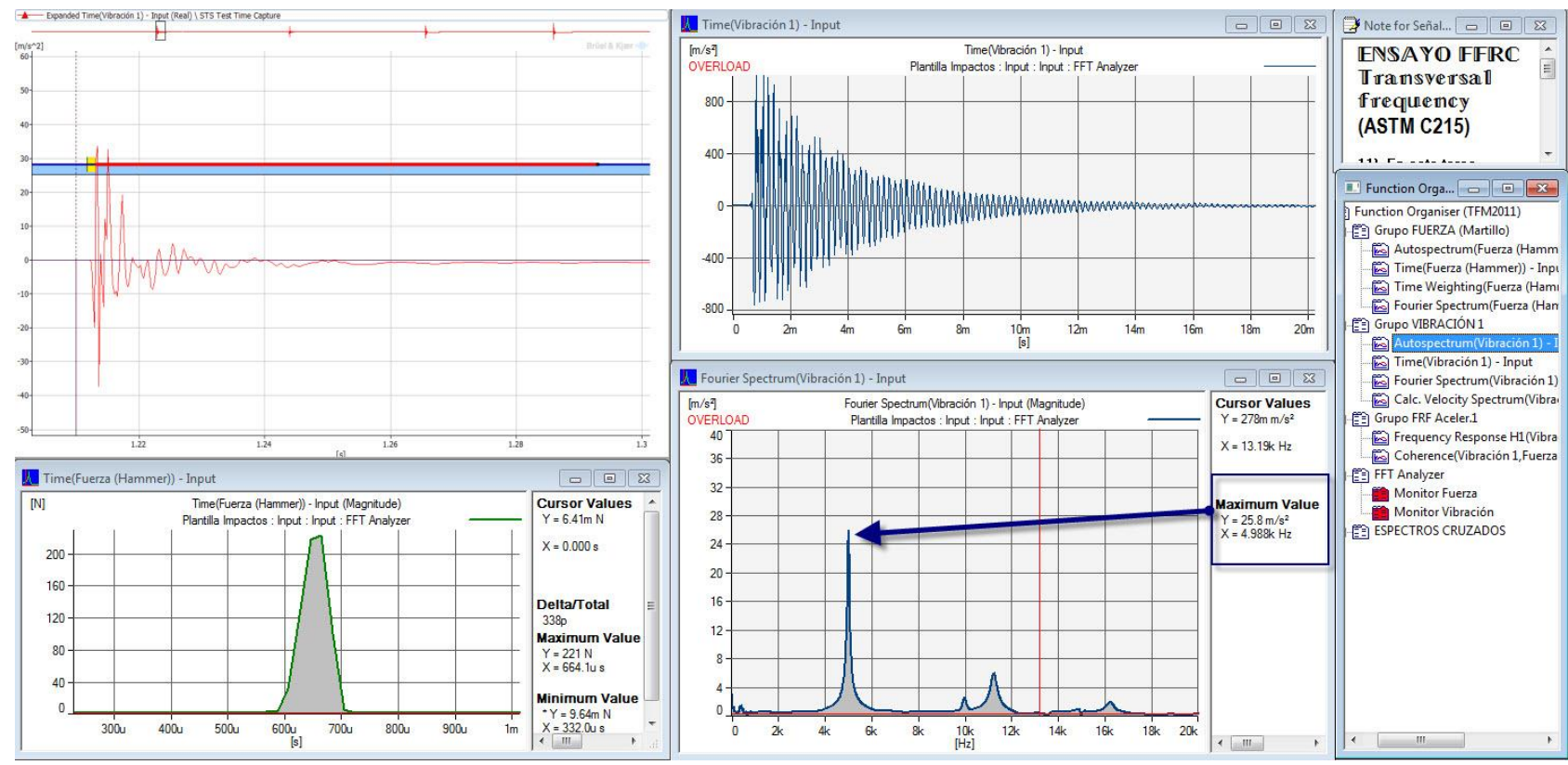

(Fig. 84). Configuración en PULSEv.16 de señal generada para Fs:20KHz y N:1024 ptos minimo en ensayos FFRC.

$>$ Repetimos el test de 2 a 3 veces y se obtiene el promedio de la frecuencia de resonancia (con desviación $<2 \%)$. En caso de error se repiten los ensayos hasta concordancia. Aplicamos las fórmulas 
asociadas al método y obtenemos los valores dinámicos de los módulos para correlacionarlos con los obtenidos en rotura variabilidad a edad temprana:

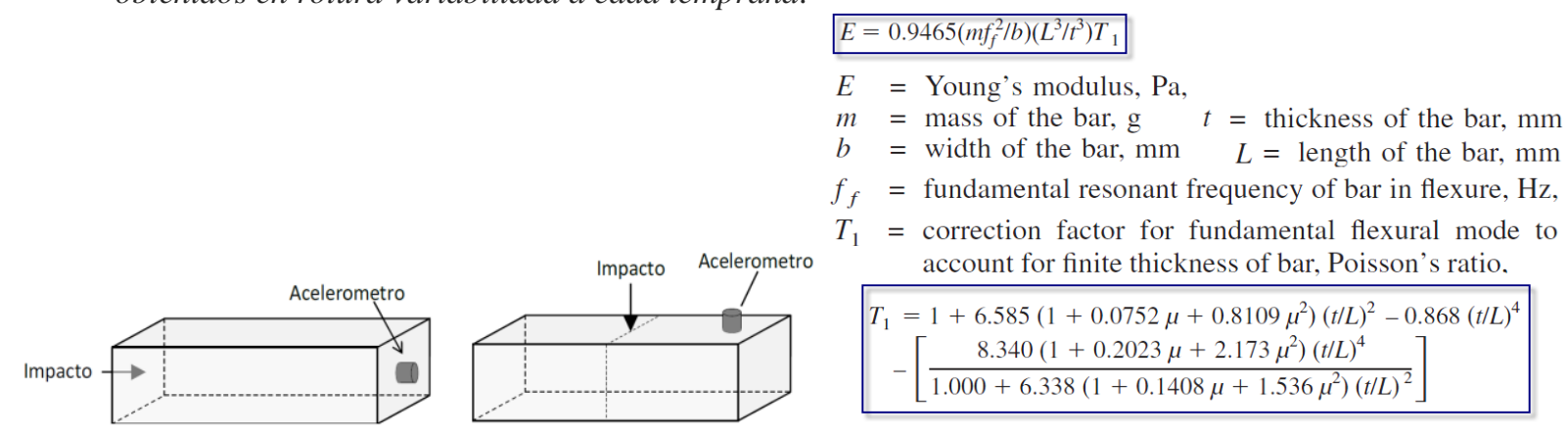

> Se asignan las frecuencias de resonancia en la tabla, y mediante el promedio de 3 probetas deducimos el resto de parámetros del material (coef. Poisson, módulo de rigidez y amortiguamiento). Mediante teoría de ondas relacionamos las velocidades de propagación con módulos obtenidos:

$$
\begin{aligned}
& A S T M M_{-} C 215: E_{D_{T}}=0,9464\left(l^{3} T / b t^{3}\right) \cdot m \cdot \omega_{r}^{2} \quad E_{D L}=4 \cdot(l / b t) \cdot m \cdot \omega_{r}^{2} \quad G_{D}=4 \cdot\left(l \cdot R / b^{2}\right) \cdot m \cdot \omega_{r T O R S I O N}^{2} \quad E=\mu=(E / 2 G)-1
\end{aligned}
$$

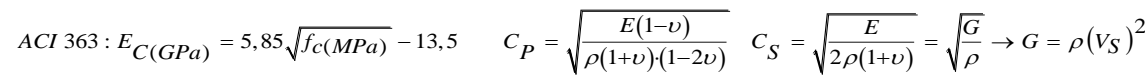

$$
\begin{aligned}
& \frac{C_{S}}{C_{P}}=\sqrt{\frac{1-2 v}{2(1-v)}} \quad 0<v<0,5 \rightarrow C s \approx 0,61 C_{P} \quad \frac{C_{R}}{C_{S}}=\frac{0,87+1,12 v}{1+v} \quad 0,87<\frac{C_{R}}{C_{S}}<0,96 \rightarrow C_{R} \approx 0,92 C_{S} \quad C_{R} \approx 0,56 C_{P}
\end{aligned}
$$

\begin{tabular}{|c|c|c|c|c|c|c|c|c|c|c|c|c|c|c|c|c|c|c|c|}
\hline & \multirow{2}{*}{\multicolumn{2}{|c|}{$6^{4}$ amasadta mortero $[1 / 0,4 / 2,70]$}} & \multicolumn{4}{|c|}{ ENSAYO A ROTURA (UNE EN 196/1- UNE EN 1015/11) } & \multicolumn{13}{|c|}{ ENSAYOS "NDT FUNDAMENTAL RESONANT FREQUENCIES" (ASTM C215 } \\
\hline & & & \multirow{2}{*}{$\begin{array}{c}\text { FLEXIÓN } \\
\begin{array}{c}\text { Probetas } \\
\text { 40x40x160mm }\end{array}\end{array}$} & \multicolumn{3}{|c|}{ COMPRESIÓN } & & & & & & & & & & & & & \\
\hline & $\begin{array}{r}\text { Edad } \\
\text { Fabricacic }\end{array}$ & $\begin{array}{l}\text { [8h-28dilasl } \\
\text { n: V30/03/2012; } \\
\text { 23:00h }\end{array}$ & & Semiprisma A & Semiprisma B & $\begin{array}{l}\text { Resistencia } \\
\text { compresion } \\
\text { (Mpa) [Roturp] }\end{array}$ & $\begin{array}{l}\text { Longitud } \\
\mathrm{L}(\mathrm{m})\end{array}$ & $\begin{array}{c}\text { Cross } \\
\text { section, } \\
b(m)\end{array}$ & $\begin{array}{l}\text { Correct. } \\
\text { factor } \\
\mathrm{T}=\mathrm{KL} .\end{array}$ & $\begin{array}{l}\text { Shape } \\
\text { factor R }\end{array}$ & $2 \begin{array}{c}\text { Masa } \\
(\mathrm{g})\end{array}$ & $\begin{array}{c}v \\
(\mathrm{~cm} 3)\end{array}$ & $\begin{array}{c}\text { Densida } \\
d \\
(g / \mathrm{m} 3)\end{array}$ & $\begin{array}{c}\text { Frequency } \\
\text { Transverse } \\
(\mathrm{Hz})\end{array}$ & $\begin{array}{l}\text { Resosonan } \\
\text { frequency } \\
\text { (Averag) }\end{array}$ & $\begin{array}{c}\begin{array}{c}\text { Frequency } \\
\text { Longitudin. } \\
(\mathrm{Hz})\end{array}\end{array}$ & $\begin{array}{l}\text { Resonanant: } \\
\text { fequency } \\
\text { (Averag): }\end{array}$ & $\begin{array}{l}\text { Frequency } \\
\text { Torsional } \\
\text { (Hz) }\end{array}$ & $\begin{array}{l}\text { Resonant } \\
\text { frequency } \\
\text { (Averag) }\end{array}$ \\
\hline \multirow{2}{*}{ ఉ } & \multirow{2}{*}{\begin{tabular}{|l} 
PROBETA 3.01 \\
[masa 604g]
\end{tabular}} & Fuerza máxima & 1.2568 & 3.6893 & 3.8992 & \multirow{2}{*}{$\underline{2.3714}$} & \multirow{2}{*}{0.16} & \multirow{2}{*}{0.04} & \multirow{2}{*}{1.39} & \multirow{2}{*}{1.183} & \multirow{2}{*}{604} & \multirow{2}{*}{256} & \multirow{2}{*}{2.359} & 1888 & \multirow{2}{*}{1912} & 4352 & \multirow{2}{*}{4378} & 2712 & \multirow{2}{*}{2344} \\
\hline & & Resistencia máxima (Mpa) & 2.946 & 2.3058 & 2.4370 & & & & & & & & & 1936 & & 4404 & & 1976 & \\
\hline \multirow{2}{*}{ 密 } & \multirow{2}{*}{$\begin{array}{l}\text { PROBETA 3.04 } \\
\text { [masa 607g] }\end{array}$} & Fuerza maxima & 0.4688 & 3.5644 & 5.5582 & \multirow{2}{*}{$\underline{2.8509}$} & \multirow{2}{*}{0.16} & \multirow{2}{*}{0.04} & \multirow{2}{*}{1.39} & \multirow{2}{*}{1.183} & \multirow{2}{*}{ 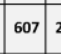 } & \multirow{3}{*}{256} & & 2416 & 2384 & 5424 & 5392 & 3312 & 3328 \\
\hline & & Resistencia máxima (Mpa) & 1.099 & 2.2278 & 3.4739 & & & & & & & & 2.371 & 2352 & 2384 & 5360 & 3392 & 3344 & 3328 \\
\hline$\equiv$ & PROBETA 3.13 & Fuerza maxima & 0.7018 & 8.0131 & 7.9276 & & 0.16 & 0.04 & 139 & 1.183 & 623 & & 2434 & 2712 & 2768 & 6216 & 6226 & 3864 & 3860 \\
\hline$=$ & [masa 623g] & \begin{tabular}{|l|} 
Resistencia máxima (Mpa) \\
\end{tabular} & 1.645 & 5.0082 & 4.9548 & 9813 & & & & & & 236 & & 2824 & & 6236 & & 3856 & \\
\hline$=$ & PROBETA 3.16 & Fuerza maxima & 0.9463 & 11.6214 & 11.4288 & & 0.16 & 0.04 & & & 628 & 256 & 2453 & 3136 & 3168 & 6912 & 6928 & 4240 & 423 \\
\hline \pm & [masa 628g] & \begin{tabular}{|l} 
Resistencia máxima (Mpa) \\
\end{tabular} & 2.218 & 7.2634 & 7.1430 & 7.2032 & 0.16 & 0.04 & 1.39 & 1.183 & $\begin{array}{l}3628 \\
3\end{array}$ & 256 & 2.453 & 3200 & 3168 & 6944 & 6928 & 4224 & 42 \\
\hline$\overline{8}$ & PROBETA 3.25 & Fuerza maxxima & 1.0694 & 13.7272 & 13.1745 & 8.4068 & 0.16 & 0.04 & 1.39 & \begin{tabular}{|l}
1.183 \\
\end{tabular} & $\begin{array}{l}622 \\
3\end{array}$ & 256 & 2.430 & 3362.5 & 3350 & 7575 & 7550 & 4625 & 4638 \\
\hline \pm & [masa 622g] & \begin{tabular}{|l|l} 
Resistencia máxima (Mpa) \\
\end{tabular} & 2.506 & 8.5795 & 8.2341 & 8.4008 & 0.16 & 0.04 & 1.39 & 1.183 & 622 & 256 & 2.430 & 3337.5 & 3090 & 7525 & 1500 & 4650 & 4030 \\
\hline$=$ & PROBETA 3.12 & Fuerza máxima & 1.1349 & 14.4456 & 14.4945 & 9.0438 & 0.11 & 0.04 & 139 & 1183 & 608 & 256 & 2375 & 3440 & 3480 & 7784 & 792 & 4712 & \\
\hline 猺 & [masa 608g] & \begin{tabular}{|l} 
Resistencia máxima (Mpa) \\
\end{tabular} & 2.660 & 9.0285 & 9.0591 & 9.0438 & & & & 1.183 & $\begin{array}{l}3608 \\
3\end{array}$ & & 2.375 & 3520 & 3480 & 7800 & /IYZ & 4736 & 24 \\
\hline$\equiv$ & PROBETA7 & Fuerza maxxima & 1.4580 & 19.325 & 17.772 & 15930 & 0.16 & 0.04 & 139 & 1183 & 617 & 256 & 2410 & 3728 & 3744 & 8275 & 8263 & 5163 & 5188 \\
\hline$=$ & [masa 617g] & Resistencia máxima (Mpa) & 3.417 & 12.0781 & 11.1078 & 1.5830 & & & & & & & & 3760 & 3144 & 8250 & 8263 & 5213 & \\
\hline 齿 & $\begin{array}{l}\text { PROBETA } 19 \\
\end{array}$ & Fuerza maxima & 1.2228 & 22.3807 & 22.8608 & & 0.16 & & & & & 256 & 2406 & 3975 & 4019 & 8931 & 8903 & 5525 & 5531 \\
\hline 象 & [masa 616g] & Resistencia máxima (Mpa) & 2.866 & 13.9879 & 14.2880 & 4.1380 & 0.16 & 0.04 & 1.39 & 1.183 & $\left|{ }^{3}\right| 16$ & 256 & 2.406 & 4063 & 4019 & 8875 & 8903 & 5538 & 5531 \\
\hline$\Xi$ & $\begin{array}{l}\text { PROBETA } 24 \\
\end{array}$ & Fuerza maxima & 1.5093 & 25.2130 & 25.8856 & & & & & & & & & 4104 & 4136 & 9048 & & 5656 & \\
\hline జี & [masa 599g] & \begin{tabular}{|l} 
Resistencia máxima (Mpa) \\
\end{tabular} & 3.537 & 15.7581 & 16.1785 & & 0.16 & 0.04 & 1.39 & 1.183 & 3 & 256 & 2.340 & 4168 & 4136 & 9248 & & 5648 & 5652 \\
\hline$\Sigma$ & PROBETA 27 & Fuerza maxima & 1.8007 & 30.2780 & 30.2043 & 008 & 0.16 & 0.04 & 1.39 & 1.183 & \begin{tabular}{l|l}
615 \\
\end{tabular} & 256 & 402 & 4275 & 4294 & 9725 & $96 / 6$ & 5913 & \\
\hline జ & [masa 615g] & Resistencia maxxima (Mpa) & 4.220 & 18.9238 & $18.8 m$ & 08 & & 0.04 & 1.39 & 1.183 & 615 & 256 & 402 & 4312.5 & 4294 & 9625 & $96 / 5$ & 5938 & 325 \\
\hline$=$ & PROB & Fuerza maxima & 2.1510 & 36.5577 & 35.9890 & & 159 & 039 & 13 & 18 & 671 & 256 & & 4475 & & 9975 & & 6100 & \\
\hline ป & Imas & Resistencia máxima (Mpa) & 5.041 & 22.8486 & & 22.6709 & 159 & 039 & 1.39 & 183 & 621 & 256 & 26 & 4425 & 4450 & 10000 & 88 & 6125 & 3 \\
\hline
\end{tabular}

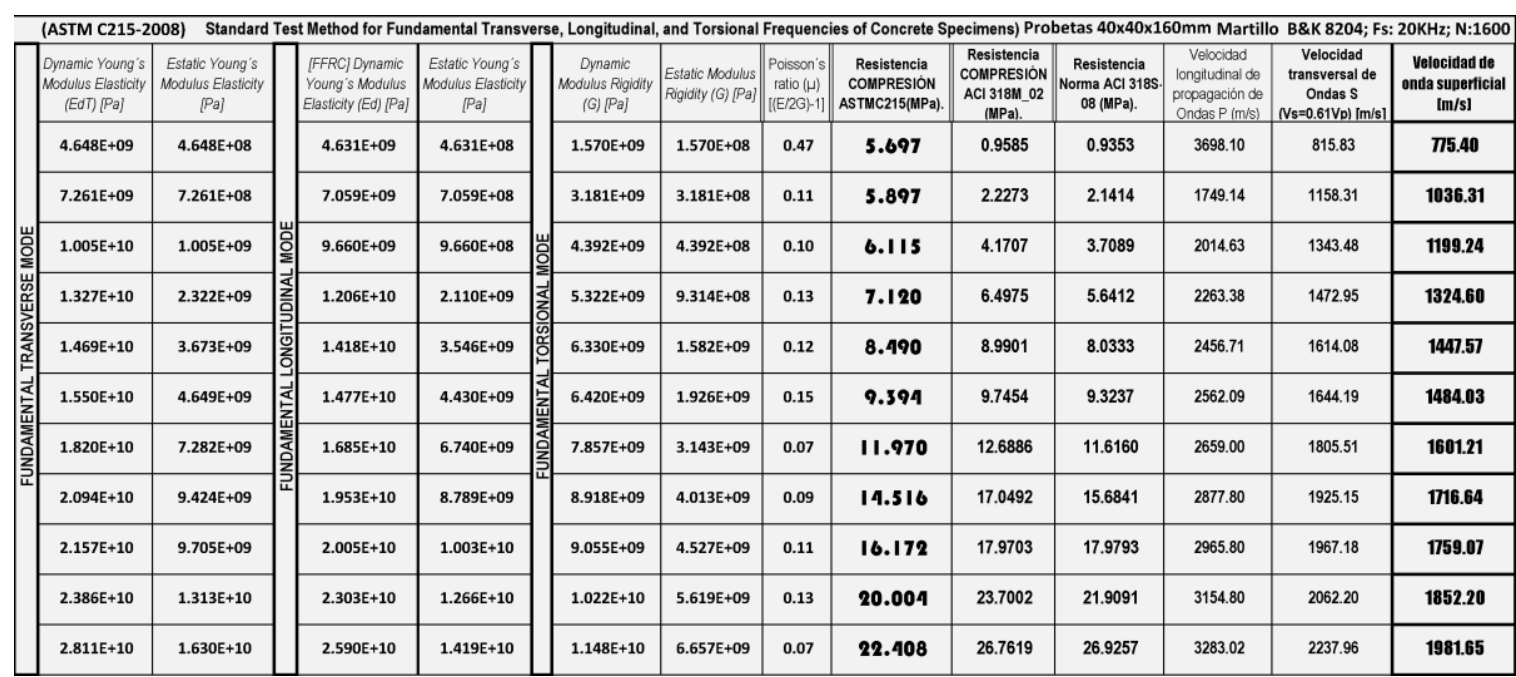

(Fig. 85). Tablas resumen de procesamiento de datos para determinación de módulos mediante FFRC en mortero tricapa. 


\section{Análisis Espectral de Ondas Superficiales (AEOS)}

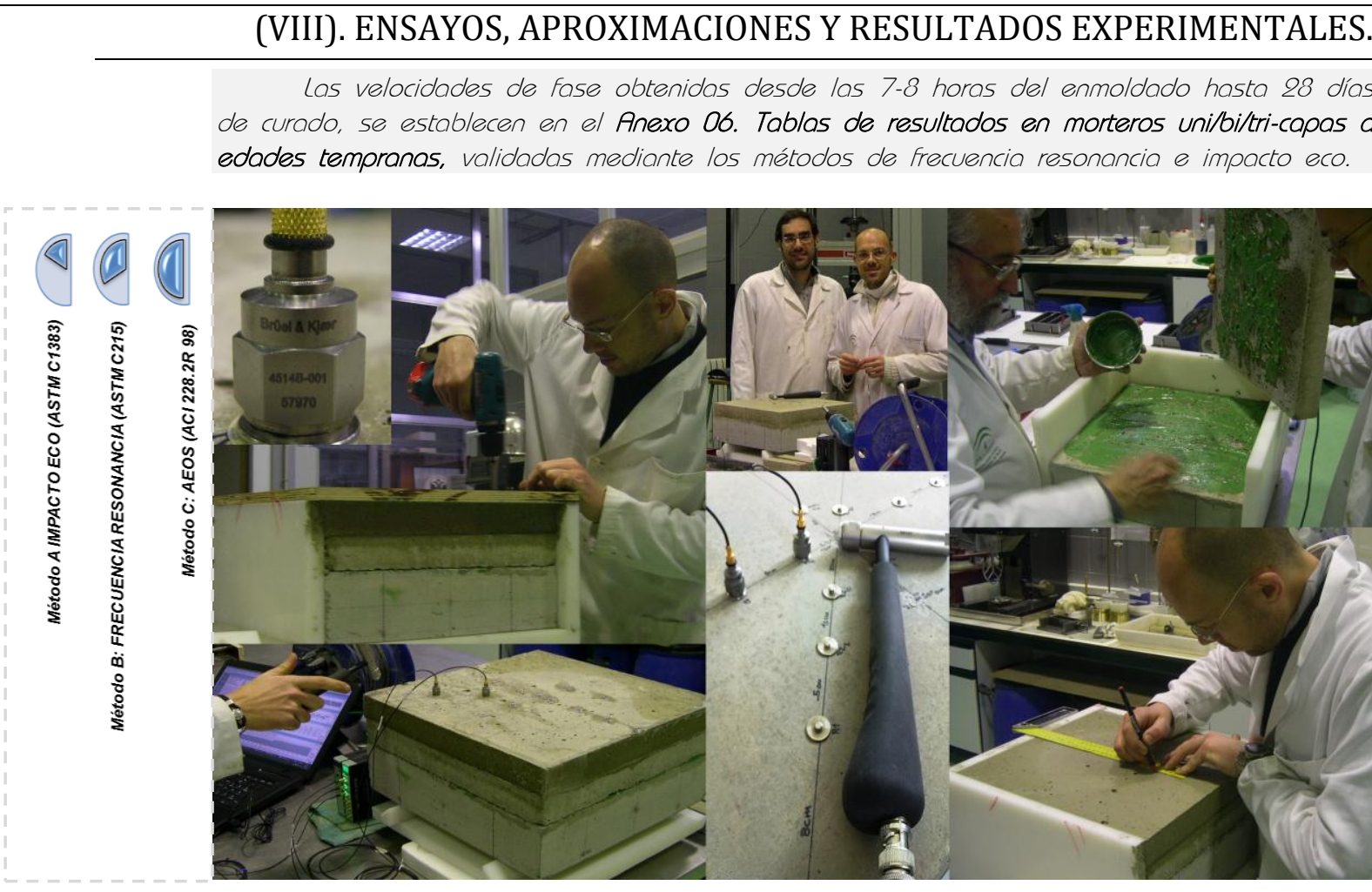

(Fig. 86). Las mediciones, y desarrollo analítico-experimental del método AEOS, se realizó en el Laboratorio de Materiales de la E.T.S. Ingeniería de Caminos, Granada, durante Noviembre 2011-Abril 2012, período de fabricación, fraguado y curado de especímenes de morteros confeccionados para este trabajo, bajo la atención personalizada del tutor Prof. D. Rafael Gallego Sevilla (Dpto. Mecánica de estructuras) y la colaboración del Prof. D. José Rodríguez Montero, responsable del Laboratorio y maquinaria.

Desarrollo experimental.

En el capítulo I se avanzaba el plan experimental adoptado al describir las dosificaciones realizadas para distintos morteros. Ahora, se definen los modelos o especímenes fabricados para el desarrollo y éxito del método AEOS, justificando dimensiones y proporciones. Los resultados experimentales se presentan en el Anexo 06 junto a tablas, gráficas y detalles para todas las edades de curado ensayadas y a cada modelo de los principales que validan la técnica. Justificando que los modelos debían servir tanto para las técnicas AEOS, FFRC e I-ECO, se ha trabajado en losas de 40-40-espesor variable de 1, 2 y 3 capas, que desde las 7horas de su enmoldado recrearon fielmente perfiles dispersivos en morteros estructurales en proceso de curado.

El desarrollo del método, la puesta a punto de los equipos, el trabajo de laboratorio... han requerido una batería de ensayos previos considerable, varias amasadas desechadas y un proceso intenso de ensayo-error. Finalmente, debido a la rápida ejecución, aplicabilidad con todas las técnicas vistas, correspondencia con probetas $4 \times 4 \times 16 \mathrm{~cm}$, porque son ideales para cada método END y porque recrean los modelos estructurales reales... se ha optado por presentar 3 modelos de LOSAS de 40x40x(10/15/20)cm de distintas edades, dosificaciones y ejecución... 3 modelos...3 perfiles (unicapa homogéneo, bicapa y tricapa dispersivos). 
Se utiliza el equipo proporcionado por la empresa Bruel\&Kjaer, con martillos de impacto de frecuencias hasta $60 \mathrm{kHz}$. La propagación de las ondas se detecta utilizando dos acelerómetros receptores piezoeléctricos y la señal analógica se transmite al analizador espectral mediante un módulo LAN XI 12 PULSE 3053b 12 canales y transferida digitalmente al equipo portátil. El martillo - fuente de impacto transitorio, tiene una fuerza de compresión máxima equivalente a $8,9 \mathrm{kN}$ y una masa efectiva de 100gramos, y un rango amplio de frecuencias del orden de $10 \mathrm{~Hz}$ a $90 \mathrm{kHz}$, debido al impacto en un corto espacio de tiempo que podemos generar con las puntas disponibles de aluminio, plástico o goma (bajas frecuencias). Los acelerómetros recogen la información de la componente de desplazamiento vertical de la señal superficial, medida de interés para el ensayo AEOS.

El equipo utilizado en la realización del estudio es el siguiente:

- 2 acelerómetros monoaxiales de electrónica integrada marca Bruel \& Kjaer modelo 4514-B-001, de titanio, con TEDS, Ø12mm, cabeza hexagonal h.23mm, sensibilidad $100 \mathrm{mV} / \mathrm{g}$, sensibilidad transversal $<5 \%$, conector superior, amplitud de respuesta de 1 a 10000Hz, rango de medición max. 50(g) pico, peso 8.7gramos, base aislada y cable de pantalla simple coaxial, 10-32 UNF (M) a SMB $(F)$, de $2 \mathrm{~m}$, rango temperatura $-51^{\circ} \mathrm{C} a+105^{\circ} \mathrm{C}$. Impedancia salida $100 \Omega$.

- 1 módulo de batería marca Bruel \& Kjaer modelo 2831-A para PULSE LAN XI, incluyendo cargador alimentador ZG-0469 y adaptador ZH0686, carga directa y panel frontal de conexiones con LEDS modelo $B N C: U A-2107-120$. Cable SMB a BNC,1m, max. $+85^{\circ} C$. Incluye adaptador JJ-0081 BNC hembra-BNC hembra.

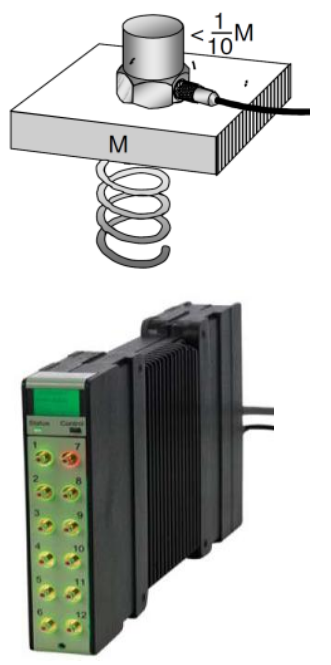

- 1 módulo analizador PULSE LAN-XI marca Bruel \& Kjaer modelo 3053-B-120, con capacidad hasta 12 canales con entradas CCLD hasta frecuencia 25,6kHz. 7 horas autonomía batería, $T^{a} \max . \quad+80^{\circ} \mathrm{C}, \quad$ conector $R J 45$, dimensiones 132.6x27.5x250mm, peso 750gramos, filtro paso-alto, precisión amplitud $0.01 \mathrm{~dB}$, filtro anti-aliasing.

- 1 martillo de impactos modelo 8206-003, voltaje sensibilidad $1.14 \mathrm{mV} / \mathrm{N}$, fuerza compresión $4448 \mathrm{~N}$ a max. 8896N, cabezal 100g, 3 puntas intercambiables (goma, plástico y aluminio). Voltaje salida $5 \mathrm{~V}$, impedancia $<100 \Omega, 2$ a $20 \mathrm{~mA}$, rango de temperaturas $73 a+60^{\circ} \mathrm{C}$, longitud $221.5 \mathrm{~mm}$, mango de fibra de vidrio, conector BNC.

- 1 martillo de impactos modelo 8204, voltaje sensibilidad $22.7 \mathrm{mV} / \mathrm{N}$, fuerza $220 \mathrm{~N}-890 \mathrm{~N}$, cabezal $2 \mathrm{~g}$. Voltaje salida $\pm 5 \mathrm{~V}$, long. $122 \mathrm{~mm}$, mango de fibra de vidrio, conector 10-32UNF. Punta de acero.

- 1 Software de análisis de señales "PULSE 16.1” y 1 Portátil.
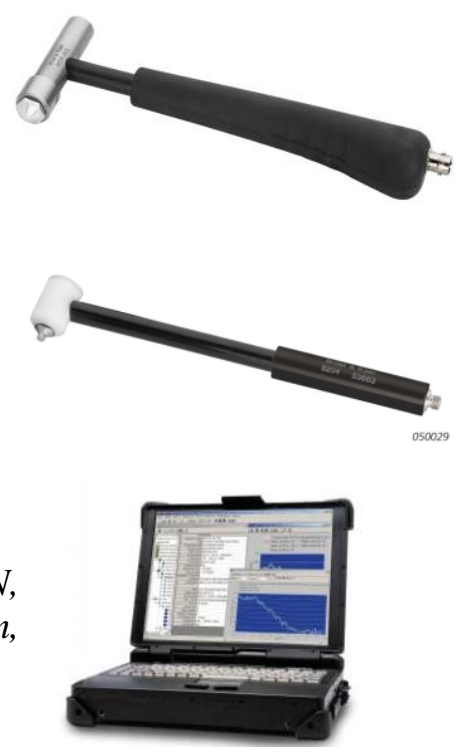
Se hace especial hincapié en el tipo de martillo y acelerómetro usados. En función de la aplicación que se le dé al transductor de vibraciones, condicionará el tamaño y resto de características del trabajo. En este caso, el módulo LAN XI 12 canales está especialmente indicado para análisis modal de ensayos estructurales, monitoreo sísmico y registro de varios rangos de vibraciones con distintas frecuencias con tratamiento posterior de las señales temporales grabadas. Por el tamaño de los modelos (probetas 40x40x160mm y losas 400x400mm) se opta por transductores de impulsos de corta duración. En este caso, acelerómetros piezoeléctricos de carga o Deltatron, modelo Delta Shear ${ }^{\circledR} 4514-B-001$ de uso común, por los siguientes factores:

- Sensibilidad (Rango dinámico):10 mV/ms-2. Rango de frecuencias: 1-10KHz

- Tamaño y masa $(m)$ del acelerómetro en proporción al modelo $(M)-m \approx 1 / 10 M$

- Cableado largo provoca ruido triboeléctrico y reduce la respuesta en altas frecuencias (efecto de filtrado capacitivo).
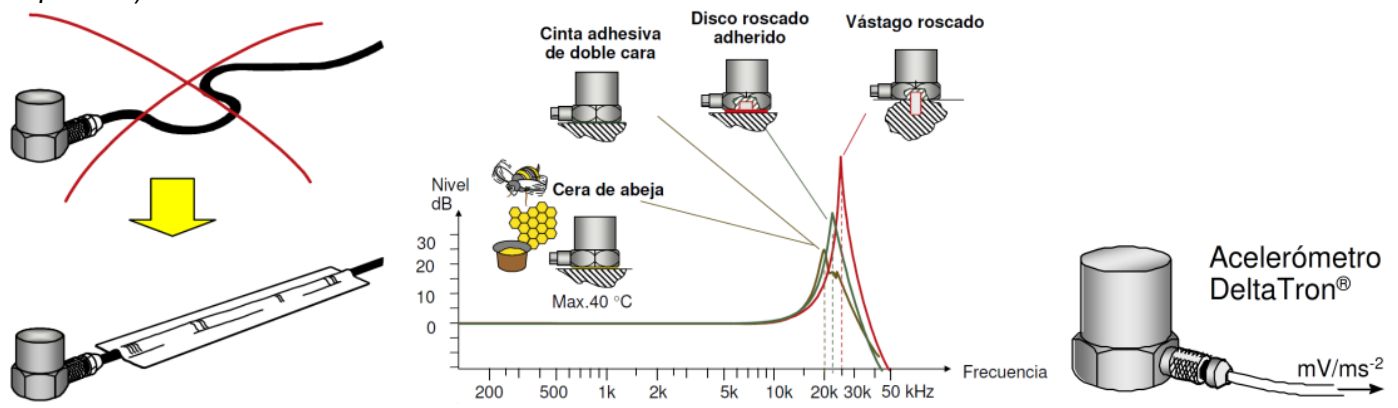

(Fig. 87). Explicación del acelerómetro piezoeléctrico y sus efectos. Ruido triboeléctrico. Adhesivos.

Los acelerómetros piezoeléctricos se usaron como receptores por su alta sensibilidad. El voltaje inducido es proporcional a la aceleración superficial para el rango de frecuencias en torno a la frecuencia natural del acelerómetro (B\&K 4514-B001 fr $\approx 32 \mathrm{kHz})$. Sin embargo, la calidad de los resultados ha dependido del acoplamiento a la superficie (superficie lisa, áspera, sucia, mojada...) así como del adhesivo de contacto (cera de abeja, perno roscado o placa adherida).

En los ensayos con probetas se utilizó cera de abeja, ya que por debajo de $20 \mathrm{KHz}$ no hay diferencia apreciable entre las formas de colocar el acelerómetro. No obstante, como se observa en imágenes del trabajo, es recomendable recurrir a pernos roscados, y para este trabajo, se recurrió a placas adheridas a la superficie con un adhesivo, como el caso de las losas de $40 \times 40 \mathrm{~cm}$, donde se elimina el ruido incoherente y las señales muestran espectros más acentuados.

Se han ensayado varias configuraciones de posición entre fuente y receptores para diferentes profundidades de ensayos en morteros. La medición para la prueba AEOS considera la separación entre receptores por el punto medio entre ambos, además, el espaciado mayor entre los acelerómetros asociado a una fuente de altas frecuencias proporciona un muestreo exhaustivo en la curva de dispersión global para precisar la velocidad de onda correspondiente a un espesor asociado. Adoptando que la distancia entre la fuente y el receptor más cercano sea igual a la distancia entre los receptores, se consigue reducir el efecto de campo cercano. 


\section{Análisis integral del mortero a edad temprana mediante la aplicación de los 3 métodos [FFRC+I_E+SASW]. Ensayos a Losas 40x40 cm y Probetas 4x4x16cm.}

En esta aplicación, el área bajo la superficie para ser investigada es de pocos centímetros de profundidad $(5 \mathrm{~cm}$ a $20 \mathrm{~cm})$, por lo que se requiere un rango de frecuencias de $5 \mathrm{~Hz}$ a $60 \mathrm{kHz}$ aproximadamente para lograr suficiente resolución espacial. Como fuente de excitación en losas se selecciona el martillo B\&K 8206 apto para bajas frecuencias y análisis superficial de ondas, ya que cada golpe es distinto y limitado a un rango de frecuencia menor.
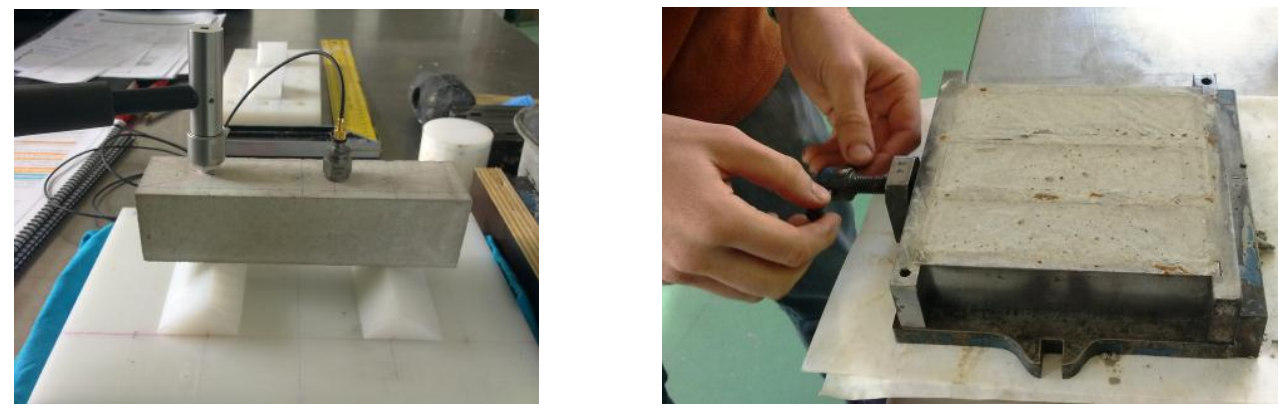

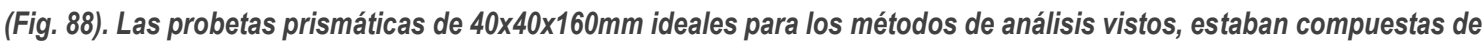
cemento Portland I, agua y áridos lavados de $\varnothing_{\text {nominal }} 2,5-4 \mathrm{~mm}$ a nivel general.

\section{Amasada_01 mortero $(1 / 0,5 / 3) \ldots . .$. ((Ejecución LOSA UNICAPA 40x40x5cm))}

Se fabricó una losa inicial de $40 \times 40 \times 5 \mathrm{~cm}$ para ensayos aislados a un modelo unicapa similar al modelo unicapa definitivo de espesor $10 \mathrm{~cm}$. En este caso se dosificó con la proporción (1/0,5/3) para 15 litros de mortero. Además de analizar y comparar las mediciones entre modelos a edad temprana, y determinar las propiedades elásticas del mortero, se

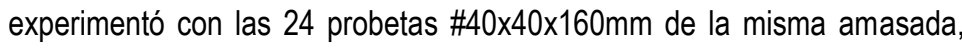
con la finalidad de determinar defectos internos, cavidades y velocidades de onda. La $1^{a}$ medición se efectuó a las $\underline{8 \text { horas }}$ del enmoldado, y a

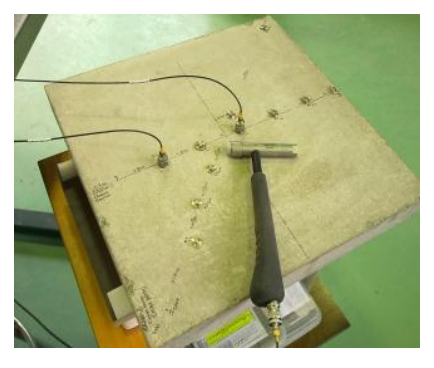
edades posteriores de 11h, 12h, 13h, 14h, 15h, 16h, 18h, 20h, 22h, 24h, 36h, 48h, 60h, 72h, 4, 5, 6, 7, 14 y 28 días.

\begin{tabular}{|c|c|c|c|c|c|c|c|c|c|c|c|c|c|c|c|c|c|c|c|}
\hline $\begin{array}{c}\text { № } \\
\text { Ensayo }\end{array}$ & 01 & 02 & 03 & 04 & 05 & 06 & 07 & 08 & 09 & 10 & 11 & 12 & 13 & 14 & 15 & 16 & 17 & 18 & 19 \\
\hline EDAD & 10h & 11h & 12h & 13h & 14h & $15 \mathrm{~h}$ & 16h & 18h & $20 \mathrm{~h}$ & $22 h$ & $24 \mathrm{~h}$ & $36 \mathrm{~h}$ & 48h & 60h & $72 h$ & $4^{0} d$ & $5^{0} d$ & $6^{0} d$ & $7^{0} \mathrm{~d}$ \\
\hline Fecha & \multicolumn{11}{|c|}{ MIERCOLES 21} & $\mathrm{~J} 22$ & J 22 & V 23 & V 23 & S24 & D25 & L26 & M27 \\
\hline Hora & $8: 00$ & $9: 00$ & 10:00 & $11: 00$ & $12: 00$ & $13: 00$ & $14: 00$ & $16: 00$ & $18: 00$ & $20: 00$ & $22: 00$ & $10: 00$ & $22: 00$ & $10: 00$ & $22: 00$ & $10: 00$ & $10: 00$ & 9:00 & $9: 00$ \\
\hline TEST & \multicolumn{19}{|c|}{ Losa +3 probetas $\cdot($ FFRC + I-ECO + SASW $)+1$ probeta $\cdot($ ROTURA $)$} \\
\hline
\end{tabular}

(Fig. 89). El ensayo AEOS se preparó con posición inicial "Common source" entre los acelerómetros, con distancia contorno-fuente $=4 \mathrm{~cm}$; impacto-receptor, $d 1=6 \mathrm{~cm}, d_{2}=5,10,20 \mathrm{~cm}$ (SASW_01), y contrastando a distancias $d_{2:}: 6,12,18,24$, $30 \mathrm{~cm}$, de un segundo ensayo (SASW_02), ortogonal al anterior.

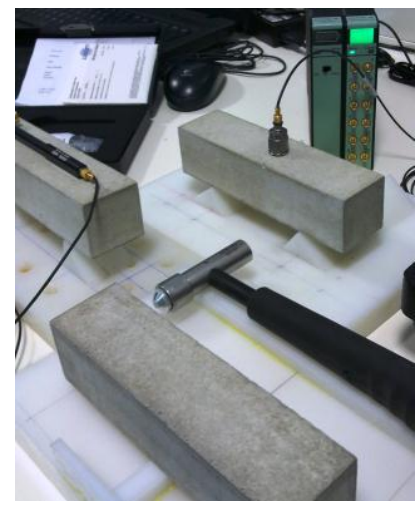

Aplicando el método AEOS se comprobó que era necesario aplicar los "criterios de filtrado" [Filtering criterion] (ver desarrollo del método, pag.35), ya que los mejores resultados se dieron para separaciones $d_{2}=6 \mathbf{c m} ; d_{2}=10 \mathrm{~cm} y d_{2}=\mathbf{1 2} \mathbf{c m}$. En estos ensayos las velocidades mantienen la mayor semejanza con las obtenidas por las otras técnicas de análisis estudiadas. 
Inicialmente, se evaluaron mediante Frecuencia_Resonancia e Impacto_Eco en aplicación de la normativa de ensayo (ASTM C215, ASTM C1383) los parámetros elásticos del material y la velocidad de propagación longitudinal para la capa de mortero a edad temprana con probetas prismáticas (UNE EN 196, EN 1015) de 40×40×160mm. Posteriormente se ensayaba a rotura f/c, una de las 3 probetas testeadas, por lo que se obtenían resultados válidos. De la monitorización de estos resultados, se evaluó el potencial del método AEOS en modelos de mortero de laboratorio, reduciendo el margen de error en los cálculos por debajo del $2 \%$ al no estimar ningún parámetro de forma aleatoria, ya que se conocían espesores y parámetros elásticos de cada mortero (densidad, módulos, coeficiente Poisson...). De esta manera se muestra el desarrollo del método desde el punto de vista práctico, de la implementación de la rutina computacional en modelos reales:

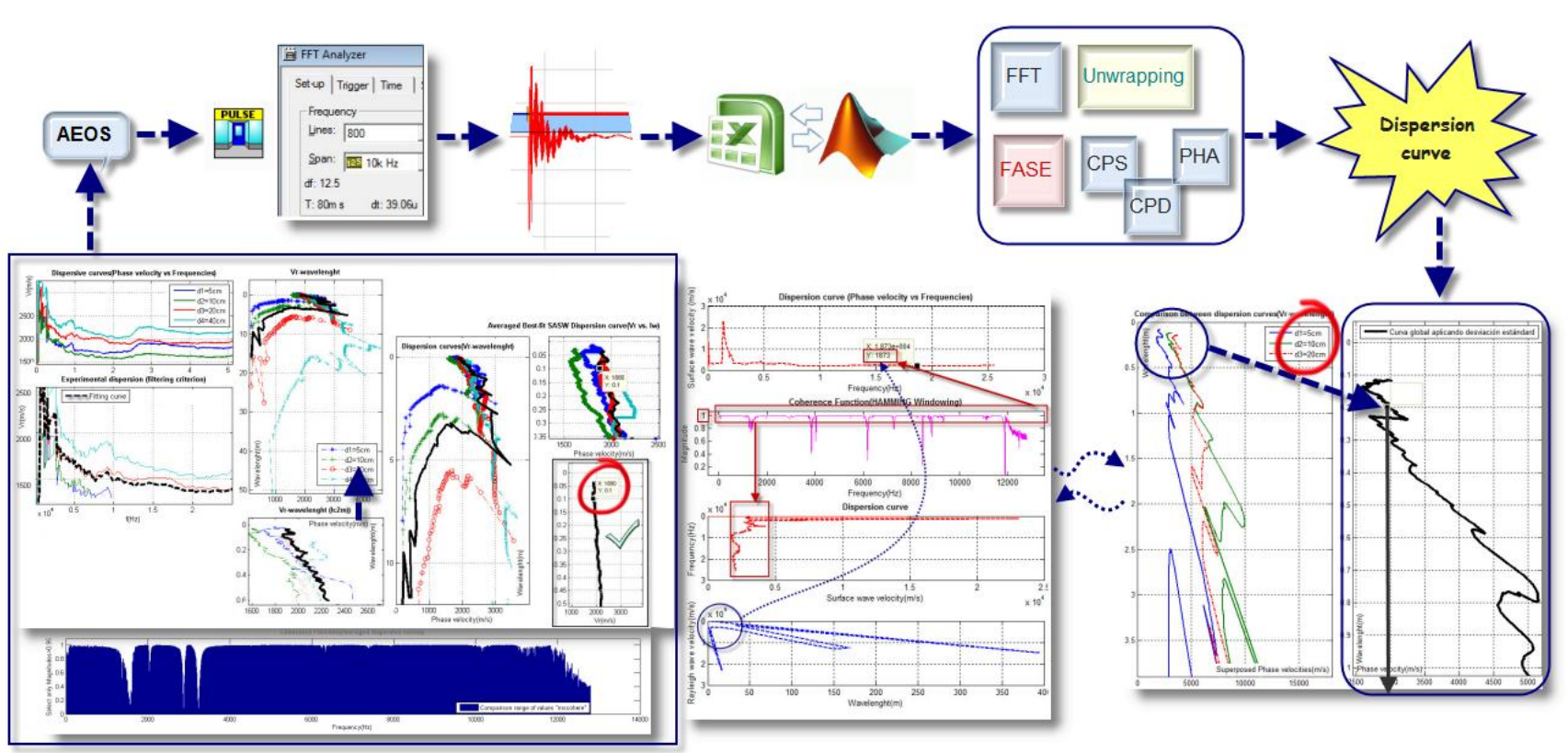

(Fig. 90). Esquema proceso del método AEOS desde la adquisición de datos, procesamiento de señales hasta la curva de dispersión bruta y global [promedio de ensayos a distancias $d 2: 6 / 12 / 18 / 24 \mathrm{~cm}$ ].

Una vez que se asumen los resultados experimentales, a partir de la velocidad de onda determinada del análisis espectral (curva de dispersión), determinamos una estimación del resto de parámetros que caracterizan al mortero: módulo Young, modulo dinámico de elasticidad, Módulo Rigidez, Poisson y resistencia a compresión, mediante:

$$
\begin{aligned}
& A C I 363: E_{C(G P A)}=5,85 \sqrt{f_{C(M P a)}}-13,5 \quad A C I_{-} 318: E_{C\left[M P P_{a}\right]}=\gamma_{m\left(k g / m^{3}\right)}^{1.5} \cdot 0,043 \sqrt{f_{C[M P a]}^{\prime}} \quad E_{D L}=4 \cdot(l / b t) \cdot m \cdot \omega_{r}^{2} \quad o \quad E_{D L}=4 \cdot l^{2} \cdot \rho \cdot \omega_{r}^{2} \\
& A C I_{-} 318 M: E_{C}=4730 \sqrt{f_{C}^{\prime}(M P a)} \\
& E_{L}=2 G(1+v) \quad G=(\gamma / g) V_{S}^{2}
\end{aligned}
$$

Siendo $\boldsymbol{G}$ el módulo de rigidez transversal, el peso específico, $\boldsymbol{\gamma}$, la aceleración de la gravedad, $\boldsymbol{g}(9,81 \mathrm{~m} / \mathrm{s} 2), \boldsymbol{V} \boldsymbol{s}$ la velocidad de onda $\mathrm{S}$, el módulo de Young, $\boldsymbol{E}$, y el coeficiente de Poisson, $\boldsymbol{U}$.

El módulo de elasticidad es el $67 \%$ del módulo dinámico a 6 días, $75 \%$ a partir de 14 días de su amasado, y a los 28 días alcanza su valor estable del $80 \%$ del Módulo dinámico de Elasticidad. Conocidas las velocidades de fase y estimadas el resto de propiedades del material podemos determinar una resistencia a compresión equiparable a las conseguidas mediante rotura de probetas y técnica FFRC, mediante códigos $\mathrm{ACl}$. Como desarrollo futuro se implementará el método de inversión que calcule estos valores de forma exacta. 


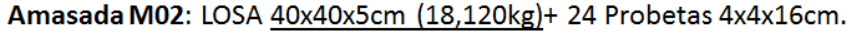

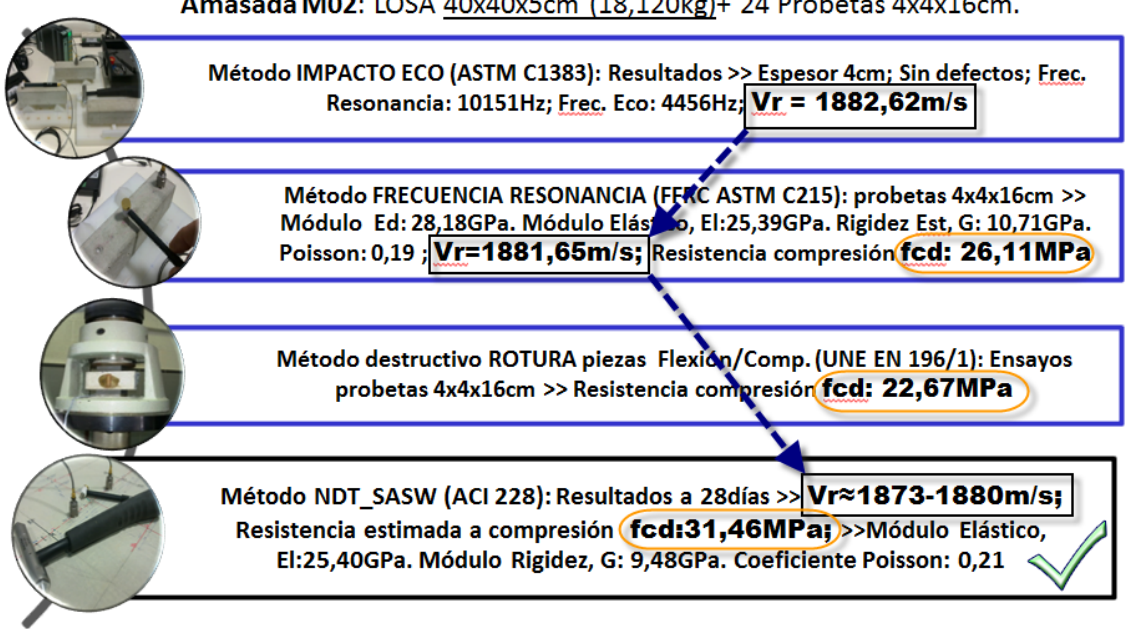

Averaged Best-fit SASW Dispersion curve $($ r v vs. Iw)

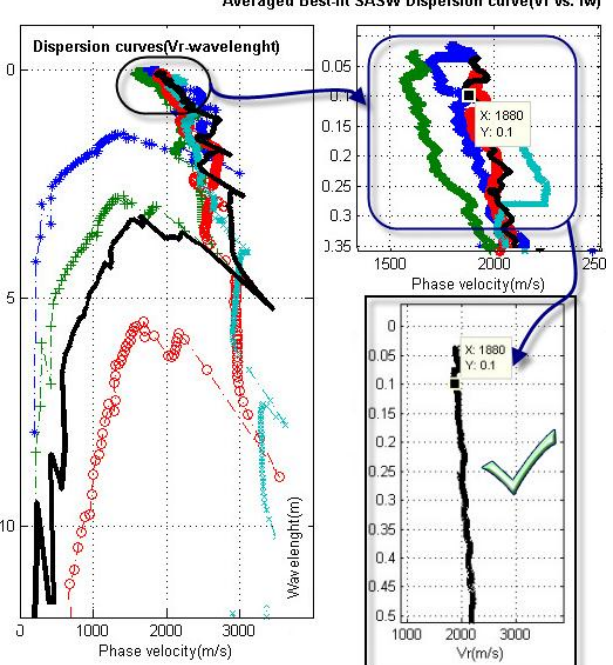

(Fig. 91). Comparativa de resultados a la edad de 6 días para cada método de ensayo no destructivo. Validez del método AEOS en modelo de losa unicapa homogénea. Obsérvese como la curva de dispersión es de Vr constante vs longitud onda $5 \mathrm{~cm}$. La linealidad de la curva de dispersión muestra la homogeneidad de la mezcla de mortero ensayada.

\section{— Amasada_02 mortero $(1 / 0,6 / 3,25) \ldots . .$. ((Ejecución LOSA UNICAPA 40x40x10cm))}

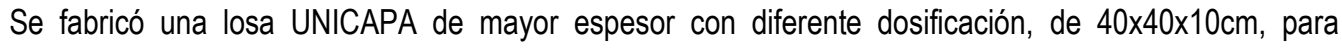
contrastar resultados experimentales en modelos unicapa de distintos morteros. En este caso se dosificó con la proporción $(1 / 0,6 / 3,25)$. Se debe precisar que en este modelo la velocidad de onda es mayor al caso anterior incluso a la edad de 6 días, mostrando una velocidad creciente de $\mathrm{Vr} \approx 2100 \mathrm{~m} / \mathrm{s}$, justificable por la mezcla realizada (relación a/c, contenido en finos/cemento...). El proceso de ensayos fue similar al anterior modelo de $5 \mathrm{~cm}$. Los resultados confirman y validan las técnicas en modelos homogéneos de 1 capa a cualquier edad, dosificación y proporción del espécimen de mortero:

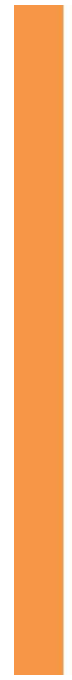

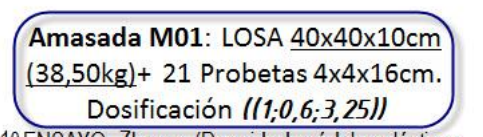

$1^{\circ}$ ENSAYO: 7horas. (Densidad, módulos elásticos y dinámicos, Poisson y Rigidez transversal, velocidad de onda y resistencia a flexocompresión).

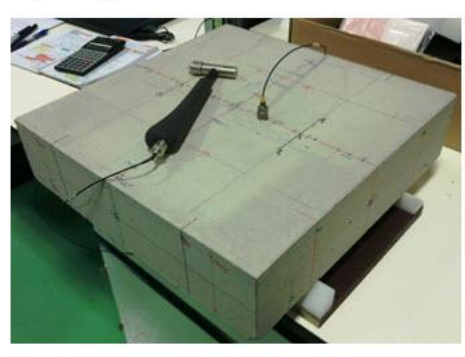

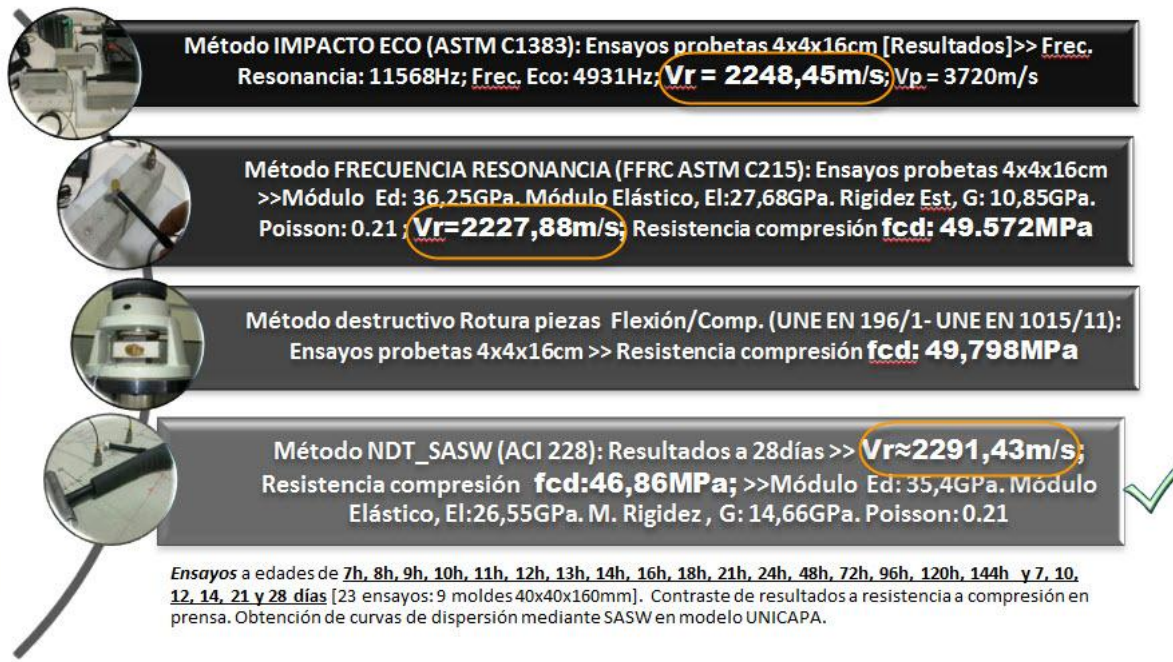

(Fig. 92). Comparativa de resultados a la edad de 28 días para cada método de ensayo no destructivo. Validez del método AEOS en modelo de losa unicapa homogénea de mayor espesor. (Error<5\%).

\section{* Amasada_03 mortero $(1 / 0,5 / 2,25)$...... ((Ejecución LOSA BICAPA 40x40x(10+5)cm))}

Se realizó una nueva amasada usando el espécimen de losa de 40×40×10cm como base de la nueva amasada, encofrada dentro del molde de polietileno solidarizando ambos morteros en una pieza bicapa de e.15cm total. En este caso se modificó la dosificación:(1/0,5/2,25) para 20 litros

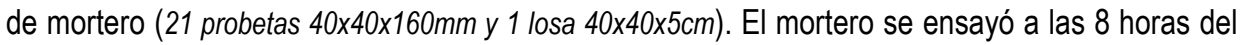
enmoldado, luego a intervalos regulares de 1,5horas: $8 \mathrm{~h} / 9,5 \mathrm{~h} / 11 \mathrm{~h} / 12,5 \mathrm{~h} / 14 \mathrm{~h} / 15,5 \mathrm{~h} / 17 \mathrm{~h} /$ $18,5 \mathrm{~h} / 20 \mathrm{~h} / 22 \mathrm{~h} / 24 \mathrm{~h} / 36 \mathrm{~h}, 48 \mathrm{~h}, 60 \mathrm{~h}, 72 \mathrm{~h}$, y a $4,5,6,7$ y 14 días [20 ensayos]. 
NOTA: El ensayo AEOS se realizó para su validación doble; primero, a distancias $\mathrm{d}_{2}: 6,12,18,24,30 \mathrm{~cm}$ (contorno-fuente:4cm; impacto-receptor 1: $6 \mathrm{~cm}$.) en paralelo. Un segundo test AEOS, que al igual que el anterior mantenían ambos la posición de fuente común ("common source") pero que por la heterogeneidad del material y la presencia de defectos en el medio de unión entre ambas capas de mortero, como ya se ha visto, se registró una desviación de las velocidades a edad temprana, así se puede ver en los valores de la tabla de resultados del ANEXO 06 y en la gráfica $n^{015}$ para el modelo

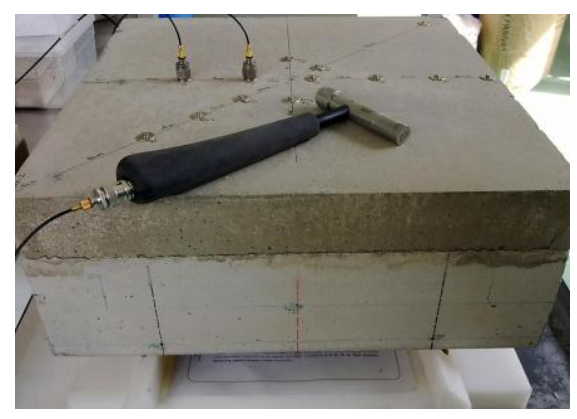
de losa $40 \times 40 \times 15 \mathrm{~cm}$, de que hay cierta dispersión de velocidades conforme alejamos los acelerómetros. Las distancias en este caso fueron $d_{2}: 5,10,20,40 \mathrm{~cm}$ (contorno-fuente:4cm; impacto-receptor 1: $8 \mathrm{~cm}$ ) en diagonal.

Repetimos el proceso complejo representado por el siguiente organigrama:

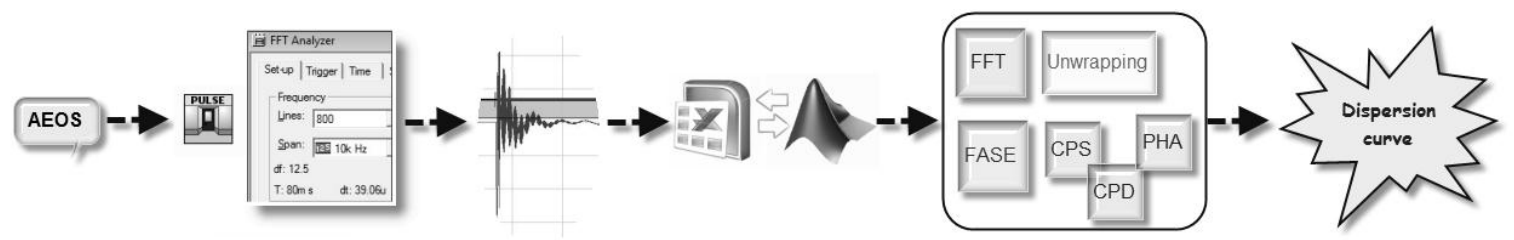

(Fig. 93). Esquema de los pasos a seguir para obtener la curva de dispersión en un ensayo tipo por el método AEOS.

Se obtiene la siguiente curva de dispersión promediada con 4 registros $\left(d_{2}: 5,10,20,40 \mathrm{~cm}\right)$ :
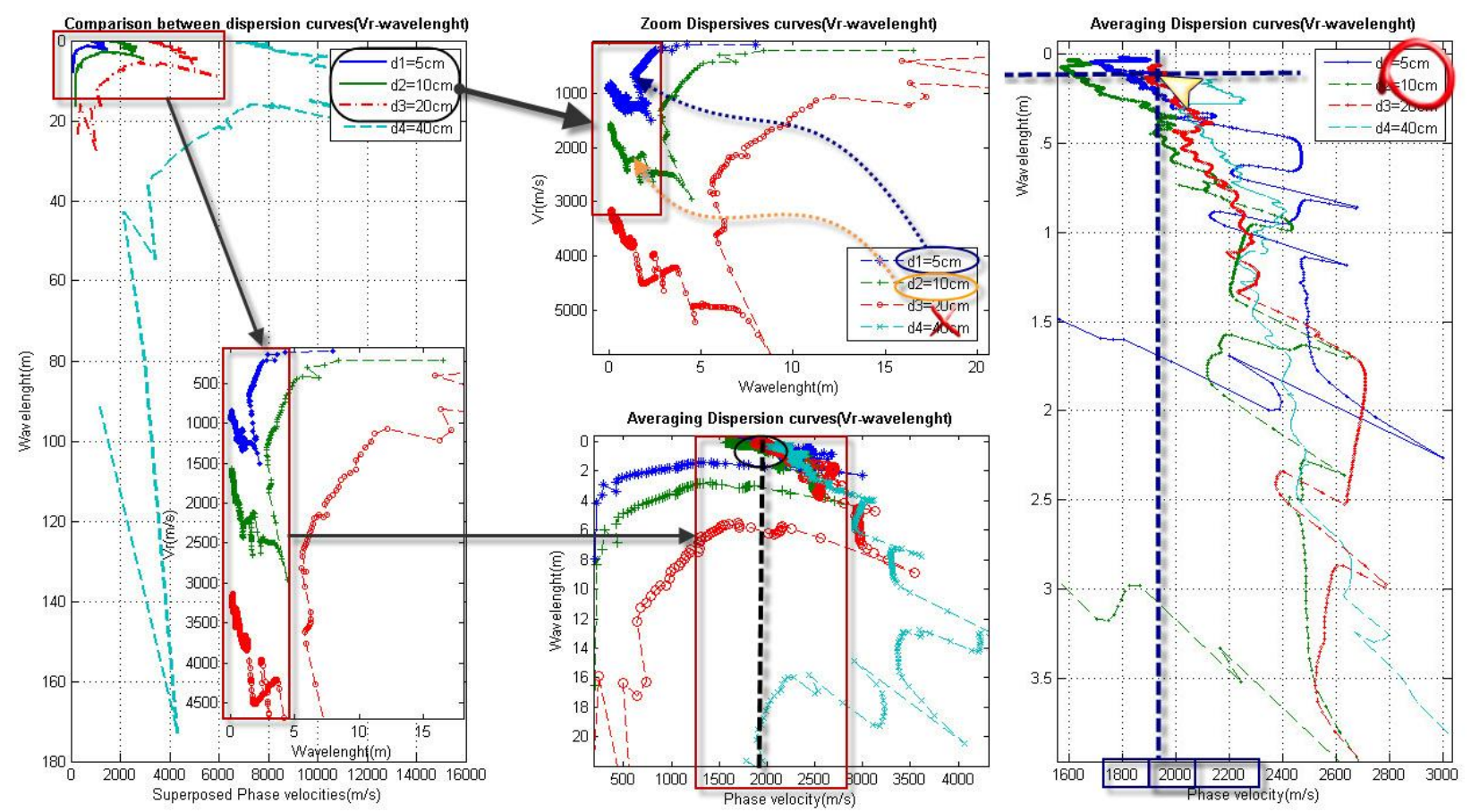

(Fig. 94). AEOS mediante rutina en Matlab para determinar la curva de dispersión (velocidad de fase vs $\lambda$ ). Edad $\underline{36 \text { horas. }}$

Conviene matizar como observaciones a este caso particular la anotación citada antes, y es que el mortero fabricado como capa adicional sobre el modelo ya existente de $10 \mathrm{~cm}$ con una edad de curado de 46 días, mostraba heterogeneidad apreciable en este caso. Como se indicó esta capa se desprendió del modelo inferior ya que presentaba oquedades apreciables en los ensayos de Impacto-Eco. Así se observa si comparamos los 2 ensayos AEOS realizados. Aunque a edades de curado final las velocidades se igualan, la semana inicial se aprecia dispersión en los resultados: 

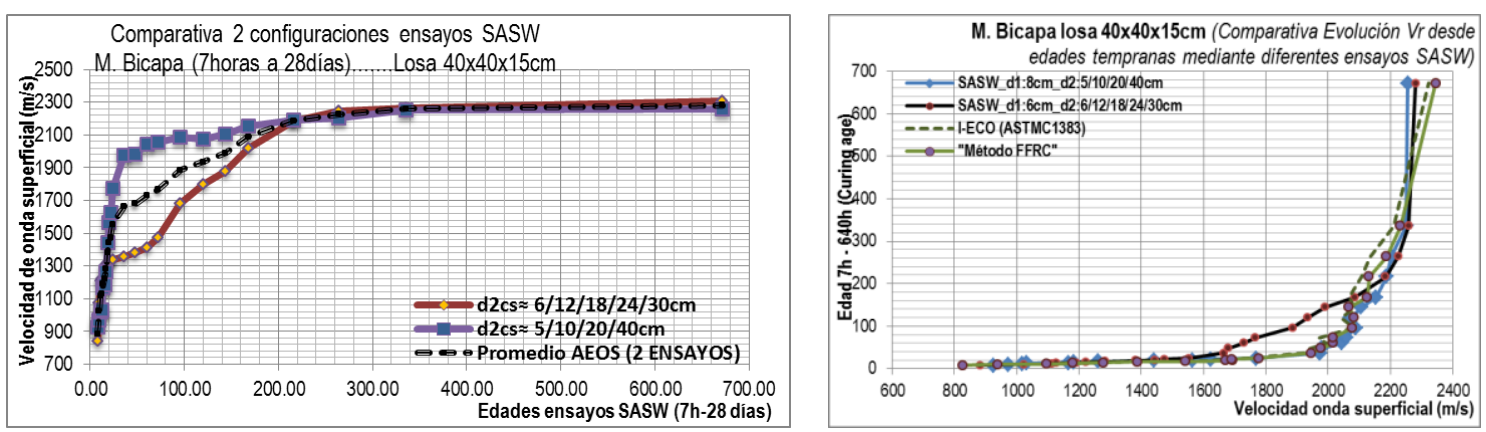

(Fig. 95). Evolución velocidades de onda vs Edad curado [Mientras que el ensayo AEOS_02 muestra similitud con las técnicas I-E y FFRC, el ensayo AEOS_01 se aleja en un margen intermedio para despues alcanzar un paralelismo].

Si comparamos los resultados entre métodos para la edad de $\mathbf{3 6}$ horas (por ejemplo) se obtiene:
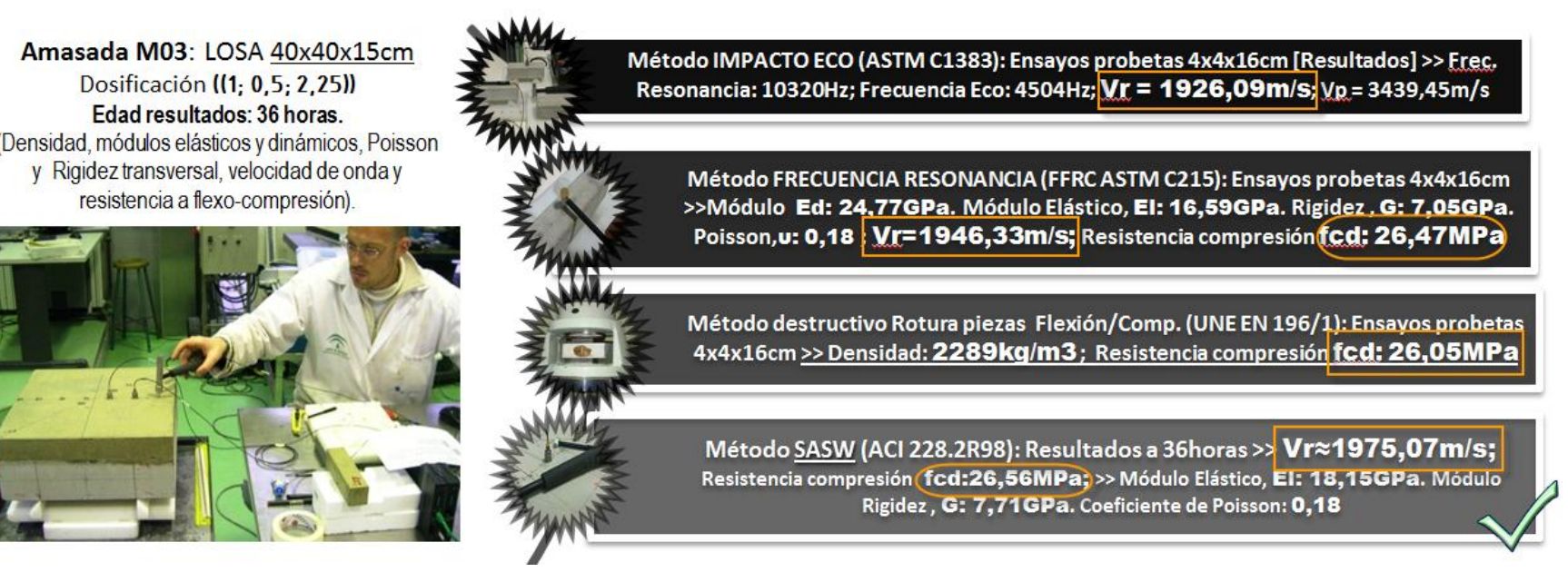

(Fig. 96). Comparativa resultados a la edad final de 36 horas por cada método para la losa de $40 \times 40 \times 15 \mathrm{~cm}$. (Error<2\%).

\section{— Amasada_04 mortero $(1 / 0,4 / 2,71) \ldots \ldots .(($ Ejecución LOSA TRICAPA 40x40x(10+5+5)cm $))$}

Sobre el anterior modelo de $15 \mathrm{~cm}$, se le añadió una semana más tarde una nueva capa de $5 \mathrm{~cm}$ de dosificación más seca, por lo que el modelo final presentaba capas diferentes en cualquier aspecto. En este caso se modificó la dosificación a la proporción $(1 / 0,4 / 2,71)$ y se confeccionaron 20 litros de mortero para 21 probetas $40 \times 40 \times 160 \mathrm{~mm}$ y una losa $40 \times 40 \times 5 \mathrm{~cm}$.

El mortero se fabricó a las 23:00h del día 30/03/2012, realizando la $1^{\text {a }}$ medición a las 8 horas, ensayando a edades: $8 \mathrm{~h} / 9,5 \mathrm{~h} / 11 \mathrm{~h} / 12,5 \mathrm{~h} / 14 \mathrm{~h} / 15,5 \mathrm{~h} /$ $17 \mathrm{~h} / 18,5 \mathrm{~h} / 20 \mathrm{~h} / 22 \mathrm{~h} / 24 \mathrm{~h} / 36 \mathrm{~h}, 48 \mathrm{~h}, 60 \mathrm{~h}, 72 \mathrm{~h}$, y a $4,5,6,7$ y 14 días $[20$ ensayos].

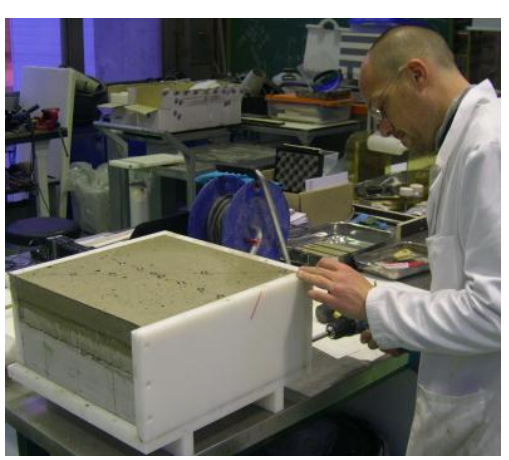

Repetimos el proceso representado por el siguiente organigrama:

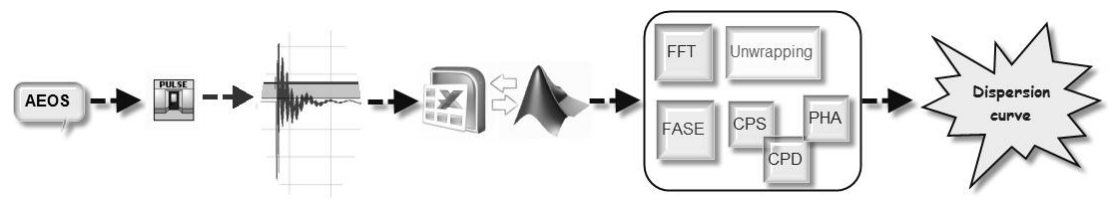

(Fig. 97). Esquema de la reducción de pasos que constituyen un ensayo del método espectral de ondas superficiales para determinar la curva de dispersión.

En este caso, ejecutando el método, se muestran los resultados y el desarrollo de la extracción de velocidades por medio de la curva de dispersión, para el modelo de losa tricapa de espesor $20 \mathrm{~cm}$ con una media de 5 registros correspondientes a las mediciones con las distancias adoptadas entre acelerómetros (en este caso, el ensayo mantenía la posición "common source" con d1:6cm y d2: 6,12 18, 24 y 30cm). 
- Configuración de disparo ("trigger") en el módulo de adquisición de señales. Realización de un promedio de 5 impactos con separaciones diferentes $\left(\mathbf{d}_{1}=6 \mathrm{~cm} \_\mathbf{d}_{2}=6 \_12 \_18 \_24 \_30 \mathrm{~cm}\right)$.

- Durante el ensayo, la fuente de impacto se situó a $6 \mathrm{~cm}$ del primer acelerómetro, con el criterio de $\mathbf{d}_{1}>\mathbf{h}_{\text {capa superior. }}$
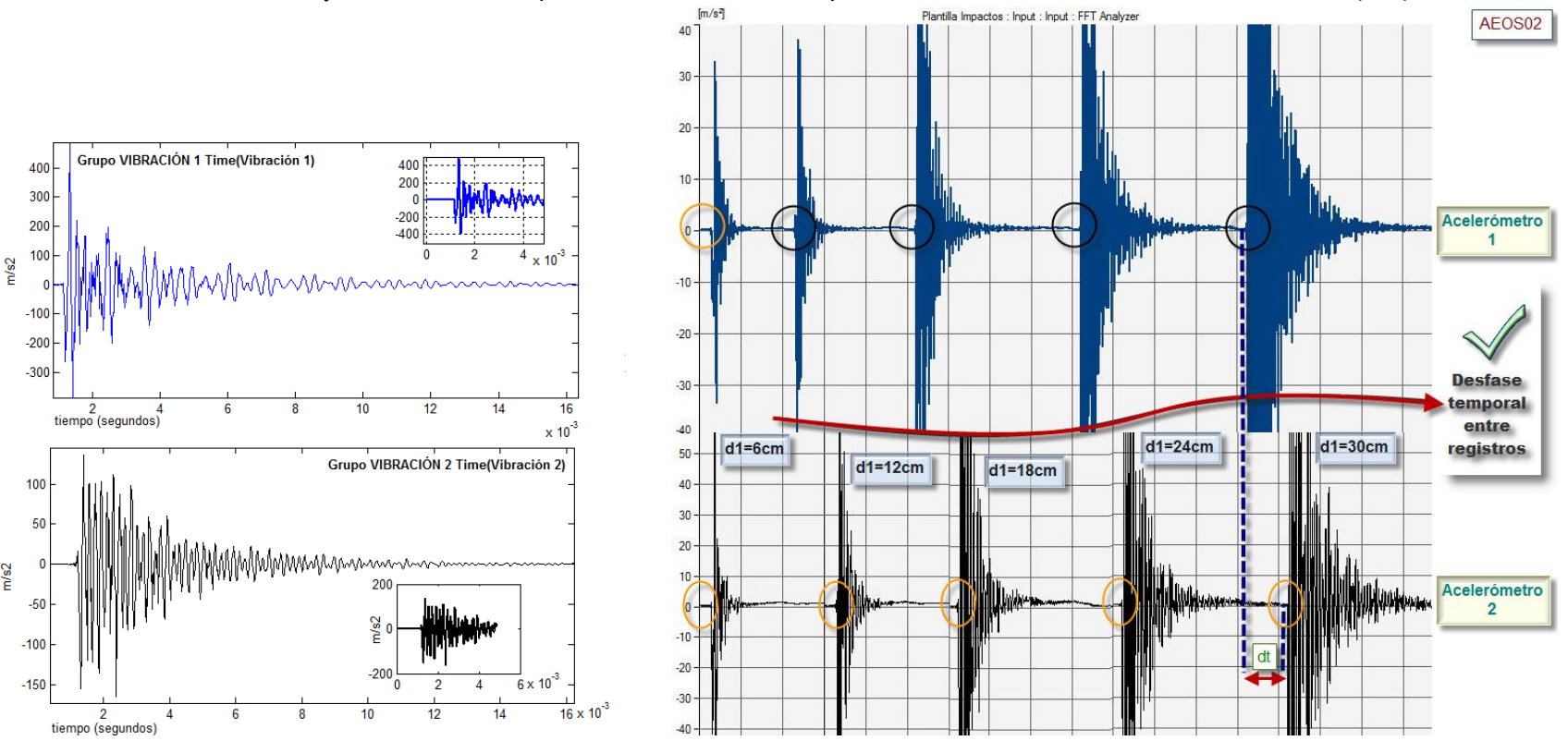

(Fig. 98). Configuración de "Trigger". Impactos realizados. Procesamiento de señales temporales identificando desfase.

- Desarrollo de la rutina computacional del método para cada ensayo hasta llegar a la curva de dispersión para cada registro (FFT, autoespectros, función de transferencia, densidad espectral cruzada, espectro de potencia cruzado, coherencia, espectro de fases, unwrapping phase...).

(Fig.99). Configuración de disparo (trigger) en módulo de señales "Pulse v.16".
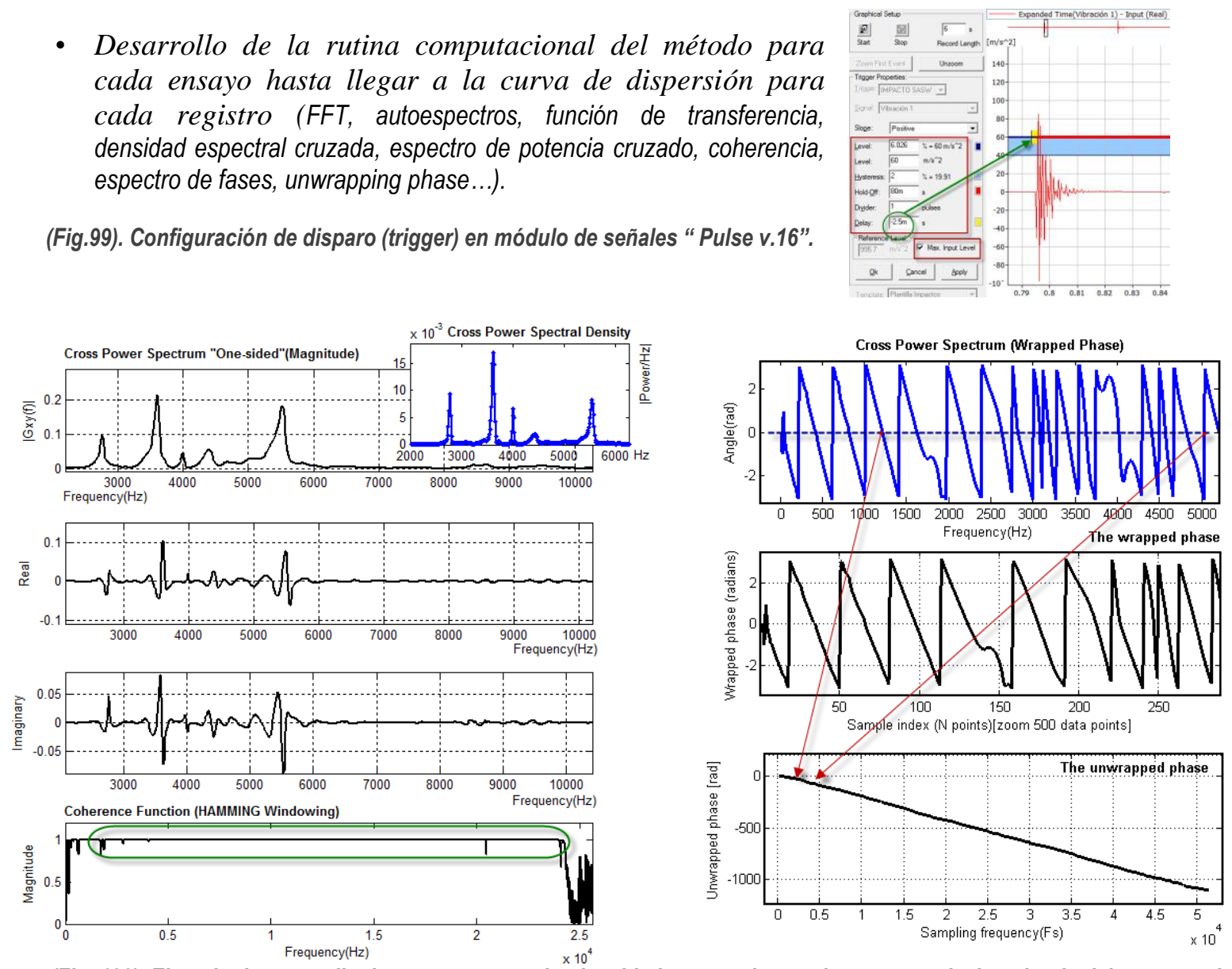

(Fig. 100). Ejemplo de promedio de espectro cruzado, densidad espectral cruzada, partes real e imaginaria del espectro de fases y rango válido de frecuencias a partir de la función de coherencia. Detalle del método de despliegue de fase. 
- El siguiente paso es crucial en el método AEOS. El filtrado de las señales cuando existen saltos de fase se hace necesario por los efectos ya citados de campo cercano, leakage o aliasing. En este ejemplo se debe a la presencia de un ruido incoherente o ambiental, ya que los ensayos se realizaron en el Laboratorio en actividad de otros trabajos ajenos.

Observar que mediante el análisis de la historia temporal podemos intuir que la onda viaja a una velocidad de 1900-2000m/s, ya que: $V r=d 2 / \Delta t \rightarrow 0.12 /(0.001211-0.001152)=2033.89 \mathrm{~m} / \mathrm{s}$
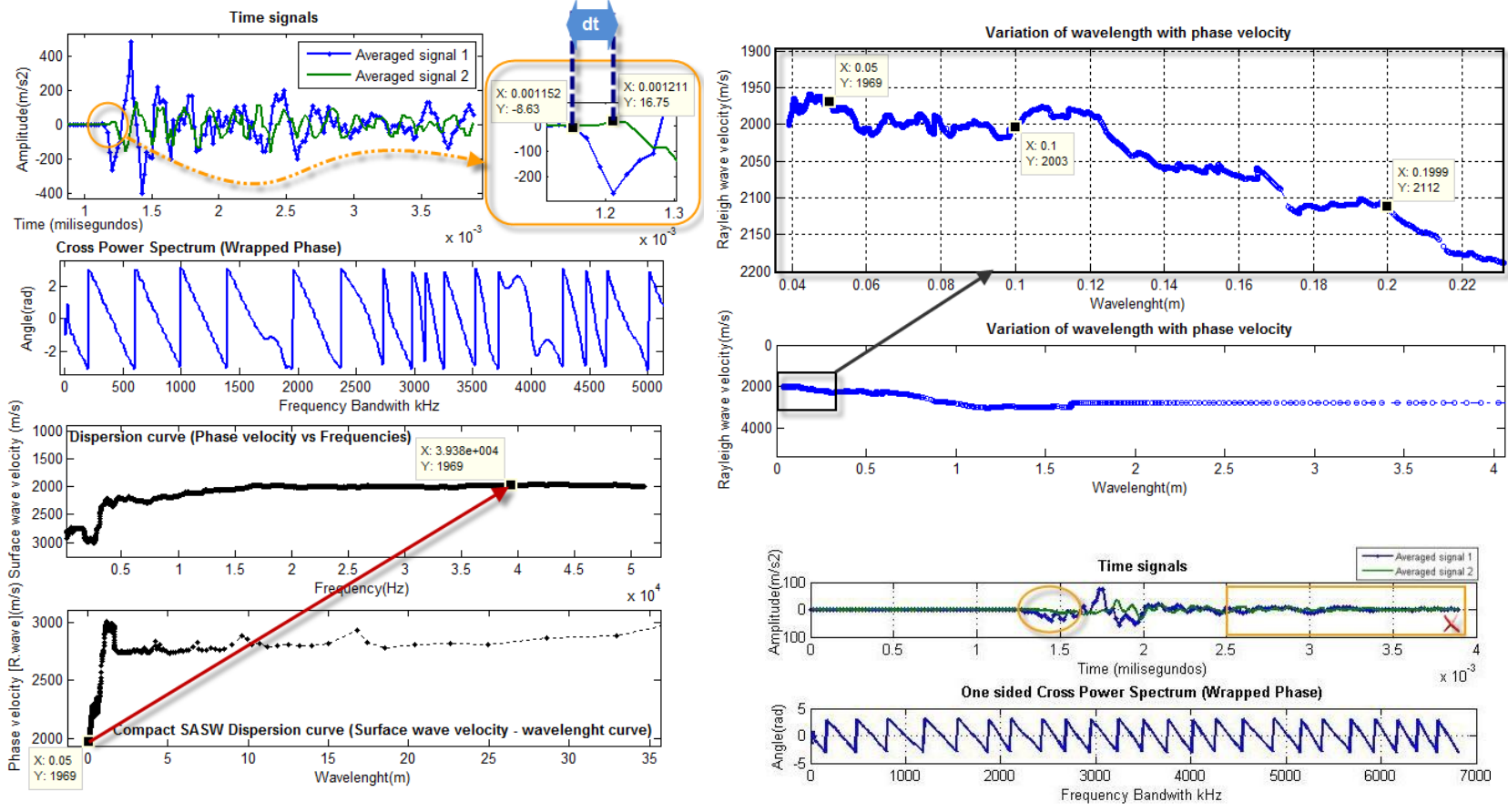

(Fig. 101). Proceso de filtrado de discontinuidades de fase y frecuencias incoherentes para la construcción de la curva local de dispersión. Observar como se elimina de las señales en el tiempo el intervalo de ruido correspondiente a las reflexiones de onda con el contorno del modelo. (Arriba): Curva de dispersión final evitando fallos locales.

- Obtenemos 5 curvas de dispersión que una vez filtradas las frecuencias válidas conforme a la función de coherencia y determinado el espectro de fases dicho rango de frecuencias, se obtiene la curva bruta de dispersión o curva local:
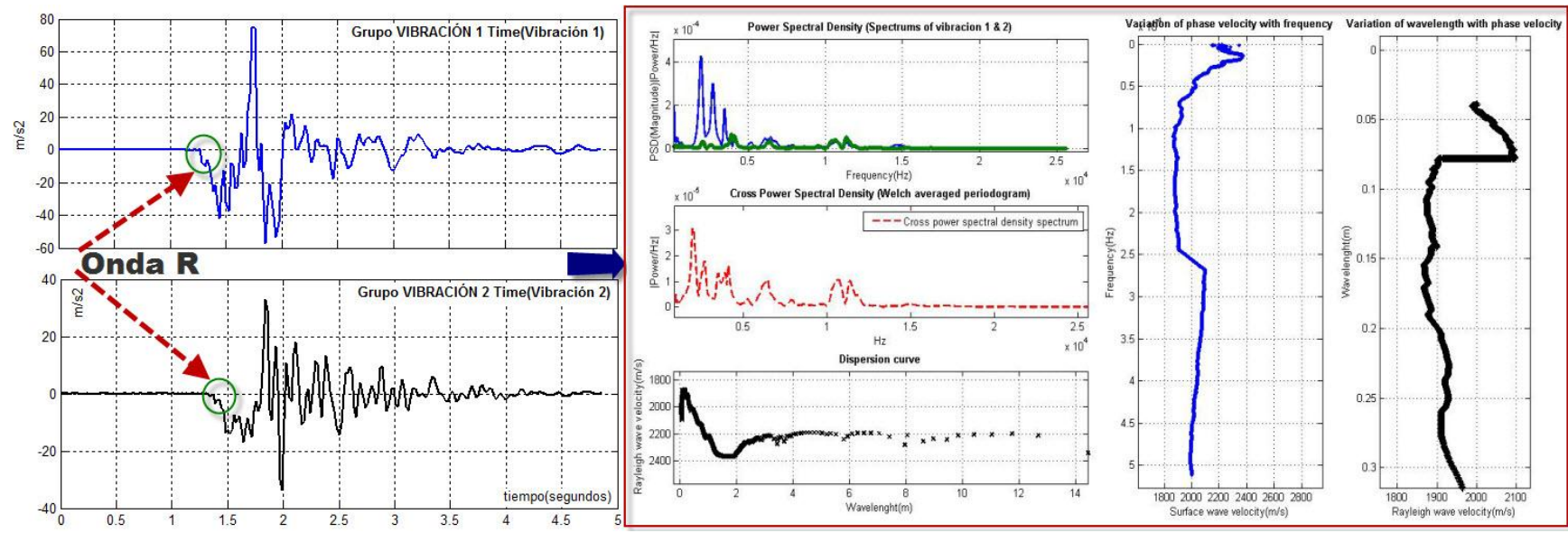

(Fig. 102). Ejemplo para el registro con $d_{1}: 6 \mathrm{~cm}$ y $d_{2}: 12 \mathrm{~cm}$. Obsérvese el efecto de las discontinuidades de fase en la curva bruta de dispersión, por lo que será necesario filtrar las frecuencias no válidas. 
- Repetimos este proceso para los 4 registros restantes y desarrollamos la curva de dispersión resultante:
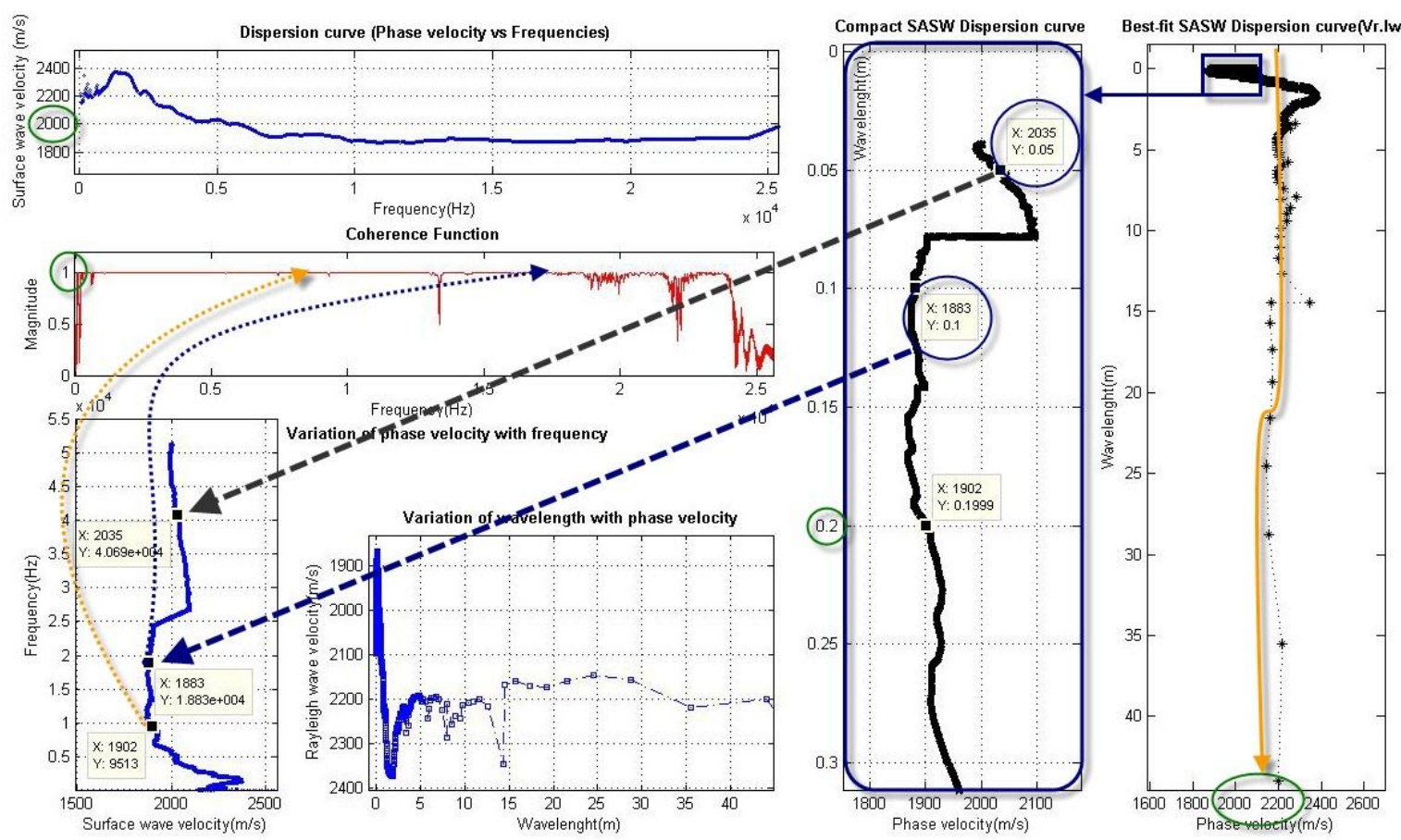

(Fig. 103). Filtrado de la curva de dispersión para el ensayo con $d_{2}: 24 \mathrm{~cm}$

- Seleccionamos la función de coherencia que unifique las frecuencias aptas para el set de registros de cada curva de dispersión local. La curva global de dispersión se obtiene del conjunto de curvas individuales que se han construido manteniendo únicamente las frecuencias que cumplen con la coherencia por encima de un valor del 95\%.:
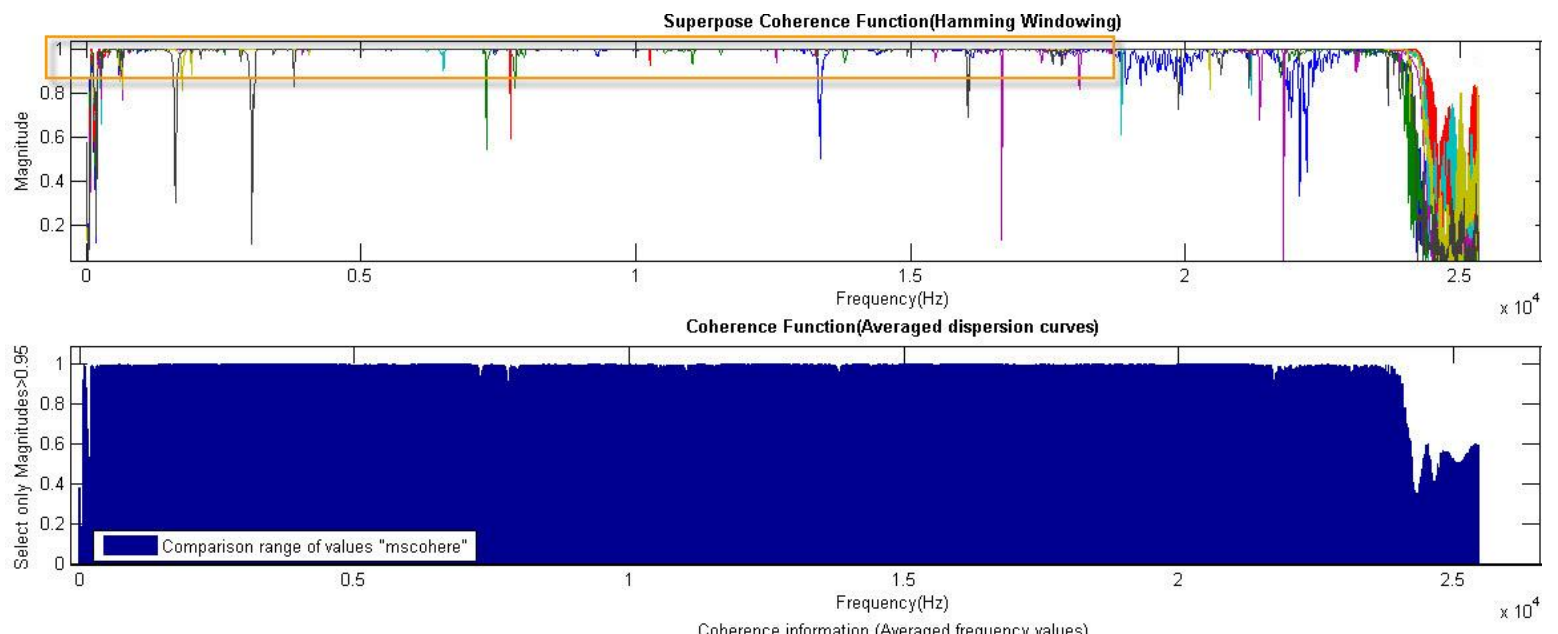

Coherence information (Averaged frequency values)

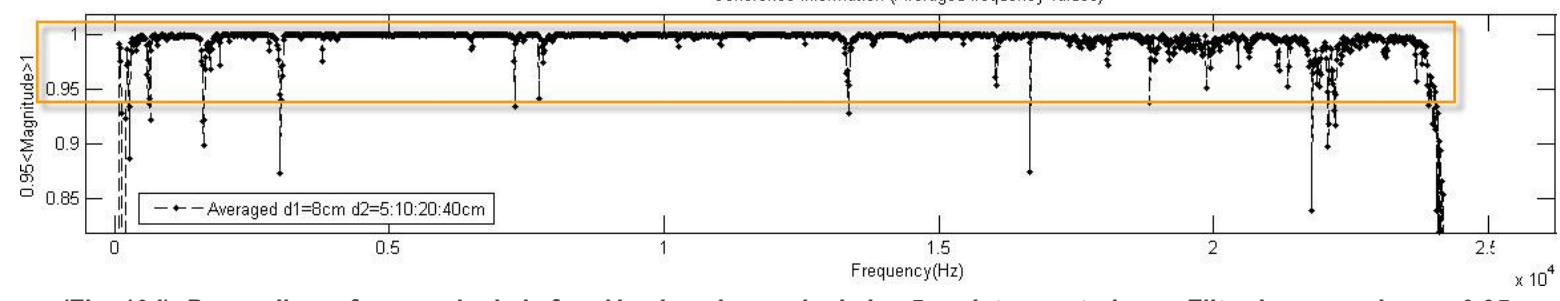

(Fig. 104). Promedio en frecuencia de la función de coherencia de los 5 registros anteriores. Filtrado para valores $>0.95$ 
- El último paso es obtener la curva de dispersión global mediante el conjunto de registros. Esta curva se basa en la definición de los espectros de potencia cruzados de cada ensayo (5 en este caso) a través del promedio de las estimaciones espectrales de cada registro:
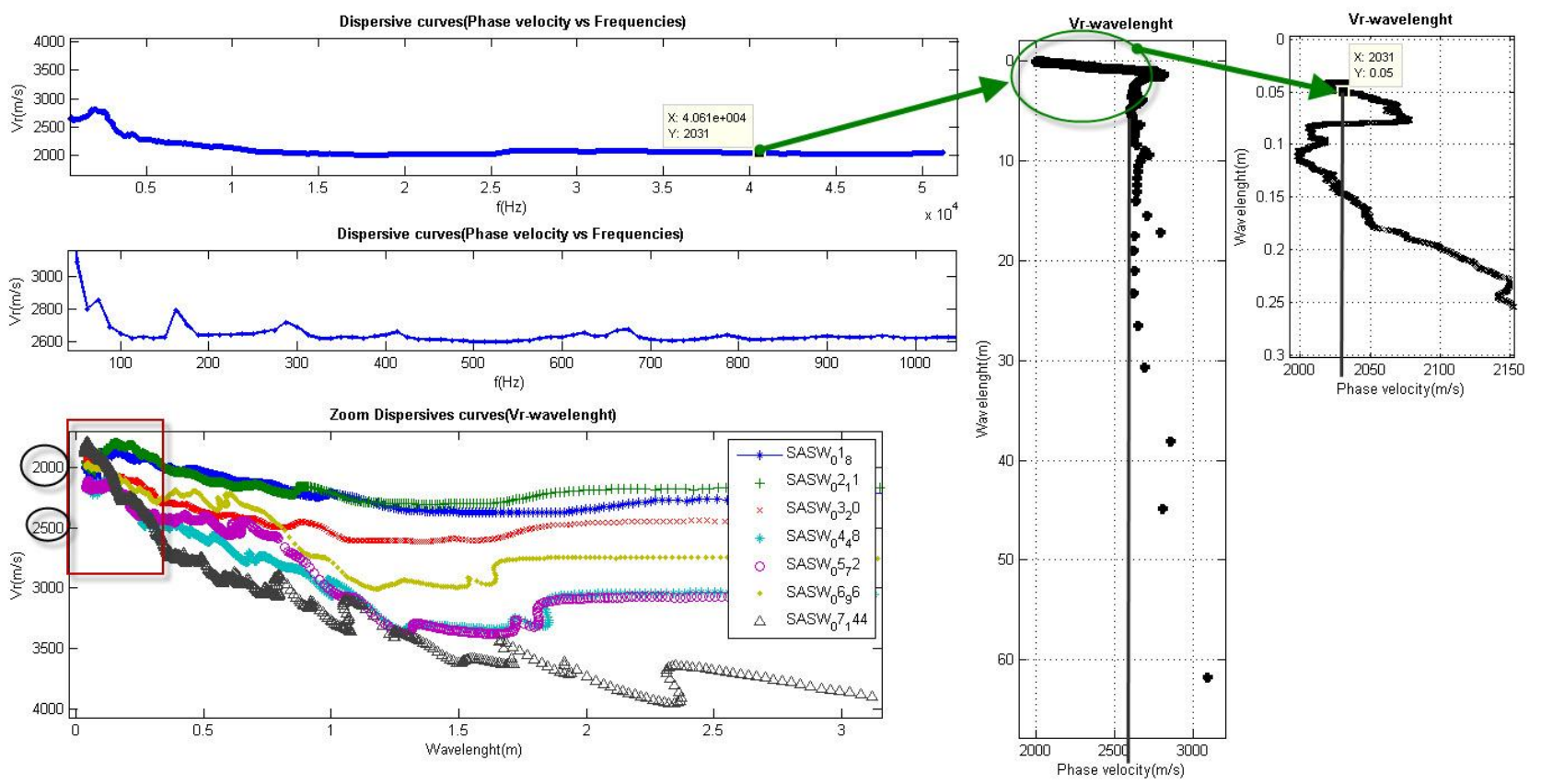

(Fig. 105). Detalle del procesamiento de las curvas de dispersión en Matlab. Obtención de una velocidad de onda superficial de $2031 \mathrm{~m} / \mathrm{s}$ para una longitud de onda de $5 \mathrm{~cm}$, un valor aceptable para un mortero estructural de buena calidad.

- Curva final de dispersión para el modelo de losa 40x40x20cm a la edad de 5 días:
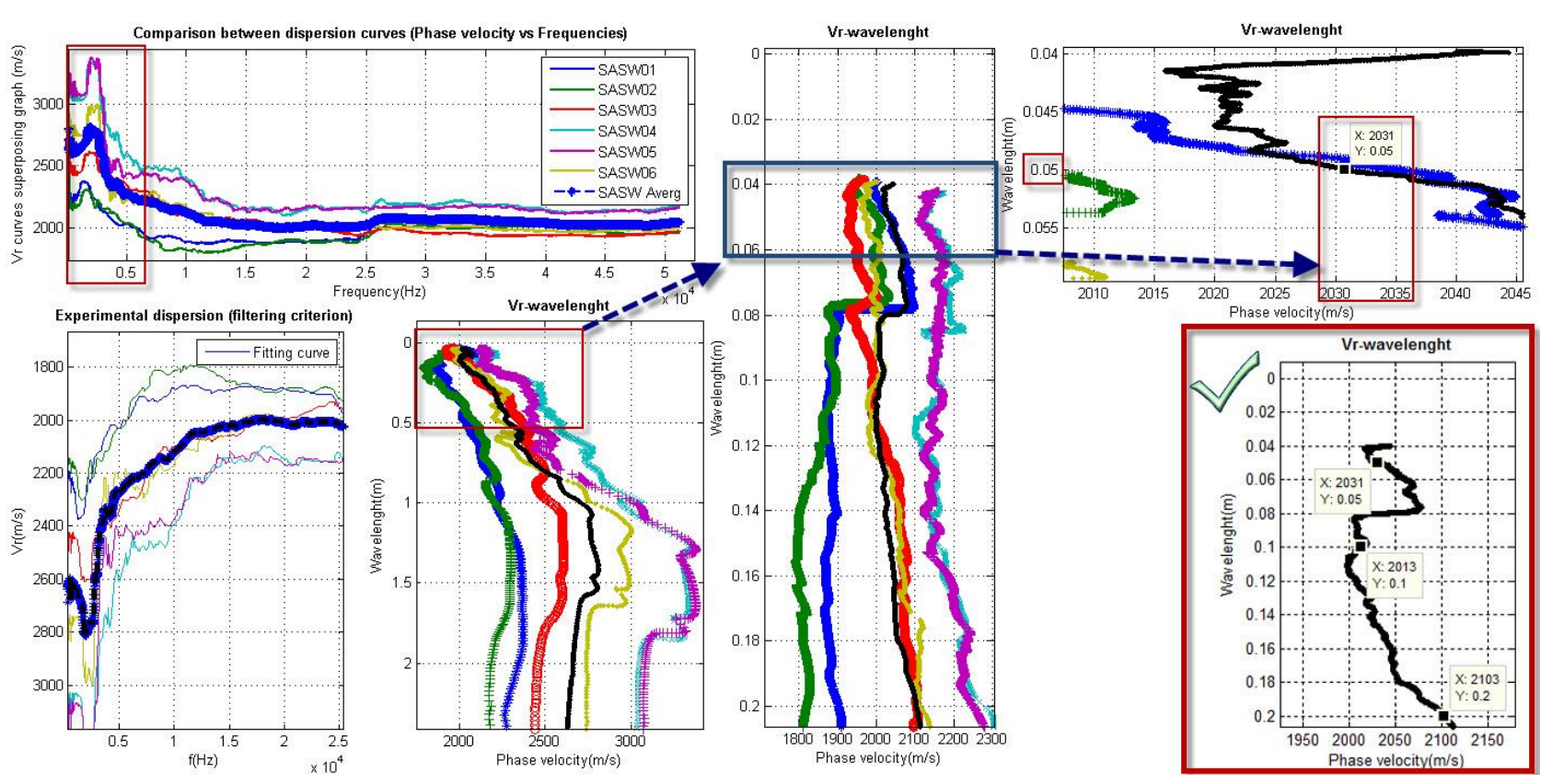

(Fig. 106). Curva global de dispersión mediante promediado de curvas y considerando desviación estándar .

Al igual que ocurría en el modelo de 2 capas, los ensayos realizados con distanciamientos más cercanos entre sí muestran una dispersión de la velocidad en un rango de edades que difiere del

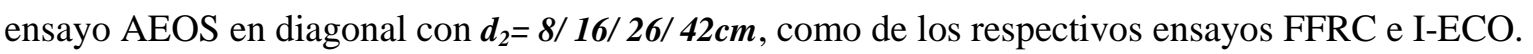


Aunque para la tabla final de valores de velocidad se han promediado posteriormente ambos AEOS_(01+02)/2, resulta necesario estudiar con más detalle la influencia de los distanciamientos en modelos de mayor heterogeneidad:
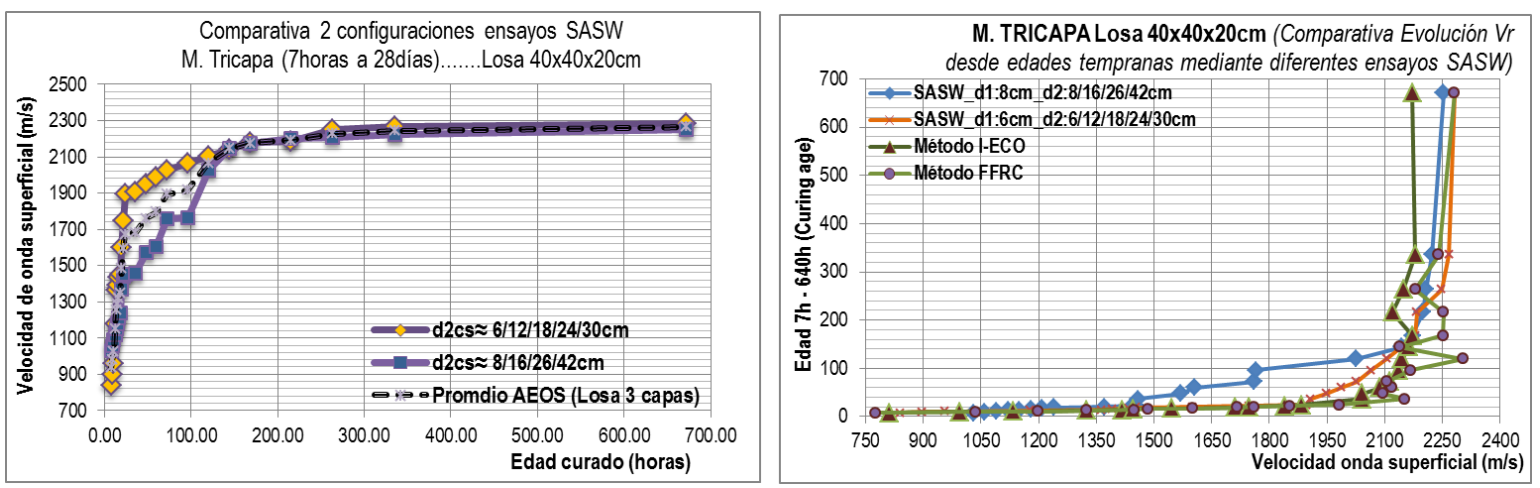

(Fig. 107). Evolución velocidades de onda vs Edad curado [En este caso, las distancias mayores ofrecen mayor dispersión de datos, y es debido a que separaciones del orden de $30-40 \mathrm{~cm}$ se alejan del criterio de filtrado establecido]. Recordemos que un ensayo $A E O S$ es válido mientras $d_{2} \leq \lambda$.

- Este estudio muestra que el método SASW detecta las características dispersivas en losas de mortero multicapa de espesor finito. Parece que el método es una herramienta END razonable para aplicarse en el campo del control de calidad y análisis de la integridad de las estructuras. El método AEOS se ha aplicado con eficacia en modelos tipo placa con diferentes dosificaciones.

- Para el ejemplo del método a 5 días se establecen los siguientes resultados mediante el promedio de 6 registros correspondientes a las señales adoptando las distancias entre acelerómetros $d_{2}=6 / 12 / 18 / 24 / 30 \mathrm{~cm}$, que han demostrado arriba ser más fiables:

Amasada M04

LOSA $40 \times 40 \times 20 \mathrm{~cm}$

Dosificación $((1 ; 0,4 ; 2,71))$

(Densidad, módulos elásticos y dinámicos,

Poisson y Rigidez transversal, velocidad de onda y resistencia a flexo-compresión)
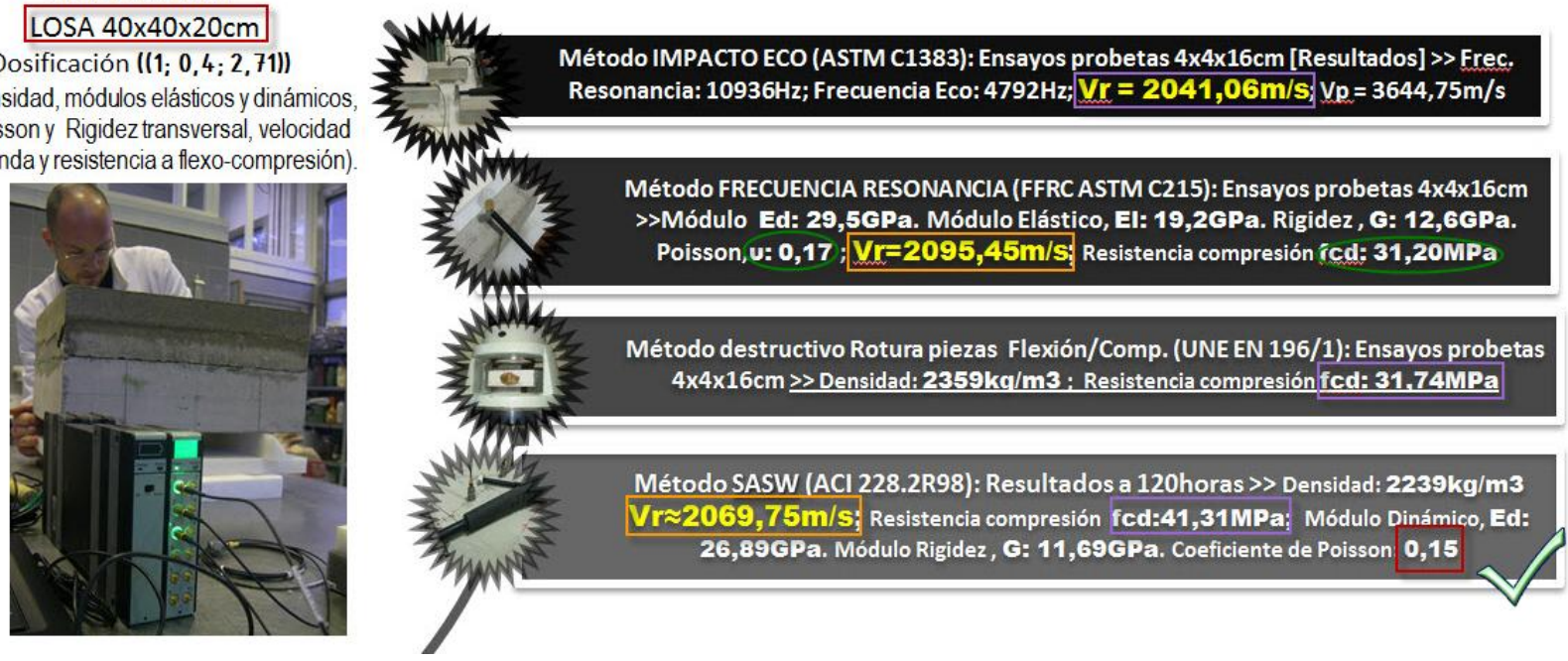

(Fig. 108). Comparativa resultados a la edad final de $\underline{120 h}$ para cada técnica reservada para validación del método AEOS. 


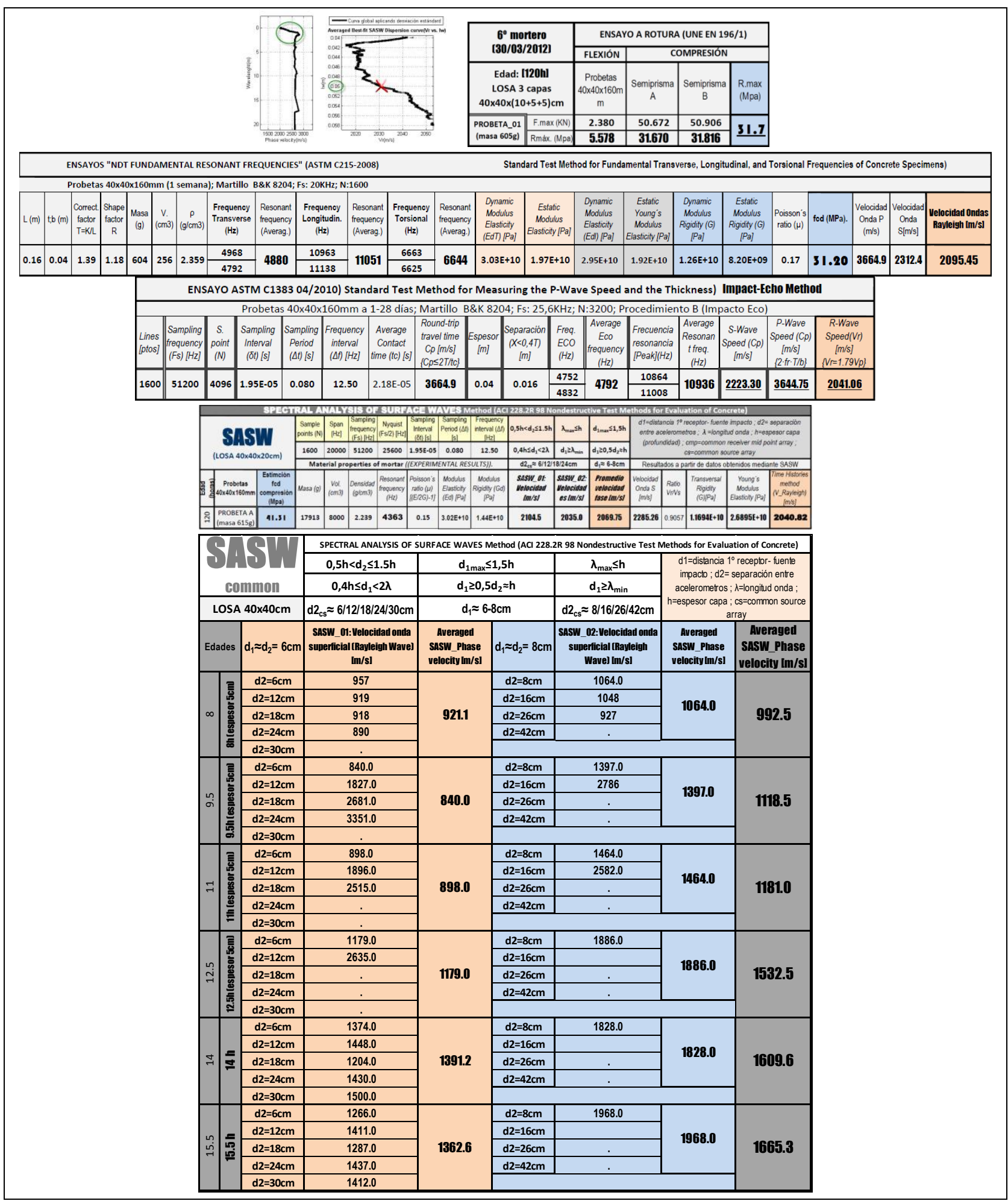

(Fig. 109). Modelo de tabla para procesado de datos del método AEOS. [Incluye rutina desarrollada para cálculo automatizado de los ensayos mediante FFRC, I-ECO y ensayo de resistencia a rotura]. Velocidades de fase para Losa e. $20 \mathrm{~cm}$. 


\section{Análisis Espectral de Ondas Superficiales (AEOS)}

(IX). CONCLUSIONES.

Con el enfoque experimental de procesamiento de datos por la técnica SASW se ha conseguido un método válido en morteros para la determinación de parámetros elásticos del material y procesamiento de las señales de ondas superficiales para inferir la curva de dispersión, destacando la superación de aspectos como reducción de ruido incoherente, dispersión y atenuación.

pueden obtenerse mediciones de velocidad de onda superficial en apenas un día y sin necesidad de extraer testigos ni usar técnicas destructivas. Además, las mediciones son a una misma cara del elemento facilitando la monitorización en estructuras de difícil acceso.

Tales medidas son adecuadas para la continuación del método en futuros trabajos de supervisión de la ganancia de resistencia en hormigones en masa $y$ reforzados con acero a edad temprana.

C 01. Comportamiento dispersivo del mortero.

Durante el presente trabajo, se llevó a cabo una serie de mediciones a cada mortero a edades tempranas paralelas al ensayo AEOS. Se estudiaron rangos amplios de frecuencias $(10 \mathrm{~Hz}$ a $60 \mathrm{KHz})$ y los resultados destacaron la dependencia de atenuación de velocidad a altas frecuencias mientras que la relación agua/cemento influía decisivamente en los parámetros del material (Resistencia y módulo de Elasticidad). Podemos concluir que se deduce:

- Debido a la atenuación a altas frecuencias del mortero sobre el Ø del árido, así como la absorción a bajas frecuencias, se asume que la dispersión de las ondas puede proporcionar información valiosa desde parámetros de defectos internos o inclusiones de partículas en la matriz del mortero, influyendo en el frente de ondas superficiales.

- Sobre la base del análisis del comportamiento de la propagación de ondas superficiales, se concluye que las curvas de dispersión obtenidas para los 3 modelos de mortero (uni/bi/tri capas) mediante SASW son fiables. En mi opinión, la técnica podría utilizarse para estimar las propiedades en estructuras reales a edad temprana, recomendando esta técnica al estudio de las propiedades, resistencia e identificación de defectos en materiales de naturaleza heterogénea (hormigón en masa, reforzado con acero...).

Se hace mención a las siguientes observaciones experimentales:

- El mortero es un material sensible a las tensiones (módulo de Elasticidad y rigidez) aumentando con la velocidad de deformación creciente (perfil dispersivo).

- A + contenido en arena >> + atenuación a frecuencias altas $\gg>$ - velocidad de onda.

- El aumento del contenido de arena tiene un impacto positivo atenuando en altas frecuencias y un impacto negativo sobre las bajas frecuencias.

- El módulo de Young disminuye lentamente por la presión y se debilita rápidamente ante un estado tensional unidimensional en caso de impactos repetidos. 
- La mayor dispersión de onda aparece alrededor de un rango de frecuencias de $15 \mathrm{Khz}$ debido al incremento de la relación a/c y, por tanto, el similar aumento de la velocidad de onda.

C 02. Método de propagación de ondas superficiales y otras técnicas END.

\footnotetext{
Se han revisado los 3 métodos (FFRC + I-ECO + AEOS) por su aplicación, fiabilidad, rendimiento y conjunción de datos, y se han explorado los principios, instrumentación, técnicas de procesamiento de señales y aplicaciones representativas de cada método de prueba y su mejora de uso en conjunción.
}

La característica común de estos métodos es que infieren en las condiciones internas del mortero, ya que se basan en el efecto que tiene una estructura en la propagación de ondas superficiales. En general, se requiere acceso sólo a una cara superficial del modelo. Dependiendo de la configuración de prueba y la respuesta obtenida, el método AEOS aporta datos del material más fiables sin necesidad de suposiciones ni técnicas destructivas.

- Se ha establecido la base teórica del método de IMPACTO-ECO mediante simulaciones de propagación de ondas transitorias en los distintos morteros, demostrando su capacidad para detectar defectos internos y la velocidad de onda $P$, generando un pulso de tensión de alta energía y midiendo los desplazamientos superficiales cerca del punto de impacto.

- El método de FRECUENCIA-RESONANCIA, rápido y limpio de ejecutar, perite determinar las propiedades elásticas/dinámicas del material de ensayo (Módulos, rigidez global...)

- El método AEOS utiliza técnicas de procesamiento de señales similares a los métodos anteriores de forma más completa, pero se extrae la mejor información acerca de la estructura de la onda superficial creada por el impacto; la curva de dispersión con las velocidades de fase. Es el más complejo de los métodos cubiertos; se basa en el principio de que la longitud de onda superficial por impacto generado penetra a diferentes profundidades en la estructura de prueba.

El método AEOS aspira en futuros trabajos a confirmarse en materiales multicapa de matriz heterogénea (hormigón). Se valora la eficacia en la determinación de parámetros elásticos del material necesarios para la propia metodología [espesor, densidad, coeficiente de Poisson y módulo de Young de cada capa] con un margen de error mínimo en comparación con las otras técnicas.

C 03. Ventajas/Inconvenientes del desarrollo experimental del método AEOS.

\section{Ventajas:}

- Destaca su naturaleza no destructiva, la capacidad de analizar sub-estratos del mortero sin perturbarlos y en zonas de imposible muestreo por la posible dificultad de acceso, o la incapacidad de realizar ensayos destructivos. 
- El uso de ondas superficiales, al proporcionar mayor energía que las ondas $P$ o $S$, son más sensibles al estudio de las velocidades, y a la atenuación de onda debido a la presencia de heterogeneidades.

- Es un método de ensayo no destructivo in situ que se puede realizar rápidamente, barato y preciso. La información que proporciona es dependiente de la fuente de impacto utilizada, de las propiedades del modelo y separación entre la fuente y los sensores.

- Frente a los otros métodos ensayados, AEOS globaliza las propiedades afectando a toda la capa estudiada. El método es igual independientemente del tamaño del modelo.

- Sirve para zonificar superficies en las que se espera la existencia de diferente rigidez (morteros) y evalúa la resistencia y daños por microfisuración.

- El gasto involucrado en el desarrollo y realización de testigos, extracción de muestras y traslado de equipos, con otras técnicas, son mucho mayores a los involucrados en un ensayo espectral de ondas superficiales.

- La curva de dispersión proporciona las velocidades de un material sin saber los espesores de las capas inferiores a la superficie de estudio.

\section{Inconvenientes:}

- La profundidad de investigación depende de la frecuencia generada, necesitando bajas frecuencias para obtener información en mayor profundidad.

- La técnica AEOS muestra un compromiso de fiabilidad, ya que un pequeño error de medición puede producir importantes desviaciones en la estimación de velocidades a determinadas frecuencias (Ej, desarrollo del "phase unwrapping”).

- Debido a la naturaleza heterogénea del material, las reflexiones producidas por los contornos laterales afectan a la curva de dispersión. Igualmente el ruido ambiente de naturaleza aleatoria captado por el impacto precisa de mediciones consecutivas para eliminarse o el filtrado previo de los registros con funciones ventana tipo Hanning.

- Parte del supuesto de considerar estratos de capas en horizontal para simular perfiles en dispersión y sólo considera la influencia del primer modo fundamental.

- No es preciso en la gama de frecuencias por encima de la frecuencia de "corte". Necesita ajustarse a los criterios de filtrado fijados (distancias, rangos de frecuencia...), por lo que los acelerómetros no pueden alejarse arbitrariamente.

C 04. Aspectos clave del método.

La variabilidad en los ensayos se debe a las características de atenuación del material como "efecto intrínseco" causado por la absorción y la dispersión. Por otro lado, se ha comprobado que el efecto del árido (filler, arena $<\varnothing 4 \mathrm{~mm} \ldots$...), la proporción a/c, tiempo de curado, son factores dominantes en la velocidad de onda. Por lo tanto, la composición del material afecta a la atenuación material del mortero, y por lo tanto las velocidades de fase son dependientes de la frecuencia y de la longitud de onda.

Los resultados a las probetas de 40x40x160mm a edades de 7 h a 28 días indican conclusiones relevantes para los posteriores ensayos experimentales futuros en hormigón: 
- A + relación agua/cemento (a/c) \>-velocidad de onda de propagación.

- A + relación agua/cemento $(\mathrm{a} / \mathrm{c})$ > + tiempo de curado.

- A - tiempo de fraguado >> + velocidad de onda.

- A + tamaño de árido >> - velocidad de onda de propagación.

- $A-a / c y-\varnothing$ árido >> + resistencia a compresión a edad temprana.

- A + contenido en arenas >>+ atenuación a frecuencias altas.

Se asumen las siguientes hipótesis basadas en resultados experimentales:

- La distancia entre fuente y primer receptor debe ser igual (recomendable) a la distancia entre los dos receptores $(\boldsymbol{D} \approx \boldsymbol{x})$.

- Longitudes de onda más grandes que 3 veces la distancia entre receptores no deben ser consideradas debido al fenómeno de atenuación de onda $(\lambda \leq 3 x)$.

- Las longitudes de onda superiores a la profundidad de la capa de análisis, no son deseables porque no producen resultados fiables $(\lambda \leq \boldsymbol{H})$.

Para que sea práctico el método SASW debemos considerar 2 hipótesis:

- Un modelo heterogéneo como el mortero compuesto de varias capas horizontales puede aproximarse a un medio unicapa de propiedades constantes.

- Se ignora el efecto de las ondas primarias y participan sólo ondas Rayleigh. [La validez de este supuesto muestra que ignorar el efecto de onda P está justificado mientras la geometría fuentereceptor en relación con la longitud de onda se mantenga dentro de los criterios establecidos arriba].

C 05. Discusión de variabilidad en resultados.

Los resultados demuestran la exactitud de las ondas Rayleigh en el diagnóstico del mortero en fase de curado. A 28 días el promedio de velocidad de la curva de dispersión indica una velocidad de fase de onda-R de $\approx 2200 \mathrm{~m} / \mathrm{s}$, aproximadamente para toda longitud de onda menor a (0,8 espesor del volumen, es decir, entre 5 y $20 \mathrm{~cm}$; resistencia a compresión de 40MPa y módulo de Young 35GPa). Los mejores resultados se dieron con velocidades $\approx \mathbf{1 9 0 0 - 2 1 0 0 m} / \mathrm{s}$.

* La mala colocación de un acelerómetro puede provocar un cambio significativo en la frecuencia central. En superficies rugosas el empleo de pernos roscados o las placas homologadas por Brüel\&Kjaer, atenuaron las señales y filtraron los registros.

* La mayor optimización de los receptores se obtuvo aumentando la longitud de onda y reduciendo la separación o distancia a recorrer desde la fuente al acelerómetro en base a los criterios de filtrado presentados (distanciamiento receptores $\approx$ espesor modelo). 
C 06. Experiencias propias en los ensayos experimentales.

* Cuando se crea una onda por el impacto, en este caso, de un martillo con punta de acero de $\emptyset 5$ a 12mm, la mayor parte de la energía generada es en forma de onda superficial.

* En conjunción con la técnica de Impacto-Eco podemos extrapolar el método a estructuras en las que se desconozca el espesor o profundidad de capa, y determinar el módulo de Young, E, y de rigidez transversal, $G$.

* Las ondas de Rayleigh producidas por la fuente de impacto deben tener una amplia gama de frecuencias con amplitudes más altas que el ruido incoherente de fondo para mantener un espectro de Fourier sin interferencias en torno a la frecuencia de resonancia.

* Un impacto de tiempo corto produce ondas de altas frecuencias que se propagarán en la parte superior del espécimen de ensayo. Por lo tanto, la fuente de impacto tendrá en cuenta la rigidez de la capa, la distancia entre receptores y la profundidad del modelo.

* En aquellas probetas realizadas con una relación a/c mayor, condiciones de curado a temperatura ambiente y con excesivas pérdidas por evaporación, manifestaron una pérdida de velocidad de onda tanto en Impacto-Eco como en Frecuencia-Resonancia, lo cual era indicativo de un consistente deterioro y bajada de resistencias.

* Las mediciones con la técnica AEOS muestran que reducciones de la velocidad de onda superficial indican un descenso proporcional del módulo de elasticidad.

* Un promedio de cuatro registros por ensayo, permite obtener una curva de dispersión global con un margen de error inferior al $2 \%$ en comparación a las técnicas FFRC e IECO. Se debe a que los registros mantienen buena coherencia entre sí:
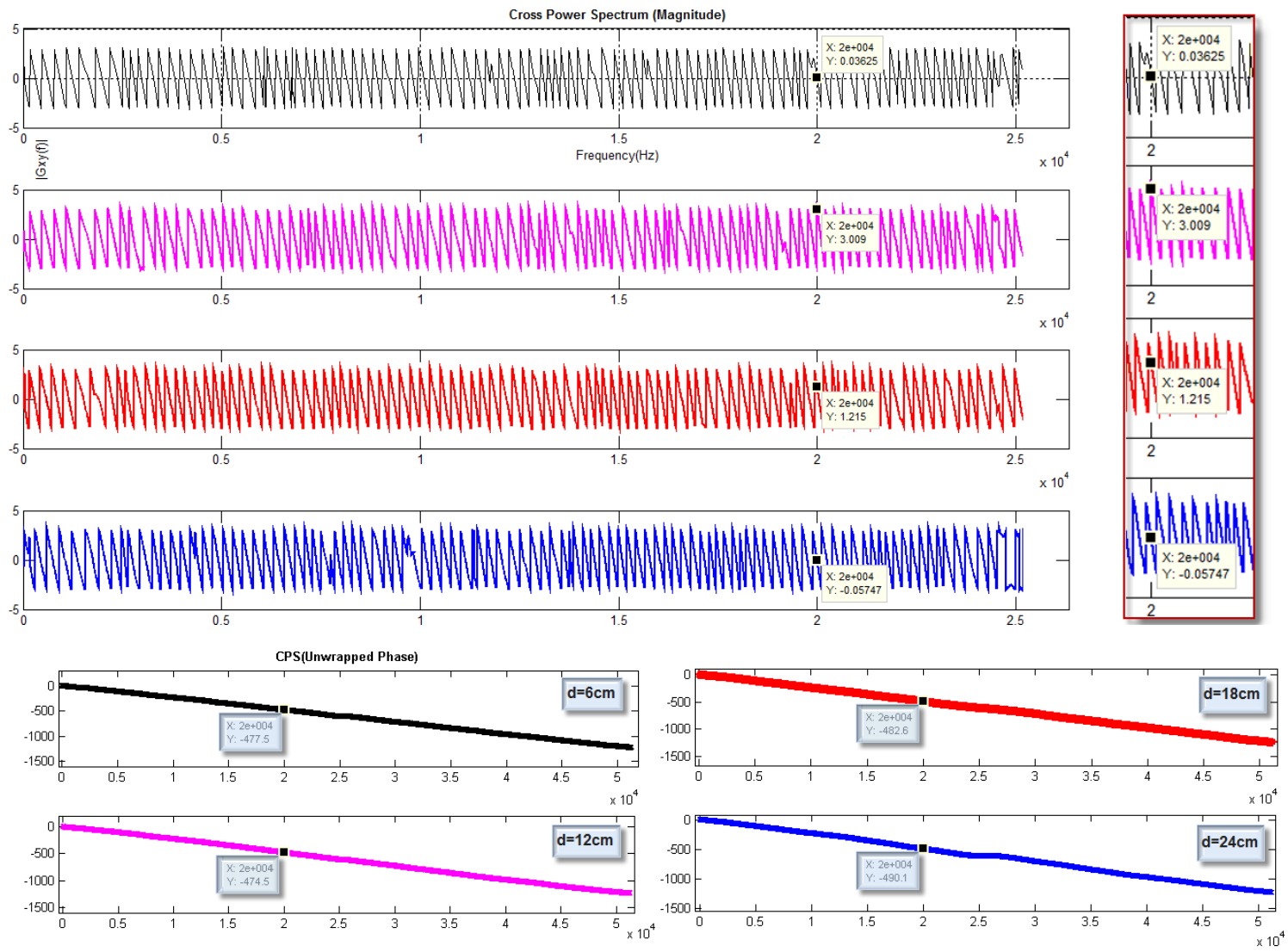

(Fig. 110) Similitud de espectros de fase y fase desplegada para 4 registros diferentes para un mismo ensayo. 
* Para mejorar la calidad de la señal, se aplicó una "VENTANA" (Hanning, Hamming, Flat top...) a la señal en el dominio del tiempo antes de realizar el análisis espectral. Las "ventanas" sobre la señal son necesarias para obtener los diagramas de fase de forma clara, ya que afectan a la suavidad y la magnitud del espectro, y minimizan los efectos del "picket fence" o fuga espectral (LEAKAGE) actuando como un filtro de banda.

* Los resultados de frecuencias fundamentales son más precisos mediante el método de Frecuencia-Resonancia (ASTM C215) y en pequeños especímenes que mantengan una proporción longitud=4.espesor (Ej: probetas $4 \times 4 \times 16 \mathrm{~cm}$ ).

* Los espectros obtenidos mediante la FFT en Impacto-Eco que muestran excesivos picos o una línea de señal temporal dispersa, no ofrece resultados fiables debido a un exceso de ruido o de reflexiones de la onda con el contorno del modelo.

C 07. Conclusiones en el desarrollo de la rutina computacional.

Los resultados expuestos en la realización de los métodos computacionales empleados reflejan un desarrollo complejo del método de análisis espectral de ondas superficiales. Partiendo de conceptos generales como las series de Fourier para el tratamiento de señales temporales de carácter transitorio, se llegan a implementar comandos que han requerido sub-rutinas dentro del propio programa desarrollado en Matlab, debido a la manipulación de una gran cantidad de datos representados en matrices.

Cabe destacar la importancia decisiva del proceso denominado "unwrapping method" empleado para obtener la fase real entre las dos señales, valor clave para determinar una curva de dispersión coherente. Cualquier modificación de este parámetro, bien sea por una mala ejecución del filtrado de las señales o por despreciar rangos de frecuencias que proporcionen información espectral necesaria, ocasionarían unos resultados totalmente distintos a los correspondientes a la realidad. Se hace constar la obligatoriedad de aplicar los criterios de filtrado expuestos, la configuración del ensayo experimental no es aleatoria, se deben estudiar previamente los distanciamientos entre acelerómetros, ya que de ellos dependen la calidad de nuestros registros, ya que todo el método se sustenta en dos señales en el dominio del tiempo registradas por los receptores. Un análisis previo de qué información necesitamos, a que espesores tenemos pensando llegar en profundidad, un análisis superficial del aspecto del mortero, su aspereza, color... nos aportan en la mayoría de los casos datos muy valiosos, que con cierta experiencia serán determinantes en la elección del tipo de martillo que usaremos como fuente de impacto, de la sensibilidad requerida por nuestros transductores, del tipo de adhesivo o accesorio que se empleará para la sujeción a la superficie, dependiendo de la calidad de la misma y de su orientación (vertical...) y de otros parámetros que configuran un buen ensayo por el método de análisis espectral de ondas superficiales. 
(IX). CONCLUSIONES.

ANÁLISIS EXPERIMENTAL DE LA CURVA DE DISPERSIÓN DE VELOCIDADES DE ONDAS SUPERFICIALES EN MORTEROS A EDAD TEMPRANA AlUMnO: FERNANDO MARTÍNEZ SOTO 


\section{Análisis Espectral de Ondas Superficiales (AEOS)}

(X). FUTURAS LÍNEAS DE INVESTIGACIÓN.

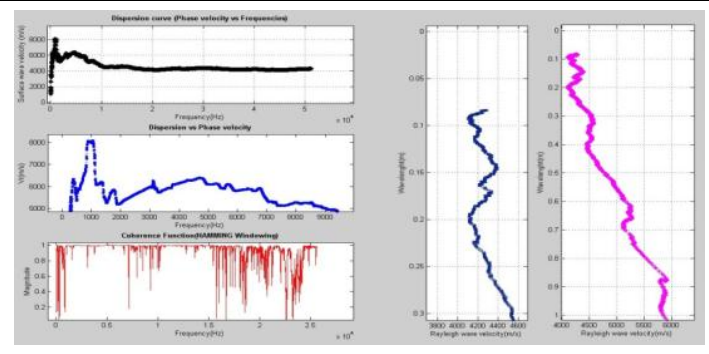

Objetivos, aplicaciones en desarrollo y trabajos futuros.

Simulación analítica y teórica mediante implementación numérica de la aplicabilidad de la técnica de exploración del perfil de propiedades mecánicas basada en la propagación de ondas elásticas superficiales al caso del mortero y el hormigón en proceso de endurecimiento, generada a partir de los desarrollos experimentales efectuados a modelos estructurales reales.

$>$ Implementación a un programa automatizado de la rutina computacional creada para el método AEOS. Mejora de la técnica en cuanto a depuración de coherencia entre señales, efecto de campo cercano, atenuación, absorción y promedio de las curvas de dispersión.

$>$ Desarrollar una red neuronal o un algoritmo genético para mejora del proceso de inversión.

> Aplicación de la técnica de análisis espectral con múltiples acelerómetros (técnica MSASW).

$>$ Investigar el método AEOS en modelos numéricos de elementos finitos tipo placa.

$>$ Desarrollo del equipo de adquisición de datos para lectura de deformaciones mediante bandas extensométricas adheridas en probetas de ensayo.

$>$ Desarrollo de modelos experimentales a mayor escala (Ej. Cubos de hormigón de Im3). Adquisición de datos para longitudes de onda mayores. Análisis de la atenuación de ondas en profundidad y correlación con resistencias a edad temprana.

$>$ Continuidad en el desarrollo del método: aplicación del proceso iterativo de inversión para inferir el perfil de velocidades y el perfil de rigidez del medio de ensayo mediante un modelo teórico de prueba.

$>$ Extender el trabajo al uso de otros tipos de cemento, ya que en este trabajo se ha restringido al CEM I 42,5R. Estudiar la incorporación de adicciones y aditivos.

$>$ Abordar un estudio más profundo para aumentar la precisión del método dentro de las 24horas de su fabricación. Desarrollo de una formulación empírica que defina el comportamiento del material a esas edades tempranas (velocidad, módulos, resistencias...).

$>$ Correlacionar el ensayo AEOS con otras técnicas (Ej. Método de la Madurez, modelado de elementos finitos, desarrollo de algoritmos genéticos o red neuronal para optimización de la curva de dispersión...). 
Las estructuras de hormigón, suelen estar sometidas a ataques agresivos, meteorización, variación de temperatura, ataques químicos, abrasión y otros procesos de degradación, que pueden actuar simultáneamente en la superficie del hormigón y reducir al mínimo su durabilidad. El mantenimiento y rehabilitación de zonas dañadas requiere una evaluación de la profundidad de su degradación. El uso de propagación de ondas superficiales con el método AEOS, parece ser un enfoque prometedor.

- El método asume la dominación del modo fundamental de onda $R$ y pasa por alto la importancia del resto de modos. Varios estudios han demostrado que los modos superiores pueden contribuir de manera significativa en la evaluación de la curva de dispersión y así afectar a la precisión del método. Como reto futuro a este problema y para desarrollar curvas de dispersión más exactas se proponen nuevos procedimientos de tratamiento de las señales, con algoritmos capaces de identificar y separar los modos fundamentales.

- Actualmente se evalúa con mayor aplicación la técnica SASW para inspeccionar daños bajo la superficie en estructuras de hormigón a gran escala, requeriendo rangos de frecuencias mayores a $100 \mathrm{kHz}$. Mediciones tan precisas de la velocidad de fase y atenuación son necesarias, por 10 que se precisarán fuentes de impacto apropiadas, mayor precisión y alcance del equipo analizador de señales para generar eficientemente bajas frecuencias.

- Una sugerencia para futuros estudios es la aplicación de acelerómetros de baja frecuencia que, aunque no son tan sensibles como otro tipo de receptores (ej. transductores de emisión acústica) podrían resultar más adecuados para las frecuencias bajas aplicadas en hormigón.

- Se recomienda analizar la sensibilidad de las curvas de dispersión con un arreglo de varios sensores, cambiando la fuente hacia posiciones simétricas. De la misma manera, sería posible evaluar cómo influye un mayor control sobre el rango de frecuencias utilizadas, o bien otro tipo de fuentes para muestrear mayores profundidades.

- Se recomienda el desarrollo de nuevos procesamientos de señales, que definan automáticamente la fase en los registros, permitiendo asi la identificación de modos superiores, detectando zonas de menor velocidad en profundidad.

- Para el cálculo del problema directo, se recomienda desarrollar un algoritmo eficiente que permita el cálculo de curvas de dispersión minimizando el efecto de las altas frecuencias.

- El uso de sismogramas sintéticos permitiría definir criterios por longitud de onda para establecer la equivalencia entre sistemas multicapa y unicapa, minimizando esfuerzos de optimización, pudiendo determinar sólo dos valores que caractericen la velocidad de onda superficial. 


\section{Análisis Espectral de Ondas Superficiales (AEOS)}

REFERENCIAS A NORMATIVA DE APLICACIÓN ACTUAL.
$\begin{aligned} & \text { En este capítulo se exponen las normas de aplicación a lo largo } \\ & \text { del presente estudio } \psi \text { se indican especificaciones de aquellas que } \\ & \text { guardan relación directo con los parámetros del material. }\end{aligned}$

Normativa ASTM.

Algunas normas ASTM tienen correspondencia con la normativa UNE, por lo que serán de aplicación consultando diferencias entre sí y aplicando la más restrictiva en su caso.

\begin{tabular}{|c|c|}
\hline \multirow{9}{*}{ 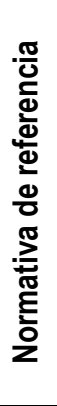 } & ASTM Standards Concrete \& Aggregates. \\
\hline & ASTM C31M "PRACTICE FOR MAKING AND CURING CONCRETE TEST SPECIMENS IN THE FIELD" \\
\hline & ASTM C125 "STANDARD TERMINOLOGY RELATING TO CONCRETE AND AGGREGATES" \\
\hline & ASTM C192M "MAKING AND CURING CONCRETE TEST SPECIMENS IN THE LABORATORY" \\
\hline & ASTM C138M "TEST METHOD FOR DENSITY, YIELD \& AIR CONTENT OF CONCRETE" \\
\hline & ASTM C469 "STATIC MODULUS OF ELASTICITY AND POISSON'S RATIO OF CONCRETE IN COMPRESSION" \\
\hline & ASTM C470M "MOLDS FOR FORMING CONCRETE TEST CYLINDERS VERTICALLY" \\
\hline & $\begin{array}{l}\text { ASTM C } 215 \text { "FUNDAMENTAL TRANSVERSE, LONGITUDINAL \& TORSIONAL RESONANT FREQUENCIES OF CONCRETE } \\
\text { SPECIMENS (IMPACT RESONANCE METHOD)" }\end{array}$ \\
\hline & 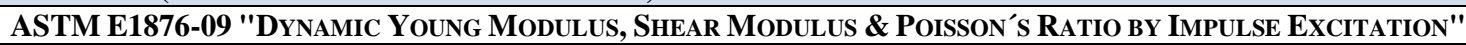 \\
\hline
\end{tabular}

Códigos ACI.

\section{ACl Codes. Concrete \& Mortars}

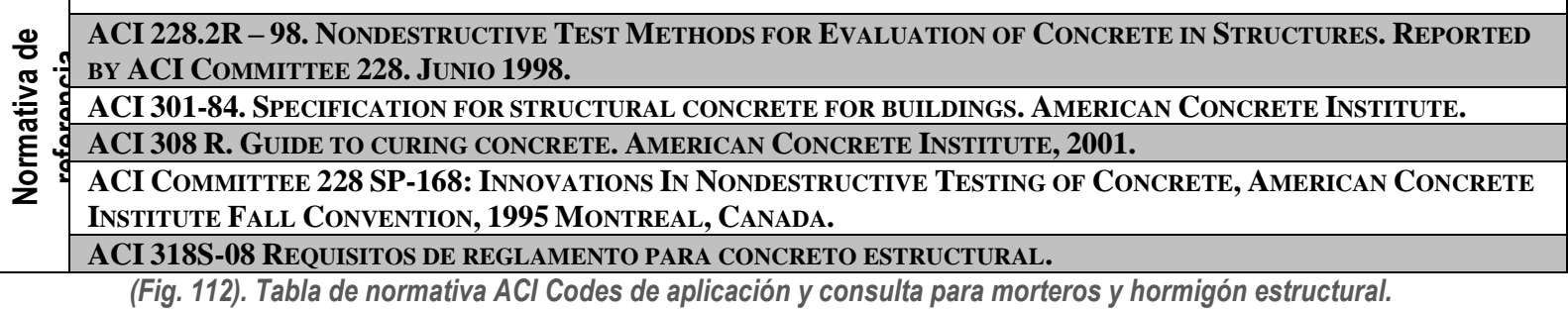

Normativa UNE.

Se centra en las normas referentes a cemento, áridos y morteros.

\begin{tabular}{|c|c|}
\hline \multirow{12}{*}{ 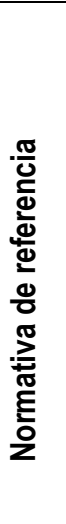 } & Norma Española UNE \\
\hline & UNE EN 196-1 (2005) "MÉTODOS DE ENSAYO DE CEMENTO: RESISTENCIAS MECÁNICAS" \\
\hline & UNE EN 197-1 (2000) "CEMENTO: COMPOSICIÓN, ESPECIFICACIONES Y CRITERIOS DE CONFORMIDAD" \\
\hline & UNE EN 146901 (2002) "ÁRIDOS: DESIGNACIÓN" \\
\hline & UNE EN 480-1 (2007) "ADITIVOS PARA MORTEROS: MÉTODOS DE ENSAYO (I): MORTERO DE REFERENCIA" \\
\hline & UNE EN 480-2 (2007) "ADITIVOS PARA MORTEROS: MÉTODOS DE ENSAYO (II): TIEMPO DE FRAGUADO" \\
\hline & UNE EN 1015-2 (1999) "MÉTODOS DE ENSAYO MORTERO ALB.: TOMA MUESTRAS Y PREPARACIÓN ENSAYO" \\
\hline & UNE EN 1015-6 (1999) "MÉTODOS DE ENSAYO MORTERO ALB.: DENSIDAD APARENTE DEL MORTERO FRESCO" \\
\hline & UNE EN 1015-9 (2000) "MÉTODOS DE ENSAYO MORTERO ALB.: TRABAJABILIDAD Y TIEMPO ABIERTO FRESCO" \\
\hline & UNE EN 1015-10 (2000) "MÉTODOS DE ENSAYO MORTERO ALB.: DENSIDAD APARENTE EN SECO ENDURECIDO" \\
\hline & UNE EN 1015-11 (2000) "MÉTODOS DE ENSAYO MORTERO ALB.: RESISTENCIA A FLEXIÓN Y COMPRESIÓN" \\
\hline & UNE EN 83316 (1996) "ENSAYOS DE HORMIGÓN: MÓDULO DE ELASTICIDAD EN COMPRESIÓN" \\
\hline
\end{tabular}

(Fig. 113). Tabla de normativa UNE de aplicación y consulta para cemento, áridos y morteros. 
Especificaciones de aspectos de normativa relevantes para la designación del mortero:

\begin{tabular}{|c|r|}
\hline \multicolumn{2}{|c|}{ DETERMINACIÓN PROPIEDADES DEL MATERIAL MEDIANTE ENSAYOS NDT } \\
\hline \hline \multirow{3}{*}{ UNE } & Densidad aparente del mortero fresco y endurecido. \\
\cline { 2 - 2 } & Módulos de Elasticidad estático y dinámico \\
\cline { 2 - 2 } & Coeficientes de Poisson estático y dinámico \\
\cline { 2 - 2 } & Resistencias a compresión y flexión \\
\hline \hline \multirow{2}{*}{ ASTM } & Velocidad de onda P y frecuencia de resonancia mediante ensayo Impacto-Eco \\
\cline { 2 - 2 } & Espectro de amplitud de la señal grabada mediante la FFT \\
\hline
\end{tabular}

- ASTM C469: aplicable a probetas prismáticas 40x40x160mm y en probetas $\varnothing 100 x 200 m m$ el módulo estático de elasticidad, $E_{S}$, coeficiente estático de Poisson, $\mu_{S}$, y la resistencia a compresión, $f_{C D} a$ edades de 7, 14, 28 y 56 días.

- ASTM C215 y ASTM E1876: método de la frecuencia fundamental transversal, longitudinal de resonancia, aplicable en prismas 40x40x160mm y cilindros $\varnothing 100 x 200 \mathrm{~mm}$ antes del ensayo destructivo de resistencia a compresión, determina el módulo dinámico de Young, $\boldsymbol{E}_{d}$, y el coeficiente dinámico de Poisson, $v_{D}$.

- ASTM C1383: método de Impacto-eco y SASW a una cara. Para las mismas probetas anteriores y en modelos prismáticos con espesor variable, ha permitido determinar la velocidad de onda por método de impacto-eco $V_{P}$ en el espécimen de mortero unicapa 40x40x20cm.

\begin{tabular}{|c|c|c|}
\hline \multicolumn{3}{|r|}{ CARACTERÍSTICAS DEL ENSAYO A PROBETAS DE MORTERO SEGÚN NORMATIVA } \\
\hline \multirow{3}{*}{$\stackrel{4}{\mathscr{\Phi}}$} & \multicolumn{2}{|r|}{ ASTM Standards Vol.04 Concrete \& Aggregates. } \\
\hline & \multicolumn{2}{|r|}{ Normas UNE } \\
\hline & \multicolumn{2}{|r|}{ Códigos ACl } \\
\hline \multirow{7}{*}{ 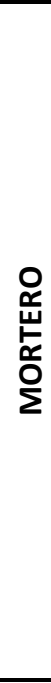 } & Tipo ensayo & Resistencias mecánicas \\
\hline & $\begin{array}{l}\text { Objeto y campo } \\
\text { de aplicación }\end{array}$ & $\begin{array}{l}\text { Determinación de las resistencias mecánicas a compresión y a flexión del mortero de cemento } \\
\qquad a 24,48,72 h, 7 \text { o } 28 \text { días. } \\
\end{array}$ \\
\hline & $\begin{array}{l}\text { Normativa de } \\
\text { consulta }\end{array}$ & UNE EN 196-1; UNE EN 197-1, UNE EN 197-7; UNE EN 1015-11 \\
\hline & $\begin{array}{l}\text { Fundamento del } \\
\text { ensayo }\end{array}$ & $\begin{array}{c}\text { Determinación de las resistencias a compresión, y opcionalmente a flexión, de probetas } \\
\text { prismáticas } 40 x 40 x 160 \mathrm{~mm} \text {. fabricadas con un mortero plástico: } 1 \text { parte en masa de cemento, } \\
3 \text { partes en masa de arena normalizada CEN, y } 1 / 2 \text { parte de agua (a/c: } 0,50) \text {. Cada amasada } \\
\text { para } 3 \text { probetas se compone: } 450 \mathrm{CEM}-\mathrm{I} 42,5 ; 1350 \mathrm{ARENA} ; 225 \mathrm{~A} \text { AGUA. }\end{array}$ \\
\hline & $\begin{array}{l}\text { Laboratorio, } \\
\text { equipo y } \\
\text { materiales }\end{array}$ & $\begin{array}{l}\text { El laboratorio de preparación de las probetas debe mantenerse a } \mathrm{T}^{a}=20 \pm 2{ }^{\circ} \mathrm{C}, \text { y } \mathrm{Hr}>50 \% \text {. } \\
\text { La cámara húmeda para la conservación de las probetas a } \mathrm{T}^{a}=20 \pm 1{ }^{\circ} \mathrm{C}, \text { y } \mathrm{Hr}>90 \%\end{array}$ \\
\hline & $\begin{array}{l}\text { Observaciones y } \\
\text { detalles del } \\
\text { ensayo }\end{array}$ & $\begin{array}{l}\text { Se confeccionan } 3 \text { probetas prismáticas de 40x40x160mm en molde compartimentado de } \\
\text { espesor 10mm y dureza Vickers HV200. } \\
\text { El molde debe ser de acero, con un espesor de }\end{array}$ \\
\hline & $\begin{array}{l}\text { Dimensiones } \\
\text { modelo ensayo: }\end{array}$ & $400 \times 400 \times 160 \mathrm{~mm}$ \\
\hline
\end{tabular}




\section{BIBLIOGRAFÍA (CATEGoRías).}

- ARTÍCULOS EN PERIÓDICO.

- ARTÍ́CULOS EN REVISTA CIENTÍFICA.

- DOCUMENTOS, TESIS Y TRABAJOS DE INVESTIGACIÓN.

- LIBROS Y CAPÍTULOS BIBLIOGRÁFICOS.

- ASTM STANDARDS, NORMATIVAS, REGLAMENTOS.

- SYMPOSIUMS, CONFERENCIAS.

- WEBS.

\section{ARTÍCULOS EN PERIÓDICO.}

- ADDIS, B.J., A rational approach to the assessment of concrete strength on the basis of core strength, Concrete Beton, Nov.1992.

- G.J. RIX \& E.A. LEIPISKI. Accuracy \& resolution of surface wave inversion, in Recent Advances in Instrumentation, Data Acquisition \& Testing in Soil Dynamics, v. 17. Bhatia, S.K. \& Blaney, G.W., Eds., Reston, VA, 1991.

- G.W. FARNELL. Properties of elastic surface waves, in Physical Acoustics. Mason, W.P., \& Thurston, R.N., Eds., Academic Press, New York, 1972.

- KRSTULOVIC-OPARA, N.; WOODS, R. D. \& AL-SHAYEA, N., "Nondestructive Testing of Concrete Structures Using the Rayleigh Wave Dispersion Method," ACI Materials Journal, V. 93, No. 1, Jan.Feb. 1996, pp. 75-86.

- MCLASKEY, G., \& SANSALONE, M., "Nondestructive Dynamic Evaluation of a Concrete Reaction Wall, ” ASCE Journal of the Performance of Constructed Facilities, August 2006.

- LIN, J.M., SANSALONE, M. \& STREETT, W.B., "A New Procedure for Determining the Thickness of Concrete Highway Pavements Using Surface Wave Speed Measurements \& the Impact-Echo Method," Innovations in Nondestructive Testing, Special Publication of the American Concrete Institute, 1997.

- LIN, J.M. \& SANSALONE, M., "A Procedure Based on the use of Rayleigh Waves for Determining PWave Speed for Use in Impact-Echo Testing of Concrete" Innovations in Nondestructive Testing, a Special Publication of the American Concrete Institute, 1997.

- LIN, Y., SANSALONE, M., \& CARINO, N.J., “Impact-Echo Response of Concrete Shafts," American Society of Testing \& Materials - Journal of Geotechnical Testing, June, 1990.

- RIX, G.J., BAY, J.A., \& STOKOE, K.H., II, Assessing in situ stiffness of curing portland cement concrete with seismic tests, Transp. Res. Rec., 1284, 8, 1990.

- SANSALONE, M., CARINO, N.J., \& HSU, N.N., "A Finite Element Study of the Interaction of Transient Stress Waves with Planar Flaws,” National Bureau of Standards Journal of Research, July/Aug., 1987, pp. 279-290.

- SANSAlONE, M., 1986, "Flaw Detection in Concrete Using Transient Stress Waves," Ph.D. Dissertation, Cornell University, 220 pp.

- SANSALONE, M., \& Carino, N.J., 1986, "Impact-Echo: A Method for Flaw Detection in Concrete Using Transient Stress Waves," NBSIR 86-3452, National Bureau of Standards, Gaithersburg, Maryl\&, Sept., 222 pp. 
- SANSALONE, M. \& CARINO, N.J., 1988, "Laboratory \& Field Studies of the Impact-Echo Method for Flaw Detection in Concrete," in Nondestructive Testing of Concrete, Special Publication of the American Concrete Institute, pp. 1-20.

- SANSALONE, M. \& N.J. CARINO. Impact-echo: a method for detection in concrete using transient stress waves. Volume NBSIR 86-3452. National Bureau of Standards (NTIS PB 87-104444/AS), Sept. 1986.

- SANSALONE, M., KESNER, K. \& POSTON, R.W., "Detection \& Quantification of Distributed Damage in Concrete Using Transient Stress Waves, ACI Materials Journal, July-August 2004.

- S. D. BOONE; P. J. BARR; \& J. A. BAY. Nondestructive Analysis of a Concrete Tunnel Model Using a Newly Proposed Combined Stress Wave Propagation Method. JOURNAL OF PERFORMANCE OF CONSTRUCTED FACILITIES C ASCE / NOVEMBER/DECEMBER 2009

- WILliamS, T., NOZICK, L., SANSALONE, M., POSTON, R. \& KESNER, K., "Use of Sampling Techniques to Assist in the Evaluation of Large Concrete Structures, Part II, ACI Structures Journal, June 2006.

\section{ARTÍCULOS EN REVISTA CIENTÍFICA.}

- A. ABO-QUDAIS. "Effect of concrete mixing parameters on propagation of ultrasonic waves". Construction \& Building Materials 19 (2005) 257-263. 2004 Elsevier Ltd.

- A. EL AYADI, B. PICOUX, G. LEFEUVE-MESGOUEZ, A. MESGOUEZ, y C. PETIT, “An improved dynamic model for the study of a flexible pavement," Advances in Engineering Software, vol. In Press, Corrected Proof.

- A.M. WHITWORTH y P. CHADWICK, "The effect of inextensibility on elastic surface waves," Wave Motion, vol. 6, Jun. 1984, págs. 289-302.

- A. SADRI, K. MIRKHANI. "Wave propagation concrete NDT techniques of evaluation structures \& materials”. ASPNDE 2009 Mississauga [Canada].

- C. BARRERA-DAZ, G. MARTNEZ-BARRERA, O. GENCEL, L.A. BERNAL-MARTINEZ, y W. BROSTOW, "Processed wastewater sludge for improvement of mechanical properties of concretes," Journal of Hazardous Materials, vol. 192, Ago. 2011, págs. 108-115.

- D. AGGELIS, "Numerical simulation of surface wave propagation in material with inhomogeneity: Inclusion size effect," NDT \& E International, vol. 42, Sep. 2009, págs. 558-563.

- DIMITRIOS G. AGGELIS, SHOUHEI MOMOKI, HWAKIAN CHAI. "Surface wave dispersion in large concrete structures”. NDT\&E International 42 (2009) 304-307. 2009 Elsevier Ltd.

- D. JONGMANS y D. DEMANET, "The importance of surface waves in vibration study \& the use of Rayleigh waves for estimating the dynamic characteristics of soils, ” Engineering Geology, vol. 34, May. 1993, págs. 105-113.

- D. KIM, W. SEO, y K. LEE, "IE-SASW method for nondestructive evaluation of concrete structure," NDT \& E International, vol. 39, Mar. 2006, págs. 143-154. Elsevier Ltd.

- F. GRONDIN, H. DUMONTET, A. BEN HAMIDA, y H. BOUSSA, "Micromechanical contributions to the behaviour of cement-based materials: Two-scale modelling of cement paste \& concrete in tension at high temperatures, " Cement \& Concrete Composites, vol. 33, Mar. 2011, págs. 424-435.

- G.J. RIX \& E.A. LEIPISKI. "Accuracy \& resolution of surface wave inversion, in Recent Advances in Instrumentation, Data Acquisition \& Testing in Soil Dynamics”, v. 17. Bhatia, S.K. \& Blaney, G.W., Eds., Reston, VA, 1991. 
- HARKRIDER (1964) "Surface waves in multilayered elastic media I. Rayleigh \& Love waves from buried sources in multilayered elastic halfspace”, Bulletin of the Seism. Soc. of Am., vol. 54.

- HEISEY J.S., K.H. STOKOE \& A.H. MEYER. "Moduli of pavement systems from spectral analysis of surface waves”, volume 22. Transp. Res. Rec., 1982.

- H. WIGGENHAUSER. "Advanced NDT methods for the assessment of concrete structures". (Concrete Repair, Rehabilitation \& Retrofitting). 2009 Taylor \& Francis Group, London.

- H. YILDIRIM y O. SENGUL, "Modulus of elasticity of substandard \& normal concretes," Construction \& Building Materials, vol. 25, Abr. 2011, págs. 1645-1652.

- J. BOYD \& CHRISTOPHER FERRARO, "Effect of Curing \& Deterioration on Stress Wave Velocities in Concrete”. JOURNAL OF MATERIALS IN CIVIL ENGINEERING ASCE / MARZO-ABRIL 2005.

- J. KUMAR, "A study on determining the theoretical dispersion curve for Rayleigh wave propagation," Soil Dynamics \& Earthquake Engineering, vol. 31, Ago. 2011, págs. 1196-1202.

- JAE HONG KIM, HYO-GYOUNG KWAK. "Rayleigh wave velocity computation using principal wavelet-component analysis”. NDT\&E International 44 (2011) 47-56. 2010 Elsevier Ltd.

- JAE HONG KIM; SURENDRA P. SHAH; ZHIHUI SUN \& HYO-GYOUNG KWAK. "Ultrasonic Wave Reflection \& Resonant Frequency Measurements for Monitoring Early-Age Concrete”. JOURNAL OF MATERIALS IN CIVIL ENGINEERING @ ASCE / SEPTEMBER 2009.

- JAMES BAY, JEFF GILBERT, KWANGSOO PARK \& INTHUORN SASANKUL. "Shear Wave Velocity Profiling Using Spectral Analysis of Surface Waves (SASW)”. Asten, M.W., \& Boore, D.M., eds., Blind comparisons of shear-wave velocities at closely spaced sites in San Jose, California: U.S. Geological Survey Open-File Report 2005-1169.

- J.D.N. CHEEKE. “Fundamentals \& Applications of Ultrasonic Waves”. CRC Press, Florida, 2002.

- J.H. KIM y H. KWAK, "Rayleigh wave velocity computation using principal wavelet-component analysis,” NDT \& E International, vol. 44, Ene. 2011, págs. 47-56.

- J. KRAUTKRAMER. “Ultrasonic Testing Fundamentals”. Springer-Verlag, New York, 1969.

- J. ROESLER, G.H. PAULINO, K. PARK, y C. GAEDICKE, "Concrete fracture prediction using bilinear softening,” Cement \& Concrete Composites, vol. 29, Abr. 2007, págs. 300-312.

- J.S. DOLADO y K. VAN BREUGEL, "Recent advances in modeling for cementitious materials," Cement \& Concrete Research, vol. 41, Jul. 2011, págs. 711-726.

- J.S. HEISEY, K.H. STOKOE, II, , \& A.H. Meyer. "Moduli of pavement systems from spectral analysis of surface waves”, volume 22. Transp. Res. Rec., 1982.

• J. SLIZARD. “Ultrasonic Testing”. John Wiley \& Sons, New York, 1982.

- J. ZHU, S. KEE, D. HAN, y Y. TSAI, "Effects of air voids on ultrasonic wave propagation in early age cement pastes,” Cement \& Concrete Research, vol. 41, Ago. 2011, págs. 872-881.

- KESNER, K., SANSALONE, M., HOVER, K.C., \& POSTON, R.W., "Detection \& Quantification of Distributed Damage in Concrete Using Transient Stress Waves,” Departmental Report, No. 97-6, Structural Engineering, Cornell University, December 1997.

- KRSTULOVIC-OPARA, R.D. WOODS, \& N. AL-SHAYEA. "Nondestructive testing of concrete structures using the Rayleigh wave dispersion method”. ACI Mater. J., 75:93,1996.

- K. SONG y G. CHO, "Numerical study on the evaluation of tunnel shotcrete using the Impact-Echo method coupled with Fourier transform \& short-time Fourier transform," International Journal of Rock Mechanics \& Mining Sciences, vol. 47, Dic. 2010, págs. 1274-1288. 
- K. KOVLER y N. ROUSSEL, "Properties of fresh \& hardened concrete," Cement \& Concrete Research, vol. 41, Jul. 2011, págs. 775-792.

- LAURENCE J. JACOBS \& JOSEPH O. OWINO. "Effect of aggregate size on attenuation of Rayleigh surface waves in cement-based materials”. Journal of Engineering mechanics / Nov. 2000.

- LIN J.M., \& SANSALONE, M., "Using the Impact-Echo Method for Determining Interfacial Bond Quality in Repaired or Layered Concrete Structures”, Department of Structural Engineering Report No. 95-4, Cornell University, May 1995.

- L. OLSON y P. MILLER, "Multiple impact surface waves (MISW) - Improved accuracy for pavement system thicknesses \& moduli vs. spectral analysis of surface waves (SASW),” Geotechnical Special Publication, 2010, págs. 1402-1411.

- MALHOTRA, V.M., "Non-destructive Methods for Testing Concrete”, Mines Branch Monogr. No.875, Department of Energy Mines \& Resources, Ottawa (1968).

- M.A. CEBALLOS y C.A. PRATO, "Experimental estimation of soil profiles through spatial phases analysis of surface waves, " Soil Dynamics \& Earthquake Engineering, vol. 31, 2011, págs. 91-103.

- M. GOUEYGOU, B. PIWAKOWSKI, M. KACZMAREK, F. BUYLE-BODIN. "NDE of two-layered mortar samples using high-frequency Rayleigh waves”. Ultrasonics 42 (2004) 889-895. 2004.

- M. HAQUE, M. GOPALAN, y D. HO, "Estimation of in situ strength of concrete," Cement \& Concrete Research, vol. 21, Nov. 1991, págs. 1103-1110.

- MOURAD KARRAY, GUY LEFEBVRE. Techniques for mode separation in Rayleigh wave testing. Soil Dynamics \& Earthquake Engineering 29 (2009) 607-619. 2008 Elsevier Ltd.

- NAZARIAN S. \& K.H. STOKOE. "In-situ determination of elastic moduli of pavement systems by spectral-analysis-of-surface-waves method". Rep. Center for Transportation Research, 473-2, 1986.

- NAZARIAN S. Automated surface wave method: field testing. J. Geotech. Eng. (ASCE), 1993.

- NAZARIAN S., K.H. STOKOE \& W.R. HUDSON. "Use of spectral-analysis-of-surface waves method for determination of moduli \& thicknesses of pavement systems”. Transp. Res. 38:930, 1983.

- N. J. CARINO, "Training: Often the missing link in using NDT methods," Construction \& Building Materials, vol. In Press, Corrected Proof.

- N. GUCUNSKI, R. SAUBER, A. MAHER, y C. RASCOE, "Modulus of Rubblized Portland Cement Concrete from Surface Wave Testing," Transportation Research Record: Journal of the Transportation Research Board, vol. 2104, Dic. 2009, págs. 34-41.

- N. KRSTULOVIC-OPARA, R.D. WOODS, \& N. AL-SHAYEA. "Nondestructive testing of concrete structures using the Rayleigh wave dispersion method”. ACI Mater. J., 75:93,1996.

- P. GALVÍN y J. DOMÍNGUEZ, “Experimental \& numerical analyses of vibrations induced by highspeed trains” Soil Dynamics \& Earthquake Engineering, vol. 29, Abr. 2009, págs. 641-657.

- POPOVICS, J. S., W. SONG J. D. ACHENBACH \& J. H. LEE. "One sided stress wave velocity measurement in concrete”. JOURNAL OF ENGINEERING MECHANICS / DECEMBER 1998.

- P. PELEKIS y G. ATHANASOPOULOS, "An overview of surface wave methods \& a reliability study of a simplified inversion technique,” Soil Dynamics \& Earthquake Engineering, vol. In Press.

- $\quad$ R. AL WARDANY, J. RHAZI, J.L. GALLIAS. "Use of Rayleigh wave methods to detect near surface concrete damage”. Department of Civil Engineering; Universite de Sherbrooke, Canada 2004.

- R. JONES. "Surface wave technique for measuring the elastic properties \& thickness of roads: theoretical development”. J. Appl. Phys., 21:13, 1962. 
- RYDEN, N., PARK, C. B., ULRIKSEN, P. \& MILLER, R. D. (2004). “Multimodal approach to seismic pavement testing. ” J. Geotech. Geoenviron. Eng., 130(6), 636-645.

- S. ALI ZOMORODIAN y O. HUNAIDI, "Inversion of SASW dispersion curves based on maximum flexibility coefficients in the wave number domain," Soil Dynamics \& Earthquake Engineering, vol. 26, Ago. 2006, págs. 735-752.

- SANSALONE, M., \& CARINO, N.J., "Impact-Echo: A Method for Flaw Detection in Concrete Using Transient Stress Waves,” NBSIR 86-3452, National Bureau of Standards, Gaithersburg, Maryl\&, Sept., l986, 222 pp.

- S. KEE y J. ZHU, "Surface wave transmission measurements across distributed surface-breaking cracks using air-coupled sensors, ”Journal of Sound \& Vibration, vol. 330, Oct. 2011.

- SOUTSOS, M.N, BUNGEY J.H, LONG A.E. \& HENDERSON G.D. "In situ strength assessment of concrete”. The European Concrete Frame Building Project. Elsevier Science Ltd. 2000.

- SRI ATMAJA P. ROSYIDI, MOHD RAIHAN TAHA, ZAMRI CHIK \& AMIRUDDIN ISMAIL. "Signal Reconstruction of Surface Waves on SASW Measurement Using Gaussian Derivative Wavelet Transform”. Acta Geophysica vol.57, n³, pp. 616-635. 2009 Institute of Geophysics.

- SHUANG X.Z., LUNG S. CHANA, CHANG Y.C., FU C.D., XIAO K.S., H. ZHONG. "Apparent phase velocities \& fundamental-mode phase velocities of Rayleigh waves”. Soil Dynamics \& Earthquake Engineering 23 (2003) 563-569. Elsevier Science Ltd. 2003.

- SUNG WOO SHIN, PH.D.; JIYOUNG MIN; \& JAE-YONG LEE, Ph.D. Effect of Concrete Compositions in Energy Transmission of Surface Waves for Nondestructive Crack Depth Evaluation. JOURNAL OF MATERIALS IN CIVIL ENGINEERING ASCE / JULY 2010.

- SUNG WOO SHIN, CHUNG BANG YUN, JOHN S. POPOVICS \& JAE HONG KIM. "Improved Rayleigh wave velocity measurement for nondestructive early-age concrete monitoring". Research in Nondestructive Evaluation, 18: 45-68, American Society for Nondestructive Testing 2007.

- TA-PENG CHANG, HUANG-CHIN LIN, WEN-TSE CHANG, JU-FANG HSIAO. "Engineering properties of lightweight aggregate concrete assessed by stress wave propagation methods". Cement \& Concrete Composites 28 (2006) 57-68. 2005 Elsevier Ltd.

- T.P. PHILIPPIDIS, D.G. AGGELIS. "Experimental study of wave dispersion \& attenuation in concrete”. Ultrasonics 43 (2005) 584-595. 2004 Elsevier B.V.

- YOUNG S. CHO. "Spectral analysis of surface wave response of multi-layer thin cement mortar slab structures with finite thickness”. NDT\&E International 34 (2001) 115-122. 2001 Elsevier Ltd.

- YOUNG S. CHO A, FENG-BAO LIN. "Nondestructive evaluation of in-place cement mortar compressive strength using spectral analysis of surface waves". Construction \& Building Materials 19 (2005) 738-745. 2005 Elsevier Ltd.

- YOUNG S. CHO A. "Non-destructive testing of high strength concrete using spectral analysis of surface waves”. NDT\&E International 36 (2003) 229-235. Elsevier Science Ltd.

- YOUNG S. CHO A. "Dispersive characteristic measurement of multi-layer cement mortar slabs using SASW method \& neural network”. Computers \& Structures 81 (2003) 2491-2499. Elsevier Ltd.

- YOUNG S. CHO A. "NDT response of spectral analysis of surface wave method to multi-layer thin high-strength concrete structures”. Ultrasonics 40 (2002)227-230. 2002 Elsevier Science B.V.

- VOIGT T., YILMAZ AKKAYA \& SURENDRA P. SHAH. "Determination of Early Age Mortar \& Concrete Strength by Ultrasonic Wave Reflections". JOURNAL OF MATERIALS IN CIVIL ENGINEERING @ ASCE / MAY/JUNE 2003. 


\section{DOCUMENTOS, TESIS Y TRABAJOS DE INVESTIGACIÓN.}

- CZELADA J..A \&. SFRISO A.O. Criterios para la interpretación de ensayos SASW. XX Congreso Argentino de Mecánica de Suelos e Ingeniería Geotécnica 2010 CAMSIG 2010, Argentina.

- LAI C.G. (1998) "Simultaneous inversion of Rayleigh phase velocity \& attenuation for near-surface site characterization”, PhD Diss., Georgia Inst. Of Techn., Atlanta (Georgia, USA).

- NAZARIAN S. (1984) "In situ determination of elastic moduli of soil deposits \& pavement systems by Spectral-Analysis-of-Surface waves method”, PhD Diss., Univ. of Texas at Austin.

- NORMAN D. DENNIS, Jr., Ph.D., KYLE A. BENNETT, E.I. "Development of Testing Protocol \& Correlations for Resilient Modulus of Subgrade Soils, Department of Civil Engineering for Arkansas State Highway \& Transportation Department”, Little Rock, Arkansas, January 2006.

- PEETERS, B., System Identification \& Damage Detection in Civil Engineering, PhD thesis, Department of Civil Engineering, K.U.Leuven, Belgium, December 2000.

- RIX G.J. (1988) "Experimental study of factors affecting the Spectral-Analysis-of- Surface-Waves method”, PhD Diss., Univ. of Texas at Austin.

- S. FOTI (2001). “Multistation method for geotechnical characterization using surface waves”. Ph.D thesis, Politecnico di Torino, Italy.

- V. Roma (2001). “Soil Properties and Site Characterization by means of Rayleigh Waves”. Ph.D thesis, Politecnico di Torino, Italy.

\section{LIBROS Y CAPÍTULOS BIBLIOGRÁFICOS.}

- AKI, K, RICHARDS, P. (1980). Quantitative seismology, Theory \& methods.

- A.M. NEVILLE. Properties of concrete. Prentice Hall Ud, Essex, 2000.

- BRIAN HAHN \& DANIEL VALENTINE. Essential MATLAB® for Engineers \& Scientists ( $3^{a}$ ed.)

- C. HEWLETT PETER \& LEA F.M. Chemistry of cement \& concrete. Elsevier España 2007.

- CHEEKE, J. DAVID N. Fundamentals \& applications of ultrasonic waves. CRC Press, 2000 N.W.

- FERNÁNDEZ CÁNOVAS, M., Hormigón. $7^{a}$ Ed., Colegio de Ingenieros de Caminos, Canales y Puertos, Madrid, 2004.

- GÉRARD BLANCHET, MAURICE CHARBIT. Digital signal \& image processing using Matlab. Translation of Signaux et images sous Matlab. ISBN-13: 978-1-905209-13-2.

- I. VIKTOROV. Rayleigh \& Lamb Waves: Physical theory \& applications (Ultrasonic technology). Plenum, New York, 1967.

- J. HELLIER CHARLES, Handbook of Nondestructive Evaluation. McGraw-Hill Companies 2003.

- JAVIER G. JALÓN, JOSÉ I. RODRÍGUEZ. Manual Aprenda Matlab 7.0; Univ. Pol. Madrid 2005;

- J.D.N. CHEEKE. Fundamentals \& Applications of Ultrasonic Waves. CRC Press, Florida, 2002.

- J.\& H. KRAUTKRAMER. Ultrasonic Testing Fundamentals. Springer-Verlag, New York, 1969.

- J. SHULL PETER. Nondestructive Evaluation. Theory, Techniques, \& Applications. The Pennsylvania State University Altoona, Pennsylvania 2002 by Marcel Dekker, Inc.

- J. SLIZARD. Ultrasonic Testing. John Wiley \& Sons, New York, 1982. 
- NEVILLE, A.M., Properties of Concrete, Longman, Harlow, 1995.

- NEWLAND, D.E. An introduction to random vibrations, spectral \& wavelet analysis, 1993.

- M. MALHOTRA \& N.J. CARINO. Handbook on Nondestructive Testing of Concrete, CRC Press, Inc., 2000 N.W. Corporate Blvd., Boca Raton, Florida 33431.

- STEVEN T. KARRIS. Signals \& Systems with Matlab® Computing \& Simulink Modeling. Orchard Publications 2007 ( $3^{a}$ ed.).

- TAYLOR H.F.W. \& TELFORD THOMAS. Cement chemistry (2 ${ }^{a}$ ed.). 1997 American Society of Civil Engineers, Publications Sales Department, 345 East 47th Street, New York.

\section{ASTM STANDARDS, NORMATIVAS, REGLAMENTOS...}

- ACI 228.2R - 98. Nondestructive Test Methods for Evaluation of Concrete in Structures. Junio 1998.

- ACI 301-84. Specification for structural concrete for buildings. American Concrete Institute.

- ACI 308 R. Guide to curing concrete. American Concrete Institute, 2001.

- ACI Committee 228 SP-168: Innovations In Nondestructive Testing of Concrete, American Concrete Institute Fall Convention, 1995 Montreal, Canada.

- ACI 318S-08 Requisitos de reglamento para concreto estructural y comentario; American Concrete Institute 2007.

- AENOR. Características de las máquinas de ensayo, publicada el 31 de enero de 2001. Asociación Española de Normalización y Certificación.

- ASTM C31/C31M-03 Practice for making and curing concrete test specimens in the field. Annual Book of ASTM Standards, Vol. 04.02, ASTM, 100 Barr Harbor Drive, West Conshohocken, PA, 2003

- ASTM C125-06 Standard terminology relating to concrete \& aggregates; ASTM Committee C09.91.

- ASTM C192/C192M-06 Standard practice for making and curing concrete test specimens in the laboratory; Annual Book of ASTM Standards, Vol. 04.02, ASTM, West Conshohocken, PA, 2006.

- ASTM C215 Test Method for Fundamental Transverse, Longitudinal, and Torsional Resonant Frequencies of Concrete Specimens. Annual Book of ASTM Standards, Vol. 04.02, ASTM, 2006.

- ASTM C469-02 Standard test method for Static Modulus of Elasticity and Poisson's ratio of Concrete in Compression; Annual Book of ASTM Standards, Vol. 04.02, ASTM, West Conshohocken, PA, 2006.

- ASTM E1316 Terminology for Nondestructive Examinations.

- ASTM C1259 Test Method for Dynamic Young's Modulus, Shear Modulus, and Poisson's Ratio for Advanced Ceramics by Impulse Excitation of Vibration.

- ASTM E1876-09 Standard Test Method for Dynamic Young's Modulus, Shear Modulus, and Poisson's Ratio by Impulse Excitation of Vibration; ASTM Committee E28, Abril 2009.

- ASTM C1383-04 (2010), Standard Test Method for Measuring the P-Wave Speed \& Thickness of Concrete Plates Using the Impact-Echo Method, Annual Book of ASTM Standards, Vol. 04.02. 2006

- Concrete Society Technical Report No 11 Concrete core testing for strength. Concrete Society, 1976.

- Instrucción de Hormigón Estructural EHE-08, RD 1247/2008 de 18 de julio de 2008.

- UNE-EN 196-1; Noviembre 2005. Métodos de ensayo de cementos. Parte 1: Determinación de resistencias mecánicas. Asociación Española de Normalización y Certificación, AENOR. 
- UNE-EN 196-7; Septiembre 2008. Métodos de ensayo de cementos. Parte 7: Métodos de toma y preparación de muestras de cemento. AENOR.

- UNE-EN 197-1; Diciembre 2000. Cemento. Parte 1: Composición, especificaciones y criterios de conformidad de los cementos comunes. AENOR.

- UNE-EN 933-1: 1998/A1. Ensayos para determinar las propiedades geométricas de los áridos. Parte 1: Determinación de la granulometría de las partículas. Métodos del tamizado.

- UNE-EN 934-1, Abril 2009. Aditivos para hormigones, morteros y pastas: Requisitos comunes.

- UNE-EN 1015-1; Junio 1999. Métodos de ensayo de los morteros para albañilería Parte 1: Determinación de la distribución granulométrica (por tamizado).

- UNE-EN 1015-2; Junio 1999. Métodos de ensayo de los morteros para albañilería Parte 2: Toma de muestra total de morteros y preparación de los morteros para ensayo.

- UNE-EN 1015-3; Septiembre 2000. Métodos de ensayo de los morteros para albañilería Parte 3: Determinación de la consistencia del mortero fresco (por la mesa de sacudidas).

- UNE-EN 1015-6; Junio 1999. Métodos de ensayo de los morteros para albañilería Parte 6: Determinación de la densidad aparente del mortero fresco.

- UNE-EN 1015-11; Marzo 2000. Métodos de ensayo de los morteros para albañilería Parte 11: Determinación de la resistencia a flexión y a compresión del mortero endurecido.

- UNE-EN ISO 12680-1:2007. Determinación del módulo de Young dinámico (MOE) por excitación de la vibración por impulso.

- UNE-EN 12504-1:2001 Ensayos de hormigón en estructuras. Parte 1: Testigos. Extracción, examen y ensayo a compresión, publicada el 30 de abril de 2001. AENOR.

- UNE-EN 13791:2009 Evaluación de la resistencia a compresión in-situ en estructuras y elementos prefabricados de hormigón, publicada el 20 de mayo de 2009. AENOR.

\section{SYMPOSIUMS, CONFERENCIAS.}

- B. ROSENBLAD, E.M. RATHJE \& K.H. STOKOE, "Shear Wave Velocity Profiling by the SASW Method at Selected Strong-Motion Stations in Turkey” (2000)

- GUCUNSKI N., WOODS R.D. (1991) "Inversion of Rayleigh wave dispersion curve for SASW test", 5th Int. Conf. on Soil Dyn. \& Earthq. Eng., Kalsruhe.

- GUCUNSKI N., WOODS R.D. (1991) "Use of Rayleigh modes in interpretation of SASW test”, Proc. 2th int. Conf. Recent Advances in Geot. Earthq. Eng. \& Soil Dyn.-S.Louis.

- J.C. MASO, Interfaces in Cementitious Composites Proceedings of the International Conference. (The International Union of Testing \& Research Laboratories for Materials \& Construction) at the Université Paul Sabatier, organised by RILEM Technical Committee 108 \& the laboratory for Materials \& Durability of Constructions (LMDC), Toulouse, France. October 21-23, 1992.

- JOH, S.H., ROSENBLAD, B.L. \& STOKOE, K.H., “Improved Data Interpretation Method for SASW Tests at Complex Geotechnical Sites, ” Proceedings, 7th ISOPE Conference, 1997.

- KESNER, K., SANSALONE, M., \& POSTON, R. "Numerical Simulation: Providing Reliability to Nondestructive Testing, " Proceedings of Structural Faults, Edinburgh, June, 2006.

- KESNER, K., SANSALONE, M., HOVER, K., \& POSTON, R., "Detection of Distributed Damage in Concrete Using Transient Stress Waves," Proceedings of Structural Materials Technology III, SPIE Vol. 3400, San Antonio, Texas, March 1998. 
- KOCIU, S., LUNA, R., \&ERSON, N., \& ZHENG, W. "Non-Linear Soil Response to Strong Ground Motion: Determinations Based on SASW Velocity Profiles”. $3^{\circ}$ International Conference on Applied Geophysics. Dec. 2003.

- MALOVICHKO, A., MALOVICHKO, D., SHYLAKOV, D., \& BUTIRIN, P. Estimation of NearSurface Shear-Wave Velocities by SASW Method in Southeast Missouri. $3^{\circ}$ International Conference on Applied Geophysics, 2003.

- NAZARIAN S., STOKOE II K.H., "In situ shear wave velocities from spectral analysis of surface waves”, 8th Conf. on Earthquake Eng. - S. Francisco, 1984.

- SANSALONE, M., \& STREETT, W.B., "The Use of the Impact-Echo Method \& Field Instrument for Nondestructive Testing of Concrete Structures, ” Proceedings of the International Symposium on NonDestructive Testing in Civil Engineering, Berlin, Germany, September 1995.

- SANSALONE, M., CARINO, N.J., \& HSU, N.N., "Flaw Detection in Concrete \& Heterogeneous Materials using Transient Stress Waves, ” in Journal of Acoustic Emission, Vol. 5, No. 3, July-Sept., 1986, pp. S24-S27.

- WILliams, T., GRIGORIU, M., SANSALONE, M., \& POSTON, R.W., "Reliability Based Approach to Nondestructive Testing," Proceedings of 12th ASCE Engineering Mechanics Conference, San Diego, California, April, 1998.

\section{WEBS.}

- http://ww2.mackblackwell.org/web/research/ALL_RESEARCH_PROJECTS/2000s/2032/MBTC\%202032.htm

- http://www.forcetechnology.com/en/Menu/Services/Inspection+\&+Testing/NonDestructive+Testing/concrete \&reinforcement.htm

- http://www.gdsinstruments.com/products/sasw.htm.

- http://www.pcte.com.au/concrete-non-destructive-testing-products/Defect-LocationTesting/SASW.aspx.

- http://www.ndt.net/article/v05n09/berke/berke1.htm.

- www.dot.state.fl.us/statematerialsoffice/geotechnical/conference/geophysics.htm.

- http://www.bksv.es/Products/TransducersConditioning/VibrationTransducers.

- http://www.promedyasistemas.com/view/catalogo/ls_catalogo.

- http://www.proetisa.com/catalogo.

- https://www.aenor.es/aenor/suscripciones/

- http://www.controls.es/productos.htm.

- http://www.asocem.org.pe/web/mercadocemento.aspx 


\title{
AneXo 01. CARACTERÍSTICAS MECÁNICAS DEL MORTERO.
}

(UNE EN 196-1:2005; UNE-EN 1015-11:2000).

\begin{abstract}
La resistencia a compresión de una amasada se obtiene a partir de los resultados de ensayos no destructivos realizados por el método de frecuencia resonancia (ASTM C215) y posterior comprobación de los datos recogidos mediante ensayos de resistencia a rotura en prensa a flexión/compresión de las probetas prismáticas 40x40x160mm desde edades tempranas hasta los 28 días según normativa UNE EN 196/1 y ASTM C469. Los resultados varían con la edad conforme el mortero varía su endurecimiento, con el fin de caracterizar las propiedades mecánicas a diferentes edades. A continuación se explica la metodología experimental que se ha seguido durante el desarrollo del TFM con diversas dosificaciones.
\end{abstract}

\section{Resistencia a flexión y compresión de los especímenes de mortero.}

Estos ensayos se realizaron en el Laboratorio de ETSICCP Granada mediante los equipos propios del Dpto. Materiales (ver Anexo 02), sobre las probetas prismáticas de 40x40x160mm de las 3 amasadas iniciales de prueba realizadas en Octubre 2011 para calibración de equipos de vibraciones mediante primeras pruebas de resistencias y módulos mediante rotura en prensa para comparación con resultados por impacto y análisis de ondas (Equipo Brüel\&Kjaer):

\begin{tabular}{|c|c|c|c|c|c|c|c|}
\hline MORTERO Dosificación & CEM 42,5N & \multicolumn{2}{|c|}{ ARENA FINOS 0/4 } & \multicolumn{2}{|c|}{ AGUA } & \multicolumn{2}{|c|}{ ADITIVO PLASTIF. } \\
\cline { 2 - 8 } (Trabajos PFC ETSICCP) & $\mathbf{1 m}^{\mathbf{3}} \mathbf{( k g}$.) & $\mathbf{k g}$. & $\mathbf{f} / \mathbf{c}$ & $\mathbf{L}$ & a/c & $\mathbf{K g} / \mathbf{m}^{3}$. & f/c \\
\hline Mezcla A & $\mathbf{5 7 1}$ & $\mathbf{1 4 9 6 . 6}$ & 2.62 & $\mathbf{2 9 0}$ & $\mathbf{0 . 5 1}$ & $\mathbf{3 . 4 3}$ & $\mathbf{0 . 3}$ \\
\hline Mezcla B & $\mathbf{4 9 2}$ & $\mathbf{1 5 5 4 . 2}$ & 3.16 & $\mathbf{2 9 5 . 1 7}$ & $\mathbf{0 . 6}$ & $\mathbf{2 . 9 5}$ & $\mathbf{0 . 6}$ \\
\hline Mezcla C & $\mathbf{6 1 3}$ & $\mathbf{1 4 9 1 . 7}$ & $\mathbf{2 . 4 3}$ & $\mathbf{2 7 5 . 8 3}$ & $\mathbf{0 . 4 5}$ & $\mathbf{8 . 5 8}$ & $\mathbf{1 . 4}$ \\
\hline
\end{tabular}

RESISTENCIA MECÁNICA del cemento

\section{Determinación de las resistencias mecánicas}

\begin{abstract}
La determinación se realiza confeccionado unas probetas prismáticas con un mortero normalizado del cemento en cuestión, es decir, con una mezcla del cemento y de arena fina y con una dosis de agua determinada. Estas probetas se ensayan sometiéndolas a cargas hasta su rotura, especialmente a cargas de compresión.
\end{abstract}

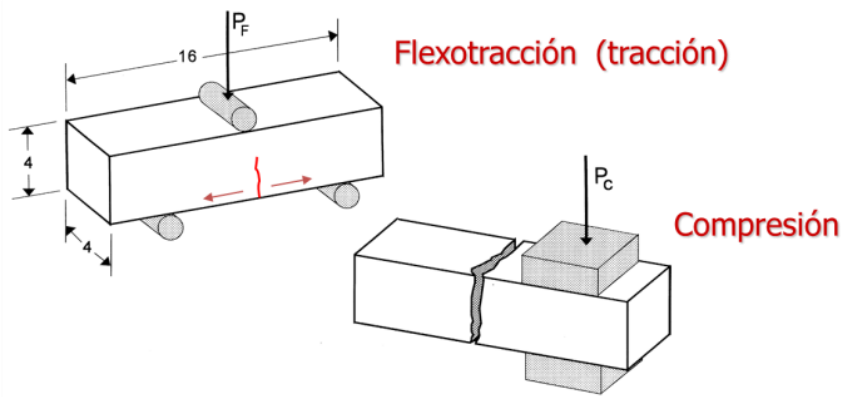

Las clases resistentes (resistencias normalizadas a compresión, a 28 días), para los cementos comunes son:32,5; 42,5 y $\mathbf{5 2 , 5 M P a}$

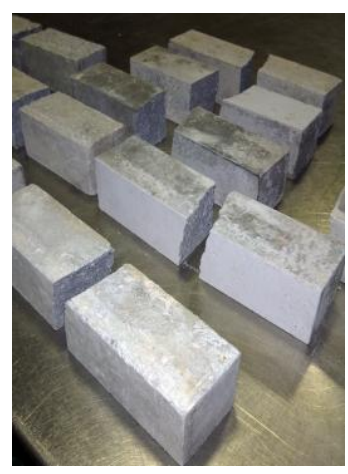

(Fig. 114). Determinación de resistencias mecánicas en un cemento mediante ensayo UNE EN 196/1.

Los ensayos a flexión se realizan aplicando una carga centrada a una velocidad de $50 \pm 10 \mathrm{~N} / \mathrm{s}$ sobre la probeta biapoyada con una luz de 100mm, determinando su resistencia $\operatorname{Rf}(M P a)$ según:

$R_{f}=\frac{1,5 \cdot F_{f} \cdot l}{b^{3}}$ Dónde: $F f=$ carga aplicada $(N) ; l=$ distancia entre soportes $=100 \mathrm{~mm} ; b=$ lateral de la probeta $=40 \mathrm{~mm}$. (Conforme a normas UNE EN 196-1:2005 y UNE EN 1015/11). 
Del ensayo se obtienen dos mitades que posteriormente se ensayan a compresión aplicando una carga sobre las caras laterales (moldeadas) en una superficie de $40 \times 40 \mathrm{~mm}$ a una velocidad de $2400 \pm 200 \mathrm{~N} / \mathrm{s}$, obteniendo la resistencia a compresión $\mathrm{R}_{\mathrm{c}}$ en $\mathrm{MPa}\left(\mathrm{N} / \mathrm{mm}^{2}\right)$ según:

$R_{C}=F_{C} / S \quad$ Donde $F c=$ carga máxima a rotura $(N) ; S=$ superficie de carga $40 x 40=1600 \mathrm{~mm}^{2}$

EJEMPLO_01.

Se calibró la prensa hidráulica Ibertest $100 K N$ presente en el Laboratorio de Materiales con los siguientes parámetros idénticos para cada ensayo previsto, mediante el software Wintest:

\begin{tabular}{|c|c|c|c|}
\hline \multicolumn{2}{|c|}{ Parámetros rotura } & FLEXIÓN & COMPRESIÓN \\
\hline \multirow{2}{*}{$\approx$} & Detección de rotura & $\mathbf{1 0 \%}$ & $\mathbf{1 0 \%}$ \\
\cline { 2 - 4 } & Inhibición de rotura & $\mathbf{1 \%}$ & $\mathbf{1 \%}$ \\
\cline { 2 - 4 } & Tolerancia de velocidad & $\mathbf{5 \%}$ & $\mathbf{5 \%}$ \\
\cline { 2 - 4 } & Velocidad ensayo & $\mathbf{0 , 0 5 K N} / \mathbf{s}$ & $\mathbf{0 , 5 K N} / \mathbf{s}$ \\
\cline { 2 - 4 } & Frecuencia de muestreo, Fs & $\mathbf{1 0 0 0}$ & $\mathbf{1 0 0 0}$ \\
\hline
\end{tabular}

(Fig. 115). Parámetros de configuración de ensayos en prensa hidráulica.

Para la amasada A, se ensaya a rotura una de las probetas curadas a temperatura ambiente, compactada en dos tongadas y de dosificación 1:0,6:3,25 sin aditivo plastificante. En un ensayo a 3-4 días se obtuvo una resistencia a flexión $\boldsymbol{R}_{f}=6,374 \mathrm{MPa}$ para una carga máxima $\boldsymbol{F}_{f}=2,719 \mathrm{KN}$, y un promedio a compresión $\boldsymbol{R}_{c}=71,44 M P a$ con una media de carga $\boldsymbol{F}_{c}=69,94 \mathrm{KN}$.

$$
R_{f}=\frac{1,5 \cdot F_{f} \cdot l}{b^{3}}=\frac{1,5 \cdot 2719,6 \mathrm{~N} \cdot 100 \mathrm{~mm}}{40^{3} \mathrm{~mm}^{3}}=6,374 \mathrm{MPa} \quad \text { Siendo: } F f=6500 \mathrm{~N} ; l=100 \mathrm{~mm} ; \mathrm{b}: \text { lateral }=40 \mathrm{~mm} \text {. }
$$

Con los semi-prismas restantes se realiza el ensayo a compresión sometiendo cada parte a un ensayo propio, obteniendo los dos resultados siguientes:

$$
R_{C}^{A}=\frac{F_{c}}{S}=\frac{65,865 \cdot 10^{3} \mathrm{~N}}{40^{2} \mathrm{~mm}^{2}}=41,165 \mathrm{MPa} \quad ; \quad R_{C}^{B}=\frac{F_{c}}{S}=\frac{74,019 \cdot 10^{3} \mathrm{~N}}{40^{2} \mathrm{~mm}^{2}}=46,2624 \mathrm{MPa}
$$

Del promedio de ambas resistencias a compresión se obtiene la resistencia de la pieza, valor que se contrasta con los obtenidos mediante la técnica no destructiva de Frecuencia Resonancia, rechazando aquellos ensayos con un margen de error superior al 2\%. Este procedimiento se realizó en series de 3 probetas a cada edad temprana.

Para las series de amasadas analizadas, cuyas dosificaciones responden a mezclas usuales en

\begin{tabular}{|c|c|c|c|c|c|c|c|}
\hline \multicolumn{8}{|c|}{ Resistencia a compresión (MPa) } \\
\hline \multicolumn{2}{|c|}{$(c / c ; a / c ; f / c ; a d / c)$} & \multicolumn{2}{|c|}{ MEZCLA A $(1 / 0,5 / 2,6 / 0,3)$} & \multicolumn{2}{|c|}{ MEZCLA B $(1 / 0,6 / 3,25)$} & \multicolumn{2}{|c|}{ MEZCLA C $(1 / 0,45 / 2,45 / 1,4)$} \\
\hline & Ta curado & $20 \stackrel{\circ}{ } \mathrm{C}$ & $5 \circ \mathrm{C}$ & $20 \stackrel{\circ}{\circ} \mathrm{C}$ & $5 \circ \mathrm{C}$ & $20 \stackrel{\circ}{ } \mathrm{C}$ & $5 \cong \mathrm{C}$ \\
\hline \multirow{6}{*}{ 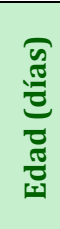 } & 1 & 29.82 & & 22.06 & & 13.70 & \\
\hline & 2 & 38.03 & 5.62 & 31.29 & 3.60 & 41.57 & 3.50 \\
\hline & 4 & 41.93 & 25.40 & 34.91 & 17.60 & 52.43 & 14.17 \\
\hline & 8 & 47.10 & 40.67 & 38.69 & 29.66 & 54.80 & 38.20 \\
\hline & 16 & 49.07 & 52.73 & 42.33 & 42.57 & 61.30 & 56.13 \\
\hline & 32 & 55.23 & 57.73 & 43.33 & 48.60 & 67.50 & 66.90 \\
\hline
\end{tabular}
estructuras, se obtienen los resultados y conclusiones experimentales siguientes: 


\begin{tabular}{|c|c|c|c|}
\hline \multicolumn{4}{|c|}{ MEZCLA A (1/0,5/2,6/0,3) } \\
\hline \hline \multicolumn{3}{|c|}{20 ․ C } & \multicolumn{3}{|c|}{5 C } \\
\hline \hline Edad & Resistencia & Edad & Resistencia \\
\hline \hline 1 & 30.4016 & 1 & \\
\hline 1.5 & 34.2081 & 1.5 & \\
\hline 2 & 36.7104 & 2 & 5.6587 \\
\hline 2.5 & 38.5446 & 2.5 & 11.8786 \\
\hline 3 & 39.9773 & 3 & 17.0893 \\
\hline 3.5 & 41.1441 & 3.5 & 21.4489 \\
\hline 4 & 42.1228 & 4 & 25.1216 \\
\hline 4.5 & 42.9622 & 4.5 & 28.2443 \\
\hline 5 & 43.6945 & 5 & 30.9252 \\
\hline 5.5 & 44.3422 & 5.5 & 33.2481 \\
\hline 6 & 44.9216 & 6 & 35.2781 \\
\hline 6.5 & 45.4446 & 6.5 & 37.0660 \\
\hline 7 & 45.9204 & 7 & 38.6520 \\
\hline 7.5 & 46.3564 & 7.5 & 40.0679 \\
\hline 8 & 46.7581 & 8 & 41.3393 \\
\hline 8.5 & 47.1301 & 8.5 & 42.4871 \\
\hline 9 & 47.4763 & 9 & 43.5284 \\
\hline 9.5 & 47.7996 & 9.5 & 44.4771 \\
\hline 10 & 48.1027 & 10 & 45.3452 \\
\hline 10.5 & 48.3878 & 10.5 & 46.1422 \\
\hline 11 & 48.6566 & 11 & 46.8767 \\
\hline 11.5 & 48.9109 & 11.5 & 47.5557 \\
\hline 12 & 49.1520 & 12 & 48.1852 \\
\hline 12.5 & 49.3810 & 12.5 & 48.7704 \\
\hline 13 & 49.5991 & 13 & 49.3159 \\
\hline 13.5 & 49.8071 & 13.5 & 49.8255 \\
\hline 14 & 50.0059 & 14 & 50.3027 \\
\hline 14.5 & 50.1961 & 14.5 & 50.7504 \\
\hline 15 & 50.3785 & 15 & 51.1713 \\
\hline 15.5 & 50.5535 & 15.5 & 51.5678 \\
\hline 16 & 50.7218 & 16 & 51.9419 \\
\hline 16.5 & 50.8837 & 16.5 & 52.2955 \\
\hline 17 & 51.0397 & 17 & 52.6302 \\
\hline 17.5 & 51.1902 & 17.5 & 52.9474 \\
\hline 18 & 51.3354 & 18 & 53.2486 \\
\hline 18.5 & 51.4758 & 18.5 & 53.5349 \\
\hline 19 & 51.6116 & 19 & 53.8073 \\
\hline 19.5 & 51.7431 & 19.5 & 54.0669 \\
\hline 20 & 51.8706 & 20 & 54.3146 \\
\hline 20.5 & 51.9941 & 20.5 & 54.5511 \\
\hline 21 & 52.1141 & 21 & 54.7772 \\
\hline 21.5 & 52.2305 & 21.5 & 54.9936 \\
\hline 22 & 52.3437 & 22 & 55.2009 \\
\hline 22.5 & 52.4538 & 22.5 & 55.3996 \\
\hline 23 & 52.5609 & 23 & 55.5902 \\
\hline 23.5 & 52.6651 & 23.5 & 55.7734 \\
\hline 24 & 52.7667 & 24 & 55.9494 \\
\hline 24.5 & 52.8657 & 24.5 & 56.1187 \\
\hline 25 & 52.9623 & 25 & 56.2816 \\
\hline 25.5 & 53.0565 & 25.5 & 56.4386 \\
\hline 26 & 53.1485 & 26 & 56.5900 \\
\hline 26.5 & 53.2383 & 26.5 & 56.7359 \\
\hline 27 & 53.3261 & 27 & 56.8768 \\
\hline 27.5 & 53.4119 & 27.5 & 57.0129 \\
\hline 28 & 53.4958 & 28 & 57.1444 \\
\hline & & $1 F i g$ & $116)$ \\
\hline
\end{tabular}

\begin{tabular}{|c|c|c|c|}
\hline \multicolumn{4}{|c|}{ MEZCLA B $(1 / 0,6 / 3,25)$} \\
\hline \multicolumn{2}{|r|}{$20 \div C$} & \multicolumn{2}{|r|}{$5 \circ \mathrm{C}$} \\
\hline Edad & \begin{tabular}{|l} 
Resistencia \\
\end{tabular} & Edad & Resistencia \\
\hline 1 & 22.3575 & 1 & \\
\hline 1.5 & 27.3242 & 1.5 & \\
\hline 2 & 30.2321 & 2 & 3.6054 \\
\hline 2.5 & 32.1889 & 2.5 & 7.6496 \\
\hline 3 & 33.6168 & 3 & 11.2183 \\
\hline 3.5 & 34.7157 & 3.5 & 14.3460 \\
\hline 4 & 35.5940 & 4 & 17.0913 \\
\hline 4.5 & 36.3161 & 4.5 & 19.5124 \\
\hline 5 & 36.9228 & 5 & 21.6600 \\
\hline 5.5 & 37.4416 & 5.5 & 23.5764 \\
\hline 6 & 37.8915 & 6 & 25.2965 \\
\hline 6.5 & 38.2865 & 6.5 & 26.8489 \\
\hline 7 & 38.6366 & 7 & 28.2571 \\
\hline 7.5 & 38.9497 & 7.5 & 29.5405 \\
\hline 8 & 39.2317 & 8 & 30.7153 \\
\hline 8.5 & 39.4875 & 8.5 & 31.7950 \\
\hline 9 & 39.7208 & 9 & 32.7909 \\
\hline 9.5 & 39.9346 & 9.5 & 33.7126 \\
\hline 10 & 40.1316 & 10 & 34.5684 \\
\hline 10.5 & 40.3137 & 10.5 & 35.3653 \\
\hline 11 & 40.4827 & 11 & 36.1094 \\
\hline 11.5 & 40.6401 & 11.5 & 36.8058 \\
\hline 12 & 40.7872 & 12 & 37.4591 \\
\hline 12.5 & 40.9250 & 12.5 & 38.0735 \\
\hline 13 & 41.0544 & 13 & 38.6523 \\
\hline 13.5 & 41.1762 & 13.5 & 39.1986 \\
\hline 14 & 41.2912 & 14 & 39.7153 \\
\hline 14.5 & 41.3999 & 14.5 & 40.2047 \\
\hline 15 & 41.5029 & 15 & 40.6690 \\
\hline 15.5 & 41.6007 & 15.5 & 41.1102 \\
\hline 16 & 41.6936 & 16 & 41.5300 \\
\hline 16.5 & 41.7821 & 16.5 & 41.9300 \\
\hline 17 & 41.8665 & 17 & 42.3115 \\
\hline 17.5 & 41.9471 & 17.5 & 42.6760 \\
\hline 18 & 42.0242 & 18 & 43.0246 \\
\hline 18.5 & 42.0980 & 18.5 & 43.3582 \\
\hline 19 & 42.1688 & 19 & 43.6779 \\
\hline 19.5 & 42.2366 & 19.5 & 43.9846 \\
\hline 20 & 42.3018 & 20 & 44.2791 \\
\hline 20.5 & 42.3645 & 20.5 & 44.5621 \\
\hline 21 & 42.4249 & 21 & 44.8343 \\
\hline 21.5 & 42.4830 & 21.5 & 45.0964 \\
\hline 22 & 42.5391 & 22 & 45.3488 \\
\hline 22.5 & 42.5932 & 22.5 & 45.5922 \\
\hline 23 & 42.6454 & 23 & 45.8271 \\
\hline 23.5 & 42.6959 & 23.5 & 46.0538 \\
\hline 24 & 42.7448 & 24 & 46.2729 \\
\hline 24.5 & 42.7921 & 24.5 & 46.4847 \\
\hline 25 & 42.8379 & 25 & 46.6896 \\
\hline 25.5 & 42.8822 & 25.5 & 46.8879 \\
\hline 26 & 42.9253 & 26 & 47.0800 \\
\hline 26.5 & 42.9670 & 26.5 & 47.2662 \\
\hline 27 & 43.0076 & 27 & 47.4467 \\
\hline 27.5 & 43.0469 & 27.5 & 47.6219 \\
\hline 28 & 43.0852 & 28 & 47.7918 \\
\hline
\end{tabular}

(Fig. 116). Tabla de resistencias y edades para cada mezcla de mortero de ensayo.

\begin{tabular}{|c|c|c|c|}
\hline \multicolumn{4}{|c|}{ MEZCLA C $(1 / 0,45 / 2,45 / 1,4)$} \\
\hline \multicolumn{2}{|r|}{$20 \div \mathrm{C}$} & \multicolumn{2}{|r|}{$5 \div \mathrm{C}$} \\
\hline Edad & Resistencia & Edad & Resistencia \\
\hline 1 & 15.2395 & 1 & \\
\hline 1.5 & 31.5254 & 1.5 & \\
\hline 2 & 39.8802 & 2 & \\
\hline 2.5 & 44.9844 & 2.5 & \\
\hline 3 & 48.4351 & 3 & 4.4792 \\
\hline 3.5 & 50.9281 & 3.5 & 9.5282 \\
\hline 4 & 52.8160 & 4 & 14.1668 \\
\hline 4.5 & 54.2966 & 4.5 & 18.3685 \\
\hline 5 & 55.4898 & 5 & 22.1520 \\
\hline 5.5 & 56.4725 & 5.5 & 25.5536 \\
\hline 6 & 57.2963 & 6 & 28.6144 \\
\hline 6.5 & 57.9972 & 6.5 & 31.3741 \\
\hline 7 & 58.6009 & 7 & 33.8694 \\
\hline 7.5 & 59.1266 & 7.5 & 36.1324 \\
\hline 8 & 59.5885 & 8 & 38.1915 \\
\hline 8.5 & 59.9977 & 8.5 & 40.0709 \\
\hline 9 & 60.3629 & 9 & 41.7917 \\
\hline 9.5 & 60.6907 & 9.5 & 43.3721 \\
\hline 10 & 60.9868 & 10 & 44.8278 \\
\hline 10.5 & 61.2555 & 10.5 & 46.1724 \\
\hline 11 & 61.5006 & 11 & 47.4175 \\
\hline 11.5 & 61.7250 & 11.5 & 48.5734 \\
\hline 12 & 61.9312 & 12 & 49.6491 \\
\hline 12.5 & 62.1215 & 12.5 & 50.6523 \\
\hline 13 & 62.2976 & 13 & 51.5900 \\
\hline 13.5 & 62.4610 & 13.5 & 52.4681 \\
\hline 14 & 62.6131 & 14 & 53.2921 \\
\hline 14.5 & 62.7550 & 14.5 & 54.0666 \\
\hline 15 & 62.8878 & 15 & 54.7959 \\
\hline 15.5 & 63.0123 & 15.5 & 55.4837 \\
\hline 16 & 63.1292 & 16 & 56.1334 \\
\hline 16.5 & 63.2392 & 16.5 & 56.7480 \\
\hline 17 & 63.3430 & 17 & 57.3303 \\
\hline 17.5 & 63.4411 & 17.5 & 57.8825 \\
\hline 18 & 63.5338 & 18 & 58.4071 \\
\hline 18.5 & 63.6217 & 18.5 & 58.9059 \\
\hline 19 & 63.7051 & 19 & 59.3808 \\
\hline 19.5 & 63.7844 & \begin{tabular}{|l|}
19.5 \\
\end{tabular} & 59.8334 \\
\hline 20 & 63.8598 & 20 & 60.2653 \\
\hline 20.5 & 63.9317 & 20.5 & 60.6777 \\
\hline 21 & 64.0002 & 21 & 61.0721 \\
\hline 21.5 & 64.0656 & 21.5 & 61.4494 \\
\hline 22 & 64.1282 & 22 & 61.8108 \\
\hline 22.5 & 64.1881 & 22.5 & 62.1572 \\
\hline 23 & 64.2454 & 23 & 62.4896 \\
\hline 23.5 & 64.3004 & 23.5 & 62.8087 \\
\hline 24 & 64.3532 & 24 & 63.1154 \\
\hline 24.5 & 64.4038 & 24.5 & 63.4103 \\
\hline 25 & 64.4526 & 25 & 63.6941 \\
\hline 25.5 & 64.4994 & 25.5 & 63.9673 \\
\hline 26 & 64.5445 & 26 & 64.2307 \\
\hline 26.5 & 64.5880 & 26.5 & 64.4846 \\
\hline 27 & 64.6299 & 27 & 64.7296 \\
\hline 27.5 & 64.6703 & \begin{tabular}{|l|}
27.5 \\
\end{tabular} & 64.9661 \\
\hline 28 & 64.7093 & 28 & 65.1945 \\
\hline
\end{tabular}



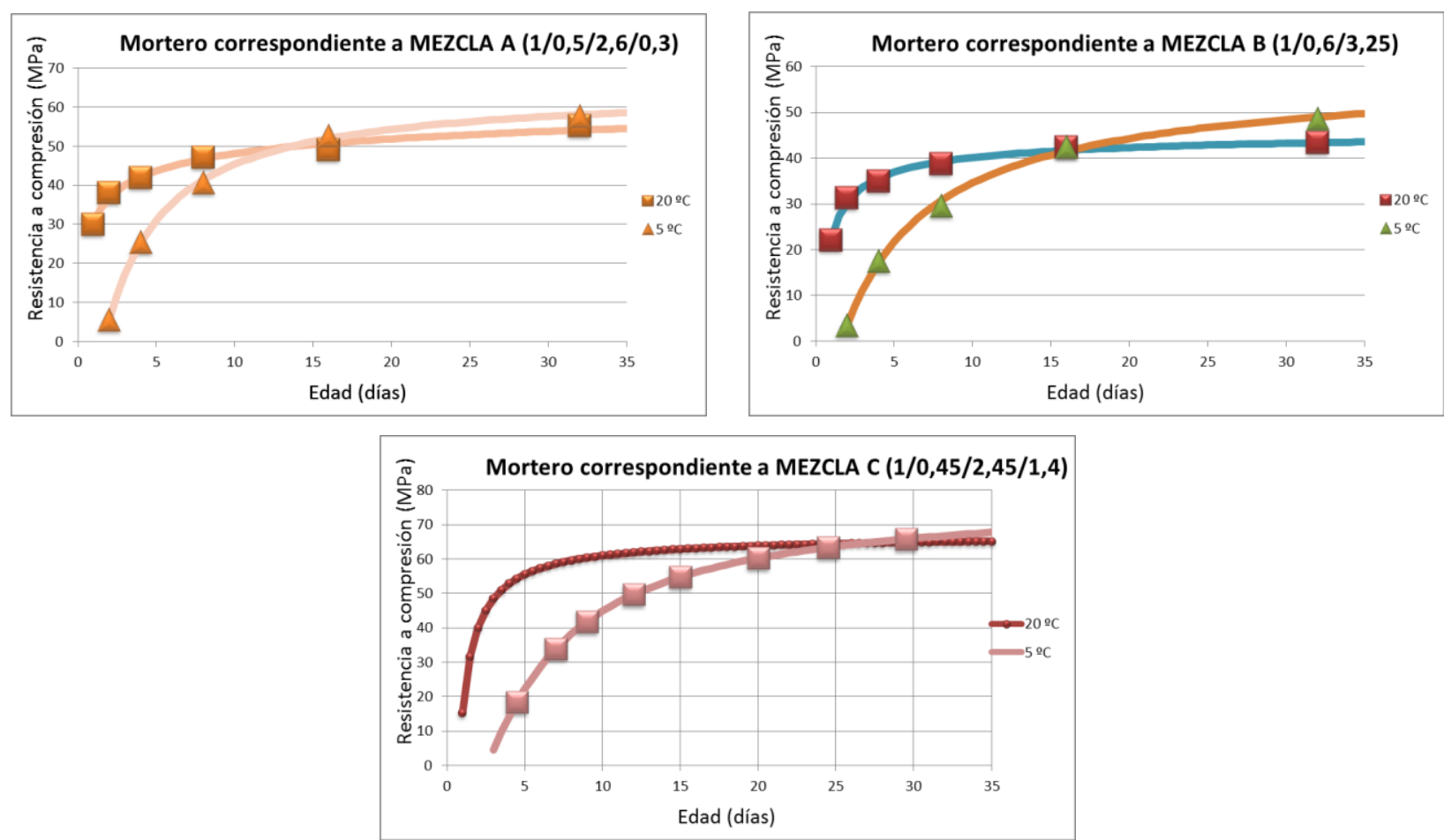

(Fig. 117) Resultados obtenidos en los ensayos de compresión de las probetas 40x40x160mm correspondientes a los morteros de mezclas $A, B$ y $C$.

- Estos resultados han servido de base a las posteriores amasadas para estimar la resistencia mínima a compresión en edades tempranas. Destaca que a 1 día del fraguado se alcanzan porcentajes en torno a 0,25-0,50\% de la resistencia a 28 días, y como a 1 semana se llega a un $85-90 \%$ de dicha resistencia.

\begin{tabular}{|c|c|c|c|c|c||}
\hline \multicolumn{5}{|c||}{ MEZCLA A (1/0,5/2,6/0,3) } \\
\hline \hline \multicolumn{3}{|c|}{20 9 C } & \multicolumn{3}{c||}{5 \%C } \\
\hline \hline Edad & Resistencia & $\begin{array}{c}\text { \% Resistencia } \\
\text { a 28 dias }\end{array}$ & Edad & Resistencia & $\begin{array}{c}\text { Restencia } \\
\text { a 28 dias }\end{array}$ \\
\hline \hline 1 & 30.40 & 0.57 & 1 & & \\
\hline 2 & 36.71 & 0.69 & 2 & 5.66 & 0.10 \\
\hline 3 & 39.98 & 0.75 & 3 & 17.09 & 0.30 \\
\hline 4 & 42.12 & 0.79 & 4 & 25.12 & 0.44 \\
\hline 7 & 45.92 & 0.86 & 7 & 38.65 & 0.68 \\
\hline 14 & 50.01 & 0.93 & 14 & 50.30 & 0.88 \\
\hline 21 & 52.11 & 0.97 & 21 & 54.78 & 0.96 \\
\hline 28 & 53.50 & 1.00 & 28 & 57.14 & 1.00 \\
\hline
\end{tabular}

\begin{tabular}{|c|c|c|c|c|c|}
\hline \multicolumn{6}{|c|}{ MEZCLA B $(1 / 0,6 / 3,25)$} \\
\hline \multicolumn{3}{|c|}{$20{ }^{\circ} \mathrm{C}$} & \multicolumn{3}{|c|}{$5 \circ \mathrm{C}$} \\
\hline Edad & ||Resistencia & \begin{tabular}{|c}
$\%$ Resistencia \\
a 28 días
\end{tabular} & Edad & Resistencia & $\begin{array}{c}\% \text { Resistencia } \\
\text { a } 28 \text { dias }\end{array}$ \\
\hline 1 & 22.36 & 0.52 & 1 & & \\
\hline 2 & 30.23 & 0.70 & 2 & 3.61 & 0.08 \\
\hline 3 & 33.62 & 0.78 & 3 & 11.22 & 0.23 \\
\hline 4 & 35.59 & 0.83 & 4 & 17.09 & 0.36 \\
\hline 7 & 38.64 & 0.90 & 7 & 28.26 & 0.59 \\
\hline 14 & 41.29 & 0.96 & 14 & 39.72 & 0.83 \\
\hline 21 & 42.42 & 0.98 & 21 & 44.83 & 0.94 \\
\hline 28 & 43.09 & 1.00 & 28 & 47.79 & 1.00 \\
\hline
\end{tabular}

\begin{tabular}{|c|c|c||c|c|c|}
\hline \multicolumn{5}{|c|}{ MEZCLA C (1/0,45/2,45/1,4) } \\
\hline \hline \multicolumn{3}{|c|}{20 ○C } & \multicolumn{3}{c|}{$5{ }^{\circ} \mathrm{C}$} \\
\hline \hline Edad & Resistencia & $\begin{array}{c}\text { \% Resistencia } \\
\text { a 28 dias }\end{array}$ & Edad & Resistencia & $\begin{array}{c}\text { \% Resistencia } \\
\text { a 28 dias }\end{array}$ \\
\hline \hline 1 & 15.24 & 0.24 & 1 & & \\
\hline 2 & 39.88 & 0.62 & 2 & 3.50 & 0.05 \\
\hline 3 & 48.44 & 0.75 & 3 & 4.48 & 0.07 \\
\hline 4 & 52.82 & 0.82 & 4 & 14.17 & 0.22 \\
\hline 7 & 58.60 & 0.91 & 7 & 33.87 & 0.52 \\
\hline 14 & 62.61 & 0.97 & 14 & 53.29 & 0.82 \\
\hline 21 & 64.00 & 0.99 & 21 & 61.07 & 0.94 \\
\hline 28 & 64.71 & 1.00 & 28 & 65.19 & 1.00 \\
\hline
\end{tabular}

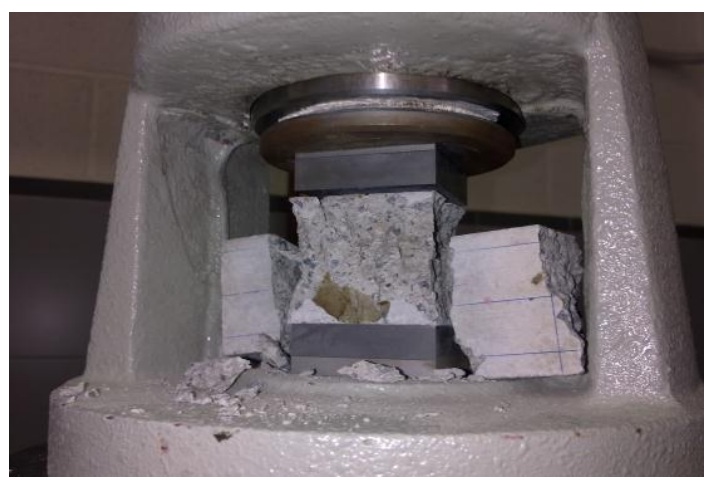

(Fig. 118) Relación existente entre las resistencias de los tres morteros referenciadas al valor máximo. 
Comparativa de resistencias mecánicas mediante rotura de probetas a flexo/compresión frente al método FFRC (Frecuencia Resonancia).

\begin{tabular}{|c|c|c||c|c|c|}
\hline \multicolumn{7}{|c|}{ MEZCLA A (1/0,5/2,6/0,3) } \\
\hline \multicolumn{5}{||c|}{ Rotura piezas } & \multicolumn{3}{c|}{ FREC_RESONANCIA } \\
\hline \hline Edad & Resistencia & $\begin{array}{c}\text { \% Resistencia } \\
\text { a 28 días }\end{array}$ & Edad & Resistencia & $\begin{array}{c}\text { \% Resistencia } \\
\text { a 28 días }\end{array}$ \\
\hline \hline 1 & 30.40 & 0.57 & 1 & & \\
\hline 2 & 36.71 & 0.69 & 2 & 30.00 & 0.52 \\
\hline 3 & 39.98 & 0.75 & 3 & 35.01 & 0.61 \\
\hline 4 & 42.12 & 0.79 & 4 & 40.00 & 0.70 \\
\hline 7 & 45.92 & 0.86 & 7 & 42.00 & 0.73 \\
\hline 14 & 50.01 & 0.93 & 14 & 50.30 & 0.88 \\
\hline 21 & 52.11 & 0.97 & 21 & 54.78 & 0.96 \\
\hline 28 & 53.50 & 1.00 & 28 & 57.14 & 1.00 \\
\hline
\end{tabular}

M. UNICAPA $(1 / 0,6 / 3,25)$

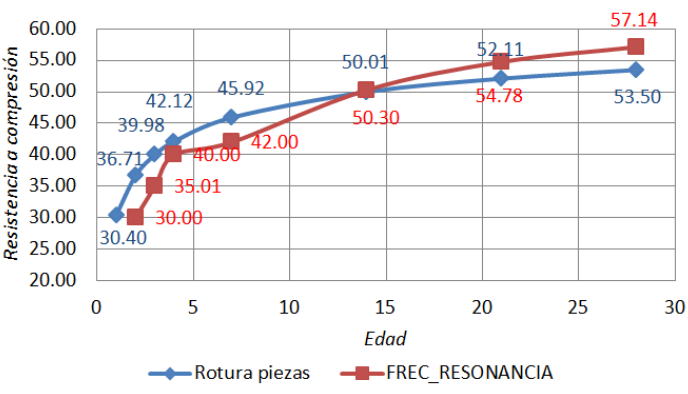

M. $\operatorname{BICAPA}(1 / 0,5 / 2,25)$

\begin{tabular}{|c|c|c|c|c|c|}
\hline \multicolumn{6}{|c|}{ MEZCLA B $(1 / 0,6 / 3,25)$} \\
\hline \multicolumn{3}{|c|}{ Rotura piezas } & \multicolumn{3}{|c|}{ FREC_RESONANCIA } \\
\hline Edad & Resistencia & $\begin{array}{c}\text { \% Resistencia } \\
\text { a } 28 \text { días }\end{array}$ & Edad & Resistencia & $\begin{array}{c}\text { \% Resistencia } \\
\text { a } 28 \text { días }\end{array}$ \\
\hline 1 & 22.36 & 0.52 & 1 & & \\
\hline 2 & 30.23 & 0.70 & 2 & 25.60 & 0.56 \\
\hline 3 & 33.62 & 0.78 & 3 & 30.11 & 0.66 \\
\hline 4 & 35.59 & 0.83 & 4 & 33.05 & 0.72 \\
\hline 7 & 38.64 & 0.90 & 7 & 37.26 & 0.81 \\
\hline 14 & 41.29 & 0.96 & 14 & 39.72 & 0.87 \\
\hline 21 & 42.42 & 0.98 & 21 & 44.83 & 0.98 \\
\hline 28 & 43.09 & 1.00 & 28 & 45.79 & 1.00 \\
\hline
\end{tabular}

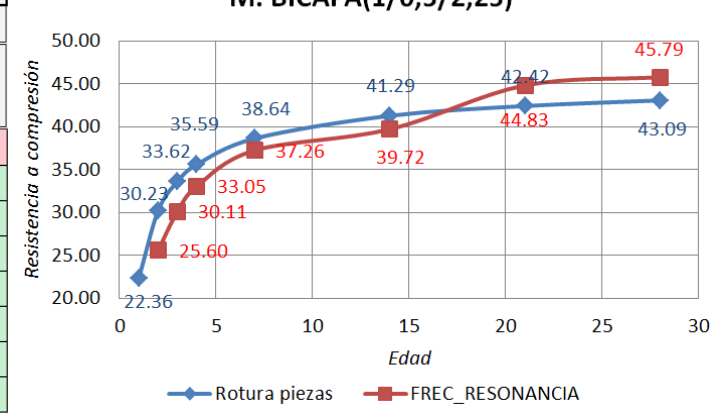

\begin{tabular}{|c|c|c|c|c|c|}
\hline \multicolumn{6}{|c|}{ MEZCLA C $(1 / 0,45 / 2,45 / 1,4)$} \\
\hline \multicolumn{3}{|c|}{ Rotura piezas } & \multicolumn{3}{|c|}{ FREC_RESONANCIA } \\
\hline Edad & Resistencia & $\begin{array}{c}\text { \% Resistencia } \\
\text { a } 28 \text { días }\end{array}$ & Edad & Resistencia & $\begin{array}{c}\text { \% Resistencia } \\
\text { a } 28 \text { días }\end{array}$ \\
\hline 1 & 15.24 & 0.24 & 1 & & \\
\hline 2 & 39.88 & 0.62 & 2 & 7.50 & 0.12 \\
\hline 3 & 48.44 & 0.75 & 3 & 6.48 & 0.10 \\
\hline 4 & 52.82 & 0.82 & 4 & 27.25 & 0.42 \\
\hline 7 & 58.60 & 0.91 & 7 & 42.87 & 0.66 \\
\hline 14 & 62.61 & 0.97 & 14 & 53.29 & 0.82 \\
\hline 21 & 64.00 & 0.99 & 21 & 61.07 & 0.94 \\
\hline 28 & 64.71 & 1.00 & 28 & 65.19 & 1.00 \\
\hline
\end{tabular}

M. TRICAPA $(1 / 0,4 / 2,70)$

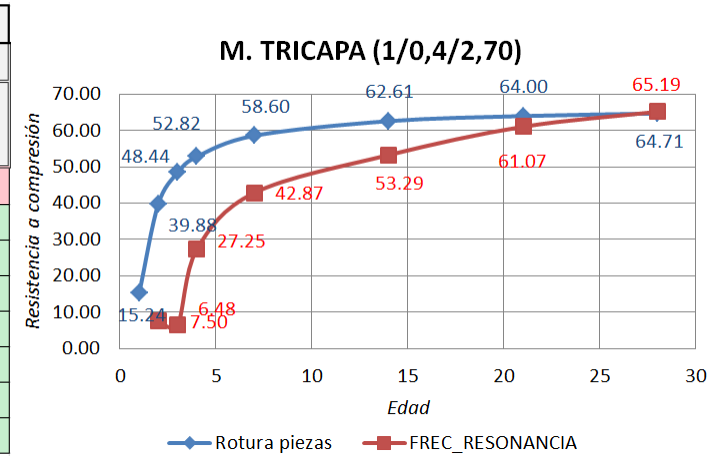

(Fig. 119). Comparativa de resistencias mecánicas mediante rotura de probetas a flexo/compresión frente al método FFRC (Frecuencia Resonancia). 


\title{
Anexo 02.
}

\author{
PARÁMETROS ELÁSTICOS DE UN MATERIAL ELÁSTICO_LINEAL_ISÓTROPO_HOMOGÉNEO.
}

Las constantes elásticas en este tipo de materiales, como el caso de un mortero unicapa a pequeña escala, se relacionan entre sí, pudiendo determinarlas partiendo únicamente de dos módulos cualesquiera de los especificados (Módulo de compresibilidad [K], Módulo de Young [E], 1a Constante de Lamé $[\lambda]$, Módulo de Rigidez transversal [G], coeficiente de Poisson [v] y Módulo de onda $\mathrm{P}[\mathrm{M}])$ :

\begin{tabular}{|c|c|c|c|c|c|c|c|c|c|c|}
\hline & $(\lambda, G)$ & $(E, G)$ & $(K, \lambda)$ & $(K, G)$ & $(\lambda, \nu)$ & $(G, \nu)$ & $(E, \nu)$ & $(K, \nu)$ & $(K, E)$ & $(M, G)$ \\
\hline$K=$ & $\lambda+\frac{2 G}{3}$ & $\frac{E G}{3(3 G-E)}$ & & & $\lambda \frac{1+\nu}{3 \nu}$ & $\frac{2 G(1+\nu)}{3(1-2 \nu)}$ & $\frac{E}{3(1-2 \nu)}$ & & & $M-\frac{4 G}{3}$ \\
\hline$E=$ & $G \frac{3 \lambda+2 G}{\lambda+G}$ & & $9 K \frac{K-\lambda}{3 K-\lambda}$ & $\frac{9 K G}{3 K+G}$ & $\frac{\lambda(1+\nu)(1-2 \nu)}{\nu}$ & $2 G(1+\nu)$ & & $3 K(1-2 \nu)$ & & $G \frac{3 M-4 G}{M-G}$ \\
\hline$\lambda=$ & & $G \frac{E-2 G}{3 G-E}$ & & $K-\frac{2 G}{3}$ & & $\frac{2 G \nu}{1-2 \nu}$ & $\frac{E \nu}{(1+\nu)(1-2 \nu)}$ & $\frac{3 K \nu}{1+\nu}$ & $\frac{3 K(3 K-E)}{9 K-E}$ & $M-2 G$ \\
\hline$G=$ & & & $3 \frac{K-\lambda}{2}$ & & $\lambda \frac{1-2 \nu}{2 \nu}$ & & $\frac{E}{2(1+\nu)}$ & $3 K \frac{1-2 \nu}{2(1+\nu)}$ & $\frac{3 K E}{9 K-E}$ & \\
\hline$\nu=$ & $\frac{\lambda}{2(\lambda+G)}$ & $\frac{E}{2 G}-1$ & $\frac{\lambda}{3 K-\lambda}$ & $\frac{3 K-2 G}{2(3 K+G)}$ & & & & & $\frac{3 K-E}{6 K}$ & $\frac{M-2 G}{2 M-2 G}$ \\
\hline$M=$ & $\lambda+2 G$ & $G \frac{4 G-E}{3 G-E}$ & $3 K-2 \lambda$ & $K+\frac{4 G}{3}$ & $\lambda \frac{1-\nu}{\nu}$ & $G \frac{2-2 \nu}{1-2 \nu}$ & $E \frac{1-\nu}{(1+\nu)(1-2 \nu)}$ & $3 K \frac{1-\nu}{1+\nu}$ & $3 K \frac{3 K+E}{9 K-E}$ & \\
\hline
\end{tabular}

(Fig. 120). Tabla de constantes elásticas de un material. Relación entre magnitudes.

\section{Determinación del Módulo de Elasticidad en morteros.}

Aunque el estudio de la resistencia a compresión no entra en los objetivos del trabajo, se ha estimado conveniente precisar su determinación porque es un dato importante que caracteriza a materiales de naturaleza heterogénea como el mortero, y porque se suele encontrar íntimamente relacionada con su durabilidad. A través de ella podrán cuantificarse diferencias en la composición y, si es posible, establecer su relación con los parámetros de durabilidad estudiados.

El módulo de elasticidad, definido por la ecuación $\boldsymbol{E}=$ esfuerzo /deformación es una medida de la rigidez, o sea la resistencia a la deformación, que varía en el mortero-hormigón entre $1,4 \cdot 10^{5}-4,2 \cdot 10^{5} \mathrm{~kg} / \mathrm{cm}^{2}$ y se suele asumir como $2,1 \cdot 10^{5} \mathrm{~kg} / \mathrm{cm}^{2}(21 \mathrm{GPa})$. En general, se determina mediante ensayos destructivos de probetas en laboratorio. Una ecuación de amplio uso para calcular el módulo de elasticidad (ACI 318M-02), lo relaciona con la Resistencia a la compresión, fc, y el peso unitario, $\gamma_{m}\left[\mathrm{~kg} / \mathrm{m}^{3}\right]$ :

$$
\left.E_{C[M P a]}=\gamma_{m\left(k g / m^{3}\right)}^{1,5} \cdot 0,043 \sqrt{f_{C[M P a]}^{\prime}} \quad \text { (para valores de } 1500 \text { y } 2500 \mathrm{~kg} / \mathrm{m}^{3}\right) \text {. }
$$

En condiciones normales, se considera:

$$
E_{C[M P a]}=4700 \sqrt{f_{C}^{\prime}}
$$

Módulos secante y tangente.- valores diferentes en cada punto y medidos por la inclinación de recta origen/punto y tangente a la curva, respectivamente:

$$
E_{C t}=d \sigma / d S \quad E_{C s}=\sigma / S
$$

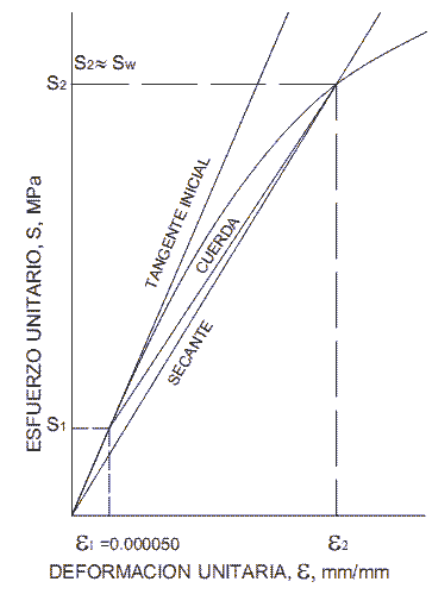




\section{ESTIMACIONES DEL MÓDULO citadas por diversos autores.}

El desarrollo de los ensayos mediante las técnicas de Frecuencia- Resonancia y rotura de probetas lleva implícito un proceso de selección y ajuste de las fórmulas existentes en normativas así como de las presentadas por diversos estudios previos de otros investigadores desde hace décadas, que se recupera aquí para contraste de resultados experimentales propios y medida de control de los mismos.

(1998) ONE-SIDED STRESS WAVE VELOCITY MEASUREMENT IN CONCRETE

J. S. Popovics, Associate Member, W. SONG, J. D. ACHENBACH, J. H. LEE.

\section{Relación entre las velocidades de propagación de onda.}

La velocidad de onda Rayleigh se obtiene simultáneamente de medidas unilaterales. Se ha demostrado que el desplazamiento normal en una posición fija desde el punto de aplicación de una carga impulsiva se compone de contribuciones de ondas P, S y Rayleigh, que se propagan a lo largo de la superficie del sólido (ACHENBACH, 1973). En un medio elástico e isotrópico, se observa que la velocidad de cada onda se relaciona:

$$
\begin{aligned}
& V_{L}=\sqrt{\frac{E(1-v)}{(1+v) \cdot(1-2 v) \cdot \rho}} \quad V_{T}=\sqrt{\frac{E}{2(1+v) \cdot \rho}} \quad l^{6}-8 l^{4}+8 l^{2}\left(3-2 n^{2}\right)+16\left(n^{2}-1\right)=0 \\
& n=\frac{V_{T}}{V_{L}} \quad l=\frac{V_{R}}{V_{T}} \rightarrow V_{R}=V_{T} \cdot l \approx 93 \% V_{T} \quad V_{R} \approx 47-56 \% V_{L} \quad 0,2<v<0,33
\end{aligned}
$$

(2007) IMPROVED R-WAVE VELOCITY MEASUREMENT FOR NDT EARLY-AGE CONCRETE. SUNG WOO SHI; CHUNG BAN YUN; JOHN POPOVICS; JAE HONG KIM.

\section{Relación entre la fuerza y la velocidad de la onda $R$.}

La velocidad de onda $\mathrm{R}$ se aplica para controlar la resistencia a la compresión del hormigón de temprana edad. Para sólidos homogéneos linealmente elásticos:

$$
C_{R}=\frac{0,87+1,12 v}{1+v} \sqrt{\frac{E}{2 \rho(1+v)}} \quad E_{C}=4730 \sqrt{f_{C}^{\prime}(M P a)}
$$

Donde $v$ es el coeficiente de Poisson y $\rho$ es la densidad. Además, la evidencia empírica muestra que la resistencia a la compresión y el módulo de Young "estático" $\left(E_{C}\right)$ del hormigón están relacionados entre sí.

(2011) MODULUS OF ELASTICITY OF SUB-STANDARD AND NORMAL CONCRETES HASAN YILDIRIM, OZKAN SENGUL.

Relación entre la resistencia a compresión y el módulo de elasticidad.

El módulo de elasticidad aumenta con la resistencia a compresión, siendo más densa y resistente la interfaz de la pasta de cemento con los áridos. Para el caso de morteros con bajo contenido de cemento o alta relación a/c (interfaz débil), surgirán microfisuras conforme se sometan a mayores cargas, llegando a penetrar las grietas en la matriz. Una red interconectada de discontinuidades en el material, es una confirmación de la interfaz débil árido/cemento, pudiendo desmenuzarse en los dedos los agregados del cemento. Otro factor es el sangrado del mortero que 
ocasiona en exceso un bajo módulo de elasticidad, ya que el agua de sangrado al evacuarse produce deposición del árido en el fondo. Hay varias expresiones para estimar el módulo de elasticidad del hormigón, y la relación con la resistencia a compresión:

$$
\begin{aligned}
& \text { Norma TS500 } \rightarrow E_{c j}=3250 \sqrt{f_{c k j}+14000} \quad(\mathrm{MPa}) \quad ; \quad \text { Código ACI318 } \rightarrow E_{c j}=0,043 \cdot \gamma_{c}^{1,5}\left(\mathrm{~kg} / \mathrm{m}^{3}\right) \cdot \sqrt{f_{c}^{\prime}} \quad(\mathrm{MPa}) \\
& \text { Norma } E N 1992 / 1 \rightarrow E_{c m}=22\left[f_{c m} / 10\right]^{0,3} \quad(\mathrm{MPa}) \quad ; \quad \text { Re comendable } \rightarrow E_{c}(\mathrm{GPa})=5,85 \sqrt{f_{c}(\mathrm{MPa})}-13,5 \\
& E_{S} \approx 0,85 E_{D}
\end{aligned}
$$

\section{Correlación entre el módulo dinámico de elasticidad y resistencia a compresión.}

Estos investigadores han intentado establecer relaciones empíricas entre el módulo de elasticidad estático, dinámico y la resistencia del hormigón. Observaron que el módulo de Young dinámico $\mathrm{E}_{\mathrm{D}}$ es mayor que el módulo estático $\mathrm{Es}$, y la expresión que los relaciona puede ser de forma aproximada: $E_{D}=40 \% E_{S}$. Esta fórmula genérica puede variar para diferentes clases de áridos y otros parámetros $(\mathrm{a} / \mathrm{c} \ldots)$. Pero de una manera general se admite que la discrepancia entre el módulo elástico estático y el dinámico se debe al efecto plástico durante los ensayos:

$$
\begin{aligned}
& E_{D}=\frac{8,67 \cdot 10^{6} \cdot f_{C}}{f_{C}+1550}(p s i) \quad ; \quad 100{ }_{p s i} \equiv 6,894_{M P a}=68,9{ }_{\mathrm{kg} / \mathrm{cm}^{2}} \\
& E_{S} / E_{D}=0,368+600 E_{S}(\mathrm{MPa})
\end{aligned}
$$

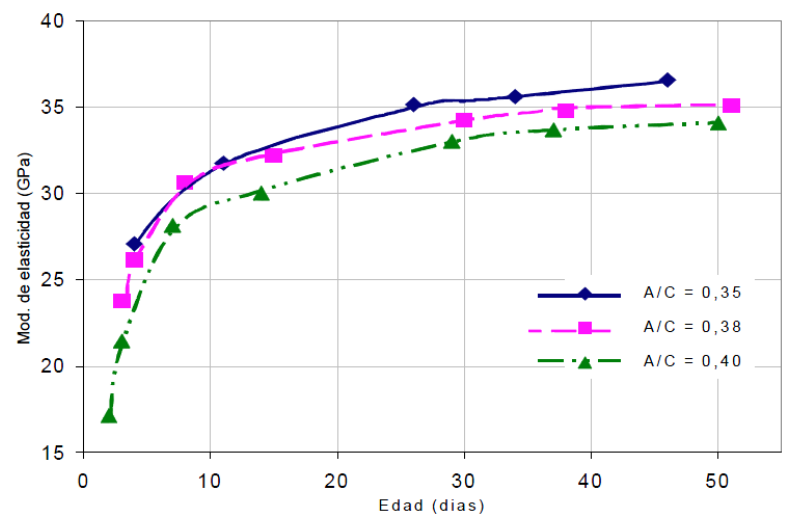

(Fig. 121). Tablas de Correlación entre el módulo dinámico de elasticidad y resistencia a compresión.
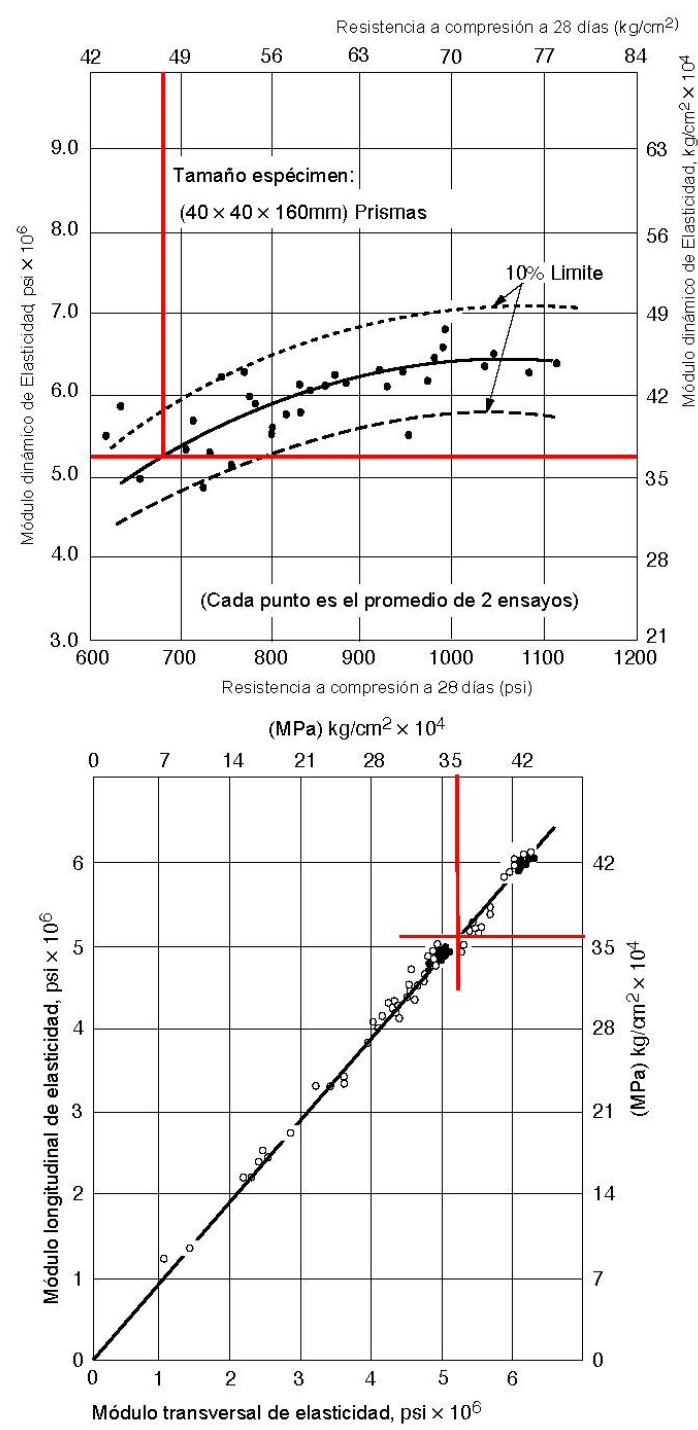


\section{Anexo 03. MATERIALES, MEDIOS, EQUIPOS E INSTRUMENTOS DE ENSAYO.}

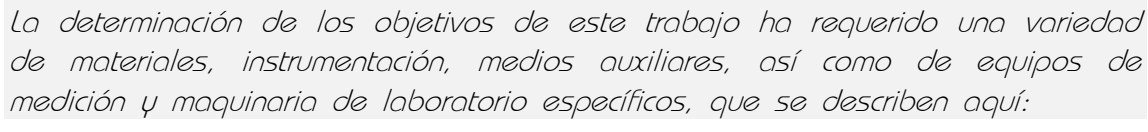

Características del mortero.

El mortero analizado de uso estructural se compone de un árido reducido $\varnothing 4 \mathrm{~mm}$. El rendimiento aproximado es de $2200 \mathrm{~kg} / \mathrm{m}^{3}$ y alcanza resistencias a compresión del orden de $45 \mathrm{~N} / \mathrm{mm}^{2}$. El cemento constituyente se caracteriza por su composición: Cemento Portland tipo I $42,5 R$, árido fino normalizado suministrado con un tamaño máximo de $4 \mathrm{~mm}$ y alto contenido en fíller, agua en proporción a/c: 0,5 y aditivo plastificante (0,6\% del peso del cemento). El cemento empleado es el CEM I 42,5N/R.

En el estudio se ha comprobado como el uso de aditivos mejora las prestaciones del mortero, en este caso, se emplean en amasadas diferentes dos tipos de aditivo plastificante: un superplastificante (Glenium ACE 324) idóneo en hormigón y mortero estructural, y un aireante/plastificante (Rheomix 550) para morteros, cuya finalidad es influir en gran medida retardando el fraguado del cemento. A continuación se presentan las características proporcionadas por el fabricante "BASF Construction Chemicals España S.L."

\begin{tabular}{|l|l|}
\hline Propiedades & \\
\hline Función principal: & Superplastificante/Reductor de agua de alta actividad. \\
\hline Función secundaria: & Acelerante de endurecimiento. \\
\hline Efecto secundario por sobredosificación: & Riesgo de disgregación por sobredosificación. \\
\hline Aspecto físico: & Líquido turbio amarillento. \\
\hline Densidad, $20^{\circ} \mathrm{C:}$ & $1,042 \pm 0,02 \mathrm{~g} / \mathrm{cm}^{3}$ \\
\hline $\mathrm{pH}, 20^{\circ} \mathrm{C}:$ & $6 \pm 1$ \\
\hline Contenido en cloruros: & $\leq 0,1 \%$ \\
\hline Viscosidad $20^{\circ} \mathrm{C}$ Brookfield Sp00/100rpm: & $<95 \mathrm{cps}$. \\
\hline $\begin{array}{l}\text { Los datos técnicos reflejados son fruto de resultados estadísticos y no representan mínimos } \\
\text { garantizados. Si se desean los datos de control, pueden solicitarse las "Especificaciones de Venta" a } \\
\text { nuestro Departamento Técnico. }\end{array}$ \\
\hline
\end{tabular}

(Fig. 122). Características del aditivo superplastificante GLENIUM ACE 324 proporcionadas por el fabricante. 

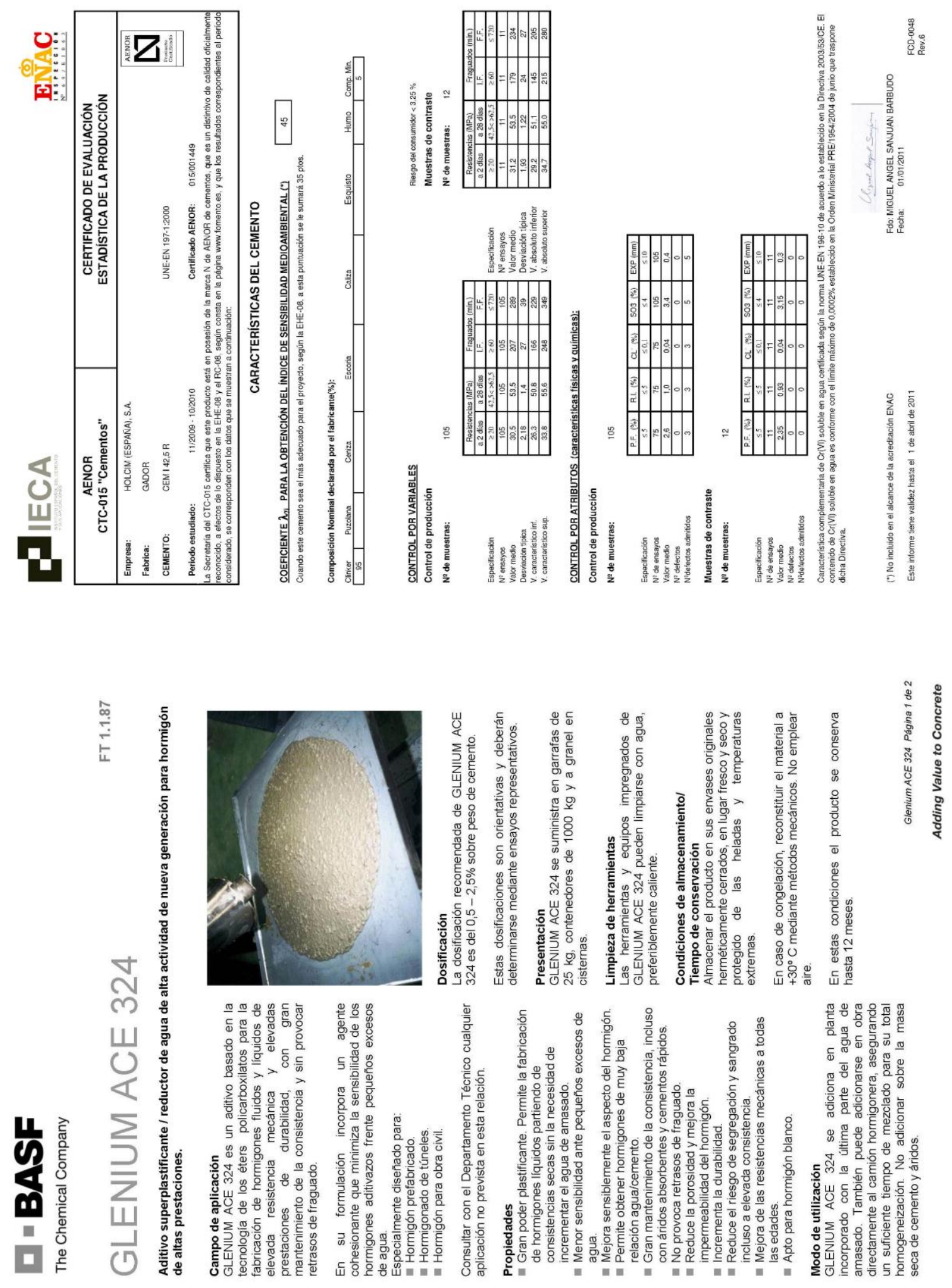

(Fig. 123). Tablas de características técnicas de aditivo empleado en las mezclas. Ficha técnica AENOR del tipo de cemento suministrado. 
Medios y equipos de ensayo.

Se citan los equipos, materiales, maquinaria, medios auxiliares y accesorios de uso común para la realización de los ensayos presentados durante este trabajo en el laboratorio de materiales ETSICCP, bajo la supervisión del Prof. José R. Montero:

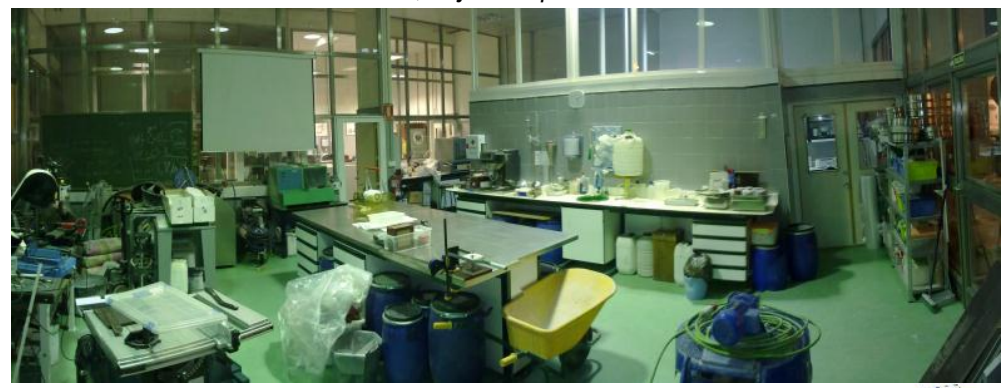

10 Moldes triples para probetas de 40x40x160mm (PROETI S.A.)

Construido en acero tratado y rectificado, desmontable, con dureza superior a 200HV. Piezas con marcado de identificación para su montaje correcto y pulidas según normativa EN 196; ASTM C109, C348. Dimensiones 290x195x50mm y $8 \mathrm{~kg}$ de peso. Cubretapas de la cara superior de politileno reticulado 200x200x25mm. Juego accesorio de espátulas para enrasar la amasada.
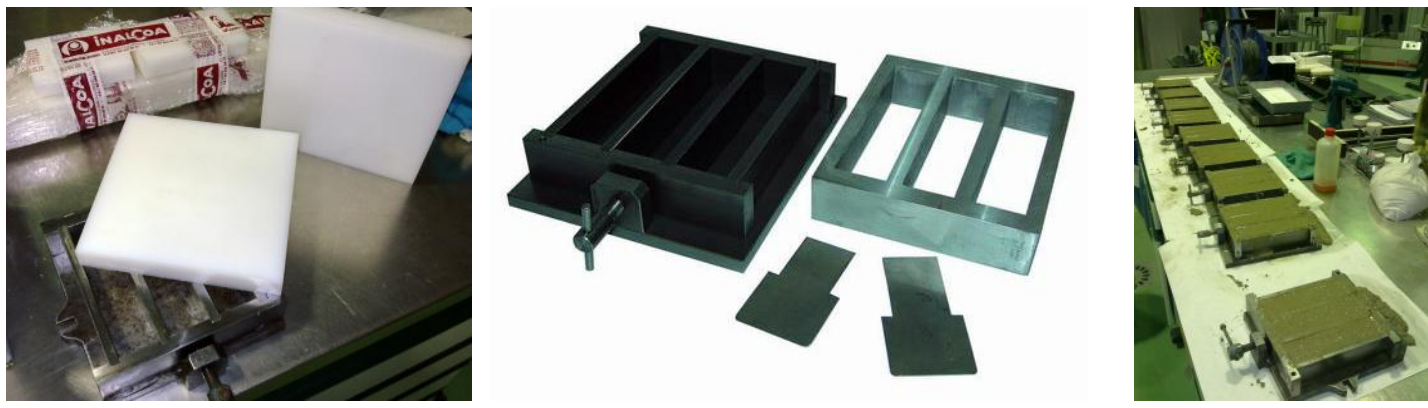

Equipo de medición con bandas extensiométricas “MODEL P3” (Vishay M\&M).

Indicador y registrador de las deformaciones con bandas extensométricas, portátil, operado por batería capaz de aceptar simultáneamente cuatro entradas de galgas y con diferentes circuitos de puente, con 4 canales de entrada, pantalla LCD de lectura directa, almacenamiento de datos con salida analógica de 0 a 2.5Vdc, Cuarto, lectura de galgas de resistencias 120, 350 y $1000 \Omega$ y conectores de transductores de 10-pin.

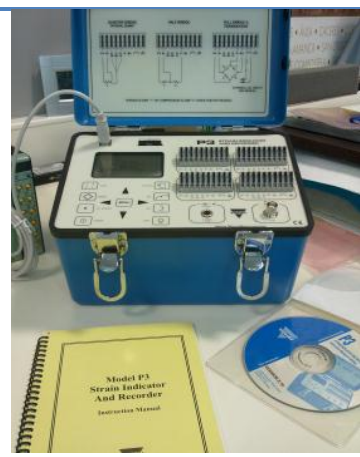

Bandas extensométricas + adhesivo [Long. 20-30mm.]

Realización de medición de deformaciones transversales con galgas de longitud de base 20-30mm. Incorpora un agente de limpieza superficial y un adhesivo bicomponente para la realización del ensayo mediante perfecta adherencia banda-probeta de 40x40x160mm con el objetivo de establecer un método para la determinación de las curvas tensión-deformación, del módulo de elasticidad (Young) y del coeficiente de Poisson en compresión uniaxial. 

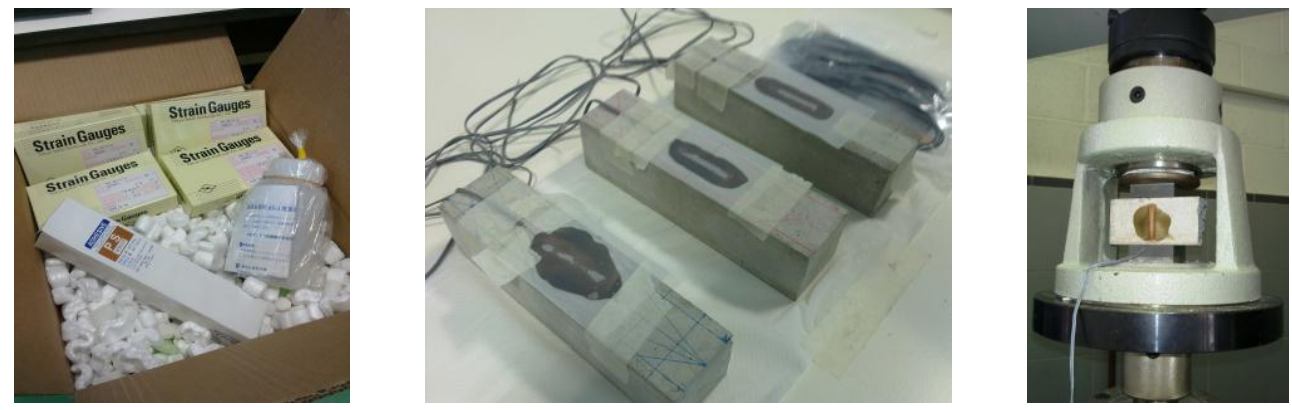

Mesa de sacudidas de accionamiento manual para mortero (EN 196/1; UNE 83258).

Compactador de probetas de 40x40x160mm para facilidad de maniobra de colocación y retirada del molde, con un desnivel de $15 \mathrm{~cm}$ para los golpes de amasado. Es una mesa circular con cristal de Ø350mm, base de acero fundido en forma de trípode y una manivela que deja caer la mesa.
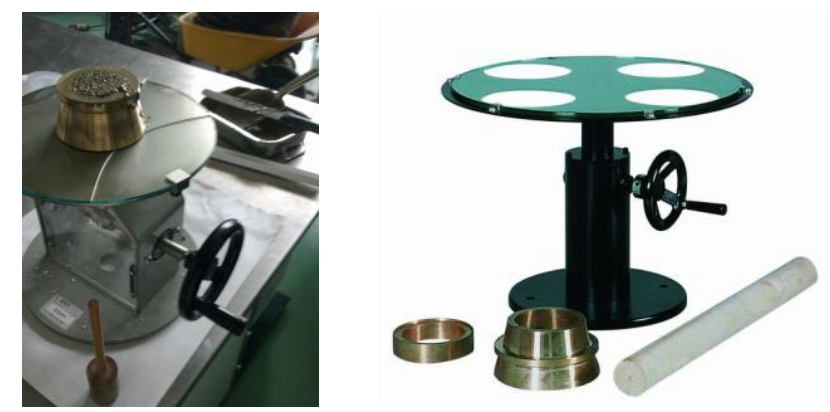

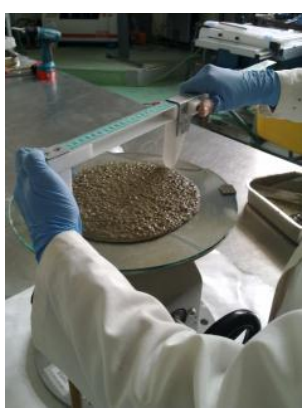

Amasadora de cemento

\section{iharkntit:}

Sistema de cambio de velocidades eléctrico que permite la automatización del ciclo completo de amasado mediante módulo electrónico de programación y tolva de vertido automático de la arena. Dispositivo antiproyecciones, con cierre eléctrico de seguridad y dispositivo para el vertido automático de agua en el cazo de la amasadora.

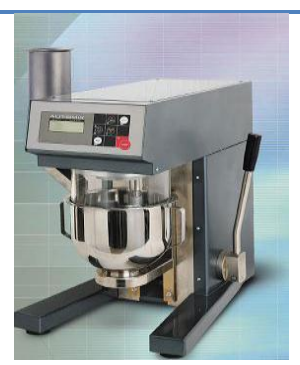

Máquina de tracción hidráulica (SERIE EUROTEST).

inartint:

Equipo de capacidad 100KN. Su aplicación principal es la realización de ensayos de tracción de materiales, conforme a EN 10002-1 y normativa equivalente (principalmente ASTM y ASME). Se utiliza para realizar ensayos de compresión y flexion. Dispone de software propio WINTest 32.
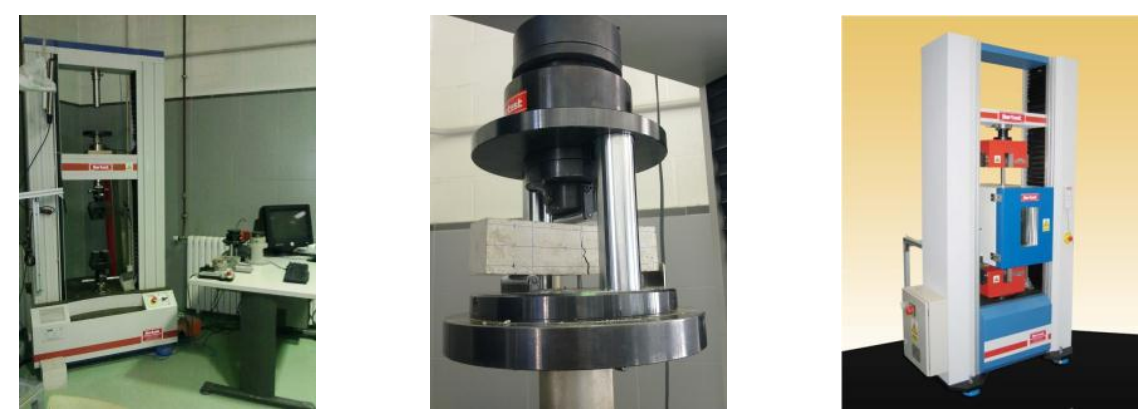
Balanza hidrostática (densidad aparente). Balanza electrónica de precisión.

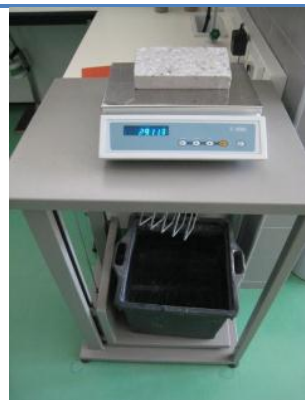

Con calibración automática del fondo de escala. Tiempo de respuesta: 2-3 seg.

Tensión: $220 \mathrm{~V} .+10 \%$

Capacidad: $1000 \mathrm{~g}$.

Precisión: 0,01 g. Plato:

$150 \mathrm{~mm}$. Peso $5,8 \mathrm{~kg}$

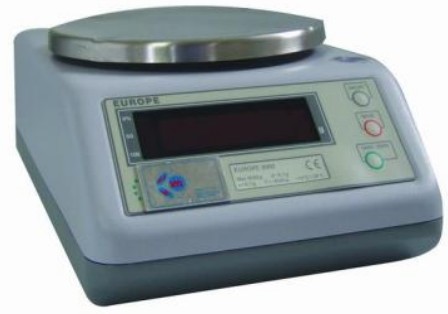

Cámara de curado de gran capacidad para las muestras de mortero.

Conforme a Normas EN 196/1; ASTM C87, C109, C190, C191;

UNE 80102. Diseñada para el curado de grandes cantidades de muestras de mortero. Construida en aluminio y policarbonato, termostato digital de precisión y cuatro bandejas porta-muestras. Rango de humedad: 95\%.

- Dim. exteriores: $1370 \times 540 \times 1490 \mathrm{~mm}$.

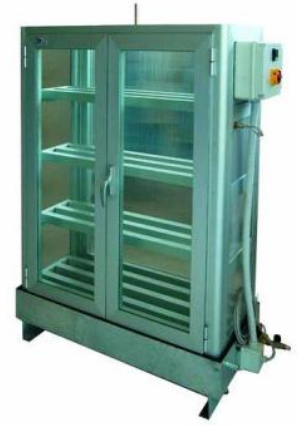

Encofrado de polietileno reticulado e.2,5cm para especímenes de mortero.

Para el encofrado del espécimen de mortero de 400x400x200mm se recurre a realizarlo mediante paneles de politileno de $2,5 \mathrm{~cm}$ de espesor, dotado de la suficiente resistencia para evitar la deformación una vez se rellene con la tongada de la pasta de cemento. Antiadherente, blanco y liso. Las uniones son estancas mediante perforaciones con taladro y atornillado en todo su perímetro.
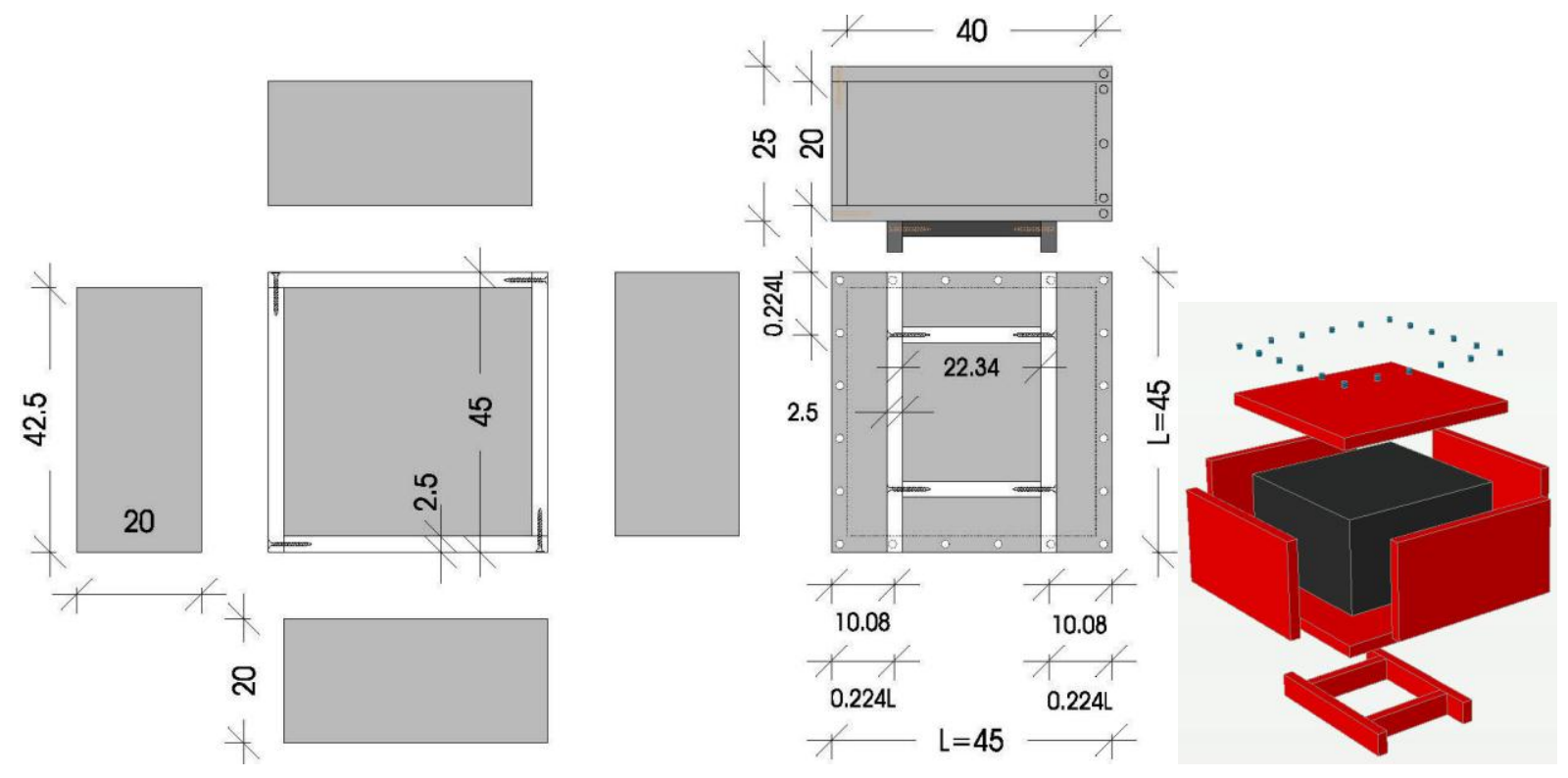


\section{Anexo 04. HERRAMIENTAS DE PROCESAMIENTO DE SEÑALES.}

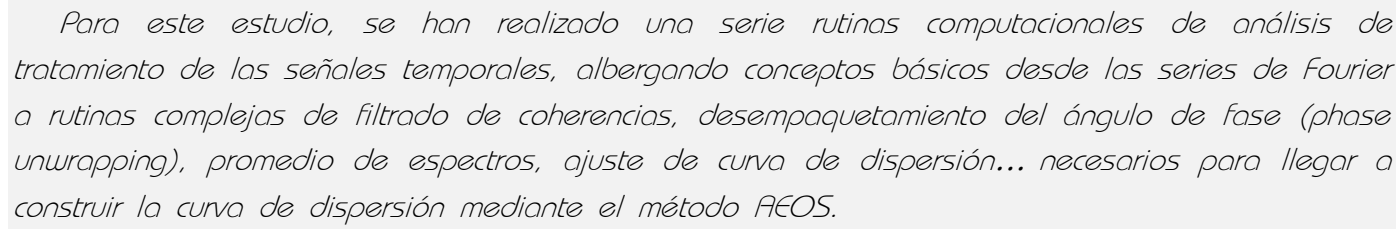
tratamiento de las señales temporales, albergando conceptos básicos desde las series de fourier a rutinas complejas de filtrado de coherencias, desempaquetamiento del ángulo de fase (phase unurapping), promedio de espectros, ajuste de curva de dispersión... necesarios para llegar a construir la curva de dispersión mediante el método AEOS.

Planteamiento de tratamiento de señales. Conceptualización. Ideas previas.

Una forma de caracterizar la acción del impacto a efectos de respuesta de cálculo es mediante el uso del registro temporal particular como expresión de una carga periódica mediante un desarrollo en serie de Fourier, que constituyen la herramienta básica paras analizar la señal como una suma infinitesimal de funciones senoidales más simples, así como el espectro de energía y efectuar las transformaciones necesarias para filtrar la señal de ruidos coherentes.

El impacto genera una carga dinámica determinista transitoria que se puede expresar como una suma de cargas armónicas mediante el desarrollo en serie de Fourier, siendo $\boldsymbol{T}_{\boldsymbol{p}}$ el periodo de la carga, $\boldsymbol{n}$ un $\mathrm{n}^{\mathrm{o}}$ entero y $\boldsymbol{a}_{\boldsymbol{0}}, \boldsymbol{a}_{\boldsymbol{w}}, \boldsymbol{b}_{\boldsymbol{n}}$ coeficientes de Fourier expresados de forma simplificada:

$$
a_{0}=\frac{1}{T_{p}} \int_{o}^{T_{p}} p(t) d t ; a_{n}=\frac{2}{T_{p}} \int_{o}^{T_{p}} p(t) \cos \left(n \frac{2 \pi}{T_{p}} t\right) d t ; b_{n} \frac{2}{T_{p}} \int_{o}^{T_{p}} p(t) \operatorname{sen}\left(n \frac{2 \pi}{T_{p}} t\right) d t ; \quad p(t)=\sum_{n=-\infty}^{\infty} C_{n} e^{i \omega_{n} t} d t ; n=0, \pm 1, \pm 2 \ldots
$$

Una vez expresada la carga periódica como suma de armónicas mediante el desarrollo en serie de Fourier para un sistema elástico y lineal, la respuesta total del sistema se obtendrá como suma de armónicos (respuesta para cada uno de los términos de la ecuación anterior en aplicación de la ecuación del movimiento $m \ddot{v}+c \dot{v}+k v=C_{n} e^{i \omega_{n} t}$ con una solución particular del tipo $\left.v_{p}=A_{m} e^{i \omega_{m} t}\right)$. La función de transferencia $H n$ relaciona los coeficientes de Fourier $D n=C n \cdot H n$, de manera que podemos calcular su respuesta sin más que expresar mediante una serie de Fourier.

\section{APENDICE DE FORMULAS DE TRATAMIENTO DE SEÑALES.}

- Fase del espectro cruzado: $\Phi_{12}(\omega)=\tan ^{-1}\left(\frac{\operatorname{Im}\left(G_{12}(\omega)\right)}{\operatorname{Re}\left(G_{12}(\omega)\right)}\right)$

- Desfase de tiempo entre receptores: $t(\omega)=\frac{\Phi_{12}(\omega)}{\omega}$

- Velocidad de fase de onda superficial siendo D la distancia entre receptores:

$$
V_{R}(\omega)=\frac{D}{t(\omega)}
$$

- Desarrollo en serie de Fourier:

$$
x(t)=\sum_{n=-\infty}^{\infty} C_{n} e^{i 2 \pi f n t} d t ; n=0, \pm 1, \pm 2 \ldots
$$

- Función de transferencia:

$$
H_{n}=\frac{D_{n}}{C_{n}} ; n=0, \pm 1, \pm 2 \ldots \quad C_{n}=\frac{1}{T_{p}} \int_{0}^{T} x(t) e^{-i \varpi n t}
$$


- Transformada directa de Fourier:

$$
X(\omega)=\int_{-\infty}^{\infty} x(t) e^{-i \omega t} d t
$$

- Transformada inversa de Fourier (IFT):

$$
x(t)=\frac{1}{2 \pi} \int_{-\infty}^{\infty} X(\omega) e^{i \bar{\omega} t} d \varpi
$$

- Transformada discreta de Fourier (DFT):

$$
X_{K}=\sum_{n=0}^{N-1} x_{n} e^{\frac{-2 \pi i}{N} k n}
$$

- Transformada rápida de Fourier (FFT):

$$
f_{j}=\sum_{k=0}^{n-1} x_{k} e^{\frac{-2 \pi i}{n} j k}
$$

- Espectro de energía: $S\left(f_{n}\right)=\frac{A_{n}^{2}}{2 A_{f}} ; A_{f}=f_{n}-f_{n-1}=\frac{1}{b_{n}-a_{n}}$

- Función de correlación cruzada:

$$
R_{x y}(\tau)=\frac{1}{b-a} \int_{a}^{b} x(t) \cdot(y(t)+\tau) d \tau=\int_{-\infty}^{+\infty} s_{x y}(\theta) \cdot e^{i \theta \tau} d \theta
$$

- Espectro cruzado: $S_{x y}(\theta)=\frac{1}{2 \pi} \int_{-\infty}^{+\infty} R_{x y}(\tau) \cdot e^{-i \theta \tau} d \tau=H(\theta) * S_{x}(\theta)=\frac{C_{n} \cdot D_{n}^{*}}{d \theta}$

- Densidad espectral de potencia: $S_{x}(\theta)=\left|C_{n}{ }^{2}\right| / d \theta$

\section{- Función de coherencia de dos señales:}

$$
\gamma_{x y}^{2}(\theta)=\frac{\left|S_{x y}(\theta)\right|^{2}}{S_{x}(\theta) \cdot S_{y}(\theta)} \quad\left|\gamma_{x y}^{2}(\theta)\right| \in[0,1]
$$

Los coeficientes $\boldsymbol{C}_{\boldsymbol{n}}$ y $\boldsymbol{D}_{\boldsymbol{n}}$ pueden obtenerse de la expresión del desarrollo en serie de Fourier como:

$$
C_{n}=\left\{\begin{array}{c}
\frac{a_{n}}{2}-i \frac{b_{n}}{2}, n=1,2,3 \ldots \\
a_{0}, n=0 \\
\frac{a-n}{2}+i \frac{b-n}{2}, n=-1,-2,-3 \ldots
\end{array}\right\} ; \begin{gathered}
c_{0}=\frac{1}{2} a_{0} \\
c_{n}=\frac{1}{2}\left(a_{n}-j b_{n}\right) \\
c_{-n}=\frac{1}{2}\left(a_{n}+j b_{n}\right)
\end{gathered} \quad \text { para } \quad n \neq 0, c_{0}=0,5 a_{0}
$$

Teorema de Nyquist:

Es la frecuencia máxima de la que se puede tomar muestras, y es igual a la mitad del ritmo de muestreo, es decir, para poder replicar con exactitud la forma de una onda es necesario que la frecuencia de muestreo sea superior al doble de la máxima frecuencia a muestrear. El teorema demuestra que la reconstrucción exacta de una señal periódica continua en banda base a partir de sus muestras, es matemáticamente posible si la señal está limitada en banda y la tasa de muestreo es superior al doble de su ancho de banda.

Discrete Fourier Transform (DFT).

Se basa en la serie de Fourier, conforme a una serie de tiempo dada puede expresarse como la suma de infinitas sinusoides con frecuencia diferente. Teniendo en cuenta que se caracteriza por su amplitud y diferencia de fase, estos valores constituyen la representación en el dominio de la frecuencia:

$F(\omega)=\int_{-\infty}^{\infty} f(t) e^{-j \omega t} d t$

Cuando la función $\boldsymbol{f}(\boldsymbol{t})$ está dada por $\boldsymbol{N}$ valores $f\left(t_{1}\right), f\left(t_{2}\right), \ldots f\left(t_{N}\right)$ se dice discretizada o muestreada, entonces la integral que define la Transformada de Fourier se convierte en: 
$F(n)=\sum_{k=1}^{N} f\left(t_{k}\right) e^{-j \frac{2 \pi n}{N}(k-1)}, \quad$ para $1 \leq n \leq N$

(donde $k$ es la frecuencia discreta) llamada Transformada Discreta de

Fourier (DFT) que requiere el cálculo de $N$ funciones exponenciales para obtener $F(n)$, evaluable de manera rápida a través de la Transformada Rápida de Fourier (FFT).

- La representación del movimiento provocado por la onda tras el impacto en la superficie del espécimen de hormigón, está basada en la densidad espectral de potencia (cross power density) de la aceleración y en una duración equivalente del movimiento transitorio.

- Este tipo de problema sometido a una excitación, permite obtener características de la respuesta, necesarias en el análisis AEOS, como la varianza, la función de autocorrelación, la correlación cruzada o la densidad espectral cruzada.

Por tanto, la densidad espectral de potencia, $\mathbf{S}_{\mathbf{x}}$, es la TFT de la función de autocorrelación, y recíprocamente, es la IFT de la densidad espectral de potencia:

$$
S_{x}(\theta)=\frac{1}{2 \pi} \int_{-\infty}^{+\infty} R_{x}(\tau) \cdot e^{-i \theta \tau} d \tau \quad R_{x}(\tau)=\int_{-\infty}^{+\infty} s_{x}(\theta) \cdot e^{i \theta \tau} d \theta
$$

"Aliasing".

El "aliasing" es un efecto no deseado de toma de muestras a intervalos de tiempo discreto, un procedimiento que está vinculado a la digitalización necesaria para el almacenamiento y posterior análisis en el dominio del tiempo. La frecuencia más alta que puede extraerse de una señal discreta es la frecuencia de Nyquist [inversamente proporcional al intervalo de muestreo]: $f_{N Y Q}=1 / 2 F s=N / 2 \Delta T$

Todos los componentes de frecuencia por encima de este valor se pierden. El efecto de suavizado puede resumirse como la presencia de componentes de baja frecuencia ficticia creados para compensar la energía de las componentes de alta frecuencia que se pierden. Dos problemas principales están asociados con el fenómeno de aliasing:

- En primer lugar el intervalo de muestreo ha de ser cuidadosamente seleccionado de acuerdo a las frecuencias involucradas por el fenómeno bajo estudio o al menos a la gama de frecuencias de interés. Un muestreo diferente puede inducir a la pérdida de información importante en el rango de frecuencias por encima del valor de Nyquist.

- El segundo problema es que el "aliasing" provoca la alteración del espectro de Fourier si están presentes en la señal real las frecuencias por encima del umbral de Nyquist. Para evitarlo se requiere un filtro de suavizado para cortar toda la energía eficazmente asociada a altas frecuencias.

"Leakage".

El "leakage" (fuga de frecuencias) aparece inevitablemente por la presencia de componentes de frecuencias erróneas debido a la presunta periodicidad y truncamiento de señal al aplicar la DFT, causada por la longitud finita de los registros. Además se debe considerar también que la transformación es discreta en frecuencia, por lo tanto las frecuencias de la señal original no presentes en la matriz discreta deben estar representadas por los valores más cercanos. Puede reducirse aumentando la resolución en frecuencia. Por otro lado si se elige una ventana amplia de observación de la señal y se aplica, es posible obtener un registro inicial y final con valores nulos, eliminando en un principio algo del efecto de la periodicidad forzada.

Experimentalmente, en este trabajo se ha observado que en aquellos registros que presentaban ruido, el efecto de ventana en la señal provocaba un truncamiento erróneo, debiendo considerar que la energía de la señal se reducía por la aplicación de ventanas tipo Hanning, y por lo tanto, era precisa una corrección (mayor resolución). 


\section{Anexo 05. ENSAYOS PARALELOS. OBSERVACIONES.}

En los ensayos se ha observado que aquellos morteros dosificados con una cantidad de aditivo plastificante, veían comprometidas las resistencias a edades tempranas. Para saber en que medida el aditivo influía en el fraguado, se realizó una prueba al principio/final del fraguado del cemento CEM-I 42,5R con distintas dosis conforme a la norma UNE-EN 196-3.

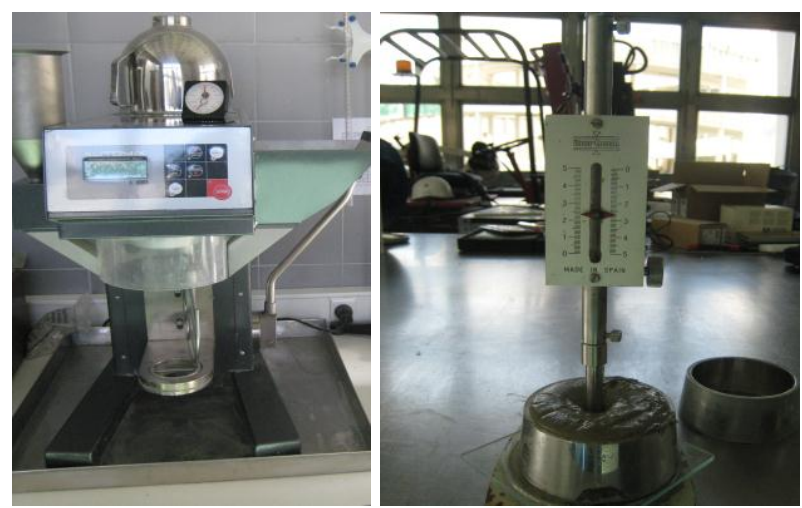

(Fig. 124).(Izq). Amasadora empleada para fabricar las pastas de cemento. (Der). Determinación de la consistencia normal de la pasta. Dispositivo de los tiempos de fraguado (UNE-EN 196-3).

Influencia del aditivo en los tiempos de fraguado del cemento.

En la tabla siguiente se presentan los resultados obtenidos donde, a medida que se aumentaba la dosis de aditivo, se producía un aumento considerable de los tiempos de fraguado:

\begin{tabular}{|c|c|c|c|c|}
\cline { 2 - 5 } \multicolumn{1}{c|}{} & $\begin{array}{c}\text { Agua para consistencia } \\
\text { normal (g) }\end{array}$ & $\begin{array}{c}\text { Principio de fraguado } \\
\text { (min.) }\end{array}$ & $\begin{array}{c}\text { Final de fraguado } \\
\text { (min.) }\end{array}$ & $\begin{array}{c}\text { Final principio } \\
\text { (min) }\end{array}$ \\
\hline Sin aditivo & 142 & 192 & 237 & 45 \\
\hline Aditivo al 1\% & 118 & 360 & 450 & 90 \\
\hline Aditivo al 2\% & 106 & 407 & 530 & 122 \\
\hline
\end{tabular}

(Fig. 125). Tiempos de fraguado para el cemento combinado con diferentes dosis de aditivo.

Influencia del tiempo de fraguado para la realización de ensayos a edad temprana.

$\mathrm{Al}$ igual que para el tema objeto de este trabajo (propagación de ondas de baja frecuencia), se han reportado varios exámenes al mortero fresco, con el objetivo de la determinación de la relación idónea a/c (Popovics 1998), del punto de fraguado (Keating 1989; SAYers \& Dahlin 1993; Garnier 1995; Labouret 1998; Ozturk 1999; Subramanian 2000; Valic 2000; Grosse \& Reinhardt, 2001; СHOTARD 2001), necesarios para establecer el momento que se podía desmoldar para la realización de las primeras mediciones a edad temprana. Además, la realización del trabajo en fechas diferentes expuso los morteros a condiciones ambientales donde se tuvo en cuenta su influencia: 


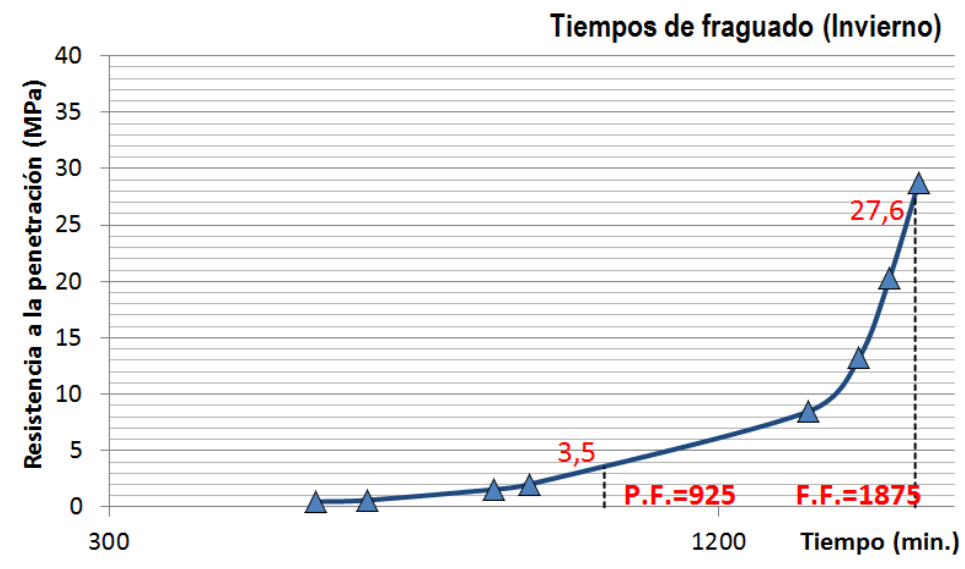

(Fig. 126). Gráfica de evolución del fraguado del mortero tipo $(1 / 0,5 / 3)[c / c ; a / c ; f / c]$ amasada Noviembre 2011 con el principio y final de fraguado marcados.

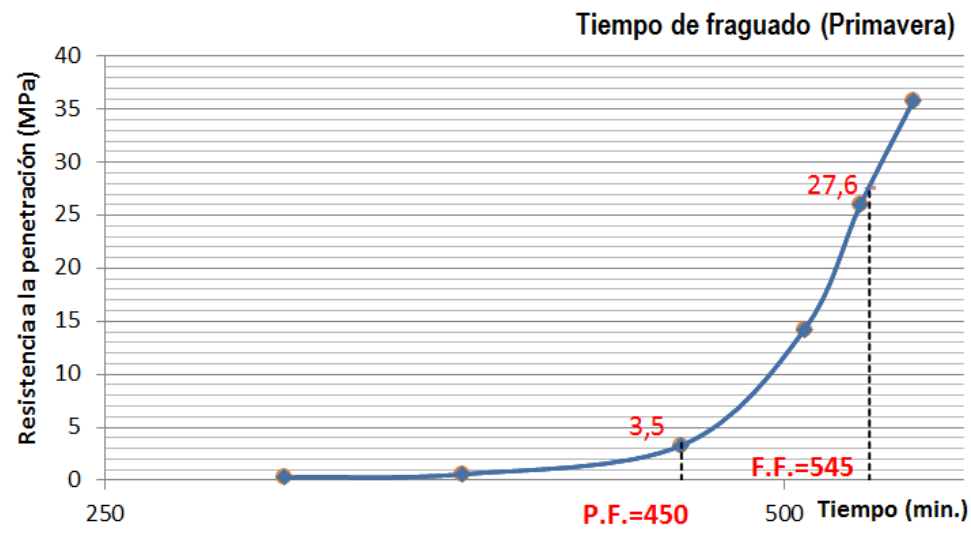

(Fig. 127). Gráfica de evolución del fraguado del mortero tipo $(1 / 0,5 / 2,25)$ $[c / c ; a / c ; f / c]$ amasada Abril 2012 con el principio y final de fraguado marcados.

La duración necesaria de curación depende de la composición y de las proporciones de la mezcla de mortero. Las pruebas han mostrado que el principio de fraguado variaba de 7 a $15 \mathrm{~h}$, por lo que se cita la problemática que surgió a edades tempranas para la colocación de acelerómetros mediante pernos roscados y la necesidad de una fuente de impacto con punta de plástico en sustitución de la punta de acero en el martillo calibrado.

Procedimiento para la determinación de los tiempos de fraguado del mortero.

El principio y final de fraguado del mortero se llevó a cabo según normativa (ASTM C 403/C 403M y UNE-EN 196-3:2005). El curado del mortero mientras se producía el final de fraguado se realizo en cámara húmeda con regulación de la temperatura a $20^{\circ} \mathrm{C}$.

En la elaboración del mortero, se contabilizó el tiempo al entrar en contacto el agua con el cemento. Una vez elaborado se colocó en el recipiente y se compactó con una barra de punta redondeada. Posteriormente se introdujo el contenedor de mortero en el baño a temperatura constante protegiendo la superficie de mortero con un trozo de plástico para evitar el lavado de ésta. El aparato empleado para realizar este ensayo es la aguja de Vicat (UNE-EN 196-3:2005, 2009). 
Observaciones del curado superficial del mortero.

A menor contenido de agua inicial, se tiene una relación a/c menor y menor porosidad inicial, siendo necesario utilizar medidas de curado que proporcionen agua adicional para mantener la hidratación del poro necesaria para lograr las deseadas propiedades del mortero. La mezcla de mortero con una relación $\boldsymbol{a} / \mathbf{c}=\mathbf{0 , 4 0}$ realizada en Abril 2012 como última capa del espécimen tricapa de 40x40x5cm, no experimentó pérdida de humedad, no llegando a desarrollar su pleno potencial de hidratación debido a la falta de agua. Tal mezcla, por tanto, se beneficiaría del agua de curado aplicada externamente. A la vez que se estudiaba a edad temprana se le hidrataba ya que mostraba gran cantidad de poros y un debilitamiento de las resistencias, debido a la desecación propia o secado interno del mortero debido al consumo de agua de hidratación (NEviLLe 1996). Como el cemento hidrata, sigue siendo insuficiente mezclar agua para mantener la hidratación. Este problema se presentó en la proporción $a / c \approx 0,40$ (N.J. CARINO 1999).

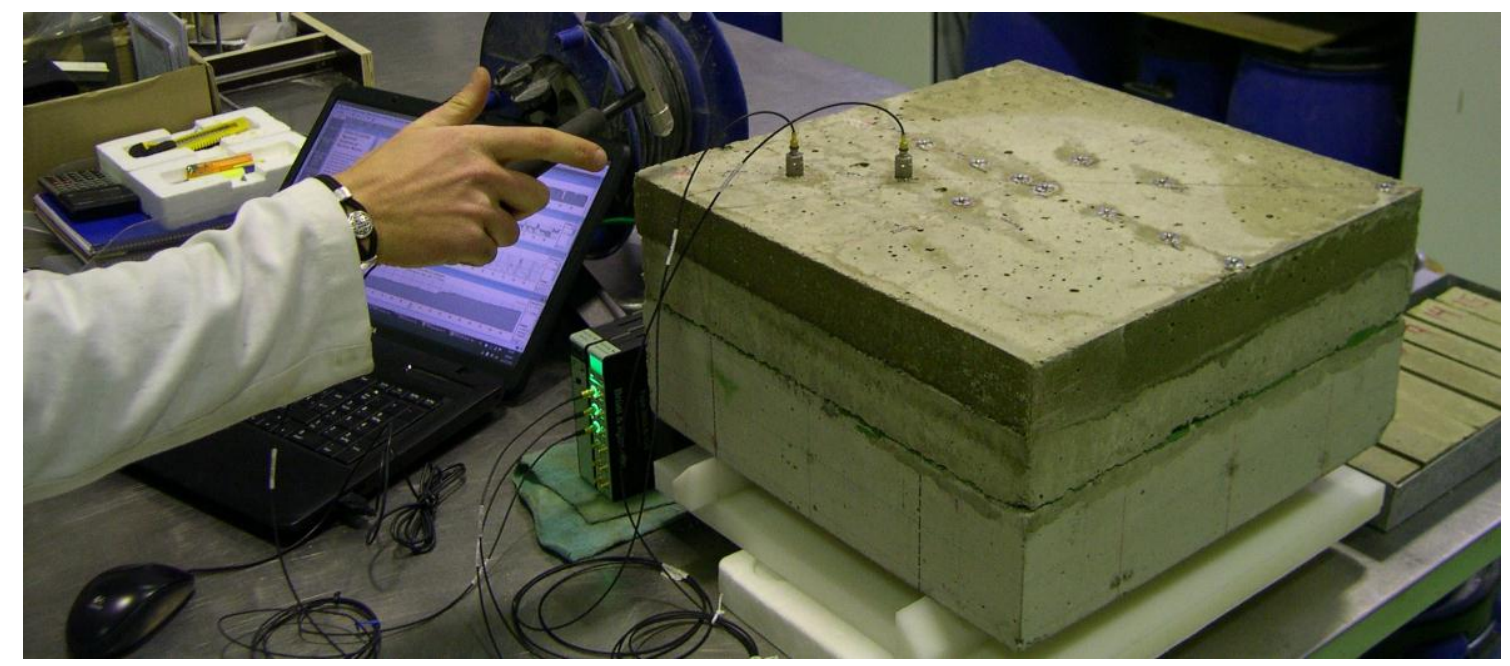

(Fig. 128). Desarrollo de los experimentos en modelos de losa tricapa donde la superficie del espécimen muestra esa baja relación agua/cemento determinante en las resistencias finales del modelo tipo (1/0,5/2,25) [c/c;a/c;f/c]- Amasada Abril 2012.

Puede remediarse cerca de la superficie del mortero proporcionando externamente al curado agua para mantener la hidratación. A tales valores bajos de a/c, sin embargo, la permeabilidad de la pasta es normalmente tan baja que externamente aplicada al curado, el agua no penetra más allá de la capa superficial. Por el contrario, la baja permeabilidad impide la restauración de humedad que se perdió en el secado de la superficie por la migración de humedad desde el interior.

Por tanto, cabe destacar la componente experimental del trabajo en cuanto a número de amasadas realizadas optando por las mejores dosificaciones para que no afectaran a los resultados del Análisis espectral de Ondas Superficiales, llegando a adoptar medidas correctoras de curado del mortero tan pronto como estaba en riesgo de secado, daño o inhibición del desarrollo de sus propiedades. Estas medidas debían mantenerse hasta que el secado de la superficie no dañase el mortero, y hasta que la hidratación hubiera avanzado para obtener las propiedades deseadas. 


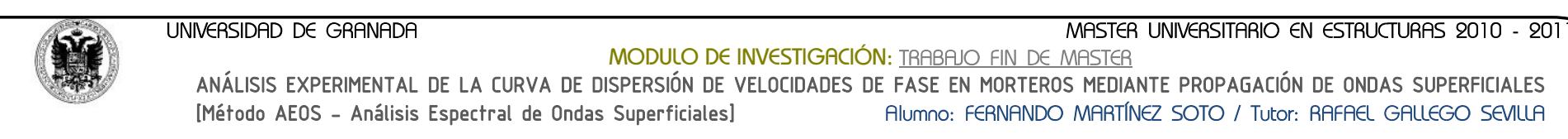

Anexo 06.1. TABLA DE RESULTADOS EN MORTERo UNICAPA A EDADES TEMPRANAS. Ejemplo LOSA 40x40x10cm

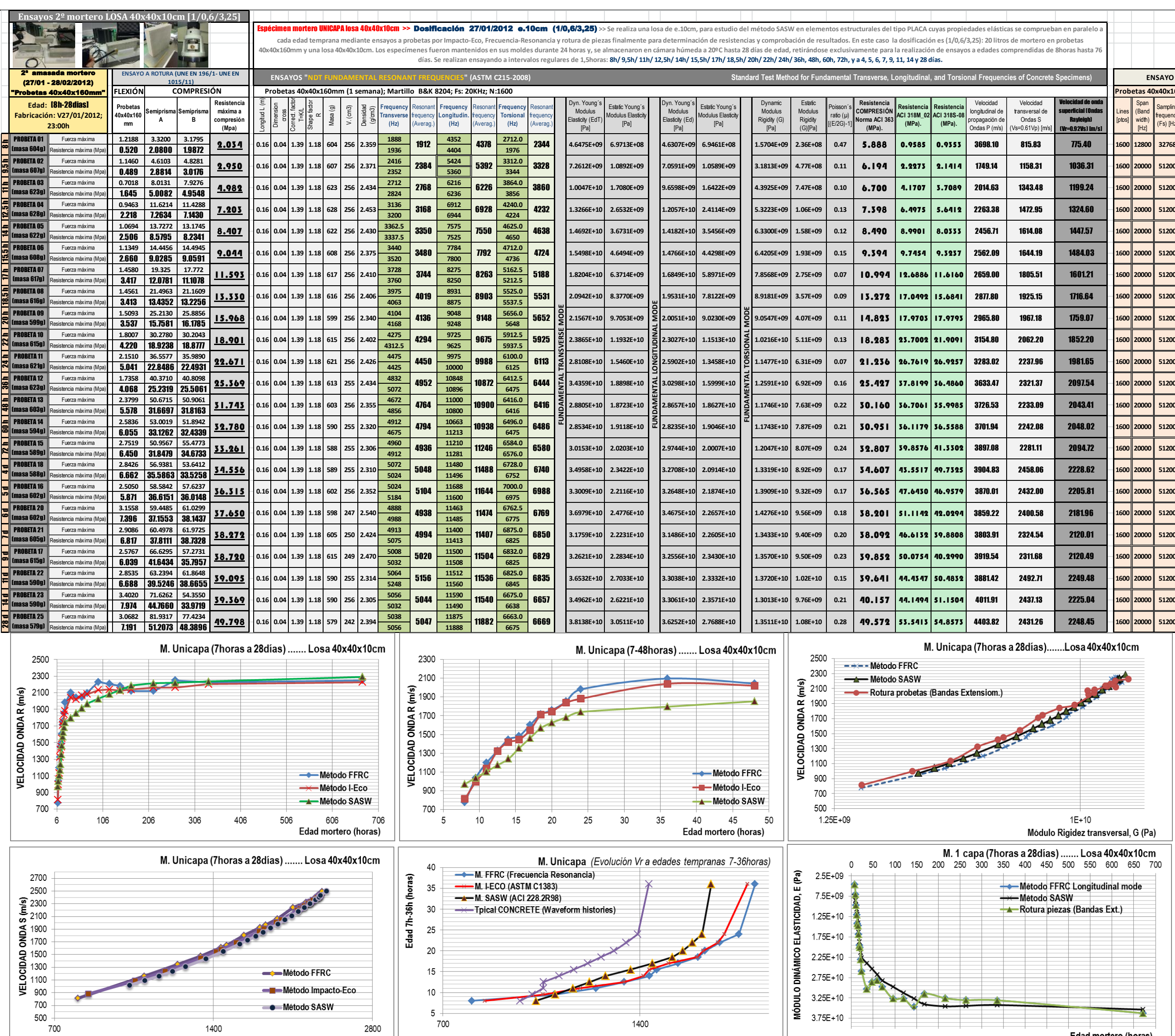

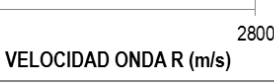
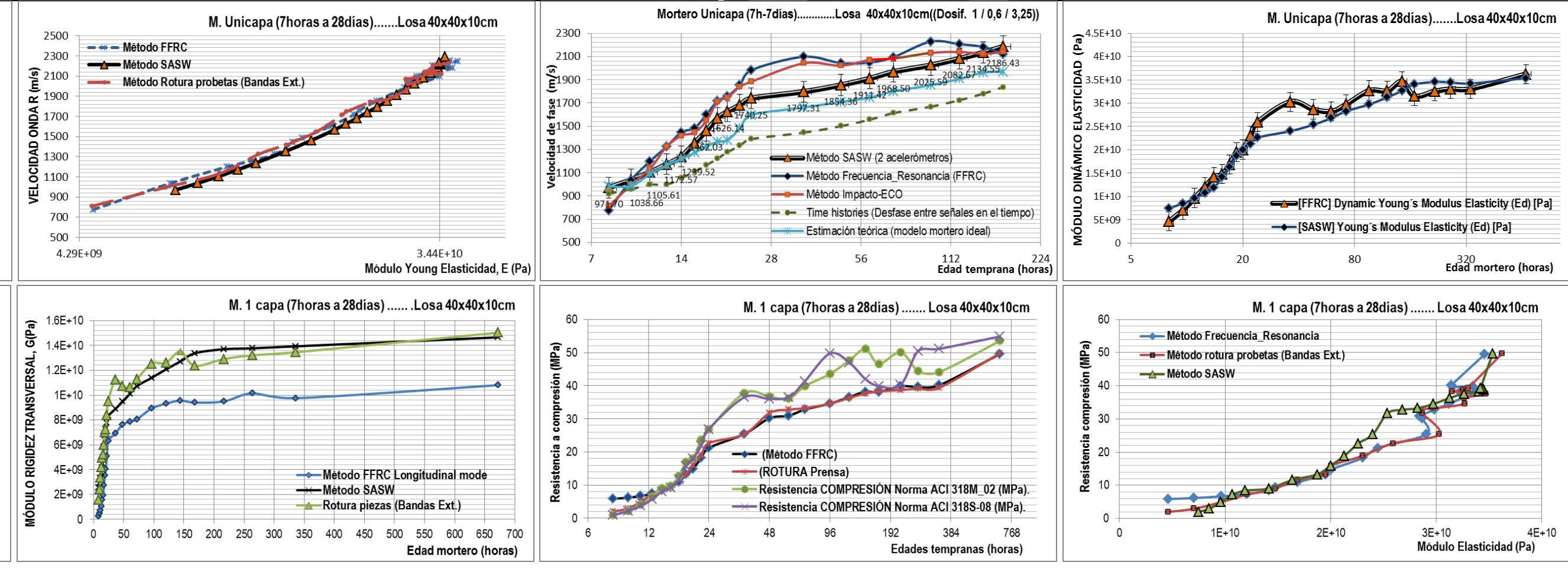


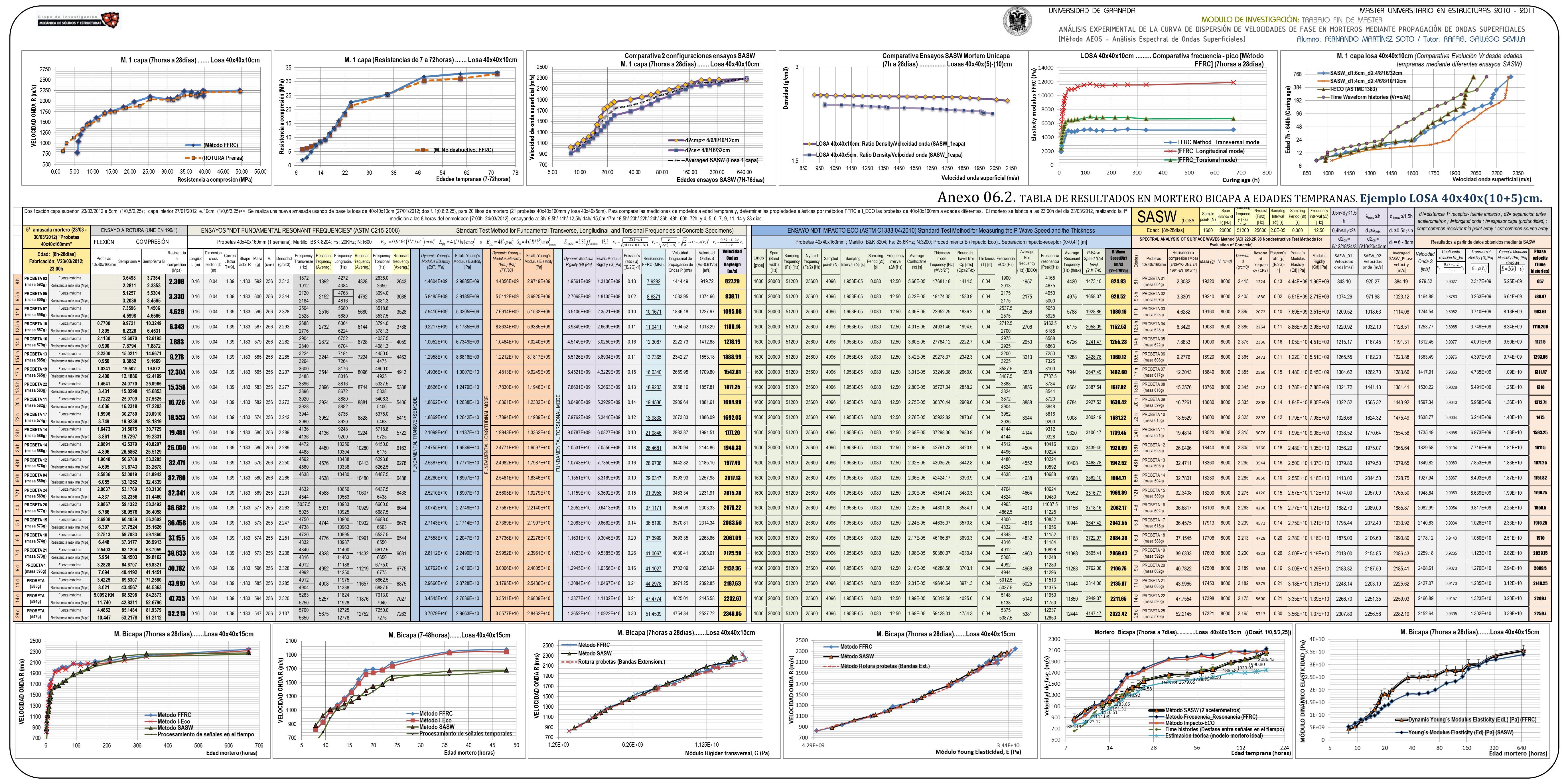




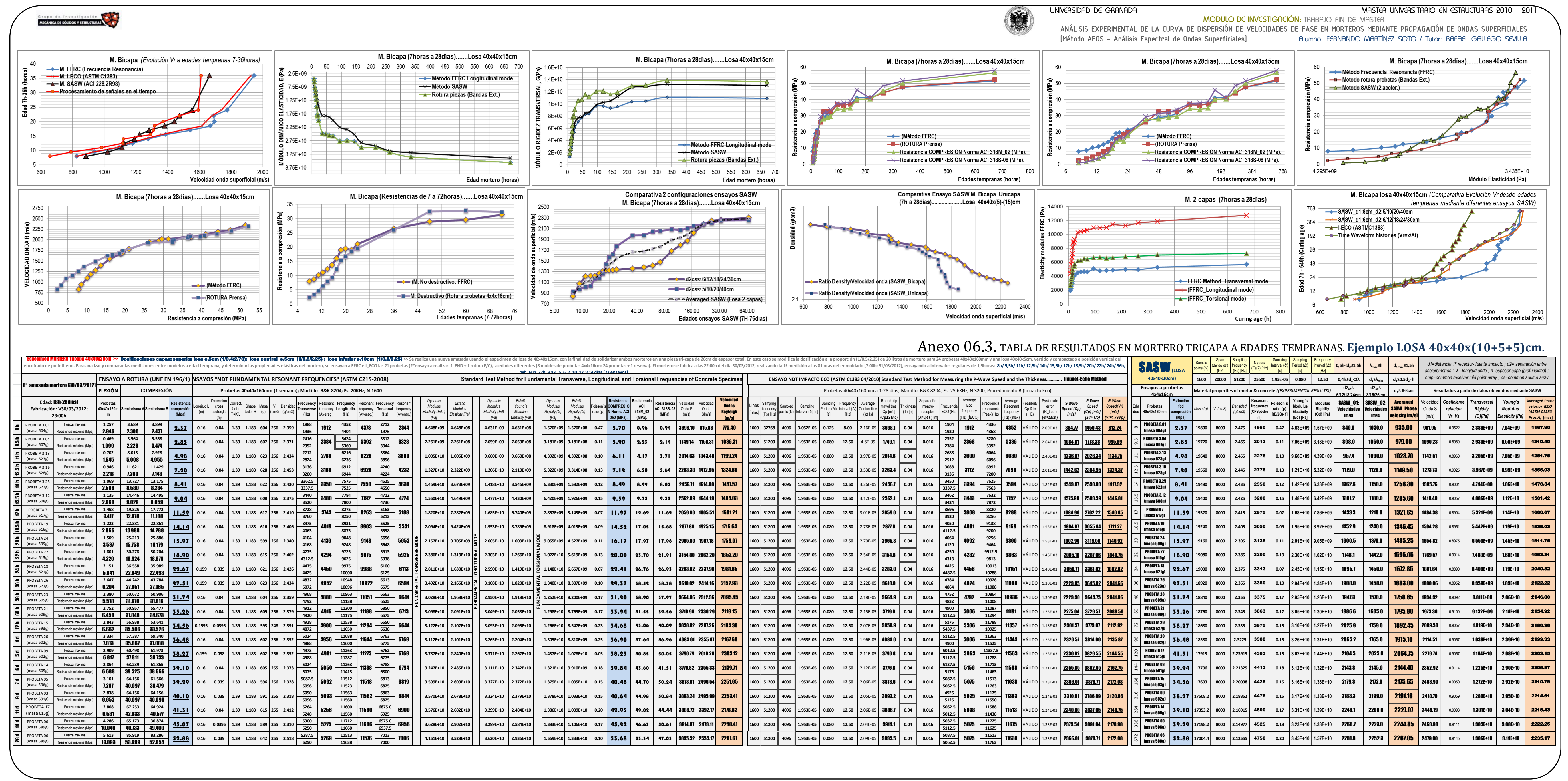




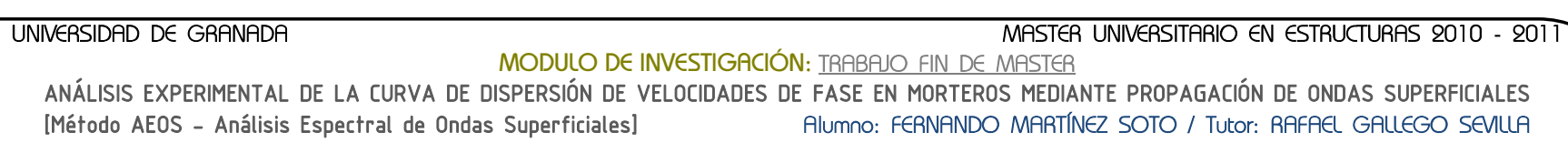
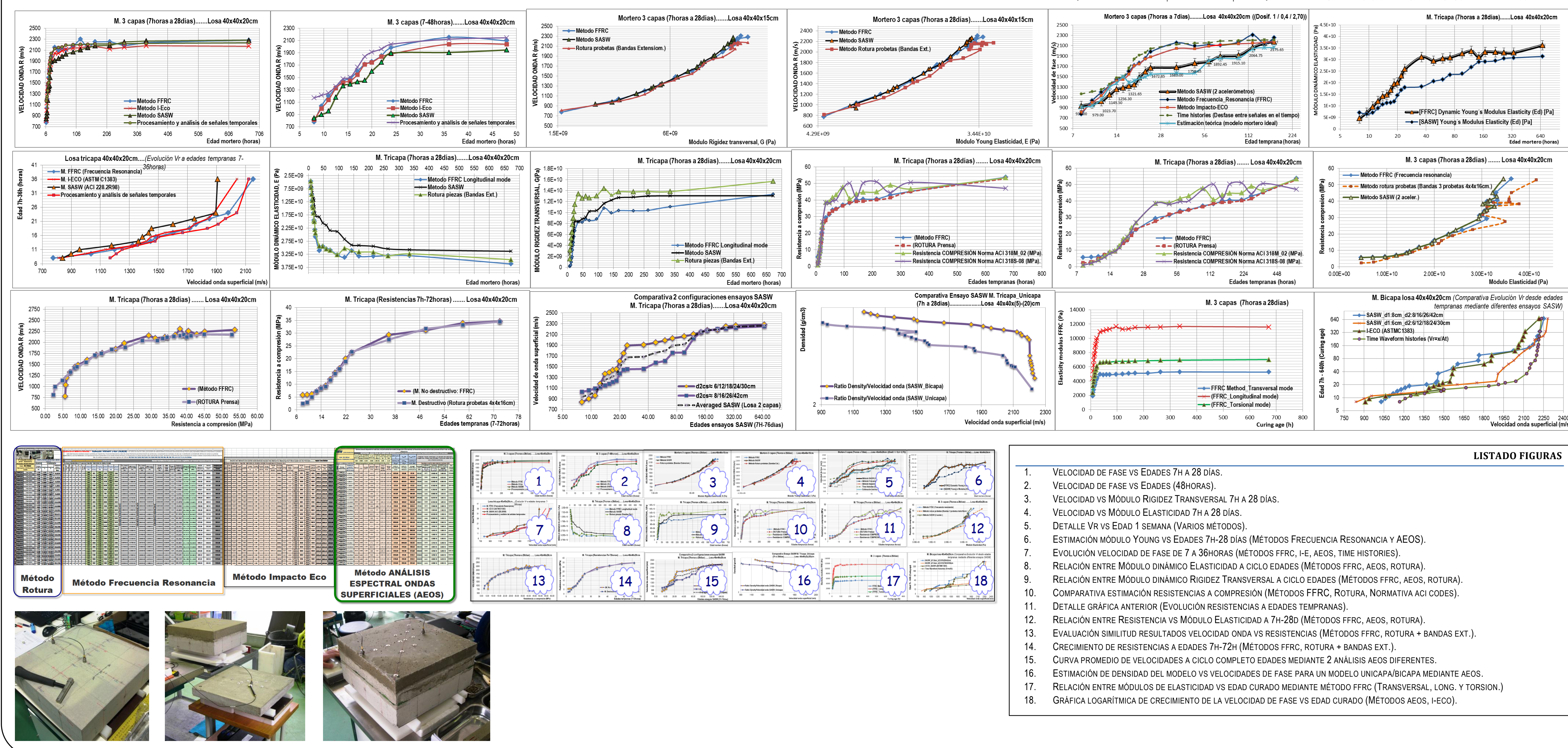

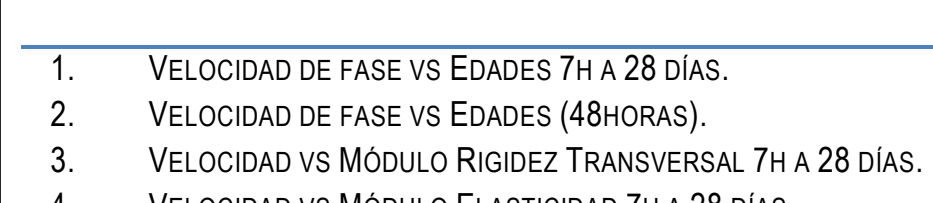

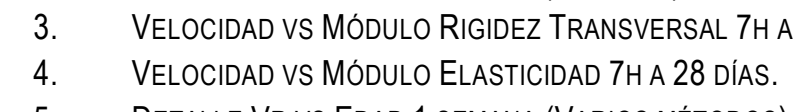

. DETALE VR VS EDAD 1 SEMANA (NARIOS METTODOS). EVOLUCION VELLOCIIAD DE FASE DE 7 A 36 HORAS (METOOOS FFRC, I-E, AEOS, TIME HISTORRES).

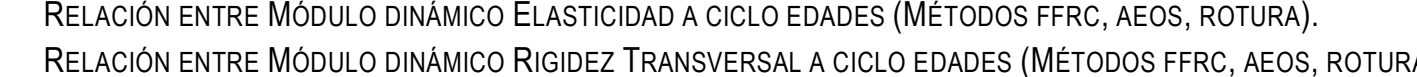
RELACION ENTRE MOOUULO DINAMICO RIIIDEZ TRANSVERSALA A CILLO EDARES (METUDAOS FFRC, AEAS, ROTURA). DETALE GRAFICA ANTERIOR (EVOLUCIÓN RESISTENCIAS A EDADES TEMPRANAS). RELACIÓN ENTRE RESIITENCIA VS MÓOULO ELASTICIDAD A 7H-28 (MÉTODOS FFRC, AEOS, ROTURA).

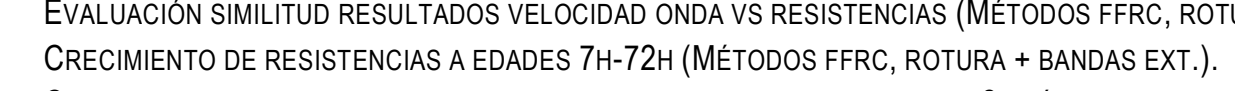

CURVA RROMEDIO DE VELOCIDADESA CLICLO COMPRETO EDADES MEDAANTE 2 ANALLIIS AEOS DIFERENTES.

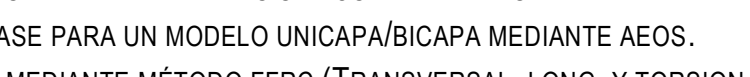

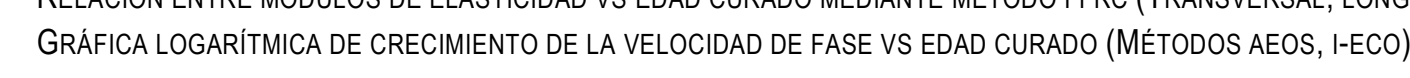

USTADO FIGURAS 